\title{
FACTORS ASSOCIATED WITH PERCEIVED QUALITY INFLUENCING BEEF CONSUMPTION BEHAVIOUR IN IRELAND
}

Submitted by:

Michael Mannion

A thesis submitted in completion of a Master of Business Studies in Marketing. 


\section{Table of Contents}

Page No.

Acknowledgements

(i)

Declaration

(ii)

Tables and Figures

(iii)

List of Abbreviations

(viii)

Abstract

\section{CHAPTER 1. INTRODUCTION}

1.1 Background 2

1.2 Rationale for Combining Consumer Behaviour 2 and Quality Policy

1.3 Approach for Thesis 3

1.4 Research Aim 4

1.5 Methodology 4

1.6 Thesis Structure 5

\section{CHAPTER 2. PERCEPTIONS OF MEAT QUALITY}

2.1 Introduction

2.2 Defining Perceived Meat Quality 7

2.3 Perception Formation 9

2.4 Understanding Perception Formation for Beef 14

2.4.1 Heuristic and Peripheral Modes of Information Processing 14

2.4.2 Central and Systematic Modes of Information Processing 15

2.5 Heuristic Reasoning and Media Coverage of the BSE Crisis 16

2.5.1 Product Category Schema 19

2.6 Heuristic Reasoning and Product Quality Assessment 21

2.7 Approaches to User Orientated Quality 22

2.7.1 Economics of Information Approach 22

2.7.2 Multi-attribute Approach $\quad 23$

2.7.3 Hierarchical Models $\quad 25$

2.7.4 Means-End Chain Models $\quad 28$

2.8 Integrated Approaches of Perceived Quality 33

2.9 Broadening the Determinants of Perceived Quality 39

2.10 Attitudes and Perceptions of Beef Quality in Ireland 41

2.11 The Symbolism of Red Meat 47

2.12 Conclusion $\quad 49$ 
CHAPTER 3. FACTORS INFLUENCING RED MEAT DEMAND

3.1 Introduction 51

3.2 Perceived Quality and Meat Demand 51

3.3 Perceived Quality and Market Share 51

3.4 Factors Influencing Meat Consumption 53

3.5 Non-Economic Factors Influencing Red Meat Demand 55

3.6 Health Issues $\quad 57$

3.7 Safety Issues 59

3.7.1 BSE $\quad 59$

3.7.2 Growth Promoters 61

3.7.3 Antibiotics $\quad 62$

3.7.4 Salmonella/Escherichia coli H:0157 62

3.8 Ethical and Animal Welfare Issues 63

3.9 Vegetarianism 64

3.10 Taste $\quad 65$

3.11 Preference for Chicken 65

3.12 Changing Lifestyles and Convenience $\quad 66$

3.13 Socio-demographic Factors $\quad 66$

3.14 Research Proposal 66

$\begin{array}{ll}3.15 \text { Conclusion } & 70\end{array}$

CHAPTER 4. INDUSTRY REVIEW

4.1 Introduction $\quad 72$

4.2 Indigenous Consumption Rates $\quad 72$

4.3 Structure of the Beef Sector 78

$\begin{array}{ll}\text { 4.3.1 Farmers } & 79\end{array}$

4.3.2 Meat Markets $\quad 80$

4.3.3 Slaughtering/Cutting $\quad 83$

4.3.4 Beef Retailing $\quad 87$

4.3.5 Household Meat Expenditure $\quad 88$

4.4 Strategic Outlook $\quad 89$

4.5 Adding Value to Beef Products 9

4.5.1 Quality Assurance Schemes $\quad 92$

4.5.2 Branding $\quad 94$

4.6 Beef Sector Study: Preliminary Findings $\quad 94$

4.6.1 Processing 95

$\begin{array}{ll}\text { 4.6.2 Market } & 95\end{array}$

4.6.3 Production $\quad 97$

$\begin{array}{ll}\text { 4.6 Conclusions } & 97\end{array}$

CHAPTER 5. RESEARCH METHODOLOGY

5.1 Introduction 99

5.2 Problem Definition $\quad 100$ 
$\begin{array}{ll}\text { 5.2.1 Research Agenda } & 100\end{array}$

5.2.1.1 First Part of Research Agenda $\quad 101$

5.2.1.2 Second Part of Research Agenda 103

5.2.1.3 Third Part of Research Agenda 103

$\begin{array}{ll}5.3 \text { Research Design } & 104\end{array}$

$\begin{array}{ll}5.3 .1 \text { Focus Group } & 104\end{array}$

$\begin{array}{ll}\text { 5.3.2 Questionnaire } & 105\end{array}$

$\begin{array}{ll}\text { 5.3.3 Unit of Analysis } & 106\end{array}$

$\begin{array}{ll}\text { 5.3.4 Sample Design } & 106\end{array}$

$\begin{array}{lr}\text { 5.3.5 Data Collection Method } & 106\end{array}$

$\begin{array}{ll}\text { 5.1 Questionnaire Design } & 107\end{array}$

$\begin{array}{ll}\text { 5.4.1 Consumption Behaviour } & 107\end{array}$

$\begin{array}{ll}\text { 5.4.2 Upon Consumption } & 108\end{array}$

$\begin{array}{ll}\text { 5.4.3 Place of Purchase } & 108\end{array}$

$\begin{array}{ll}\text { 5.4.4 Prior to Purchase } & 108\end{array}$

$\begin{array}{lr}\text { 5.4.5 Socio-demographics } & 110\end{array}$

$\begin{array}{ll}5.5 \text { Data Analysis } & 111\end{array}$

$\begin{array}{ll}5.6 \text { Factor Analysis } & 116\end{array}$

5.6.1 Rationale for Conducting Factor Analysis $\quad 116$

$\begin{array}{lr}\text { 5.6.2 Factor Analysis Technique } & 117\end{array}$

$\begin{array}{ll}\text { 5.5 Proposal for the Application of Factor Analysis } & 124\end{array}$

$\begin{array}{ll}\text { 5.7.1 Objectives } & 124\end{array}$

$\begin{array}{ll}\text { 5.7.2 Designing the Factor Analysis } & 124\end{array}$

$\begin{array}{ll}\text { 5.7.3 Assumptions } & 125\end{array}$

5.7.4 Deriving Factors and Assessing Overall Fit 125

$\begin{array}{ll}\text { 5.7.5 Interpreting the Factors } & 125\end{array}$

$\begin{array}{ll}\text { 5.7.6 Validation for the Factor Analysis } & 126\end{array}$

5.7.7 Additional Usage of the Factor Analysis Results 127

5.8 Two-group Discriminant Analysis 128

$\begin{array}{ll}\text { 5.8.1 Objectives } & 130\end{array}$

$\begin{array}{ll}\text { 5.8.2 Research Design } & 131\end{array}$

$\begin{array}{ll}\text { 5.8.3 Assumptions } & 131\end{array}$

5.8.4 Estimation of the Discriminant Model and Assessing Overall

Fit $\quad 132$

$\begin{array}{ll}\text { 5.8.5 Interpretation of the Results } & 133\end{array}$

$\begin{array}{ll}\text { 5.8.6 Validation of the Results } & 134\end{array}$

$\begin{array}{ll}5.9 \text { Conclusion } & 135\end{array}$

CHAPTER 6. DATA ANALYSIS

6.1 Introduction 139

6.2 Response Rate 139

6.3 Sample Characteristics $\quad 140$

$\begin{array}{ll}\text { 6.3.1 Gender } & 140\end{array}$

$\begin{array}{ll}\text { 6.3.2 Age of Respondents } & 140\end{array}$

$\begin{array}{ll}6.3 .3 \text { Occupation } & 141\end{array}$

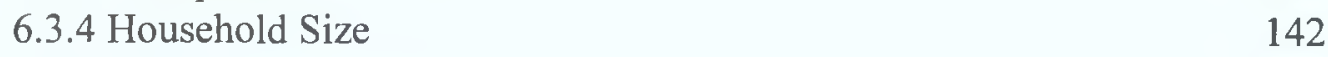

$\begin{array}{ll}\text { 6.3.5 Children } & 142\end{array}$ 
6.3.5 Children

6.3.6 Completion of Full-Time Education 143

6.3.7 Income $\quad 143$

6.4 Meat Consumption Behaviour of Sample $\quad 144$

$\begin{array}{ll}\text { 6.4.1 Frequency of Consumption } & 144\end{array}$

$\begin{array}{ll}\text { 6.4.2 Changes since } 1992 & 145\end{array}$

6.4.3 Dependent Variable $\quad 146$

6.5 Wilcoxon Test Results 146

6.5.1 Wilcoxon Results - Point of Consumption 146

6.5.2 Wilcoxon Results - Point of Purchase 148

6.5.3 Wilcoxon Results - Safety Concerns 150

6.6 PCA Results 151

6.7 Two-Way Discriminant Analysis Results 156

6.7.1 Two-Way Discriminant Analysis for Demographic Variables 162

$\begin{array}{ll}6.8 \text { Conclusion } & 163\end{array}$

\section{CHAPTER 7. DISCUSSION AND CONCLUSIONS}

7.1 Introduction 165

7.2 Beef Consumption Levels 165

7.3 Part one of Research Agenda 166

7.3.1 Quality Attributes at the Point of Consumption 166

$\begin{array}{ll}\text { 7.3.2 Quality Attributes at the Point of Purchase } & 167\end{array}$

$\begin{array}{lr}\text { 7.3.3 Safety Concerns } & 168\end{array}$

7.4 Part Two of Research Agenda 169

$\begin{array}{lr}\text { 7.4.1 The Intrinsic and Extrinsic Constructs } & 170\end{array}$

$\begin{array}{ll}\text { 7.4.2 Health and Safety Constructs } & 171\end{array}$

$\begin{array}{ll}\text { 7.4.3 Cooking/Convenience } & 171\end{array}$

$\begin{array}{lr}\text { 7.4.4 Conclusion } & 172\end{array}$

7.5 Third Part of Research Agenda 172

$\begin{array}{ll}\text { 7.5.1 Perceived quality and beef demand } & 174\end{array}$

$\begin{array}{ll}\text { 7.5.2 Socio-demographics and beef demand } & 176\end{array}$

7.6 Limitations of the Research Conducted 176

7.7 Practical Implications $\quad 177$

$\begin{array}{ll}7.8 \text { Theoretical Implications } & 179\end{array}$

$\begin{array}{ll}\text { 7.9 Suggestions for Further Research } & 180\end{array}$

7.10 Concluding Remarks 181 


\section{Acknowledgements}

This project was carried out in The National Food Centre, Teagasc under the supervision of Mr. Cathal Cowan, to whom I wish to extend my personal thanks for his continuous encouragement and support.

In addition thanks goes to Dr. Michael Gannon for his helpful advice and guidance through each stage of this dissertation.

To the partners involved in the EU project, namely Prof. Tilman Becker, Kristina Glitsch, Eckhard Benner, Dr. Spencer Henson, James Northern, Dr. Gianluca Brunori, Dr. Mara Miele, Vittoria Parisi, Dr. Mario Mahlau, Dr. Juilan Briz, Enrique Guttierrez Del Omo, Dr. Hans Anderson and Ruben Hoffman.

I am grateful to Gerry Cunningham for his commentary on the multivariate statistical techniques used.

To Maeve Henchion for proof-reading the industry review.

To all the people who took time out to respond to the questionnaire.

All staff at The National Food Centre, in particular members of the Food Market Research Department for providing a friendly and productive environment.

To Dr. Darach Turley for his insightful comments towards the completion of this work.

And as always thanks to my parents for their continuous support over the years. 


\section{Declaration}

I hereby certify that this material, which I now submit for assessment of the programme of study leading to the award of Master of Business Studies in Marketing is entirely my own work and has not been taken from the work of others save and to the extent that such work has been cited and acknowledged within the text of my work.

Signed: ID No.:

Date: 


\section{Figures and Tables}

\section{List of Figures}

Fig. 2.1 Types of Quality 9

Fig. 2.2 The Formation of Product Perceptions $\quad 10$

Fig. 2.3 The ELM and Heuristic-Systematic Model 14

$\begin{array}{ll}\text { Fig. 2.4 Amplification Effect } & 18\end{array}$

Fig. 2.5 Quality Guidance $\quad 26$

Fig. 2.6 Quality Expectation and Experience for Blade Steak 27

Fig. 2.7 Means-End Chain Model 29

Fig. 2.8 A Means-End Chain Model Relating Price, Quality and Value 31

Fig. 2.9 A Conceptual Model of the Quality Perception Process 34

Fig. 2.10 The Total Food Quality Model 37

Fig. 2.11 Research Methods and Research Questions in the TFQ Model 38

Fig. 2.12 The Determinants of Perceived Meat Quality 40

Fig. 3.1 Improving Quality - Versus Competitors - Boosts Market Share 52

Fig. 3.2 Relative Importance of Factors Influencing Meat Demand 55

Fig. 3.3 Irish Beef and Chicken Consumption kgs/person $1986-1996 \quad 58$

Fig. 3.4 Framework for Analysing Perceived Meat Quality 67

Fig. 4.1 Irish Meat Consumption kgs./head 1986 - 1996

Fig. 4.2 Retail Price and Consumption of Beef (November 1989 Based

$\begin{array}{ll}\text { Series) } & 75\end{array}$

Fig. 4.3 Retail Price and Consumption of Chicken (November 1989 Based $\begin{array}{ll}\text { Series) } & 75\end{array}$

Fig. 4.4 Per Capita Beef Consumption 1976 - $1996 \quad 77$

Fig. 4.5 EU Beef Consumption - Recent Trends and Future Prospects 78

Fig. 4.6 Important Links in the Distribution Chain 79

Fig. 4.7 Beef Export Market and Intervention ("000t cwe) 82

Fig. 4.8 The Five Biggest Companies Share of Total Adult Cattle

$\begin{array}{ll}\text { Slaughterings } & 85\end{array}$

Fig. 5.1 Framework for Analysing Perceived Meat Quality 100 
Fig. 5.2 Questionnaire Outline

Fig. 5.3 Histogram of Importance of Attributes of Beef

Fig. 5.4 Results of Wilcoxon Test for the Eating Quality of Beef

Fig. 5.5 Nine Variables Reduced to Three Factors

Fig. 5.6 Scatter Diagram. Height and Weight and the Resulting Factor of Size

Fig. 5.7 Key Stages in the Factor Analysis Procedure

Fig. 5.8 Scatter Diagram Before and After Rotation in Factor Analysis

Fig. 5.9 Geometric Representation of Two-Group Discriminant Analysis for

Two Independent Variables

Fig. 6.1 Results of Wilcoxon Test for the Eating Quality of Beef of those who had not Reduced Consumption - Point of Consumption

Fig.6.2 Results of Wilcoxon Test for the Eating Quality of Beef of those who had Reduced Consumption - Point of Consumption

Fig. 6.3 Results of Wilcoxon Test for the Eating Quality of Beef of those who had not Reduced their Consumption - Point of Purchase

Fig. 6.4 Results of Wilcoxon Test for the Eating Quality of Beef of those who had Reduced their Consumption - Point of Purchase

Fig. 6.5 Results of Wilcoxon Test for the Safety of Beef of those who had

Reduced their Consumption

Fig.6.6 Results of Wilcoxon Test for the Safety of Beef of those who had not Reduced their Consumption

Fig. 6.7 Boxplots of Within Group Distributions of Each Independent Variable

Fig. 6.8 An Illustration of the Resulting Two-Group Discriminant Analysis for the Study

Fig. 6.9 Normal Curve Superimposed Over Discriminant Scores for those who have not Decreased their Consumption

Fig. 6.10 Normal Curve Superimposed Over Discriminant Scores for those who

Decreased their Consumption

Fig. 7.1 A Comparison of the Perceived Quality Constructs as Proposed by

Issanchou (1996) and those Derived in the Study 


\section{List of Tables}

Table 2.1 Selected Means-End Chain Models and their Proposed Relationships with Quality and Value

Table 2.2 Concern About Individual Issues

Table 2.3 Levels of Satisfaction with Beef Attributes

Table 3.1 Percent Contribution to the Explanation of Beef and Veal

Consumption Change

Table 3.2 Main Reasons for Cutting Down on Red Meat Consumption

Table 3.3 Framework for Classifying Consumer Behaviour Models

Table 4.1 Beef/Veal Consumption kg./head in EU Countries 1995

Table 4.2 Ireland - Beef, Pigmeat and Poultry Consumption in kgs./head

Table 4.3 Own and Cross-Price Elasticities for Beef, Pork and Chicken 1990

Table 4.4 Number of Holdings and Average Number of Animals per Holding, 1991, 1993 and 1995

Table 4.5 Cow Numbers ('000’s)

Table 4.6 Steer Slaughterings in Ireland (\%) 1992-1997

Table 4.7 Output Volume of Cattle and Calves ('000's) 1991-1997

Table 4.8 The Ten Largest Slaughtering Companies in the EU-15 by Share of Total Adult Cattle Slaughterings in 1995

Table 4.9 Ireland - No. of Fresh Meat Outlets 1987 \& 1991

Table 4.10 Ireland - Trend for Selected Shops - Numbers

Table 4.11 Ireland - Retail Sector - Concentration in Turnover

Table 4.12 Expenditure on Meat in Ireland as a \% of Food Expenditure and a \% of Total Household Expenditure

Table 4.13 Proportion of Beef, Pork, Poultry and Other Meat Products as a \% of Total Household Meat Expenditure in 1994-1995

Table 4.14 Added Value and Employment Potential of Downstream Processing 91

Table 4.15 Exports of Irish Beef (\%) 91

Table 4.16 McKinsey's Summary of Opportunities for the Irish Beef Industry 96

Table 5.I Frequency of Consumption 
Table 5.2 Choosing a Test for Comparing Averages of Two or More

Samples of Scores

Table 5.3 Wilcoxon Results of Tenderness/Flavour Pairing 114

Table 5.4 Ranking of Attributes According to Mean Scores 115

Table 5.5 Importance of Attributes in Assessing the Eating Quality of Beef 116

Table 5.6 The Percentage of Variance Accounted for, and the Associated

Eigenvalues, for the Successively Extracted Factors in a Factor

Analysis of a Set of Nine Variables (Principle Components Solution)

Table 5.7 Principle Component Loadings Relating Quality Attributes to

Quality Dimensions After Varimax Rotation for Saveloy

Table 5.8 First Part of Research Agenda

Table 5.9 Second Part of Research Agenda

Table 5.10 Third Part of Research Agenda

Table 6.1 Telephone interview response results

Table 6.2 Sample Age Group Statistics (\%)

Table 6.3 Occupation of Respondents

Table 6.4 Occupation of Person Who Contributes Most to Household Income

Table 6.5 Household Size

Table 6.6 Children Under 16

Table 6.7 Age on Completing Full-Time Education

Table 6.8 Household Income

Table 6.9 Frequency of Consumption of Beef, Pork and Chicken in

Household (\%)

Table 6.10 Change and Rate of Change in Consumption of Beef, Pork and

Chicken over the Last Five Years (\%)

Table 6.11 Households where Beef Consumption has Decreased and Not

Decreased

Table 6.12 Importance of Attributes in Assessing the Eating Quality of Beef for those who did not Reduce their Consumption

Table 6.13 Importance of Attributes in Assessing the Eating Quality of Beef for those who did Reduce their Consumption 
Table 6.14 Helpfulness of Attributes in Assessing the Eating Quality of

Beef for those who have not Reduced their Consumption

Table 6.15 Helpfulness of Attributes in Assessing the Eating Quality of Beef of Those who did Reduce their Consumption

Table 6.16 Concerns About Beef of those who had Reduced their Consumption

Table 6.17 Concerns About Beef of those who had not Reduced their

Consumption

Table 6.18a Principle Components Analysis (PCA) of Perceived Quality

Construct for Beef

Table 6.18b Principle Components Analysis (PCA) of Perceived Quality

Construct for Beef

Table 6.19 Box's M Test

Table 6.20 Summary of Canonical Discriminant Function

Table 6.21 Box's M Test - Demographics

Table 7.1 Frequency of Consumption

Table 7.2 Methodological Comparison Between Both Studies

\section{Appendices}

Appendix 1: Questionnaire 


\section{List of Abbreviations}

$\begin{array}{ll}\text { AGV } & \text { Across Group Variation } \\ \text { ANOVA } & \text { Analysis of Variance } \\ \text { BSE } & \text { Bovine Spongiform Encepalpathy } \\ \text { CAI } & \text { Consumer's Association of Ireland } \\ \text { CAP } & \text { Common Agricultural Policy } \\ \text { CATI } & \text { Compute Assisted Telephone Interviewing } \\ \text { CBL } & \text { Clenbuterol } \\ \text { COMA } & \text { Committee on Medical Aspects of food policy } \\ \text { CSO } & \text { Central Statistics Office } \\ \text { DOAF } & \text { Department of Agriculture and Food } \\ \text { E-coli } & \text { Escherichia coli } \\ \text { ELM } & \text { Elaboration likelihood model } \\ \text { EU } & \text { European Union } \\ \text { GATT } & \text { General Agreement on Tariffs and Trade } \\ \text { HACCP } & \text { Hazard Analysis and Critical Control Points } \\ \text { LFRA } & \text { Leatherhead Food Research Association } \\ \text { LMR } & \text { Landsdowne Market Research } \\ \text { MAIDS } & \text { Modified Almost Ideal Demand System } \\ \text { MRC } & \text { Market Research Consultancy } \\ \text { MRL } & \text { Maximum Residue Limits } \\ \text { MSA } & \text { Measure of Sampling Adequacy } \\ \text { nV-CJD } & \text { new variant-Creutzfeldt Jakob Disease } \\ \text { PCA } & \text { Principle Components Analysis } \\ \text { PHLS } & \text { Public Health Laboratory Service } \\ \text { PIMS } & \text { Profit impact market strategy } \\ \text { SEM } & \text { Structural equation model } \\ \text { SPI } & \text { Strategic planning institute } \\ \text { SPSS } & \text { Statistical Package for the Social Sciences } \\ \text { TFQ } & \text { Total Food Quality } \\ \text { TQM } & \text { Total Quality Management } \\ \text { UK } & \text { United Kingdom } \\ \text { USA } & \text { United States of America } \\ \text { USDA } & \text { United States Department of Agriculture } \\ & \end{array}$


Title - Factors Associated With Perceived Quality Influencing Beef Consumption in Ireland. Author - Michael Mannion

Despite the importance of beef to the national economy, its importance is not, however, reflected in the national diet. Beef's share of the overall market for fresh meat in Ireland has nearly halved in the past ten years (1986 - 1996). As yet no empirical work has been carried out in Ireland to examine the factors influencing this trend.

This study explored the link between how Irish consumers perceived the quality of beef and how this perception affected past purchase behaviour of those who had decreased their consumption levels and those who had maintained them. The rationale for approaching the study of beef consumption from this perspective is supported by research which revealed that market share and profits are correlated with quality as perceived by the consumer. A review of the literature indeed found that many of the factors which have influenced consumers to reduce their red meat consumption were quality related. The methodology used by many of these studies was to directly ask respondents why they had reduced their consumption. The limitation of this technique is that respondents will attempt to rationalise their behaviour. In an attempt to overcome this limitation and uncover the underlying quality factors influencing consumption, a framework for analysing beef quality perception was choosen.

The research used was part of a wider international multi-disciplinary EU funded project entitled 'Meat Quality Policy and Consumer Behaviour' involving six countries. Telephone interviews were carried out among 500 respondents who carried out most of the food purchases in the household. Questions of particular interest for the dissertation were related to perceptions of beef quality at: 1) the point of consumption; 2) the point of purchase; 3) prior to purchase. Multivariate data analysis techniques were used on the data to address the research question.

Results revealed that the discriminating quality factors of safety and meat status explained only a small proportion of the difference between both groups. Explanations and suggestions for further research include the general re-examination of how quality concepts such health, safety and meat status are operationalised. In addition the social aspects of meat eating should be examined. In particular, the link between consumption patterns and the symbolic notions associated with meat. 


\section{CHAPTER 1}

\section{INTRODUCTION}




\subsection{Background}

The primary research in this study was part of an EU 4th Framework FAIR (Food and Agricultural Industrial Research) project entitled 'Quality Policy and Consumer Behaviour towards Meat'. There were six countries involved in this research; Germany, Italy, Spain, England, Sweden and Ireland. The main objective of the project was to combine consumers' expectations of meat quality with organisational efforts for quality management with a view to enabling improvements in existing quality policy. Most countries were represented by two organisations; firstly, a university or research institution to handle the consumer behaviour side of the project and secondly, an industrial partner dealing with quality policy component. In Ireland these organisations consisted of The National Food Centre and Bord Bia (the Irish Food Board) respectively.

The focus of the authors' research was towards the consumer behaviour side of the project where the objective was to identify consumers' perceptions and expectations of meat quality in Ireland, in particular that of beef, pork and chicken. A report of this work entitled 'Consumer Perceptions Towards Meat Quality in Ireland' was submitted to the EU Commission in October 1997 (Cowan \& Mannion, 1997).

\subsection{Rationale for combining consumer behaviour and quality policy}

Since the outbreak of salmonella in chicken in 1988 in the U.K. food policy has become a major political issue. Previously food policy was dominated by concern for agricultural production and discussion of food policy was largely excluded from the political agenda (Smith, 1991). This, however, is no longer the case and the views of consumers, interest groups, retailers and food manufacturers are now all integral to the food policy decision making process. In particular consumers views have become a subject for discussion. Indeed many consumer behaviour texts allocate a chapter to the topic of 'Public Policy and Consumer Behaviour' (e.g. Wilkie,1994; Horton, 1984; Williams, 1982).

An acknowledgement of the importance of combining consumer expectations with meat quality policy has been suggested in the past. For instance, Spitters et al. (1991, 
271) commenting on behalf of the meat industry note: 'It is not our opinion that matters, but that the opinions, attitudes and interests of the consumer should determine our policies'. There is an economic rationale for approaching quality policy in this manner. Janssen \& Tilburg (1997) highlight that policy makers must understand which modifications offer the highest returns towards achieving economic objectives and that this requires linking marketing research and analysis with government policy instruments. In other words issues which are of value to consumers should be a major factor dictating future food policy changes.

It is for these reasons, therefore, that a project of this nature was commissioned by the EU Commission. The meat industry, and in particular the beef industry, is currently in a very sensitive period. Issues such as Bovine Spongiform Encephalpathy (BSE), growth promoters, antibiotics, salmonella and animal welfare have been the object of media attention in recent times and have damaged perceptions of beef quality. However, lack of consistency in the quality of meat itself has also caused consumer concern. Only through understanding and listening to consumer views will meat quality policy makers be able to develop modifications and changes to existing policy which offer the highest returns to economic objectives.

\subsection{Approach for thesis}

As stated previously the authors' work in the project focused on the consumer behaviour component of the project. In particular the research centred on Irish consumer perceptions of meat quality. Due to the robust nature of the data gleaned from the study it was possible to examine specific research questions related to the area of interest. For instance, the British partner at Reading University developed a structural equation model (SEM) of the relationship between the safety concerns and safety indicators of beef among the various countries involved in the project using the data set from the study (Henson \& Northen, 1998).

The focus taken by the author in this thesis is to examine Irish consumer perceptions of beef quality and how these perceptions have influenced beef consumption in recent years. The rationale for approaching the study of consumption from this perspective is 
supported by research at the Strategic Planning Institute (SPI) in the USA. The topic of consumers' perceived quality of products and services has been recognised at SPI as an integral element to a company's success. For the past two decades researchers at SPI have been developing the Profit Impact of Market Strategy (PIMS) Databank. Through this databank researchers have been studying the strategies of approximately 3,000 companies. An initial conclusion from this research was that market share drove long-term profits. However, closer examination of the PIMS research has revealed that market share and profits are correlated with quality as perceived by the consumer (Gale, 1994).

\subsection{Research Aim}

In Ireland, beef's share of the overall market for fresh meat has, in the past ten years (1986 - 1996), nearly halved; falling from $27 \%$ in 1986 to $14 \%$ in 1996 . In the light of the finding from PIMS research concerning market share and perceived quality, the broad objective of this research is to examine the relationship between the decline of beef consumption rates and how consumers perceive the quality of beef in Ireland. Specifically, the author sought to investigate consumer perceptions to beef quality of two groups, namely those who had decreased their consumption and those who had maintained their consumption levels. It is hoped that this investigation will go some way towards explaining the country's declining beef consumption rates.

\subsection{Methodology}

There are many diverse factors influencing quality perceptions towards beef. The objective of this thesis is to identify the ones which have affected beef consumption patterns in Ireland. Many previous studies have confronted this topic by asking respondents directly to report the factor/factors of influence. However, this approach is weak. As Richardson et al. (1994) indicate motivations for reducing meat consumption are often multi-layered and thus no single issue should be considered in isolation. The author, therefore, proposes a new approach for researching this topic. In order to capture the interactions of various motivations the approach which is taken in this thesis encompasses two main stages. Firstly, using a framework for analysis derived from the literature review the holistic perceptions which Irish consumers have 
towards beef quality are perceptually mapped. Secondly, through this model a discrimination is made between the quality perceptions of those who have and those who haven't decreased their consumption rates in the last few years. Both stages involve multivariate statistical analysis.

\subsection{Thesis Structure}

The first part of this thesis reviews the literature relevant to the research question. The literature relating to two topics of a disparate but inherently related nature, perceived meat quality and the factors influencing beef consumption, will be reviewed. In this review a framework for analysing the perceived quality construct will be chosen.

The second part consists of a review of the Irish beef industry. Here an examination will be made of consumption rates, industry structure and strategic outlook.

Part three consists of the methodological outline, data analysis and finally the discussion and conclusions. 


\section{CHAPTER 2}

\section{PERCEPTIONS OF MEAT QUALITY}




\subsection{Introduction}

The objective of this chapter is to discuss and review the literature surrounding the topic of consumer perceptions of meat quality, in particular beef quality. After defining perceived meat quality the development of beef quality perceptions will be examined. The objective here is to set the context for findings in studies which have measured these perceptions and also to facilitate the interpretation of results from the primary research in this study. Next, studies examining the perception of meat quality will be reviewed. Finally, attention will be paid to Irish studies of attitudes and perceptions to beef quality.

\subsection{Defining Perceived Meat Ouality}

Herbig et al. (1994) argue that the search for quality is one of the most important consumer trends of the 1990s. However, Lassen (1993: 1) points out that there has been a remarkable absence of contributions to the relationship between consumer perceptions and food quality. Grunert et al. (1996) suggest that the lack of contribution stems from the fact that consumer evaluation of food quality is one of the more problematic areas of consumer behaviour. Kordupleski et al. (1993) note that even the Total Quality Management (TQM) movement has ignored the consumer side of quality; the movement has become internally focused in firms. They argue that to ignore the consumer side of quality is myopic because '..market success results from customer decisions. Thus, the customer is the ultimate judge of quality...[an area which] has been less adequately addressed by the quality movement so far' (Kordupleski et al., 1993, 93).

When attempting to define quality many authors including Oude et al. (1995), Holbrook et al. (1985) and Steenkamp (1989) quote Robert Pirsig's (1974) philosophical narration 'Zen and the Art of Motorcycle Maintenance' as the classic example of the impossibility of defining quality. The following is a typical quotation:

Quality... you know what it is, yet you don't know what it is. But that's selfcontradictory. But some things are better than others, that is, they have more 
quality. But when you try to say what quality is, apart from the things that have it, it all goes poof! (Pirsig, 1974, 184).

Consumers and professionals in the meat sector differ in the way they view meat quality. Professionals, such as food scientists, have knowledge and resources to establish a view of quality based on objective criteria. Consumers lack both, and they are typically concerned with many different products (Lassen, 1993). Quality perception is therefore the best way to describe how consumers relate to the quality of meat and food products.

In order to define quality perception one must first understand the expression quality concept: 'Quality concept describes the foundation on which evaluation of food quality is based; it suggests a comprehensive understanding of quality... [on the other hand] quality perception is used, as an expression that reflects the fact that the consumer's relation to quality is often incomplete and inconsistent' (Lassen 1993, 3). Fiddes $(1991,224)$ gives further credence to this notion of consumer perception: 'What people think to be true may if anything be more significant than 'facts', since belief is what governs current and future consumption'.

The modern theory of quality management defines quality as perceived by the consumer. The meat industry has traditionally been enshrouded in a product and process orientation to quality. Only recently as a result of decreasing consumption, of beef in particular, has the industry (retailers in particular) taken serious consideration of the importance of a consumer orientation to meat quality. In figure 2.1 Grunert et al. (1997b: 76) propose a distinction between four types of quality:

Product-orientated quality - measured by means of a food product's physical properties like fat percentage, muscle size of meat and so on.

Process-orientated quality - concerned with characteristics of the production process, which are not only mirrored in physical characteristics of the product, but also fulfill ecological or ethical production standards. 
Figure 2.1: Types of Quality

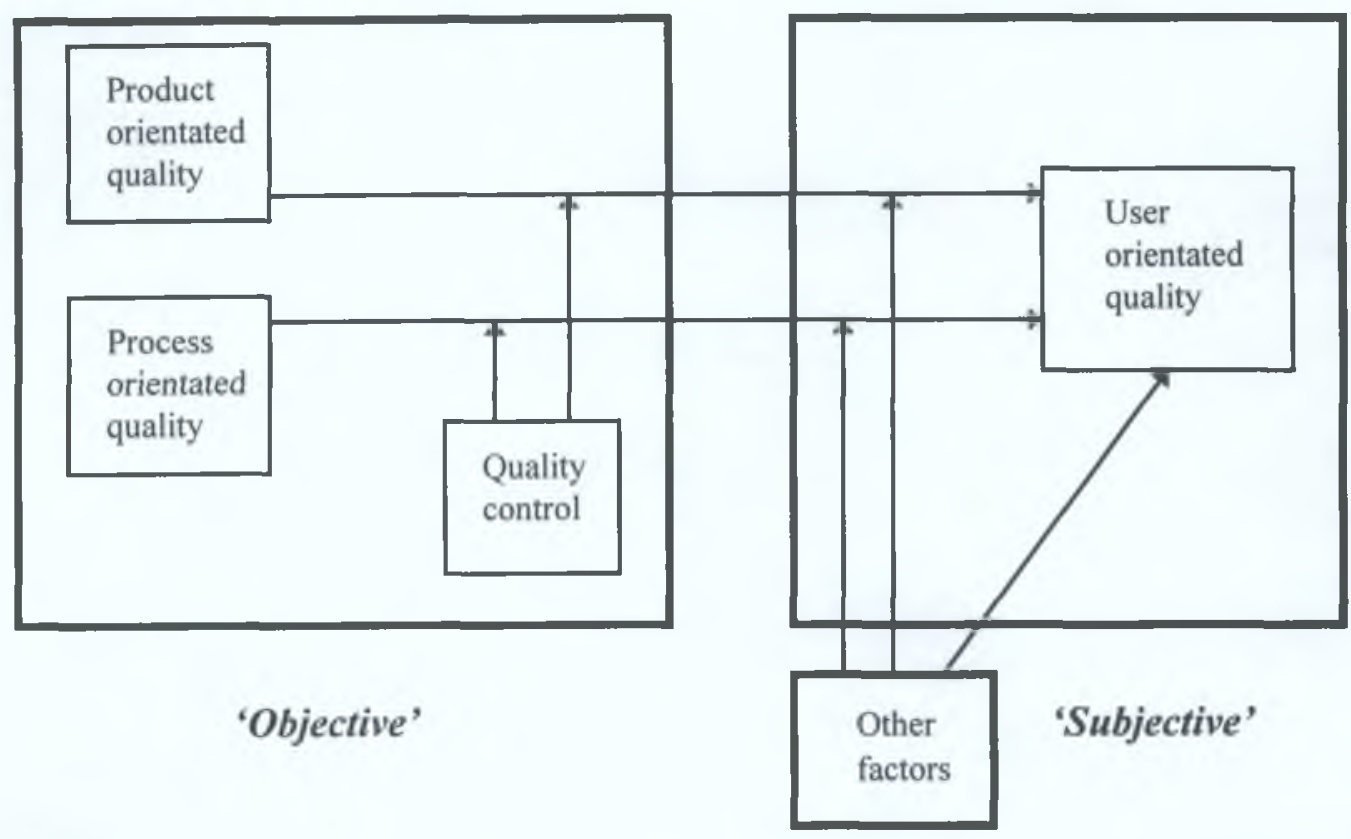

Source: Grunert, K.G., Larsen, H.H., Madsen, T.K. and Baadsgaard, A.(1997) Market Orientation in Food and Agriculture. Kluwer Academic Publishers. p.78.

Quality Control - refers to the extent to which product- and process-orientated quality remains stable at pre-specified levels (i.e. certain levels of fat percentage, muscle size, certain levels of use of pesticides and so on).

User-orientated quality - the subjective quality perception of a user.

The meat industry has traditionally operated within the 'objective' realm of product quality as denoted by the left side of figure 2.1. Similarly, meat quality policy has also been designed and implemented with the 'objective' perspective to quality in mind. The future of the meat industry requires the integration of the objective and subjective orientations to meat quality. A few studies have been carried out attempting to integrate product and consumer orientations to meat quality. Before reviewing these an examination will be made about how perceptions (beliefs) about beef quality have been formed.

\subsection{Perception formation}

Von Alvensleben (1997) highlights that product perception is the result of: 
1. The actual product information consisting of the direct product information and the product environment information which are processed together; with

2. the stored product image, using information processing programmes, which may be of very simple or complex nature.

Figure 2.2 provides an overview model of these aspects of product perception formation.

Figure 2.2: The formation of product perceptions

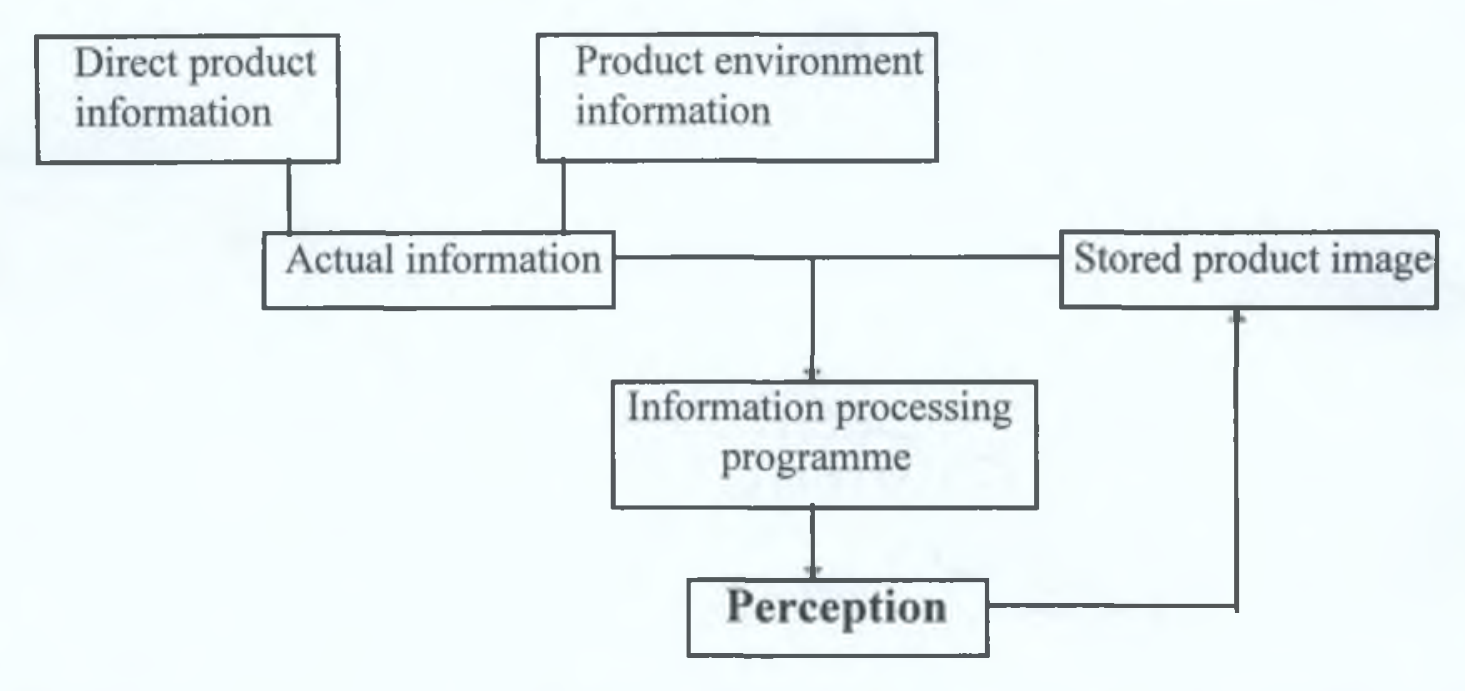

Source: von Alvensleben, R, (1997) Consumer Behaviour. In Agro-food Marketing, eds. D.I. Padberg, C. Ritson and L.M. Albsiu. CAB International, p.219.

The actual information is a complex pattern stimuli, which can be divided into the direct product information and information about the product environment.

The direct product information includes all properties of the product, the physical, technical and sensory properties as well as the price, the brand, the variety or the origin. Some of these product properties such as taste cannot be perceived directly at the point of sale. In these cases the consumer has to infer properties such as taste from indicators which can be perceived at the point of sale such as appearance.

In the case of product environment information, the consumer perception of a product is influenced by the environment in which the product is offered, such as the 
atmosphere of the store, the properties of the vendor, the assortment and the information, which together are supplied with the product. For example, beef sold in the butchery department within a supermarket may be perceived differently from the same meat offered in an independent butcher shop.

In the case of stored product image, usually the consumer has already had some experience of the product, which is stored in the memory and can be made available during the perception process. The product image plays a particularly dominant role in the case of low involvement products, which are bought in a habitual way. In most cases the consumer is applying some simplified information processing programmes, which are using the actual information and the stored product image for the further perceptual process. This can lead to perception distortions. In other words consumers use these simplified information processing programmes to transform what was 'objective' product quality information into more 'subjective' product quality information. It is this 'subjective' product quality information which is used in the consumer decision process, and is defined as perceived product quality.

Von Alvensleben (1997) describes four information processing programmes:

1. The use of information chunks or key information. Here the total product quality is deduced from one or more product properties. Widely used key characteristics are price and brand name.

2. Irradiance. This refers to the way consumers infer one product characteristic from another, such as taste from colour.

3. Halo effects. The halo-effect is referred to as an interdependency between the image which a consumer has of a product and the perception of the product properties. If the product image is positive, the consumer tends towards a selective perception of the positive product properties. If the product image is negative, the same process will take place with negative expression. In both cases the perception is distorted and the distorted positive or negative image will be stabilised. A possible explanation for this behaviour is given by the theory of cognitive dissonance. The consumer tends to avoid cognitive dissonance by a selective perception of information which leads to cognitive consistency. 
4. Image transfer. A positive or negative image of a product may affect the image of similar products. Many consumers tend to generalise their experience with a product to avoid the need for further information search and processing. This behaviour may lead to perception distortions, which are positive or negative. For example food scandals caused by single firms often have negative effects on the total food sector.

Much of the previous empirical work in the area of beef quality perception has focused on direct product information and the resulting effects of two information processing programmes; key information and irradiance, to form quality perceptions. Before reviewing this research two points concerning the model will be made.

A suggested alteration to von Alvensleben's (1997) model is proposed for how the 'product environment information' element is defined. It proposed that the definition of this element should be broadened and defined not only in terms of direct product environment information such as the store and labelling information as proposed by von Alvensleben (1997) but should also encompass elements of the macroenvironment and their influences on product perception. Kotler et al. (1996) identify six influential forces in a company's macro-environment; demographic, economic, natural, technological, political and cultural. These environmental influences can also affect product perception. To illustrate this point each factor will be briefly examined with examples for red meat/beef:

- Demographic. Young women tend to avoid red meat because the masculine images of strength and vigour associated with it are incongruent with their selfconcepts $^{1}$ (Lister \& Hodges, 1994).

- Economic. Research has indicated that there is a relationship between price and perceived quality (Olson, 1977). However, in the case of meat no studies were identified which examined this relationship.

\footnotetext{
'Self-concept can be defined as a set of perceptions whereby consumers symbolise to themselves who they are (Levy, 1981: 542).
} 
- Natural. The natural resources, both directly; the animals, and indirectly; the land and feed stuffs used, have had an influence on the perceptions of some meat consumers. These perceptions have heightened animal welfare and ecological ${ }^{1}$ considerations and in some cases have led to red meat reduction or avoidance (Santos \& Booth, 1996).

- Technological. O'Neill \& Shanahan (1993) found that in Ireland modern beef production methods which involved the use of hormones and antibiotics, were of great concern to consumers thus affecting their quality perception of beef safety.

- Political. The announcement on $20^{\text {th }}$ March 1996 from the British Secretary of State for Health concerning the possible link between BSE and the new variant Creutzfeldt Jakob Disease (nv-CJD) led to a world wide ban on beef in 1996. Despite reports of the imminent lifting of the ban (Smyth, 1998), adverse consumer perceptions of the British beef may lead to an apprehensiveness among foreign consumers to repurchase the product despite the evidence assuring safety.

- Cultural. In a cross-cultural study on the quality perception of beef Grunert (1996) found that French consumers had more sophisticated beef purchasing behaviour than consumers in other countries.

The second point concerning the model is related to the information processing element. As highlighted by von Alvensleben (1997) consumers use key information or information chunks in forming product perceptions. The following section studies in detail this particular information processing mechanism as it has direct relevance to understanding perception formation for beef and also to understanding previous research on meat quality perception.

\footnotetext{
' For example, protests over Mc Donald's; the fast food chain, alleged indirect involvement in the destruction of the South American rain forests due land clearance for beef production.
} 


\subsection{Understanding perception formation for beef}

In order to understand how consumers have formed current attitudes and perceptions towards beef quality it is necessary to briefly address two dual process theories of information processing; the Elaboration Likelihood Model (ELM) (Petty \& Cacioppo 1981) and the heuristic-systematic model (Chaiken 1980), both of which, according to Eagly \& Chaiken (1993), are complementary. Each model encapsulates two modes of information processing; the ELM encompasses central and peripheral processing, while the heuristic-systematic model, as denoted by its name, encompasses heuristic and systematic information processing. As illustrated in figure 2.3 the heuristic and peripheral modes correspond with each other since they refer to the same mode of information processing, while the systematic and central modes correspond to each other for the same reason.

Figure 2.3: The ELM and Heuristic-Systematic model

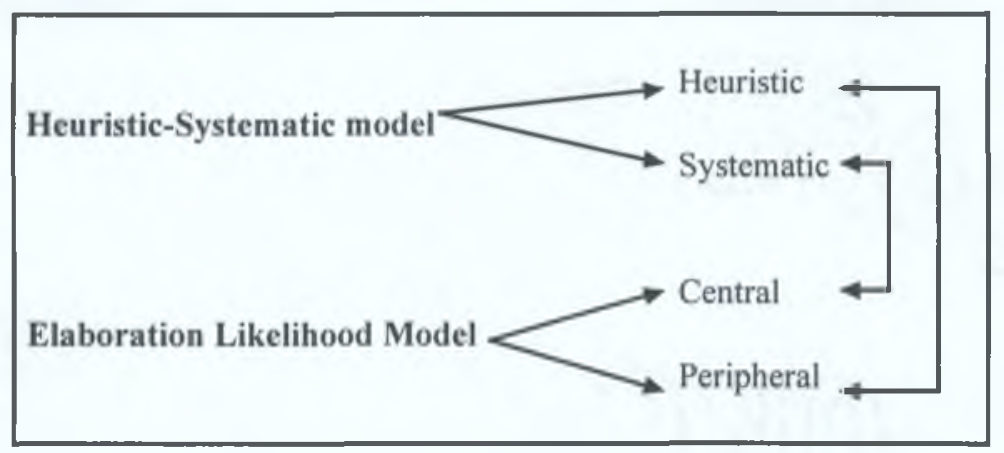

\subsubsection{Heuristic and peripheral modes of information processing}

The mode of information processing represented by the heuristic and peripheral mechanisms predominates where the individual is either unmotivated or unable to process the message. The state of mind of the consumer is similar to that of low involvement. Consumer involvement is defined by Wilkie (1994: 166) as a concept relating to personal relevance: a state of energy (arousal) that a person experiences in regard to a consumption-related activity.

In making judgements people use simplifying processes called heuristics. The term 'heuristic' was employed by Kahneman \& Tversky (1972) to refer to inexact or ruleof-thumb processes which may be used unconsciously in thinking. Their belief was 
that ideas which were more readily accessed/available tended to be given a greater weight by people. Heuristic reasoning makes more use of information that is eventful or recent which in turn affects judgement of risk and cause people to neglect information that is less available, even though it may be relevant (East, 1997). Here the media often has a significant role to play as denoted by Lichtenstein et al. (1978) who suggests that some risks are exaggerated by people because they are heard about more often in the media. The recent BSE crisis serves as support for Lichtenstein et al. 's (1978) suggestion. Indeed von Alvensleben et al. (1998) place a major part of the blame for decline of the image of red meat squarely upon the media. They suggest that critical mass media reports on meat have not only been the cause of the deterioration of the image of red meat but also the consequence. Furthermore, any attempts to regain confidence or to restore the image of red meat will be met with difficulties because they are directed to a symptom rather than to the cause of the problem. Further discussion of the topics of BSE and the media will follow later.

\subsubsection{Central and systematic modes of information processing}

The second mode of processing, represented by the central and systematic routes, predominates when the individual is highly motivated, has the ability to process the information and is able to do so in the absence of distracting factors. The state of mind is similar to that of high involvement where careful consideration is given to the information presented and there is a reasoned weighting of the facts. Consumer behaviour research on attitudes is conducted predominantly from this perspective in the form of multi-attribute attitude models ${ }^{1}$.

However, this research orientation has received much criticism because it does not describe how people really think. As East (1997:163) argues: 'People do not assign likelihoods and evaluations, multiply them and sum the products to form their attitudes'. In support Conner (1993) highlights that the mathematical perspective of decision making is too elaborate in food choice. Nonetheless, a large amount of empirical work in consumer behaviour research has been carried out from the

\footnotetext{
${ }^{1}$ Multi-attribute attitude models are the most widely used theories in consumer behaviour research and study consumer decision making on the basis that a number of alternatives must be evaluated and that these evaluations are based on multiple attributes (characteristics) of the alternatives (Grunert, 1988).
} 
perspective that consumer decision making is ordered and logical. Grunert (1988) notes that after conducting a meta-analysis of various studies in which multi-attribute attitude models were used to predict behaviour, the percentage of explained variance of predictive power ranged from $5 \%$ to $50 \%$, highlighting the erratic success rate of this research orientation.

Leaving the discussion of the distinction between the two modes of information processing aside for a moment, Eagly \& Chaiken (1993) point out that the two modes are not mutually exclusive but in fact interact at various levels. For instance, as motivation increases to some moderate level heuristic processing may predominate over systematic processing. It can be argued that information processing for beef is performed at a moderate level because while motivation is high in part due to the negative attention which beef has been receiving over the years in terms of health and safety issues, the ability of consumers to objectively interpret these messages has been brought into question. Evidence for this viewpoint will be given from the perspective of two fronts.

Firstly, the media's effect on consumer judgement at the time of the BSE crisis will be examined, giving credence to the notion that heuristic reasoning was used by consumers to process information concerning the issue. Secondly, studies examining consumers ability to assess the product quality of beef itself will be reviewed to highlight consumers' inability to objectively assess the eating quality at the point of purchase.

\subsection{Heuristic Reasoning and Media Coverage of the BSE Crisis}

The recent BSE crisis lends itself as a good example of the employment of heuristic reasoning in the formation of perceptions for beef. The crisis highlighted the novel risk associated with consuming beef which, as Harrington (1995) denotes, led to a vague uneasiness which caused some consumers to reduce their beef consumption. Harrington (1995: 3) further comments: 'The typical consumer is only vaguely aware of the real issues and the scale of the problems, and is inevitably confused'. 
The media coverage (an element influencing perception which can be classified in the product environment section of von Alvensleben's (1997) model in its redefined form) surrounding the crisis led consumers to utilise heuristic reasoning in changing their attitudes towards beef. A study by Burton \& Young (1997) gives credence to this argument. They observed the behaviour of consumers through empirically measuring the media attention to BSE and the resulting changes in expenditure patterns over the 1989-1995 period for beef, pork, chicken and lamb. The study period as can be seen relates to a time period prior to the announcement on $20^{\text {th }}$ March 1996 from the British Secretary of State for Health concerning the possible link between BSE and nv-CJD. Burton \& Young (1997) concluded that '...the media attention had a detrimental effect on the market for beef and even though the market recovered to some extent, beef producers suffered a sustained loss of market share' (Burton \& Young, 1997: 24). Standard economic influences were also accounted for in the study.

Massive media coverage was, as a result of the March $20^{\text {th }}$ announcement, driven about the uncertainty of what the statement meant for the safety of beef. As Harris \& O'Shaughnessy (1997: 30) point out '...the Government had cast the BSE issue as a technical problem with a technical solution, partly in the hope of limiting the political damage. The result, however, was a public communications crisis interwoven with a public health crisis'. The media were unable to decode the scientific discourse and thus over exaggerated the risk which was in turn communicated to the public. For instance, the Daily Mirror (March $21^{\text {st }} 1996$ ) told its' readers that 500,000 people could die of the disease.

An important consideration therefore, in the light of Burton \& Young's (1997) study, is that the moral panic which resulted from the announcement had been preceded by the accumulation of years of previous media coverage about BSE. Indeed, as Palmer (1996) suggests, the announcement led to the exacerbation of other related concerns which had been reported in the media over the years such as food safety, healthy eating, and animal welfare. This effect can be explained by what sociologists refer to as an 'amplification' effect. 
Mass media coverage can produce this 'amplification' effect; a term used to describe the way in which the media report on public concern about a phenomenon previously reported, which in turn results in increased public concern, which results in further media coverage, and so on (Beardsworth, 1990). The amplification effect quite simply results in the generation of moral panic among the public. Figure 2.4 is a simplified illustration of this effect.

\section{Figure 2.4: Amplification Effect}

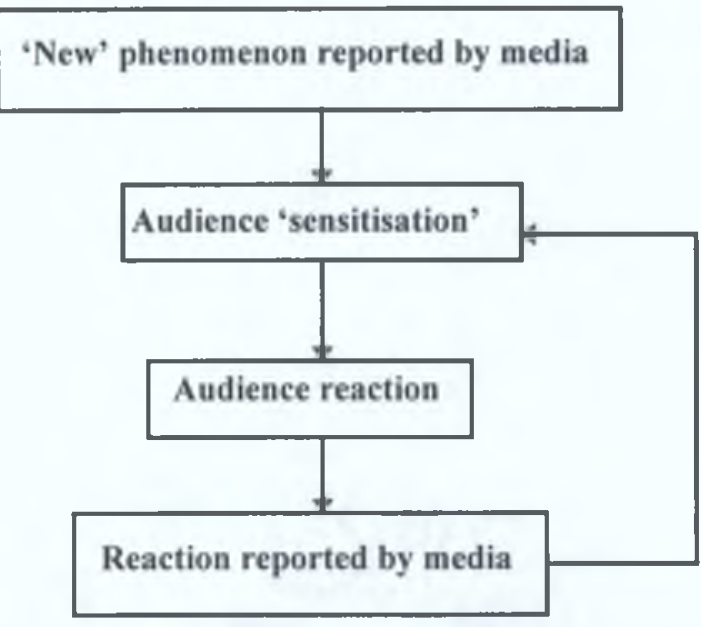

Source: Beardsworth, A.D. (1990) Trans-science and Moral Panics: Understanding Food Scares. British Food Journal. Vol.92. No.5. p.12.

The process begins when the public are sensitised to a 'new' phenomenon by the media, for whom novelty and sensation are important news values. Once sensitised, the audience reacts by changing its behaviour and/or expressing its concerns. These changes of behaviour and expressions of concern become in themselves newsworthy, and are picked up by the media and fed back to the audience in a dramatic and disturbing form and the process continues until saturation (Beardsworth, 1990).

Additional empirical evidence concerning the effects of the media and beef consumption is reported by McIntosh et al. (1995) who examined the factors associated with sources of influence/information in reducing red meat consumption by elderly subjects. Over $40 \%$ of those who reported to having reduced their red meat consumption indicated that the mass media led them to make the change. Furthermore, Konradi et al. (1994) in a study among German consumers found that 
$31 \%$ reported reducing their consumption of red meat as a result of media reports on meat safety problems.

Overall, the findings presented in this section substantiate Wilkie's $(1988,353)$ proposition that the mass media has become a potent socialising force in society and that the messages it conveys can challenge or reinforce our current values and teach us about new forms of behaviours.

\subsubsection{Product category schema}

As well as heuristics another related mechanism of information processing, productcategory schemas, can also be used to explain recent consumer behaviour towards beef. Crocker et al. (1984: 197) define a schema as '...an abstract or generic knowledge structure, stored in memory, that specifies the defining features and relevant attributes of some stimulus domain, and the interrelationships among those attributes'. A consumer's schema for a product category contains cumulative knowledge about the product (e.g. typical attributes, relationships among attributes and relationships between that product category and others) which can influence the manner in which consumers evaluate products (Stayman et al., 1992). Judgement about a concept can be revised by incorporating new information alongside existing information. However, sometimes new information may alter consumer views so that a concept is interpreted by reference to a different schema as is the case in product repositioning (Sujan \& Bettman, 1989).

One can argue that a health and safety schema have been progressively used by consumers in the 1980s and 1990s as the ones by which the evaluative judgement of beef is made. This schema has challenged and in some cases predominated (in the case of those who reduced their beef consumption) the traditional schema associated with beef which encompasses family, wholesomeness and organoleptic experiences.

Evidence for this schematic transition is provided by Tazelaar (1994) who in discussing the problems facing the meat sector argued that the image of meat has come under pressure because of consumers worrying about the safety and 
wholesomeness of the product. Similarly, von Alvenseben (1995), studying German consumers, argues that when the first image study was undertaken in 1972 the reputation of meat was still undamaged; meat was viewed as a healthy and tasty food of maximum value. This good image was maintained until the end of the Seventies. At the beginning of the Eighties, meat started to lose its good image.

In 1991 Ashwell et al. (1991, 293) commented: 'On balance, the consumers' perception of the nutritional benefits of meat, along with its traditional, esteemed place as a 'social institution' look like outweighing current (and hopefully future) scares'. The validation of this comment today is questionable when considered in the context of arguments presented above. This circumstance highlights that recent events have finally overcome the strength which the traditional symbolism of meat has had on the perceptions of many consumers.

The use of product category schema to form positive and negative images of meat, in particular beef, is similar to the idea of the halo-effect described earlier. However, with the exception of the above examples little or no work has been carried out to examine this topic for meat.

The schematic transition to health and safety schema for meat has come about through various medical reports and media coverage over the years. For instance, in the case of health reports, organisations such as COMA (Committee on Medical Aspects of Food Policy) warned about the high saturated fat content of red meat. In 1984 COMA recommended that the saturated fat content of people's diets should not exceed $15 \%$ due to its association with coronary heart disease (Tilston et al., 1993). Meat is regarded as a major source of saturated fat and beef is perceived to be one of its highest contributors. In the case of safety the extensive media coverage of such issues as BSE and hormones have caused the transition. Further discussion will be given to the topics of health and safety and their effect on beef consumption in the next chapter. 


\subsection{Heuristic Reasoning and Product Ouality Assessment}

The second aspect to be examined is consumers' ability to assess the product quality of the beef itself (the direct product information element of von Alvensleben's (1997) model) and the incidence of the use of heuristic reasoning in this process. In relation to assessing the quality of a piece of beef, research indicates that consumers show considerable uncertainty in their formation of quality expectations. In other words consumers find it difficult to assess the eating quality of beef using the quality indicators which they use at the point of purchase. To give an example, the most recent work focusing on this area examined which concrete attributes (characteristics which consumers can see/feel/smell) consumers use to infer the more abstract eating quality characteristics which they expect; taste, freshness and so on (Grunert 1996). Grunert (1996) found that two factors appeared to dominate the formation of expected quality/value of a piece of beef steak, namely the perceived fat and the place of purchase.

With regard to perceived fat, though consumers felt that it detracted from the quality, a certain amount of marbling (intramuscular fat) actually contributes to tenderness and taste, characteristics which they desire. The high importance attached to the place of purchase, in particular the butcher, shows that consumers would like to entrust their decision into the hands of an expert.

This study illustrates consumers' inability to objectively and systematically process information (quality cues/characteristics) with regards to assessing beef quality. Indeed the consumers' perception of quality by definition supports this point. Lassen's (1993: 3) definition is worth repeating again: 'Quality concept describes the foundation on which evaluation of food quality is based; it suggests a comprehensive understanding of quality...[on the other hand] quality perception is used, as an expression that reflects the fact that the consumer's relation to quality is often incomplete and inconsistent'. In other words quality concept refers to the objective evaluation of quality such as that of a food scientist, whereas quality perception refers to the evaluation of quality by consumers which studies such as Grunert's (1996) shows is not objective. Most consumers are not experts at assessing meat quality, so 
they have to focus on a few concrete characteristics in the hope that these have some connection with the desired, more abstract characteristics.

While little if any empirical work in consumer behaviour research has been carried out into heuristic information processing, its usefulness, as the previous discussion outlined, is clearly evident in relation to understanding belief formation for beef. Nonetheless, the user orientated approaches to studying meat quality referred to at the beginning of this chapter, have in recent times drawn away from the assumption that consumers use a predominantly systematic mode of information processing to realising that a heuristic mode of processing is also used by consumers. Grunert's (1996) study, just reviewed, is but one example of how user orientated approaches examine the incomplete and inconsistent relation which consumers have to meat quality. These approaches are examined in the next section.

\subsection{Approaches to User Orientated Ouality}

Grunert (1997b) highlights four approaches to user-orientated quality namely the economics of information approach, the multi-attribute approach, hierarchical approaches and the means-end chain theory. While the economics of information and multi-attribute approaches make the assumption that consumers systematically process quality information in order to form their perceptions about quality, the hierarchical and means-end chain approaches take the view that a more heuristic mode of processing quality cues is undertaken by consumers. The following section reviews these approaches from the perspective of how they apply to beef.

\subsubsection{Economics of information approach}

The economics of information approach makes the distinction between search goods, where the quality can be inferred before purchase and experience goods, where the quality can be evaluated only after purchase (Nelson, 1970). In the case of experience goods consumers will try to infer quality from surrogate factors like a brand name. This argument was then extended on two fronts. In the first instance it was identified that most goods have aspects of both search and experience goods and it therefore makes more sense to apply a multidimensional notion of quality which 
includes both characteristics (Wilde, 1980). For instance, in beef flavour is an experience characteristic whereas colour is a search characteristic.

Secondly, it was argued that there may be a third group of characteristics termed credence characteristics (Andersen, 1994). Here the consumer, even after purchase, cannot detect whether the product actually possesses the characteristic. For instance, if a piece of beef has been produced with due respect for animal welfare this is not reflected in objective characteristics in the final product.

\subsubsection{Multi-attribute approach}

The multi-attribute approaches, like the economics of information approach, assumes that quality is a multi-dimensional phenomenon and can be described by a set of characteristics (attributes). This can take several forms. In the simplest form, the degree to which a product is believed to possess an attribute is weighted against the subjective importance of that attribute. Many variations of this basic model have been used in consumer behaviour theory including the Fishbein attitude model (Fishbein \& Ajzen, 1975), the theory of reasoned action (Ajzen \& Fishbein, 1980) and the theory of planned behaviour (Ajzen, 1985).

To some extent, the distinction between search, experience and credence characteristics has been incorporated into multi-attribute models by the distinction of intrinsic and extrinsic product cues ${ }^{1}$ (Olson, 1977). Intrinsic attributes refer to attributes of the physical product, such as flavour and aroma, and cannot be changed without altering the nature of the product itself. Extrinsic attributes are related to the product and refer to search characteristics, such as price, place of purchase and brand name. The intrinsic-extrinsic dichotomy of quality cues is useful for discussing quality but is not without conceptual difficulties. For instance, in the case of meat a small number of cues are both intrinsic and extrinsic such as colour and leanness.

\footnotetext{
' Cues are stimuli used to guide the consumer in forming opinions about various phenomena (Williams, 1992).
} 
Zeithaml (1988: 9) proposes that consumers depend on intrinsic attributes more than extrinsic attributes in pre-purchase situations when intrinsic attributes are search attributes (rather than experience attributes).

However, there are criticisms of multi-attribute models. Grunert (1993) argues that these models do not take into account the inter-relationship of the attributes. For instance, some consumers may infer taste from price or healthiness from fat content; all of these are treated as attributes at the same level of abstraction in multi-attribute models. In reality consumers may use the extrinsic cues at the point of purchase in order to infer more abstract characteristics such as taste which can't be readily assessed until the point of consumption. Nonetheless, quite a number of studies have employed the Theory of Reasoned Action, a variant of the multi-attribute approach to explain the frequency of buying meat (Richardson et al., 1993; Zey \& McIntosh, 1992; Shepard \& Towler, 1992; Sapp, 1991; Sapp \& Harrod, 1989; Shepard \& Stockley, 1985). The Theory of Reasoned Action is based on the assumption that consumers are usually quite rational and make systematic use of information made available to them. The theory makes attitude to the behaviour a determinant of intention and introduces a second determinant, called subjective norm, which is the internalised influenced of people who are important to a respondent (Ajzen and Fishbein, 1980).

Zey \& Mc Intosh (1992) found in a study of women that attitudes toward consuming beef did not predict directly intent to consume beef, but the subjective norm did. Specifically, the respondent's husband and friends strongly affected their intention to consume less beef. They concluded that knowing the subjective norm permitted prediction of the womens' intentions because such intentions are not under attitudinal control.

Sapp \& Harrod (1989) expanded the theory of reasoned action using reference group ${ }^{1}$ theory. As stated the normative notion of the reference group is already incorporated into the theory of reasoned action. Sapp \& Harrod (1989) proposed that the impact of the 'generalised reference group' (social acceptability) should also be measured. 
Social acceptability measures the extent to which consumer food choices are driven by societal-wide opinions, fads and fashions. In general, the construct is meant to address the notion of 'what most people do' with respect to some behaviour. Results indicated that the social acceptability component outweighed normative and attitudinal influences on intentions to eat beef. Thus it was concluded that for beef consumption, popular opinion seemed to weigh heavily in consumer food choice and that consumers can be affected by what they feel is the opinion of their larger social system. However, in Sapp's (1991) more recent study both social acceptability and attitudes towards beef were significantly related to intentions to consume beef.

One of the principal findings with regard to beef in Richardson et al. 's (1993) study was a difference in the perceived importance of taste among those who had changed their consumption of beef. Those who had increased their consumption had a stronger attitude on this dimension. Also those who had increased their consumption of chicken held a stronger attitude towards health than those who had decreased their consumption. Similar findings were found by Zey \& Mc Intosh (1992), where women who believed health to be important viewed beef eating as having negative consequences, while those who viewed taste and appetite as important defined beef consumption as having positive consequences. This finding suggests that hedonic and health factors play an important role in beef consumption.

\subsubsection{Hierarchical models}

A group of models which deals with the above criticism of multi-attribute models are called hierarchical models. They have in common the notion that consumers infer some attribute from others. In most cases the inference is made from the concrete to the abstract. For instance, Steenkamp (1989) found in studying gammon steaks that consumers infer fatness from the colour; perceived fatness was rated higher for red gammon than pink gammon. A study which explicitly employs the hierarchical approach and deals with the relationship between expected and experienced quality is that by Steenkamp \& van Trijp (1990).

\footnotetext{
'A group to which a consumer looks for guidance for values and behaviour (Wilkie, 1994).
} 
In this study a 'quality guidance' model was used to link the physical attributes (technical product specifications) of a beef product (blade steak) to quality as perceived by consumers (see figure 2.5).

Figure 2.5: Quality Guidance

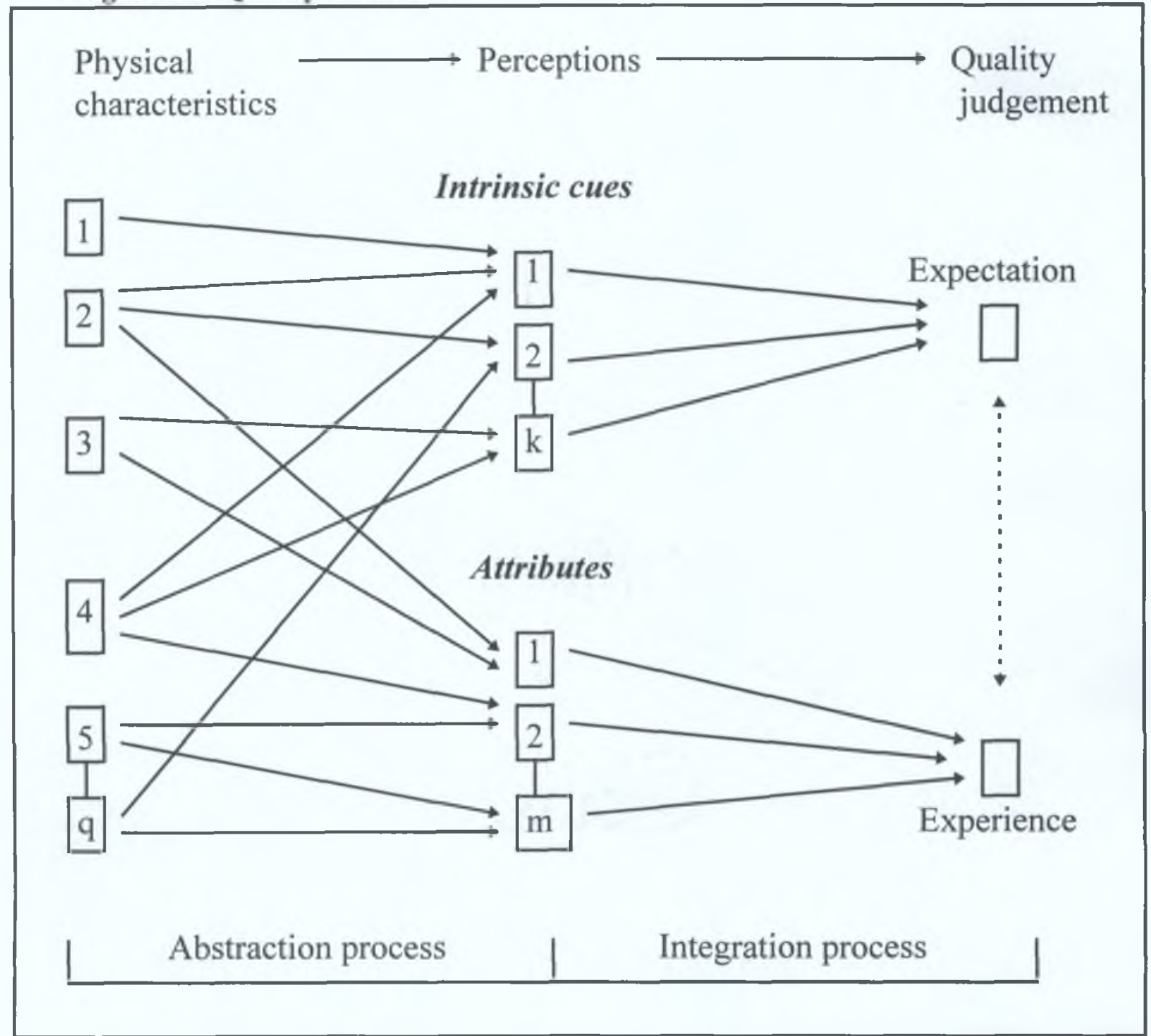

Source: Steenkamp, J-B.E.M. \& Van Trijp, H.C.M. 1989. 'Quality Guidance: A Consumer-Based Approach for Product Quality Improvement' in G.J. Alvonitis et al. (eds.), Marketing Thought and Practice in the 1990's: Proceedings of the $18^{\text {th }}$ Annual Meeting of the European Marketing Academy, Vol. 1, Athens: EMAC, p.722.

Expected quality at the point of purchase and experienced quality upon consumption were measured in order to study the quality perception process. Focusing on intrinsic cues the authors found that consumers use three quality cues when forming expectations about the quality of a blade steak; thickness, visible fat and freshness. Expected quality increases with attractive thickness and freshness, while it decreases 
with the amount of visible fat. The quality as perceived upon consumption; experienced quality, was found to increase with perceived flavour and to decrease with the amount of non-meat components (fat, sinews, tendons). These findings are illustrated in figure 2.6 .

Figure 2.6: Quality expectation and experience for blade steak.

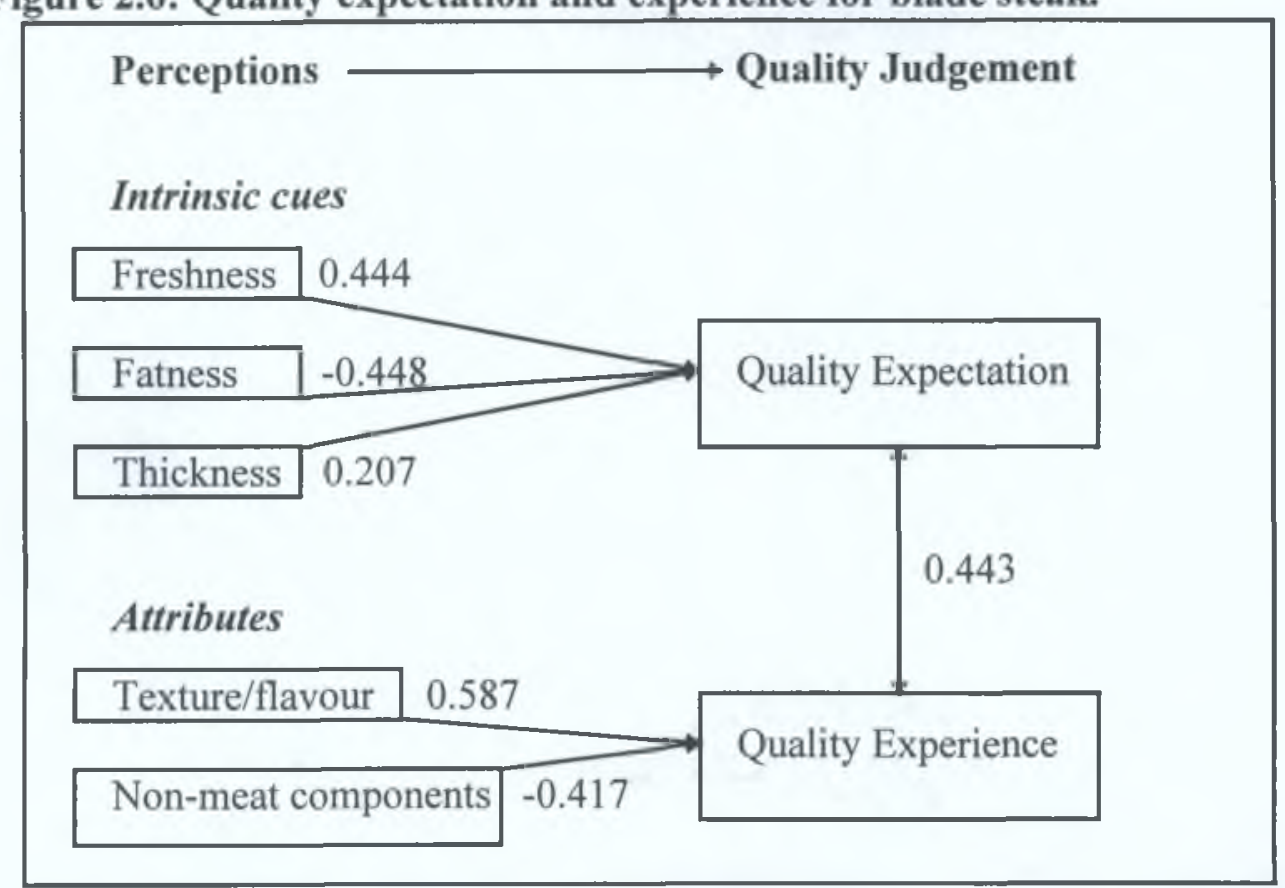

Source: Adapted from Steenkamp, J-B.E.M. \& Van Trijp, H.C.M. 1989. 'Quality Guidance: A Consumer-Based Approach for Product Quality Improvement' in G.J. Alvonitis et al. (eds.), Marketing Thought and Practice in the 1990's: Proceedings of the $18^{\text {th }}$ Annual Meeting of the European Marketing Academy, Vol. 1, Athens: EMAC, p.731

Notice that the correlation between quality expectation and quality experience was only modest at 0.443 . This indicates that consumers have difficulty in accurately predicting eating quality at the point of purchase. This phenomenon can be illustrated by examining fat in meat.

In the case of intramuscular fat (marbling) there is a negative influence related to health value. Nevertheless, intramuscular fat actually enhances the juiciness and flavour of beef; characteristics which consumers value most upon consumption (experienced quality). Indeed the United States Department of Agriculture (USDA) used to place a major emphasis on marbling in grading their beef. The three top grades - Prime, Choice and Good - were graded according to level of marbling; Prime having a higher degree of marbling than Choice, and so on (Miller et al., 1976). The marbling 
paradox is a pointed example of the incomplete and inconsistent perceptions which consumers have towards beef .

\subsubsection{Means-end chain models}

Finally, the means-end chain model is an extension of the hierarchical approach. The idea of inferring more abstract descriptors from concrete product attributes is central in means-end chain theory. The means end-chain approach to perceived quality has been adopted by some researchers most notably Grunert (1996), Zeithaml (1988) and Olson and Reynolds (1983). 'The means-end chain approach to understanding the cognitive structure of consumers', notes Zeithaml (1988), 'holds that product information is retained in memory at several levels of abstraction'. The simplest level is a product attribute; the most complex level is the value or payoff of the product to the consumer. The model, as illustrated in figure 2.7, shows how a product characteristic (concrete or abstract) is linked to consequences (functional or psychosocial) of consumption, which in turn may be linked to the attainment of life values (instrumental or terminal). 
Figure 2.7: Means-end chain model

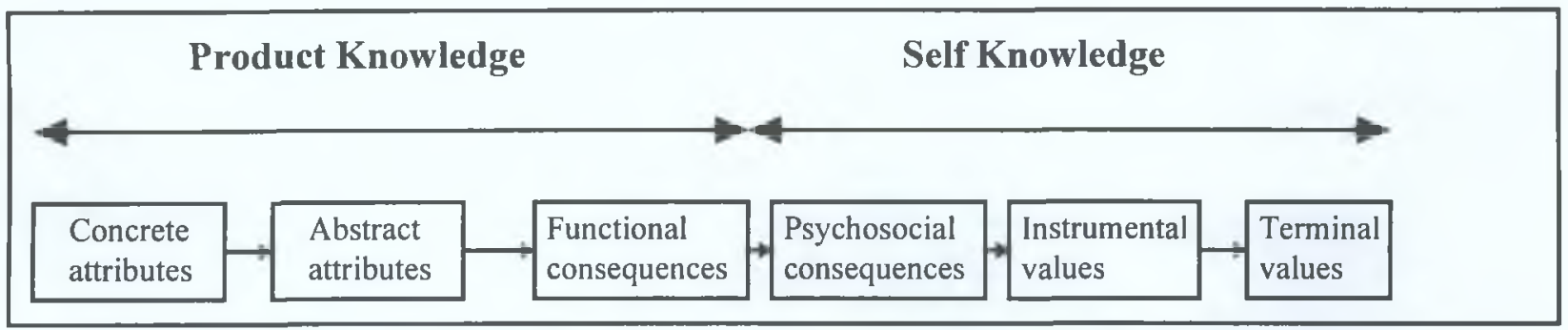

Source: Audenaert, A. \& Steenkamp, J-B.E.M. (1997) Means-end Chain Theory and Laddering in Agricultural Marketing Research. In Wierenga, B., Tilburg, A, Grunert, Steenkamp, J-B. E.M. \& Wedel, M. (eds.) (1997) Agricultural Marketing and Consumer Behaviour in a Changing World. Kluwer Academic Publishers. p.219.

Grunert $(1993,2)$ gives the following example of the theory; the concrete product characteristic low fat is linked to the abstract product characteristics fewer calories, which in turn is linked to the consequences slimming (functional) and social acceptance (psychosocial), which leads to the values self-confidence (instrumental) and self-esteem (terminal).

The idea of the means-end chain has been conceptualised by in many previous studies. Zeithaml (1988) provides a classification of these which are depicted in table 2.1 below.

Quality has been included in multi-attribute models as though it were a lower level attribute, however, Zeithaml (1988) argues that perceived quality is instead a second order phenomenon. From table 2.1 below this second order phenomenon is labelled under 'Quality Level' and referred to, for example, by Geistfeld et al. (1977) as 'somewhat abstract, multi-dimensional but measurable'.

Zeithaml (1988) provides a framework, illustrated in figure 2.8, of a means-end chain model relating the concepts of price, perceived quality and perceived value. As denoted at the top of table 2.1 the concept of value is placed at a higher level of abstraction than quality. Zeithaml (1988: 46) highlights that value differs from quality in two ways. Firstly, value is more individualistic and personal than quality and is therefore a higher level concept than quality. Secondly, value (unlike quality) involves a trade-off of give and get components. 
Table: 2.1 Selected Means-End Chain Models and Their Proposed Relationships with Quality and Value.

\begin{tabular}{|c|c|c|c|}
\hline Scheme & Attribute Level & $\begin{array}{l}\text { Quality } \\
\text { Level }\end{array}$ & $\begin{array}{cc}\text { Value Level } & \begin{array}{c}\text { Personal Value } \\
\text { Level }\end{array}\end{array}$ \\
\hline $\begin{array}{l}\text { Young and } \\
\text { Feigin (1975) }\end{array}$ & Functional benefits & Practical benefit & Emotional Payoff \\
\hline $\begin{array}{l}\text { Rokeach (1973), } \\
\text { Howard (1977) }\end{array}$ & Product attributes & Choice criteria & Instrumental values \\
\hline $\begin{array}{l}\text { Myers and } \\
\text { Shocker (1981) }\end{array}$ & Physical characteristics & $\begin{array}{l}\text { Pseudophysical } \\
\text { characteristics }\end{array}$ & $\begin{array}{l}\text { Task or outcome } \\
\text { referent }\end{array}$ \\
\hline $\begin{array}{l}\text { Geistfeld, } \\
\text { Sproles and } \\
\text { Badenhop (1977) }\end{array}$ & $\begin{array}{l}\text { Concrete, uni- } \\
\text { dimensional and } \\
\text { measurable attributes } \\
\text { (C) }\end{array}$ & $\begin{array}{l}\text { Somewhat } \\
\text { abstract, multi- } \\
\text { dimensional but } \\
\text { measurable (B) }\end{array}$ & $\begin{array}{l}\text { Abstract, multi-dimensional and difficult to } \\
\text { measure attributes }(\mathrm{A})\end{array}$ \\
\hline Cohen (1979) & Defining attributes & $\begin{array}{l}\text { Instrumental } \\
\text { attributes }\end{array}$ & Highly valued states \\
\hline $\begin{array}{l}\text { Gutman and } \\
\text { Reynolds (1979 }\end{array}$ & Attributes & Consequences & Values \\
\hline $\begin{array}{l}\text { Olson and } \\
\text { Reynolds (1983) }\end{array}$ & Concrete attributes & $\begin{array}{l}\text { Abstract } \\
\text { attributes }\end{array}$ & $\begin{array}{l}\text { - Functional consequences Terminal values } \\
\text { - Psychosocial consequences } \\
\text { - Instrumental values }\end{array}$ \\
\hline
\end{tabular}

Source: Zeithaml, V.A. 1988. "Consumer Perceptions of Price, Quality and Value: A Means-End Model and Synthesis of Evidence”, Journal of Marketing, 52, July. pp. 7.

To illustrate how both concepts differ in the case of beef consideration will be made of an incident that featured the British retail chain Sainsbury's. Soon after the announcement on March $20^{\text {th }}$ Sainsbury's 'slashed' the price of their beef and the result was a sales surge more intense than the pre-Christmas rush (Pitcher, 1996: 27). An explanation for this phenomenon is that consumers felt they were getting more value from the perceived 'lower quality' beef because the reduction in price compensated for the perceived 'reduction' in quality caused by BSE/CJD announcement.

Audenaert et al. (1997) used means-end chain theory to study purchasing motives of Belgian beef consumers. They found that consumers' motivational structure with respect to beef was primarily governed by a 'utilitarian', health related motivation and/or a hedonic, taste related motivation. 
Figure 2.8: A Means-end model relating price, quality and value.

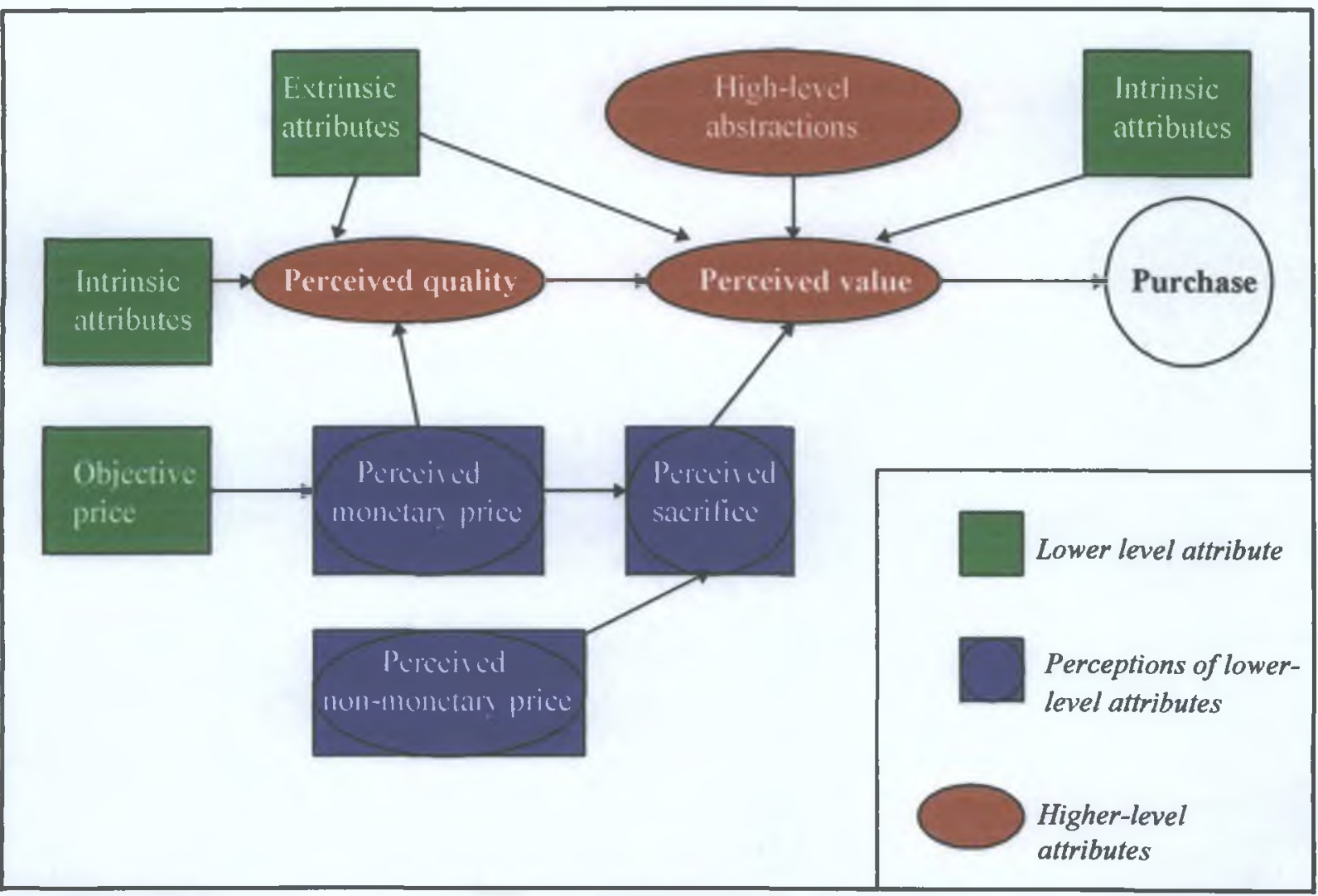

Source: Zeithaml, V.A., 1988. 'Consumer Perceptions of Price, Quality and Value: A Means-End Model and Synthesis of Evidence, Journal of Marketing, 52, July. p.6.

On the basis of these results three important segments of beef consumers could be identified (Audenaert et al.,1997: 227):

1. Utilitarian segment: the dominant attribute-value connection was 'absence of hormones' - 'safety'.

2. Utilitarian-hedonic segment: the values of 'happiness', ability to 'enjoyment life' and ability to have an 'exciting life' are linked to both the 'absence of hormones' and taste components, such as 'succulence', 'absence of visible fat' and absence of tendons'.

3. Hedonically-orientated segment: link in their cognitive structure 'friendship' and 'pleasure' to taste factors: 'succulent', 'thin', 'tender', 'without tendons' and 'without visible fat'.

Although not a means-end chain study, segmentation research of Dutch meat consumers conducted by the Product Board for Livestock and Meat (1991) found 
rather similar findings to Audeneart's (1997) study. Their findings indicated that heavy users perceptions were generally dominated by their traditional love for meat largely based on its good taste - hedonic. In contrast, light users' perceptions were dominated by their concerns for health and also price - utilitarian.

Further segmentation research in the United States found segments such as meat lovers, health orientated, price driven, creative cooks and active lifestyle (Yankelovich et al., 1989). One of the main findings in this research gives additional insight to the studies above. Consumers were found to experience a conflict between health and indulgence in their meat purchase decision making. They responded to this confusion by becoming more pragmatic about health. Recent beef advertising in the United States appears to be acting on the findings of such research. Attempts have been made to maximise on consumers' desire for meat and steer consumers' away from the utilitarian focus with the advertising focusing on the tagline 'Beef. It's what you want'. The new effort keys in on a research finding that consumers view beef as what they 'want to eat', while they view chicken as food they 'should eat' (Pollack, 1997). This type of meat advertising strategy has been urged by von Alvensleben et al. (1998) who stress that communication should put more emphasis on the emotional aspects of meat consumption rather than cognitive information.

Besides advertising other marketing tools have been used to drive this hedonistic strategic focus. For instance, Tesco is currently testing new meat shelving fixtures in some of its stores. These new fixtures are an initiative which moves away from plain clinical fixtures to a more exciting fun-based approach. The meat isle will be launched as 'World of Meat and Poultry' and will include improved merchandising and more co-ordinated packaging as well as overhead signs which will be aimed at making it easier for shoppers to put a meal together. The main objective of this initiative is to get lapsed users back eating meat (Paton, 1997).

The above findings give substantiation to Grunert's (1988) proposition that the fun and enjoyment aspects of consumption seem to have gained in importance relative to functional criteria. 


\subsection{Integrated approaches of perceived quality}

A few attempts have been made to integrate the various approaches to consumer orientated quality reviewed above into a unified framework for analysing the quality perception process for food products, the most notable cases being the work of Steenkamp (1989) and Grunert et al. (1996).

Steenkamp's (1989) model, illustrated in figure 2.9, assumes that the qualities a consumer seeks in a food product are always experience and credence qualities. Search characteristics, on the other hand, are used by the consumer only as indicators for the qualities actually sought. These search indicators cover both attributes of the product itself and other attributes, such as firm specific ones, branding for instance. Based on these observable indicators, the consumer forms expectations about experience and credence qualities, which in turn are aggregated into an overall expected one-dimensional quality. In other words the process of perceiving the quality of a piece of meat is through using quality indicators as a means to infer the eating qualities and credence characteristics desired at the point of consumption.

This process of inferral is referred to as inferential belief formation; one can infer beliefs about quality attributes which are not observable on the basis of the quality cues. For instance, in the case of countries outside Ireland the descriptive belief 'this beef comes from Ireland' signified by labelling information may lead to the inferential belief 'this beef tastes good because feeding is grass based as opposed to manufactured concentrated feed based'. The expected quality at the point of purchase may then later be compared to the experienced quality at the point of consumption, which will give rise to adjustments in the way future quality evaluations may be made. 
Figure 2.9: A conceptual model of the quality perception process

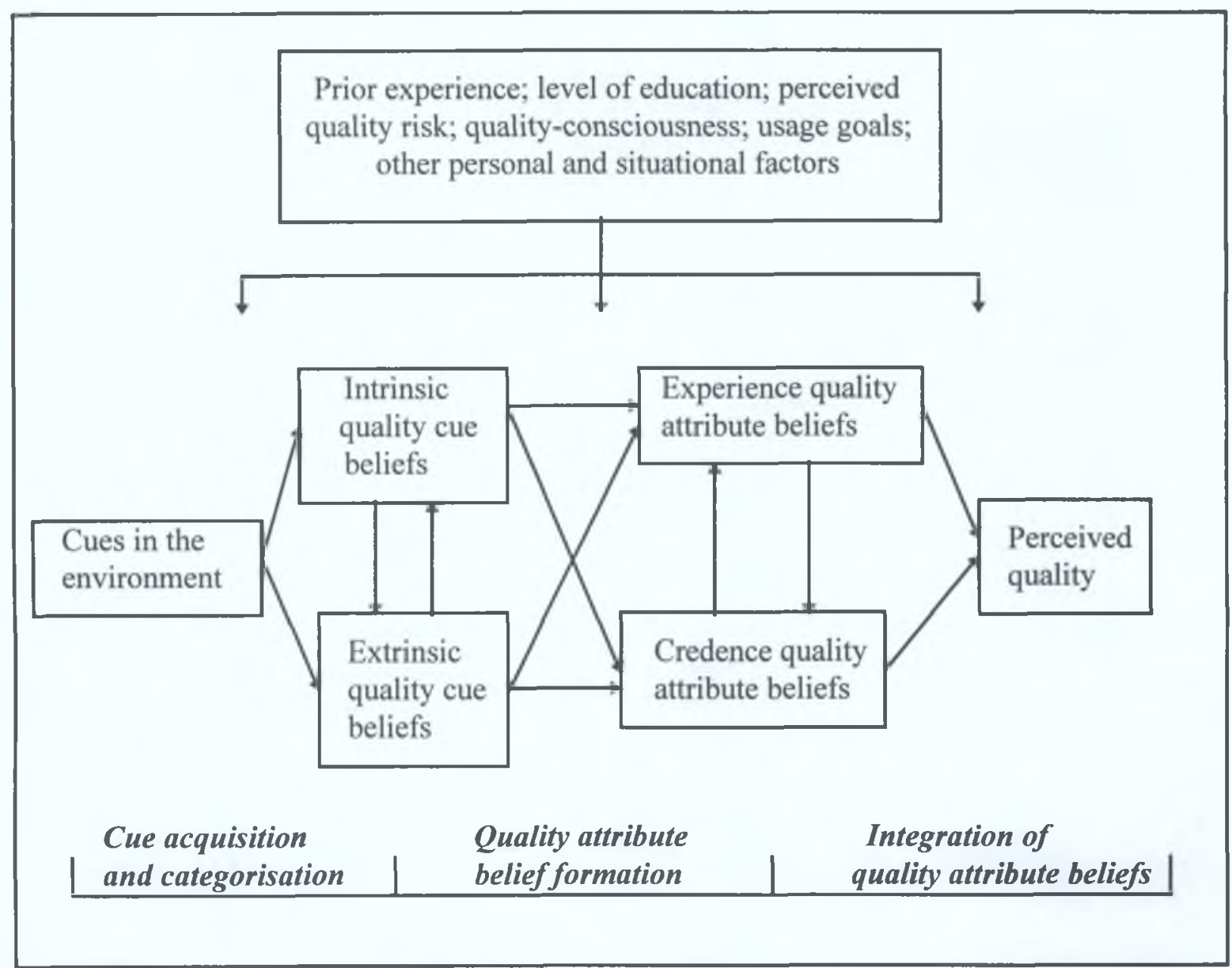

Source: Steenkamp, J-B. E.M. 1989. Product Quality: A Investigation into the Concept and how it is Perceived by Consumers. Van Gorcum, The Netherlands, p. 120.

The Total Food Quality (TFQ) Model designed by Grunert et al. (1996) elaborates further on Steenkamp's (1989) model and the various user-orientated approaches reviewed. Depicted in figure 2.10 additional aspects of the model are as follows (Grunert et al., 1996:22):

1. The model refers to the determinants of experienced as opposed to expected quality. The product characteristics the consumer uses as quality indicators in order to infer expected quality may also impact on experienced quality, and not necessarily in the way the consumer expects. In addition, experienced quality will be influenced by product characteristics not used by the consumer in his/her quality evaluation process, and by the way the product is used in a meal preparation process. 
2. The technical product specifications which will determine both the intrinsic quality cues that the consumer can perceive and the quality finally experienced.

3. The sensory characteristics of the product, which Grunert et al. (1996) regard as important mediators between technical product specifications, meal preparation and experienced quality.

4. The consumer's expected quality evaluation as such, while important, will determine the consumer's intention to buy only in relation to the perceived costs associated with the product, where costs can be both monetary and other costs. Price can be both a cost cue and an extrinsic quality cue.

5. Finally, the model goes beyond quality and looks at consumer's purchase motives, extending the means end chain of thinking.

It would not be possible for a single research study to effectively address the entire model, therefore Grunert et al. (1996) provide a schematic outline of the research questions which the model can address and the subsequent research methods to answer these questions which is illustrated in figure 2.11. For instance, in order to make the structure of consumers' evaluation of quality cues and quality aspects more transparent perceptual mapping should be used. Here product perceptions are formed into a small number of underlying latent variables by means of factor analysis or multi-dimensional scaling (MDS). These techniques can be used to derive the second order phenomena as previously discussed in the means-end chain section.

An empirical study which examines part of the TQM model is Grunert's (1996) examination of the quality perception of beef. The study was cross-cultural and aimed at examining the whole left hand section (except technical specifications) of the TFQ model, in other words the before purchase part of the model. The objective was to shed more light on how both intrinsic and extrinsic quality cues are perceived and used to infer expected quality and purchase motive fulfilment and how this affects purchase intention. As noted earlier results indicated that two factors appeared to dominate the formation of expected quality of a piece of beef, namely perceived fat and the place of purchase. Together these findings show considerable uncertainty on the part of consumers with regard to the formation of quality expectations. 
It is interesting to note that the other extrinsic quality cues tested in the study, country of origin and information about breeding and feeding, had practically no effect on the formation of quality expectations at all. This last point must be considered within the context of the time period in which the study was originally carried out; circa. 1992' a period when the BSE issue was just gaining momentum. In the light of the manner in which the BSE issue developed since this study one would expect very different results with regard to country of origin, feeding and breeding and their effect on the formation of quality expectations. For instance, the BSE crisis resulted in the renationalisation of beef demand in EU markets (Department of Agriculture and Food [DOAF], 1998), hence highlighting the recent development of the importance of country of origin in meat quality perception.

To date the majority of studies carried out in the area of meat quality perception have focused on the product itself; which characteristics are most important to the consumer and the interrelationship between expected and experienced quality expectations. However, recent events have warranted a re-examination of how perceived quality is defined and studied. The dimensions of health and safety discussed in brief earlier are examples of additional elements which have become encompassed in how consumers perceive the quality of meat. The study of these additional elements are important aspects of the study of the forces shaping how meat quality is perceived.

\footnotetext{
' The study was originally published in Denmark in 1993 - Baadsgaard, A., Grunert, K.G. \& Skytte,H. (1993) Alternativ afsoetning af dansk ungtyrekod - fase. MAPP project paper. Aarhus: The Aarhus School of Business.
} 
Figure 2.10: The Total Food Quality Model

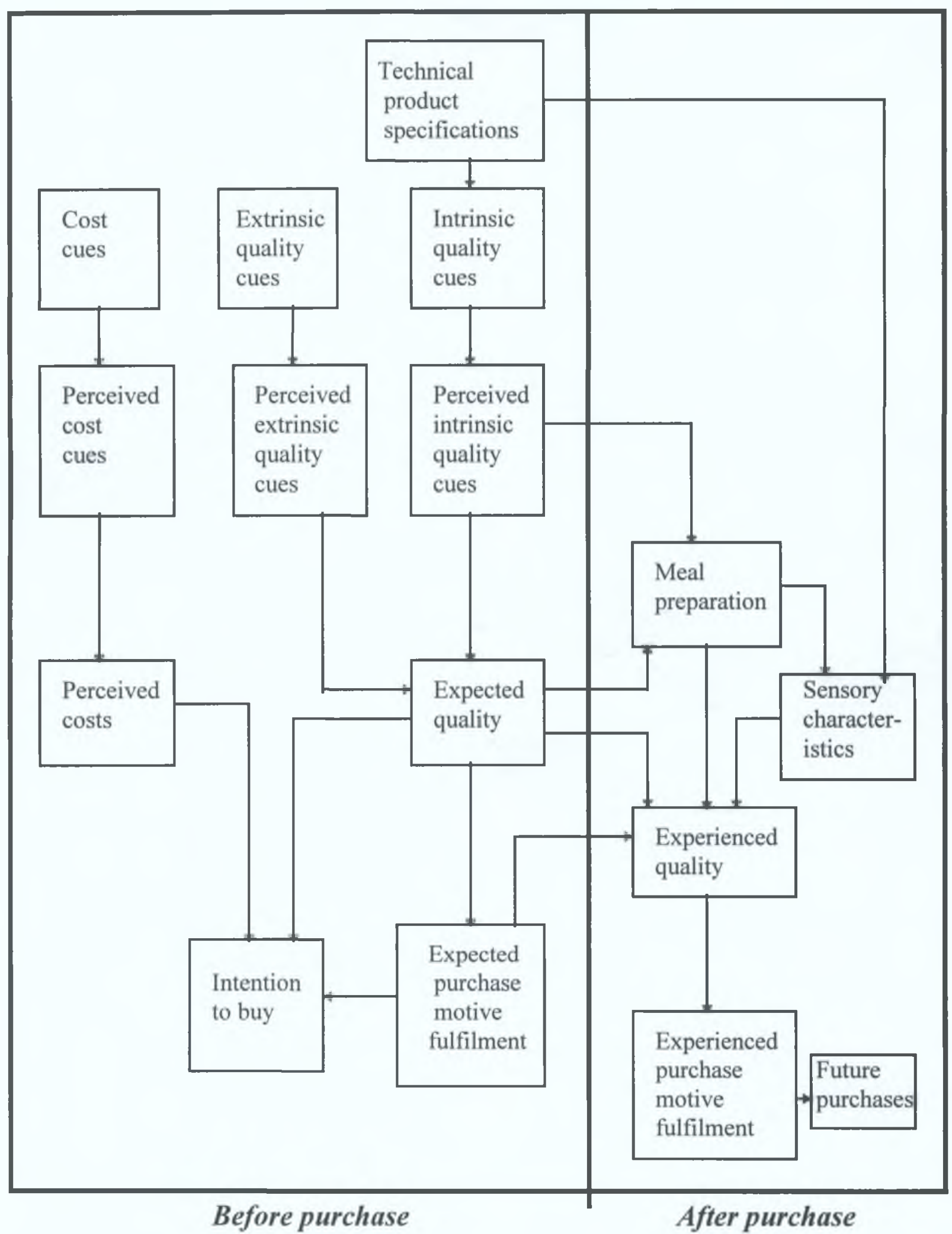

Source: Grunert, K.G., Larsen, H.H., Madsen, T.K. and Baadsgaard. 1996. Market Orientation in

Food and Agriculture. Boston, M.A: Kluwer Academic Publishers, p.82. 
Figure 2.11: Research methods and research questions in the TFQ model

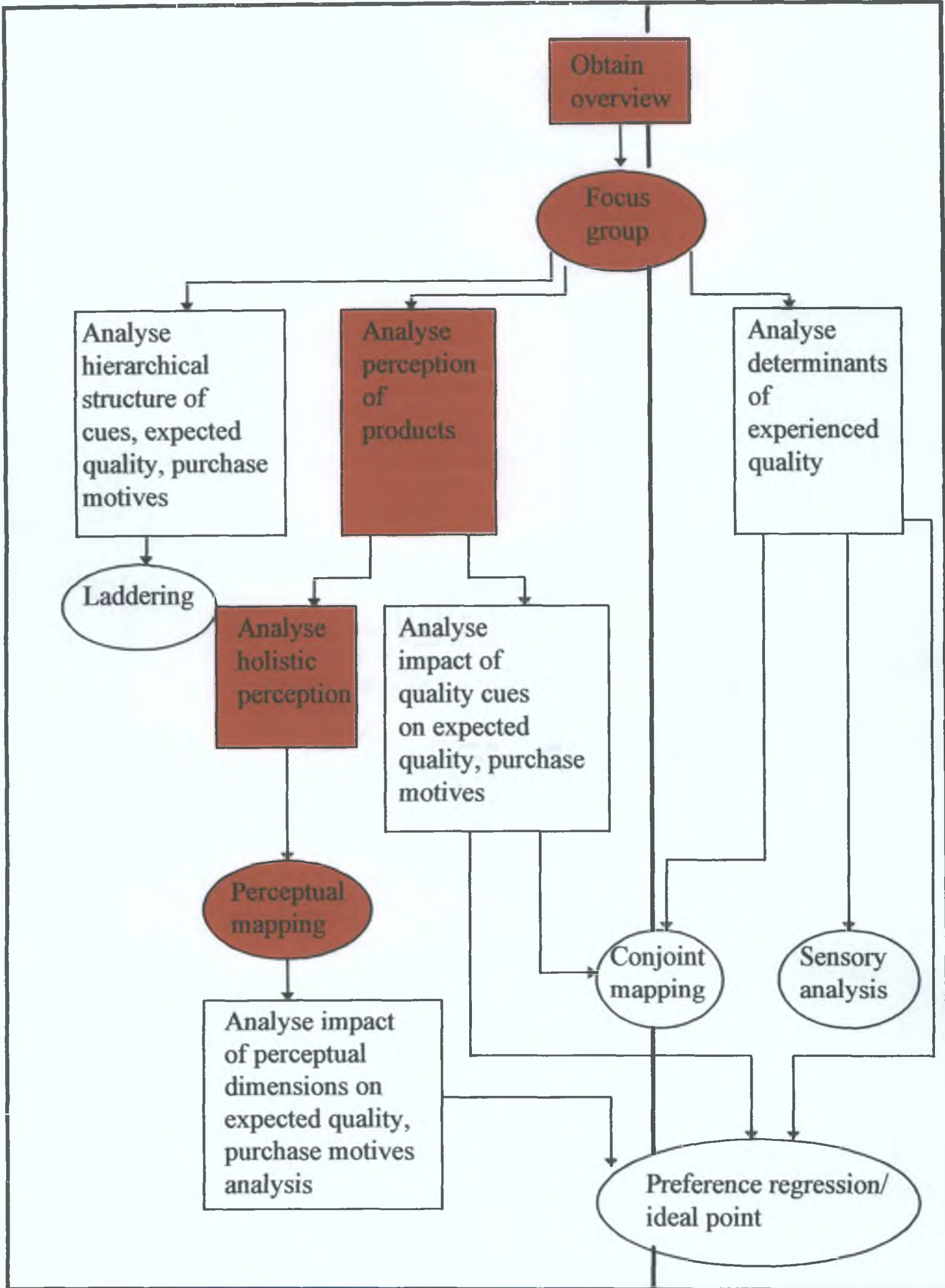

Before purchase

After purchase

Source: Grunert, K.G., Larsen, H.H., Madsen, T.K. and Baadsgaard, A. (1996) Market Orientation in Food and Agriculture. Kluwer Academic Publishers, p.111. 


\subsection{Broadening the determinants of perceived quality}

Currently, perceptions of beef quality are changing dramatically. Though they may be capricious, new considerations about quality are not simply those which allow consumers to enjoy the meat eating habit but could determine whether some people will continue to eat meat at all (Lister 1996). The traditional definition of meat quality perception was described mainly in terms of its intrinsic and extrinsic cues. However, this definition must now be broadened to encompass aspects of convenience, healthiness, safety, ethical and moral features (Issanchou, 1996; Lister,1996; Lassen, 1993). For instance, considerations must be made for animal welfare, for pathogens such as salmonella and for residues such as antibiotics. These additional features currently also affect the acceptability of meat.

Issanchou (1996) lists the factors affecting the perceived quality of meat as defined in its wider sense:

- Convenience

- Animal welfare

- Safety

- Healthiness

- Intrinsic quality cues

- Extrinsic quality cues

- Sensory factors

Note that price is not regarded as a determinant of perceived quality by Issanchou (1996). While no reason has been given as to why it has not been considered a possible explanation is put forward by Ahtola (1984) who argues against the inclusion of monetary price in multiattribute models because price is a 'give' component of the model rather than a 'get' component. This explanation can be tied back to Zeithaml's (1988) argument about the difference between quality and value. In other words, price is likely not to have been included by Issanchou (1996) as a determinant of perceived quality because it is essentially a value component, not a quality one.

An examination of price/quality relationship literature by Olson (1977) concluded that consumers use price to infer quality when it is the only available cue. When price was 
combined with other cues the evidence was less convincing. Zeithaml (1988) after reviewing the literature on this topic proposed that price was among the least important attributes that consumers associated with quality and she concluded that a general price/ perceived quality relationship did not exist.

An additional contribution to the broadening of the perceived quality construct is provided by Lister (1995: 6) who points out that determinants of perceived quality of a given product must be illustrated within the context of three stages:

1. Prior to purchase.

2. At the point of purchase.

3. Upon consumption.

The perspectives of Issanchou (1996) and Lister (1995) are inherently similar and figure 2.12 illustrate this integration. Prior to purchase considerations are deemed to be related to convenience, animal welfare, safety and health. At the point of purchase and upon consumption intrinsic and extrinsic cues predominate as determinants of quality. Finally, sensory cues are considered upon consumption a point noted in the following reasons for distinguishing perceived quality into three stages.

\section{Figure 2.12: The determinants of perceived meat quality}

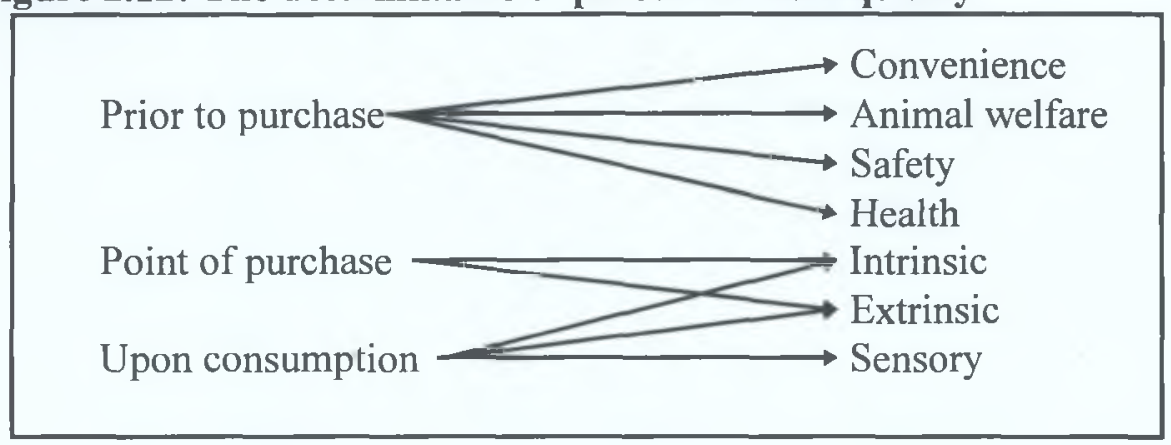

The perceived quality of a product must be distinguished within three stages for several reasons. Firstly, the buying purchase decision is a sequential process. Secondly, the main determinant factors are different for each stage though as examined previously with the interrelationship of expected and experienced quality (e.g. Steenkamp \& van Trijp, (1989)), perceived quality attributes at one of these stages can influence the perception of quality at 
another stage. Finally and above all, some factors, in particular the determinants of perceived quality prior to purchase, can be critical and thus lead the consumer not to buy or reduce their consumption of the product (Issanchou, 1996).

Many of the studies examining the perceived quality construct for meat have studied it within the context of the second reason given above; the interrelationship of expected and experienced quality. However, the primary objective of this thesis is to study perceived quality within a less well examined area, within the context of the third reason given, namely that of perceived quality factors which can lead the consumer to reduce their consumption of the product. Before examining this topic in the next chapter Irish studies examining attitudes and perceptions to beef quality will be reviewed.

\subsection{Attitudes and perceptions towards beef quality in Ireland}

An early Irish study conducted by Riordan (1974) representing Dublin households revealed interesting meat consumption patterns; beef consumption was eaten at least twice a week by over $85 \%$ of the households, pork was eaten in less than half the households and poultry in only one-third. Comparing these findings to those in McCarthy et al. 's (1998) recent study reveals the apparent substitution of beef for chicken. Household beef consumption decreased dramatically since Riordan's (1974) study. By 1998 beef was only eaten twice a week or more by $34 \%$ of the households. On the other hand chicken consumption increased and Mc Carthy et al. (1998) found that it is currently eaten a virtually every household; $99 \%$. Further discussion of Mc Carthy et al. 's (1998) study will be given later.

Riordan (1974) also found that $65 \%$ of housewives felt that beef buying was especially difficult. A considerable number of respondents expressed difficulties relating to obtaining beef with acceptable texture and toughness. It was revealed that these difficulties with beef were experienced irrespective of knowledge of the suitability of various cuts for various uses. The study suggested that the real source of dissatisfaction was the lack of product consistency, in particular the lack of reliability in the eating quality characteristics. The characteristics most sought after during consumption were tenderness followed by tastiness. These results compare with findings in Grunert's (1996) and Steenkamp's (1989) studies that consumers have always had difficulty in forming quality expectations of a piece of beef. 
Ahead of his time Riordan (1974) suggested that product design measures should be instigated throughout the beef production system and a quality mark, similar to that of the United States Department of Agriculture (USDA) referred to earlier, be used to communicate this effort to consumers.

A qualitative study of attitudes to meat by Lansdowne Market Research (LMR) (1987) revealed two trends. Firstly, the increasing demand for convenience foods and secondly, greater health consciousness. In relation to beef it was pointed out that beef was thought of as the most popular meat in Ireland, however, the study found that although beef continued to command a high level of respect its expense limited the frequency of experience. Furthermore, the expense reduced the possibility of beef being used in experimental cooking styles. As adventurous cooking was reported as becoming more popular, this trend was perceived as limiting the dependence on traditional dishes to which beef was closely aligned.

Product discussion commonly employed reference to product characteristics such as 'red', 'juicy', 'tough', 'lean' and 'fat'. The researchers interpreted this as highlighting a perception that beef was subject to variability of standards, according to price and source of purchase. Furthermore, the topic of expected and experienced quality was discussed. Housewives felt that it was difficult to predict the quality of a piece of beef in advance of purchase. This was interpreted by LMR (1987) as pointing to a further dependence on the advice of the butcher, a finding also found by Grunert (1996). However, should the experienced quality not conform with the expected quality as pledged by the butcher the reputation of the butcher would suffer.

In terms of imagery, beef was closely associated with nostalgic reminiscence of the past. It was perceived as representing traditional Ireland in 'the good old days' and was firmly linked with family imagery. Beef was thought to have maintained its popularity particularly amongst the male population. In a modern context, serving beef to a growing family ensured satisfaction and nourishment. Yet, in view of beef's premium price serving was usually associated with special occasions, shrouded in formality. This premium meant that product quality demands were higher than for other meat types; consumption was not taken lightly, but rather almost ritualised into the traditional family gathering. Furthermore, it is important 
to realise that the country was in the middle of a recession at that time, hence the constant emphasis on price.

In relation to meat in general, attitudes revealed a high level of respect for beef as the traditional and primary protein source in the Irish diet.

Changing eating patterns revealed in the LMR study foresaw the redundancy of beef's association with family imagery. It was reported that the occurrence of family members eating together was in decline. The rigid and formalised eating patterns in the past didn't fit with changing lifestyles of family members, in particular young adults. Furthermore, the emergence of health and safety associations of meat was also evident in the study.

Concern and suspicion relating to the presence of antibiotics or hormones was related to all meat types, both red and white. It was recognised, in urban and rural areas, that antibiotics were used to combat illness in beef cattle. However, media reports at this time concerning the sale of sick animals before recovery evoked concern that the law was being breached. The immediate concern was that an immunity to medically prescribed antibiotics for humans could result from the long term consumption of these residues.

On the other hand, the use of hormones was said to stimulate growth in cattle, and as such were felt to be similar to forced production in the vegetable and fruit sectors. Media reports of adverse effects of hormones on personal growth were causing concern, yet these reports did not seem to have the same credibility as the suspected side effects of antibiotics. It seems clear that the level of concern in this area was closely related to a lack of trust in law enforcement. Housewives felt that the laws relating to the use of antibiotics and hormones were not being effectively enforced to protect the consumer.

In regard to health issues LMR (1987) research revealed that concerns were directed against red meat and awareness of these issues was apparently led by the media. Red meat was said to possess a high fat content and was criticised for its cholesterol level. Due to the fat content, red meat was thought to have a higher calorie count than white meat. Yet, on the positive side red meat was complemented for its beneficial iron content which was perceived to be unparalleled by white meat. 
On the topic of decreasing consumption levels of beef, the report indicated that economic hardship was making beef consumption difficult to support in the household budget. Indeed, although medical advice supported the reduction of beef consumption cutbacks seemed easier to justify on medical grounds rather than economic grounds. It was therefore complimented by LMR (1987) that reductions in beef consumption at this time were more likely to be related to economic circumstances than real concern in the health issue. An examination of consumption rates around this period give credence to this conclusion. Between 1987 and 1988 , at the height of the recession in Ireland, beef consumption feel by nearly $2 \mathrm{~kg} / \mathrm{head}$; from $21.2 \mathrm{~kg}$. to $19.3 \mathrm{~kg}$. The only time this decrease in beef consumption has been matched over a similar period was between 1995 and 1996, when the consumption rate fell from $14.6 \mathrm{~kg}$. to $12.7 \mathrm{~kg}$., due to the BSE and hormone reports.

Another Irish study examined the dietary concerns of Irish consumers. Quantitative research carried out by O'Neill \& Shanahan (1993) in 1987, 1989 and 1991 revealed the level of concern about hormones and antibiotics in beef was greater relative fat in meat and other issues as depicted in table 2.2 . 
CHAPTER 3

\section{FACTORS INFLUENCING RED \\ MEAT DEMAND}




\subsection{Introduction}

The objectives of this chapter are to:

- Examine the relationship between perceived quality and meat demand.

- Study the factors which have influenced the decline in red meat consumption.

- Finally, to propose a framework for analysing the quality factors influencing beef consumption decline in Ireland.

\subsection{Perceived Quality and Meat Demand}

Aspects of the many approaches to user-orientated quality and their amalgamation into integrative approaches, which have been reviewed, have enabled consumer behaviour researchers to understand the importance and usefulness of this area as a means of focusing on quality compared to the objective focus. It has been suggested that the consumers' perspective of quality can advance our understanding of consumption behaviour. Issanchou (1996, S7) notes: 'It is important to consider perceived quality as what will motivate a consumer to buy a particular product'. In support Richardson (1994: 285) adds: 'Consumer perceptions of meat quality determine meat consumption in a demand driven-market'. The next section provides evidence which substatiates this proposition.

\section{$\underline{\text { 3.2 Perceived qualitv and market share }}$}

Research by SPI through their PIMS database provide general evidence to suggest a link between perceived quality and market share. According to the PIMS databank, in the long run the most important single factor affecting a business unit's performance is the perceived quality of its products and services relative to those of its competitors (Lynch, 1997). As illustrated in figure 3.1 PIMS data shows that perceived quality drives market share. Over a four-year time span businesses in the PIMS database that improved their overall market-perceived quality ratio gained market share at the rate of $4 \%$ per year. By contrast businesses that didn't change market-perceived quality managed to gain $2 \%$ per year, and those that declined in market-perceived quality didn't gain any share. However, only businesses that were around for the four year time period were used to draw these findings. This explains why no category of business showed a loss in market share; many of the companies that were going out of 
business during the four years were losing market share and probably declining in profitability as well (Gale, 1997).

Figure 3.1: Improving quality - versus competitors - boosts market share

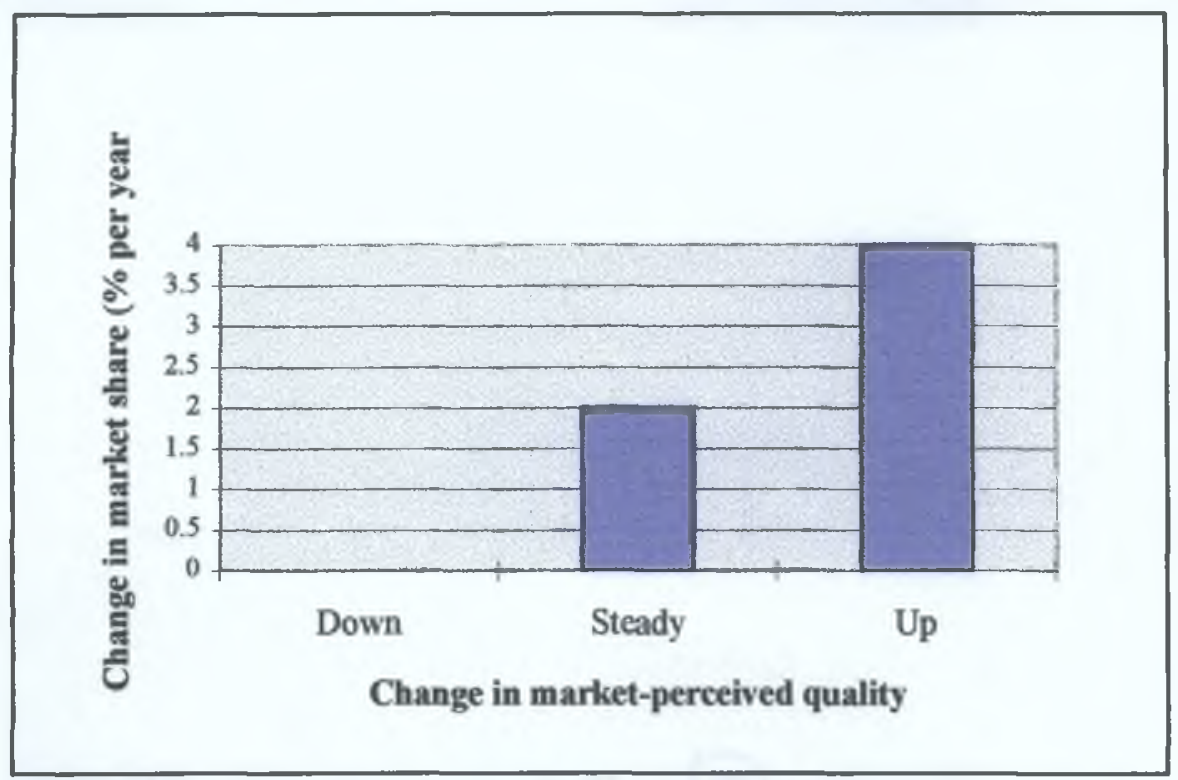

Source: PIMS Associated Ltd. in Gale, B.T., 1994. Managing Customer Value. The Free Press. New York.

While interesting, there are a number of difficulties in relating this infomation to the beef industry where market share for beef has been declining since 1981. Firstly, the PIMS database relates to companies not industries. Secondly, the companies being examined in the database sell branded goods and services. Beef, on the other hand, is predominantly an unbranded commodity type product. Finally, the beef industry in Ireland operates within the artificial European market in which intervention, subsidies and export refunds have been an integral part of the market environment. More detailed discussion of the beef industry will be provided in the next chapter.

Despite these shortcomings, how consumers perceive product quality is nevertheless an interesting construct from which to examine beef consumption. The position being taken in this study is that the determinants of the perceived quality of a product depend on the type of product being studied. As Peter $(1981,133)$ argues: 'Though psychometricians argue that constructing new measures for each situation is wasteful, marketing researchers often must do so to investigate the attributes of different products and services'. Therefore, the proposed approach being taken in this study for 
measuring the perceived quality of beef is to examine the seven dimensions which determine the perceived quality of meat as proposed by Issanchou (1996).

\subsection{Factors Influencing Meat Consumption}

Jeremiah (1982) noted a lack of research into the factors influencing the consumption, selection and acceptability of meat purchases. A major portion of the research reviewed had been carried out in the 1950s. Furthermore, most of the studies reviewed were conducted in the United States and Canada and focused on specific regions. Since Jeremiah's (1982) study there has been some interest in this area. Nevertheless, it is of interest to question why this area has not been adequately addressed. Steenkamp $(1996,143)$ provides a suggestion as to why foods have not attracted systematic attention by consumer behaviour researchers:

'At least part of the difficulty in conducting research in this important area lies in the complexity and diversity of influences at work in food choice and consumption, and in the fact that such research requires knowledge of the concepts and of and insights from a wide range of science and social science disciplines, including food science, nutrition, medicine, psychology, psychophysics, sociology, economics, marketing and anthropology'.

Another reason more specific to the topic of factors influencing meat consumption is that the nature of factors of influence have changed in recent times.

Evidence for this assumption is provided by Bansback (1995) who found that the factors influencing meat consumption are becoming increasingly non-economic in nature. Traditionally the study of meat demand has been conducted from an economic perspective. Through demand analysis of beef and veal consumption rates in the EU12 Bansback (1995) identified that economic factors; price and income, explained a lower proportion of changes in the overall beef consumption level in the period from 1975-94 than they did in the period 1955 to 1979 as illustrated in table 3.1. Explanation of consumption change in the former period in the EU was $95 \%$ while it was $73 \%$ in the U.K. For the latter period $68 \%$ of consumption change was explained by economic factors in the EU as opposed to $55 \%$ in the U.K. Unfortunately the Irish figures were not calculated. 
Table 3.1: Percent contribution to the explanation of beef and veal consumption change

\begin{tabular}{|l|c|c|}
\hline & $\mathbf{1 9 5 5 - 7 9}$ & $\mathbf{1 9 7 5 - 9 4}$ \\
\hline EU-12 & 95 & 68 \\
Price and income & 5 & 32 \\
Unexplained & & \\
UK & 73 & 55 \\
Price and income & 27 & 45 \\
Unexplained & & \\
\hline
\end{tabular}

Source: Bansback, B. (1995) Towards a Broader Understanding of Meat Demand - Presidential Address. Journal of Agricultural Economics. 46(3).p.294.

Figure 3.2 represents a qualitative illustration of Bansback's (1995) findings. The diagram depicts the relative importance of price, income and attitudes/preferences. Also highlighted is the industry's ability to influence demand through these factors. It demonstrates that attitude/preference issues are growing in importance - as is the industry's ability to influence them. Price factors are still the most important determinants of meat consumption, however, the ability of the industry to reduce its costs relative to other meat competitors is getting more limited. Income effects, which are largely determined by factors outside the control of the industry, are also of less importance in influencing demand in developed economies than in the past

This transition has left the meat industry in a state of uncertainty. As Fiddes (1991, 230) notes: 'Many producers regard themselves as almost under siege, on account of the rapid changes which have occurred in British consumer preferences in recent years'. The remainder of this section therefore explores the non-economic factors which are attributable to the reduction of red meat consumption. 
Figure 3.2: Relative Importance of Factors Influencing Meat Demand

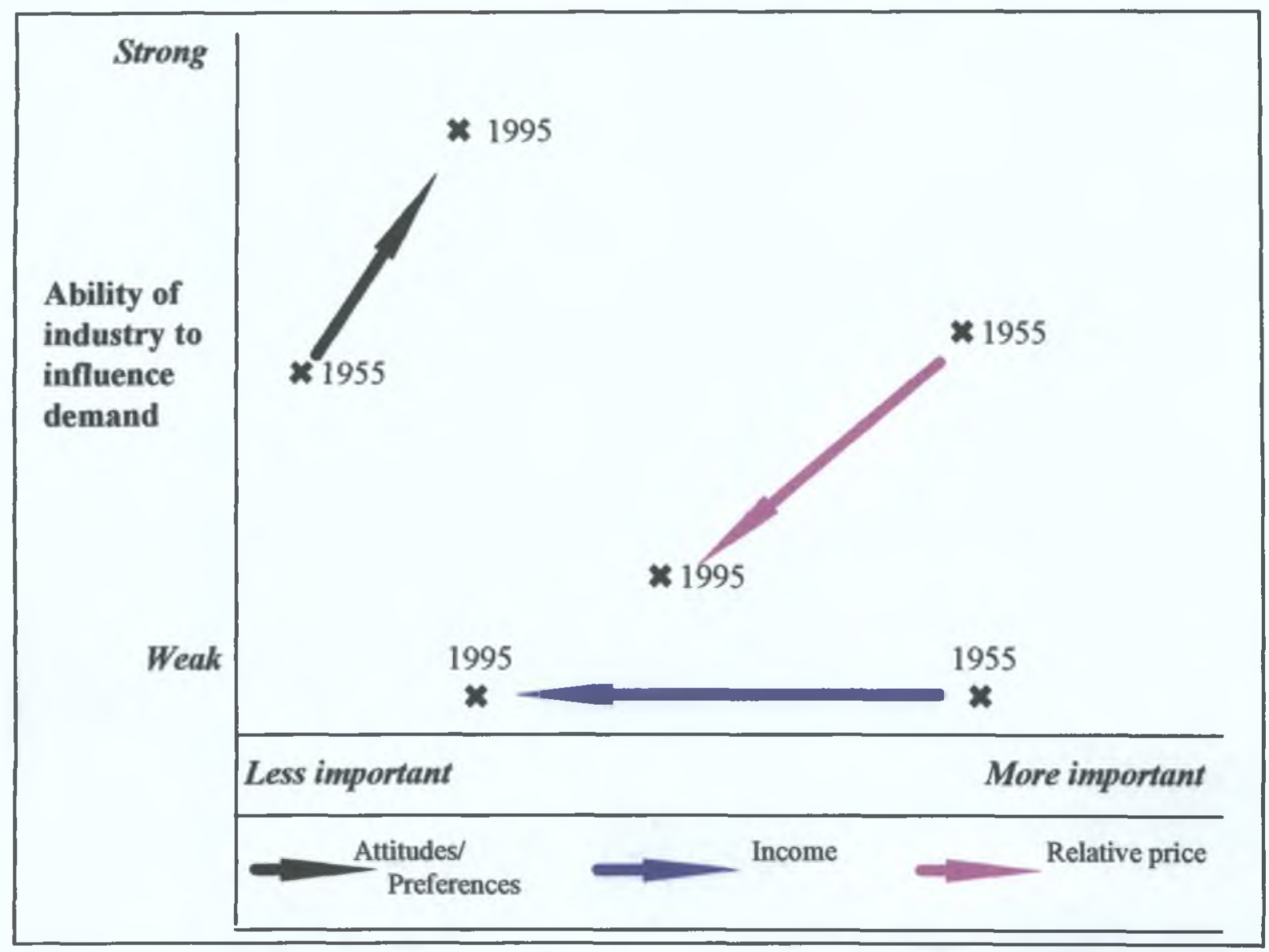

Source: Bansback, B. (1995) Towards a Broader Understanding of Meat Demand - Presidential Address. Journal of Agricultural Economics. 46(3).p. 289.

\subsection{Non-economic factors influencing red meat demand}

Throughout the developed world, some consumers have become concerned about a number of aspects of meat consumption and production to an extent that demand has been or is in danger of being affected adversely (Harrington, 1994). These concerns predominantly centre upon health and safety issues.

In a survey of consumers in the U.K. in 1994, 50\% of respondents reported a decrease in their consumption of red meat in recent years (Leatherhead Food Research Association (LFRA), 1994). As illustrated in table 3.2 the main reasons given for this decrease were health, cost and food scare issues. Not surprisingly the list of factors in table 3.2 is comparable to a study of European consumers examining the ideal attributes of a food product (Spitters, 1993). Respondents were asked to rate the three most important attributes of an ideal food product. The attribute mentioned most often 
was 'healthy' which was mentioned by $63 \%$ followed by 'no harmful substances' $(57 \%)$ and 'natural' (53\%). Attributes like 'tasty' (18\%), 'value for money' (17\%) and 'not expensive' (7\%) were apparently not important. The manner with which attributes in both studies resemble each other is uncanny. The only attribute which does not correlate in ranking terms between both studies is the cost/value attribute. The resemblance in findings indicates that beef has not sufficiently adhered to the requirements of an ideal food product and subsequently this failure has led to the decrease in demand.

Table 3.2: Main reasons for cutting down on red meat consumption

\begin{tabular}{|l|c|}
\hline Reasons & \% Respondents \\
\hline Health reasons (heart disease/cholesterol levels) & 42 \\
Cost & 24 \\
Food scares (BSE/Salmonella, etc.) & 19 \\
Moral/concern over animal husbandry practices & 15 \\
Don't like taste & 8 \\
Health reasons (cancer) & 7 \\
Dieting & 3 \\
Fat content & 3 \\
Vegetarian & 3 \\
\hline
\end{tabular}

Source : Leatherhead Food Research Association (LFRA) (1994) The UK Meat and Poultry Products Report. September. p.23.

Before examining in detail the non-economic reasons given (the cost factor is exempted from discussion since it is an economic issue) the question of operationism needs to be addressed. Operationism refers to the requirement that each construct corresponds to operations that define its application and give it specific scientific meaning (Zaltman et al., 1982). In other words the operational definition describes how the construct is to be measured. Many studies measured health according to nutrition and fat (e.g. Richardson et al., 1993; Zey \& McIntosh, 1992; Shepard \& Towler, 1992; Sapp, 1991). However, some argue that health should be operationalised to include aspects of safety. For instance, Harrington (1994) when discussing healthiness refers to not only nutrition and fat but also residues such as antibiotics and hormones. In addition Allen (1992) argues that consumers perceive food safety and diet health issues as the same issue. 
An additional definition of health is provided by Fiddes $(1991,6)$ who broadens the view and argues that:

'Health is not the straight forward causative process of nutrition and contagion that we often assume; perceptions of the healthiness of meat express wider concerns about our relationship with the world that sustains us... Health is about how well people feel and a persons entire set of beliefs and feelings is relevant to their health'.

While the interest of this work is to examine how consumers perceive the noneconomic factors influencing consumption discussion here will nevertheless, largely be placed on the objective meanings of these concepts, namely their definition from the attribute level of abstraction. Reasons for this include a general lack of empirical work studying the non-economic factors at what may be referred to as the more abstract 'quality' level of abstraction. Furthermore, the objective approach will give context to many of the issues. An Irish perspective will be presented where possible.

\subsection{Health}

Health reasons (heart disease/cholesterol), dieting and fat content can be considered one and the same issue. Concern about this area originated in the early $1980 \mathrm{~s}$ with the publication of many reports on the area of food consumption and health. For instance, in Ireland reports by the Food Advisory Committee $(1980,1984,1986)$ found among other things, that deaths in Ireland arising from cardiovascular and coronary heart disease greatly outnumbered deaths from any other group of diseases. Recommendations for fat decrease were reported, in particular advice was given for the decrease in red meat consumption and the increase of chicken and fish. If consumption figures are anything to go by consumers in Ireland have appeared to act on this advice; beef consumption has shown a downward trend since the early eighties whereas chicken consumption has followed an opposite trend as illustrated in figure 3.3 . 
Figure 3.3: Irish beef and chicken consumption kgs/person 1986-1996

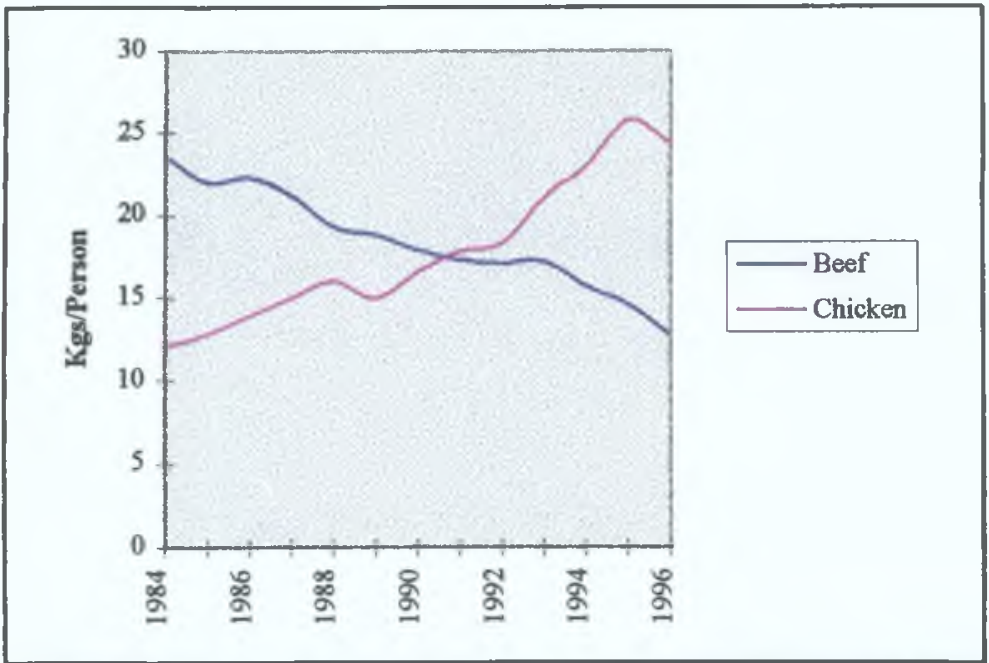

Source: Central Statistics Office (C.S.O.), (1997) personal communication. Cork. ${ }^{1}$

Nevertheless, despite the decrease in beef in the Irish diet in recent times Ireland is, nevertheless, reported to have the highest dietary fat intake of any other country in the EU (Moloney \& Lavery, 1998). In the past red meat has borne the brunt of criticism for dietary diseases. While meat is recognised as a major source of saturated fat, beef is perceived as one of the highest contributors (Tilston et al., 1993). However, now that beef consumption is low in Ireland fat intake, nonetheless, still remains high.

Beef and veal consumption figures in France, a country with low heart disease rates, provides 'food' for thought. There per capita consumption figures in 1995 were 28.2 $\mathrm{kg} /$ head while Ireland's consumption figures were just over half that; $14.6 \mathrm{~kg} / \mathrm{head}$ (Teagasc, 1997). Clearly one can argue that beef consumption has received disproportionate criticism in Ireland.

Previous empirical work gives support to LFRA'S (1994) findings that health concerns are the main reason for reduced red meat consumption. In a survey carried out by Woodward (1988) on a structured sample of U.K. consumers, health concerns ranked with price factors as being the main issues of importance amongst consumers who had reduced their red meat consumption. Similar findings were confirmed by

\footnotetext{
${ }^{1}$ While an overall figure for poultry consumption is published by the C.S.O. a breakdown of its' constituents, namely goose, duck, turkey and chicken, are not. Therefore, a personal communication by telephone was made to the C.S.O. in Cork to obtain figures for chicken.
} 
Richardson et al. (1994) although there also appeared to be some concern about ethical and welfare issues. It is interesting that these results are very much in line with results from a major project funded in the mid-1980's by the U.S. meat industry (Breidenstein, 1988).

It has been suggested that dietary advice has inevitably affected the demand for red meat because visible fat on the meat reinforces consumers 'other objections' to the product (Harrington, 1985). The next section discusses these objections.

While concern about fat in red meat and its effects on the diet have been reported in the media continuously, reports of safety issues tend to fluctuate in response to specific incidents (Harrington, 1994). In support Fiddes (1991, 182) notes: 'Medical reports, and the media, customarily highlight a single factor inducing morbidity'. Examples of safety issues related to meat and beef in particular reported in the media include BSE, hormones (growth promoters), antibiotics, salmonella and Escherichia coli 0157 (E-coli).

In 1992 Ashwell et al. (1992, 293) noted: 'On balance the consumers' perception of the nutritional benefits of meat, along with its traditional, esteemed place as 'a social institution' look like outweighing current (and hopefully future) scares'. However, this was not the case for many of the respondents in the LFRA (1994) study, in particular for the $20 \%$ who reported reducing their beef consumption due to concern about food scares.

\subsection{Safety issues}

The following section examines many of the recent meat related safety scares.

\subsubsection{BSE}

BSE is a slowly progressive and ultimately fatal neurological disorder of adult cattle. A link between diseased cattle infected with BSE and the condition nv-CJD has been found. BSE was first identified by the Ministry of Agriculture, Fisheries and Foods in the UK in November 1986 (Tilston et al., 1993). All infected cattle were found to 
have one factor in common, all had received feed-stuffs, at some point in their lives, containing animal derived protein - meat and bone meal. Meat and bone meal is a by product of the rendering of animal carcasses (fallen or otherwise) and waste animal material principally from abattoirs and butcher shops has been incorporated into certain animal feedstuffs for several decades (Wilesmith et al., 1988).

In 1988 BSE was made a notifiable disease and meat and bone meal feed was banned. The effect of BSE on consumer perceptions around this period was highlighted by Ashwell et al. (1992, 293): 'The total perception of meat in the U.K. diet in 1990 almost certainly reflected a balance between our perception of it as a nutritionally useful dietary component and our perception of it as a potential source of madness!'

However, despite the ban BSE cases continued to increase in the U.K. regardless, peaking in 1992 at 3,000 cases a month (Cocks \& Bentley, 1996). However, while the British government had continued to deny any human health risk, a potential link between BSE and CJD was conceded on March 20 $0^{\text {th }} 1996$ and a world-wide export ban on British beef followed. In other words, for years there had been media coverage about BSE and yet in all that time it remained uncertain whether there was a risk to human health. As Burton \& Young's (1997) study, reviewed previously revealed, the media coverage about BSE led to the decline beef consumption rates in the U.K.

In Ireland beef consumption rates fell in 1996 by 13\% (CSO, 1998). However, besides BSE the reduction can also be attributed to reports of the illegal use of growth hormones in Irish beef production which came to light again in 1996. The announcement affected the export of live cattle from Ireland in particular; in 1995 live cattle export numbers were 264,000 but in 1997 this figure fell to just 7,000 (DOAF, 1998). Russia imposed a regional ban on beef imports from counties Cork, Tipperary and Monaghan. The occurrence of BSE in Ireland has been small relative to the U.K. where the total number of confirmed cases to the $12^{\text {th }}$ April 1991 was 26,378 (Tilston, 1993). From 1989 to 1995 there were 112 cases in Ireland, with 73 cases in 1996 and 77 in 1997 (DOAF, 1998). 
To date there have been 23 cases of nv-CJD in the U.K. though, as yet, there have been no cases in Ireland. There are a number of forms of CJD and a survey by the Department of Health in 1996 in Ireland confirmed that CJD had killed 20 people since 1980, however, these particular strains of CJD were not linked with BSE (O'Connor, 1996). The risk of contracting nv-CJD is clearly negligible and placed in the context of other risks it seems hardly worth contemplating. The risk of dying in a plane crash in any one year is 20,000 to one, while the risk of dying from smoking ten cigarettes per day is regarded as being in the region of 200 to one (Macey, 1997).

Substances administered to animals to promote growth; carcinogenic hormones or to prevent or treat disease, such as antibiotics, will leave residues in the meat which are harmful to the health of the consumer. The next section covers both of these issues.

\subsubsection{Growth promoters}

Growth promoters were banned in the EU in 1988 despite considerable evidence that if properly used they offered no prospects of harm to beef consumers (CEC, 1993). In the U.S., where the use of growth hormones is permitted, the export market was reduced by US\$100 million as a result of the ban in the EU (World Food Regulation Review, 1996). Nonetheless, it has been suggested that the use of hormones is probably more widespread on the black market than it ever was legal. (Meat Trades Journal, 1989) Consumers are as a result in more danger from these substances than when the products were officially licensed. A large part of the problem lies in the fact that most beef is generic and so untraceable to the source so that farmers need not fear retribution. Farmers are in a position to gain between $£ 80$ and $£ 160$ per animal from their use (Cadogan, 1994).

The illegal use of these promoters in Ireland in recent times has accentuated the publics' 'cowboy' perception of the beef industry. Reports of the extensive use of growth promoters in Ireland hit the headlines again in mid-February 1996 when Dr. Peter Dangan chairman of the Consumer's Association of Ireland (CAI) strategy group and former president of the Irish Veterinary Union claimed that the clenbuterol (CBL) - also known as angel dust or angel juice - was present in 25\% of Irish beef and possibly administered by $10 \%$ of farmers (Callanan, 1996). Fines and jail sentences 
followed investigations by the Gardai. Media coverage of this issue continued right through 1996 and at the time of writing was still intermittently covered in the press as cases were brought before court.

\subsubsection{Antibiotics}

Due to intensive rearing, where risk of infection is high, the use of antibiotics is predominant in poultry and pork production more than in beef production. Nevertheless, concern about antibiotics in beef is high among Irish consumers as found by Landsdowne Market Research's (1987) study. O’Neill \& Shanahan (1993) that consumers cannot distinguish between real and unreal problems. For instance, there was as much concern about antibiotics in beef as of growth promoters (hormones) in beef. In reality the incidence of antibiotics in beef is low. Evidence for this is supplied by a study of beef, pork and chicken samples carried out in 1997 by 15 national consumer associations in the EU. The results in Ireland for beef and chicken found negligible levels of antibiotics. However, $17 \%$ of the pork samples revealed beyond the maximum residue limits (MRL) of antibiotic residue outlined by the EU (Which, 1997). This was by far the worst reported case in Europe. These findings were reported in the media and coverage of the topic lasted for a number of weeks in November 1996.

In addition, another study examining the incidence of residues in meat revealed that only $2 \%$ of the beef samples had antibiotics whereas $6 \%$ contained traces of hormones (DOAF, 1998a).

\subsubsection{Salmonella/Escherichia coli 0157 (E-coli)}

Salmonella and E-coli are forms of bacteria which can cause food poisoning. Food poisoning was recently reported to have reached epidemic proportions in the U.K. with more people being poisoned by their food than ever before in 1997 (Coghlan, 1998). Furthermore, the vast majority of food poisoning incidents are attributable to meat and animal products (Ehrlichman, 1990).

The most recent study, conducted by the Public Health Laboratory Service (PHLS) in the U.K. in 1994, revealed that one in three chilled chickens sold at British 
supermarkets contained Salmonella (Coghlan, 1998). A comparable study in Ireland revealed a similar figure (O'Sullivan et al., 1996). While the incidence of salmonella in chicken is high it nevertheless also occurs in other meats including beef albeit to a lesser extent.

Outbreaks of E-coli:0157 have been particularly prevalent in Scotland; a phenomenon which mystifies experts (Irish Farmers Journal, 1997). Towards the end of 1996 the bacteria killed 20 pensioners and left 500 ill in Scotland in an incident involving meat pies (New Scientist, 1998). Incidences have also been found in the United States where in mid-1997 an outbreak in hamburgers resulted in the biggest food recall in history - 25 million lbs of frozen minced beef - when 17 Colorado residents became infected (Hollingsworth, 1997). The bacteria has so far only claimed the life of one person in Ireland; a three-year-old child in January of 1997 (Kilfeather, 1997). Burgers and minced meat are reported to be the most likely sites for E-Coli contamination.

Consumers can act on two pieces of advice to avoid food poisoning (New Scientist, 1998a: 3):

- Ensure that meat products don't contaminate other produce. For example, never chop on a board for salad.

- Cook meat all the way through until is has reached 160 degrees Celsius. E-coli cannot survive more than 15 seconds at this temperature.

\subsection{Ethical and Animal Welfare Issues}

Issanchou (1996) suggests that some changes in quality perception such as product safety occur very rapidly whereas attitudes based on ethical and moral evaluations evolve slowly. In recent times ethical and animal welfare issues have caused consumers to question the acceptability of meat, in particular red meat, in their diet. As Lister (1996: 193) succinctly comments: 'How, for example, can caring individuals 'enjoy' meat from animals raised or slaughtered in a manner which is offensive to them?' More general ethical issues surrounding meat eating are that most people prefer not to think where the meat came from. Certainly the majority of those 
who avoid meat and red meat in particular have stressed ethical concerns as the primary motivating factor (Santos et al., 1996).

The ethics of meat eating can also be considered in a broader sense. For instance, Webster, (1994) states that there is little justification in feeding cereal to livestock to produce meat for our enjoyment while millions go hungry. Meat production is in principle less efficient than vegetable production for feeding the worlds' population. Meat animals need two to three times as much consumable energy as they produce and it is estimated that 40 to 50 percent of human consumable world grain production is fed to animals (Van Dijk, 1994).

\subsection{Vegetarianism}

Harrington (1994) suggests that consumers avoid meats in a hierarchical order, starting with red meats followed by white meats until dairy products are the only animal derived foods consumed. Results of a recent survey on U.K. meat eating habits support this assumption. It was found that $4.5 \%$ of consumers were vegetarian while $7.3 \%$ avoided red meat (The Realeat Survey, 1995). In the category females, 16-24 year olds, $25 \%$ identified that they were vegetarians or avoided red meat. This finding has important implications for red meat industries, in particular beef, as these women will become the chief food and meat purchasers of the upcoming generation. It also highlights that the traditional image of meat is no longer accepted by women. Besides the dietary related issues meat is associated with strength, vigour, a rugged out door life - images which the average young woman does not wish to associate with (Lister \& Hodges, 1994).

In the total population the extent of vegetarianism among consumers is quite low. A proposed reason for this is that vegetarianism is not only a way of eating but also reflects a life philosophy which occurs in conjunction with a complex set of beliefs, attitudes and parallel movements (Fiddes, 1991). Nonetheless, there is an increasing movement towards avoiding red meat which has negative consequences for the beef industry. 


\subsection{Taste}

The dislike of the taste of red meat is also a factor reported in LFRA's (1994) study as a reason for the decline in consumption. Support for this finding and at a similar response level (10\%) was identified in Woodward's (1988) study. Related to a dislike of taste of meat, is a feeling of repulsion at the idea of preparing or cooking animal flesh. Ironically it has been found that some established vegetarians express nostalgia for the flavour of meat (Beardsworth \& Keil, 1988). Therefore, taste plays a role both as a reason for eating and not eating red meat.

Besides the specific issues related to red meat itself broader social trends which tend to manifest themselves slowly over time have also led to beef's decline in recent times.

\subsection{Preference for Chicken}

The decline in beef consumption has been thought by some to have derived from a shift in consumer preferences in favour of chicken (Chavas, 1986). Gunner (1989) suggests that the beef industry must endeavour to compete with the poultry industry mainly on three fronts; price, convenience and a consistent product quality. The perceived healthiness of chicken must also be seen as a factor. Certainly in Ireland consumers have developed growing beliefs that there is a need to make fundamental changes in diet rather than making compensations by choosing low fat or diet options (Behaviour \& Attitudes, 1994). This proposition is apparent in the meat industry where beef has been substituted with chicken. This substitution effect for Ireland is illustrated in figure 3.3. In addition, the poultry industry has for the last decade adopted an aggressive market driven approach. Poultry products as opposed to beef products are branded, consistent and user friendly. 


\subsection{Changing lifestvles and convenience}

Increasing numbers of working women, reduced leisure time and the decline in the traditional family unit have all contributed to the erosion of traditional meal patterns (Cotter, 1998). Beef has been one of the primary foodstuffs to flounder in the light of these trends. Beef has generally not kept pace with competing foods such as chicken in the development of convenient meal solutions.

\subsection{Sociodemographic factors}

Socio-demographic factors also influence meat demand. The following section reviews studies examining socio-demographic factors and beef demand. A panel study conducted by Taylor Nelson in the U.K. in 1994 (Meat and Livestock Commission, 1994) compared different age groups' share of total beef consumption with their share of food consumption in general. It was found that young people under 16 and older people over 65 tended to consume less beef relative to other foods. According to a National Food Survey in the U.K. in 1993 (EIU Retail Business, 1995), young people under 25 ate $25 \%$ less beef and veal than the national average. This study also showed that the consumption of beef tends to increase with income and social class. Lee (1986) found that the consumption of red meat at home and the expenditures on red meat were negatively related to college education of the female head of household in the U.S.

Despite the importance of socio-demographics to beef demand no studies were found which examined the possible influences of these factors in the context of the adverse changes in beef consumption trends.

\subsection{Research proposal}

A short coming with the studies reviewed on consumers' reasons for reducing their red meat consumption is that all responses were self-reported and were therefore measuring what might be referred to as 'top-of-the-mind' reasons for reduction. In addition there is the likelihood of respondents rationalising their behaviour. Furthermore, the research only sought to examine the main reason for reducing consumption of each respondent and in turn rank the reasons in terms of percentage of 
response. This form of questioning fails to uncover the interaction of various motivations. As Richardson et al. (1994) argue motivations to reduce meat consumption are often multi-layered and thus no single issue should be considered in isolation.

A further observation of the research reviewed is that many of the reported noneconomic factors influencing consumption could be categorised as part of the perceived meat quality construct as defined at the end of the previous chapter. These factors included safety (BSE, hormones, antibiotics and salmonella), health, convenience, taste and ethical and animal welfare issues.

Therefore, taking into account both of the above observations and the PIMS finding concerning the relationship between perceived quality and market share, the proposal for this research is to measure the perceived meat quality construct as a means to interpret beef consumption decreases in Ireland.

As yet no empirical work has been attempted to examine the perceived quality of meat within the all encompassing perspective outlined in the previous chapter. This outline reproduced in figure 3.4 will serve as a framework for analysis for the study.

Figure 3.4: Framework for analysing perceived meat quality

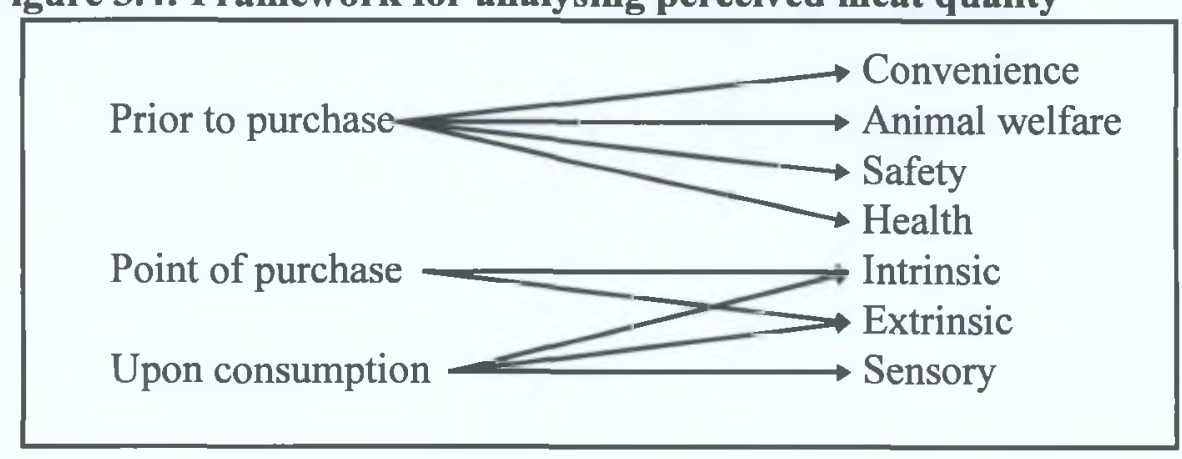

As stated previously motivations for meat reduction are multi-layered. Therefore, an alternative technique to previous studies of examining the factors influencing the reduction of beef would be to question respondents about all aspects of perceived quality as defined by Lister (1996) and Issanchou (1996) and through multivariate statistical analysis derive the underlying motivations. 
Zeithaml (1988) argued that perceived quality was a 'second order phenomenon'. The framework in its current state maps quality at this level of abstraction, namely at the quality level as denoted in table 2.1. Studying meat quality from this perspective is similar to examining the information 'chunks' which consumers use when evaluating quality. The concept of information 'chunking' was discussed in the context of von Alvensleben's (1997) model in chapter 1. The matter of 'chunking' information is a strategy used by consumers used to cope with the extensive information available. For instance, the brand name represents one of the main information 'chunks' or key pieces of information which consumers use for many products (Jacoby et al., 1977). However, as there is very little branding for beef this information cue is not expected to be a dominant source of product evaluation.

In order to study the structure of perceptions about beef a consumer behaviour model has been chosen to describe Irish consumer beliefs about beef quality. Table 3.3 represents a framework for classifying consumer behaviour models. As the objective is to study how Irish consumers evaluate beef quality, perceptual mapping has been identified as the appropriate model in order to study this. Here consumer beliefs about a product can be studied through deriving evaluation criteria and building a perceptual map. These beliefs (perceptions) can be measured directly by asking consumers how much of a feature they perceive a certain product to contain (Lilien et al., 1992). 
Table 3.3: Framework for Classifying Consumer Behaviour Models

\begin{tabular}{|l|l|}
\hline Need & $\begin{array}{l}\text { Arousal Stochastic Models of Purchase Incidence } \\
\text { Discrete Binary Choice Models }\end{array}$ \\
\hline Information Search & $\begin{array}{l}\text { Individual Awareness Models } \\
\text { Consideration Models } \\
\text { Information Integration Models }\end{array}$ \\
\hline $\begin{array}{l}\text { Evaluation } \\
\text { (b) Perception }\end{array}$ & $\begin{array}{l}\text { (a) Perceptual Mapping } \\
\text { (b) Attitude Models } \\
\text { Non-compensatory } \\
\text { Compensatory }\end{array}$ \\
\hline Purchase & $\begin{array}{l}\text { Multinominal Discrete Choice Models } \\
\text { Markov Models }\end{array}$ \\
\hline Post-purchase & $\begin{array}{l}\text { Variety Seeking Models } \\
\text { Satisfaction Models } \\
\text { Communications and Network Models }\end{array}$ \\
\hline
\end{tabular}

Source: Lilen, G.L., Kotler, P. and Moorthy, K.S. (1992) Marketing Models. Prentice Hall. p.26

The perceptual mapping technique, therefore, will be used in this study to examine whether Irish consumers perceive beef quality using the seven quality constructs proposed by Issanchou in table 3.3. In order to examine this question each quality construct will be operationalised at a lower level of abstraction (attribute level in table 2.1). For instance, in order to measure health a series of questions related to various beliefs towards nutrition and fat/cholesterol must be addressed. The proposed variables being used to operationalise each of the seven quality constructs will be discussed in Chapter 5. The task of perceptual mapping is to analyse all the variables simultaneously and examine whether they form into the seven quality constructs being examined.

Having developed the perceptual map the main question of this thesis; what perceived quality factors have influenced the decline in beef consumption, can be addressed. The hypotheses for investigation will be outlined in Chapter 5. 


\subsection{Conclusion}

PIMS research has revealed that perceived quality drives market share. In previous surveys many of the factors which consumers have indicated to have influenced them to change their red meat consumption have been quality related. A short coming of many of these studies is that the reasons reported have been spontaneously offered and so fail to uncover underlying motivations. A framework for analysing the perceive quality construct has been chosen for examination. 
CHAPTER 4

\section{INDUSTRY REVIEW}




\subsection{Introduction}

The Irish beef industry currently faces probably the greatest challenge in its entire history. As discussed in the literature review there are fundamental forces of change driving consumer behaviour of meat and beef in particular. However, the market environment in which the Irish beef industry participates has also undergone fundamental change in a remarkably short period of time. The objectives of this chapter are to:

a) Analyse indigenous beef consumption trends.

b) Analyse the structure of the Irish beef industry within the context of recent trends and developments.

c) Examine the potential of adding value in beef production. Of special interest here are the issues of branding and quality assurance schemes.

\subsection{Indigenous consumption rates}

The Republic of Ireland is the largest net exporter of beef in the Northern Hemisphere (Meat Trades Journal, 1997). In 1997 over 90\% of beef production was exported. However, indigenous consumption rates have been falling steadily over the last decade which has resulted in Ireland becoming the second lowest per capita consumer of beef in the EU as highlighted in table 4.1.

Table 4.1: Beef/Veal Consumption kg/head in EU Countries 1995

\begin{tabular}{|l|l|l|l|l|l|l|}
\hline IRI. & UK & FRA & GER & NL & BEL/LUX & ITA \\
\hline $\mathbf{1 4 . 6}$ & 17.7 & $\mathbf{2 8 . 2}$ & 16.5 & 19.9 & 21.2 & 25.9 \\
\hline DK & GRE & SPA & POR & AUS & FIN & SWE \\
\hline 17.7 & 21.8 & $\mathbf{1 2 . 7}$ & 17.6 & 20.4 & 19.1 & 18.2 \\
\hline
\end{tabular}

Source: Teagasc. (1997) Irish Agricultural Figures.

Over the ten year period 1986-1996 fresh beef consumption has decreased by $42 \%$; an average decrease of $1 \mathrm{~kg} /$ person/year. Furthermore, beef's share of the total meat market in this period has been almost halved; from $27 \%$ in 1986 to $14 \%$ in 1996 (See figure 4.1 and table 4.2 below). As yet no independent empirical research has been carried out in Ireland with the objective of explaining this adverse consumption trend. Despite the decrease in beef consumption overall meat consumption has nevertheless 
been increasing which gives an indication that Irish consumers are more than substituting their decrease in beef consumption with an increase in the consumption of other meats, chicken in particular.

In 1984 beef consumption was nearly double chicken consumption, with the consumption figures being $23.6 \mathrm{kgs} / \mathrm{head}$ and $12.1 \mathrm{kgs} / \mathrm{head}$ respectively. In 1991 the consumption rates of both meats were equal at $17 \mathrm{kgs}$. Then in 1996 chicken consumption was nearly double that of beef; $24.4 \mathrm{kgs} / \mathrm{head}$ and $12.7 \mathrm{kgs} / \mathrm{head}$ respectively. In other words in a 13 year period there has been a complete reversal of beef"s market dominance over chicken.

\section{Figure 4.1: Irish Meat Consumption kgs/head 1986-1996}

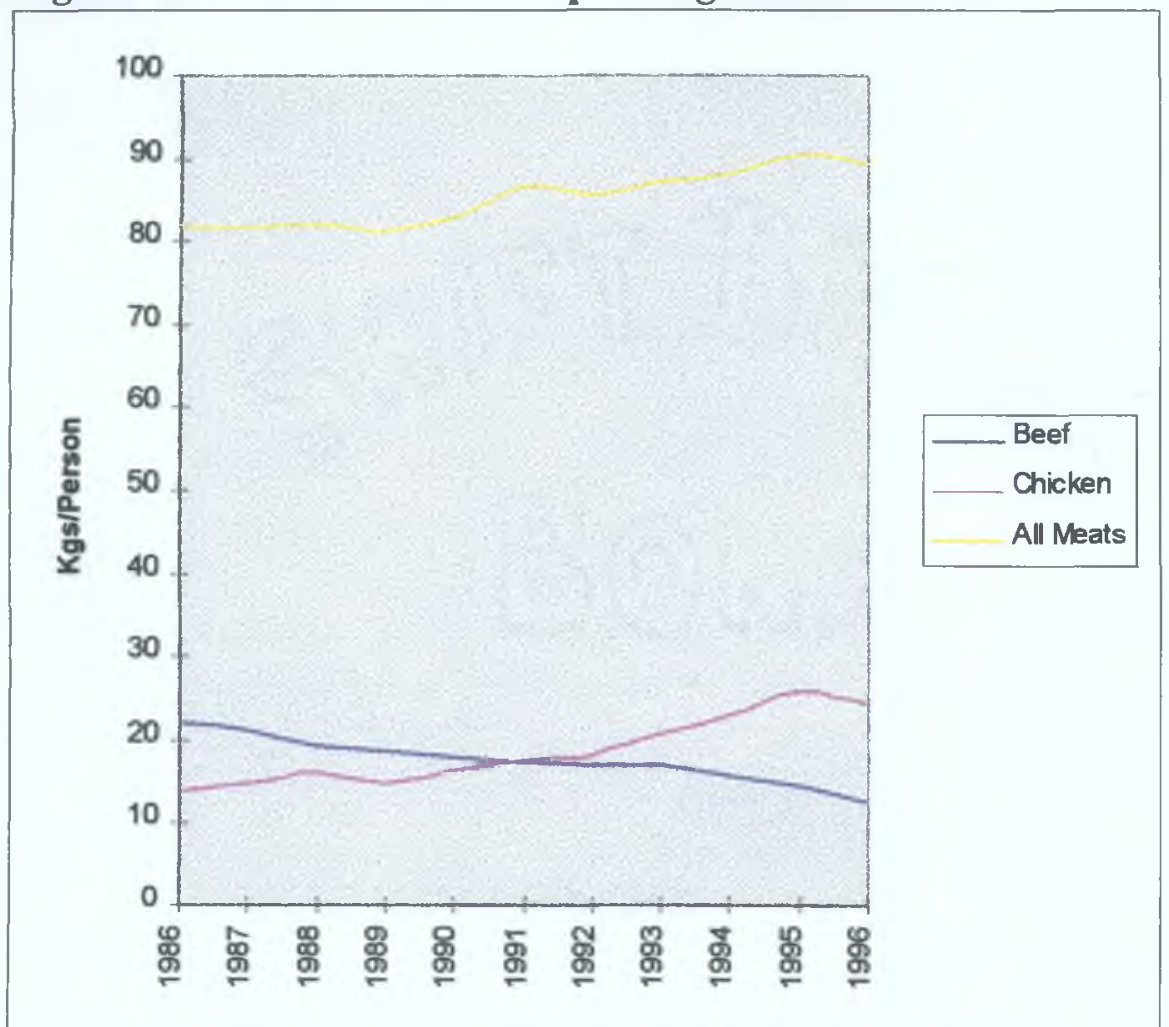

Source: Central Statistics Office (C.S.O) (1998), personal communications. Cork. ${ }^{1}$

\footnotetext{
${ }^{1}$ A previously stated contact was made to obtain figures for chicken consumption.
} 
Table 4.2: Ireland - Beef, pigmeat and poultry consumption -kgs/head

\begin{tabular}{|l|l|l|l|l|}
\hline Year & Beef & Pigmeat & Chicken & Total -all meats \\
\hline $\mathbf{1 9 8 6}$ & 22.3 & 34.5 & 13.9 & 81.9 \\
\hline $\mathbf{1 9 8 7}$ & 21.2 & 33.6 & 15.0 & 81.6 \\
\hline $\mathbf{1 9 8 8}$ & 19.3 & 35.4 & 16.0 & 82.1 \\
\hline $\mathbf{1 9 8 9}$ & 18.8 & 35.6 & 15.0 & 81.4 \\
\hline $\mathbf{1 9 9 0}$ & 17.9 & 35.2 & 16.5 & 82.9 \\
\hline $\mathbf{1 9 9 1}$ & 17.3 & 38.0 & 17.8 & 86.8 \\
\hline $\mathbf{1 9 9 2}$ & 17.1 & 37.2 & 18.3 & 85.9 \\
\hline 1993 & 17.2 & 35.9 & 21.0 & 87.4 \\
\hline $\mathbf{1 9 9 4}$ & 15.7 & 36.6 & 23.0 & 88.2 \\
\hline $\mathbf{1 9 9 5}$ & 14.6 & 37.8 & 25.8 & 90.4 \\
\hline $\mathbf{1 9 9 6}$ & 12.7 & 37.8 & 24.4 & 89.2 \\
\hline
\end{tabular}

Source: C.S.O, (1998) personal communications. Cork.

An examination of inflationary rates in beef and chicken provides some explanation for the change in consumption rates. For instance, taking November 1989 as the base year, in the period 1991-1995 beef prices inflated by 9\% whereas chicken prices deflated by $4 \%$; a total spread of $13 \%$ (however, as a result of the BSE crisis this spread disappeared). As figures 4.3 and 4.4 highlight these price changes have had a contrasting effect on consumption rates of both meats during this period and indeed this assumption can be generally extended back to 1981. As beef prices have inflated consumption rates have decreased. However, chicken prices have remained steady resulting in consumption increases. 
Figure 4.2: Retail price and consumption of beef (November 1989 based series)

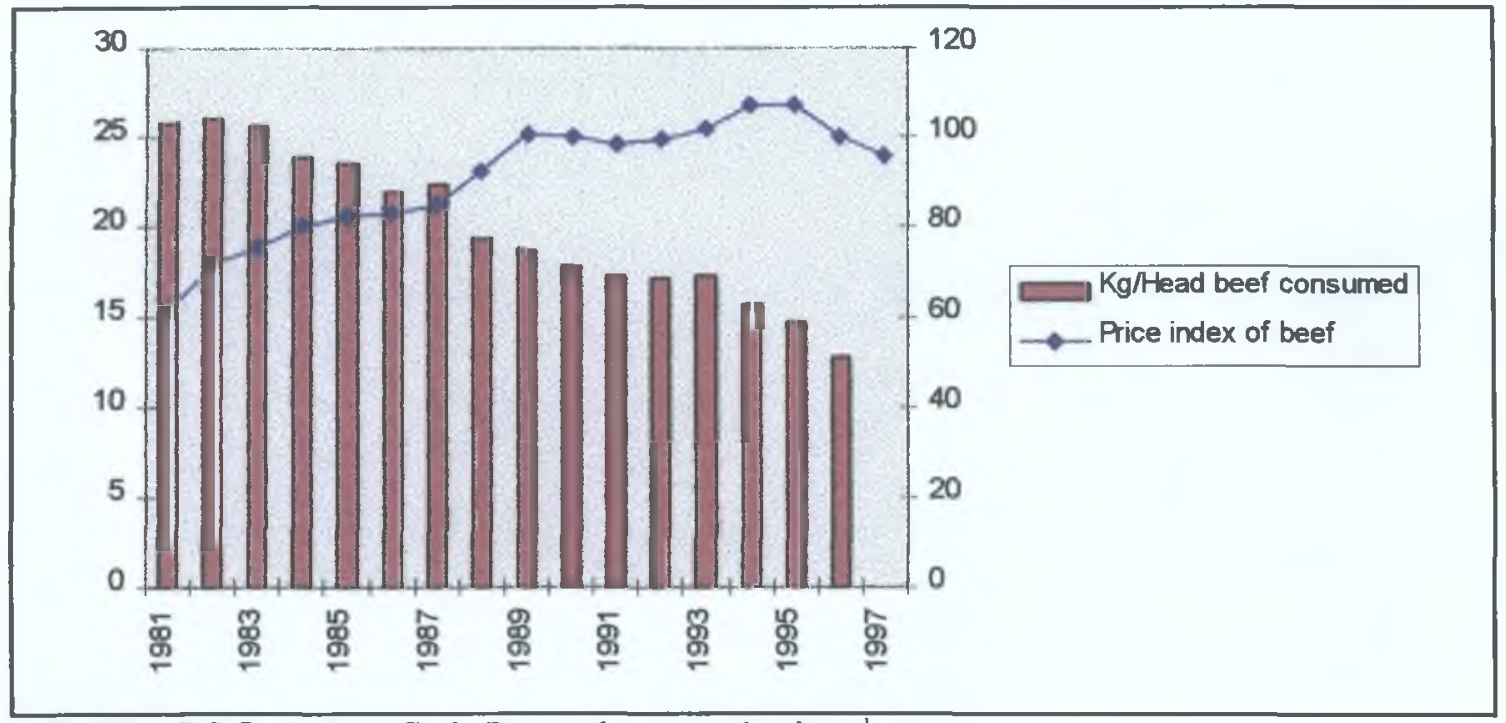

Source: C.S.O., (1998), Cork. Personal communications. ${ }^{1}$

Figure 4.3: Retail price and consumption of chicken (November 1989 based series)

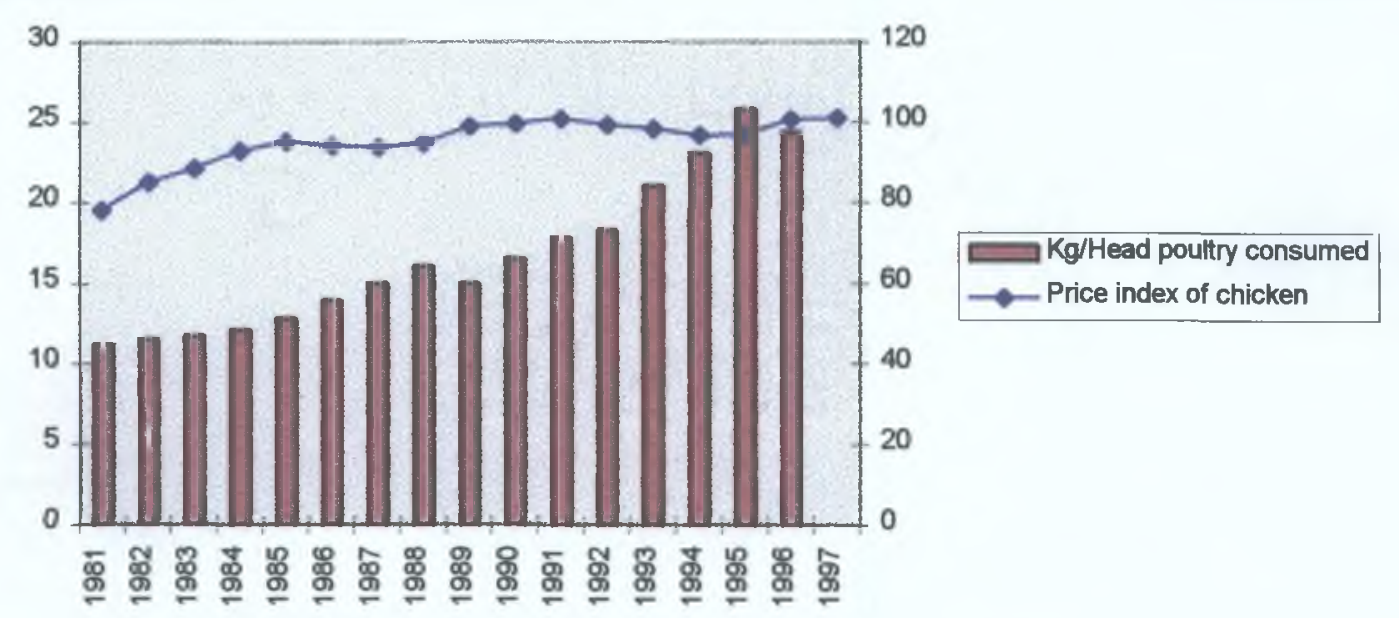

Source: C.S.O., (1998), personal communications. Cork. ${ }^{2}$

An examination of own-price and cross-price elasticities for beef and chicken provides revealing information concerning consumption rates and price. Boyle (1996) used the recently developed Modified Almost Ideal Demand System (MAIDS) (Cooper \& Mc Laren, 1992) to study Irish meat demand using time series observations from 1974 to 1990 . As illustrated in table 4.3 the MAIDS price elasticity estimates revealed that, with the exception of chicken which is zero price elastic, demand for beef and pigmeat are own price elastic. The cross price elasticity effects

\footnotetext{
${ }^{1,2}$ Price index figures are available from the C.S.O. upon request.
} 
indicate that beef substitutes with pigmeat but not with chicken. Therefore, as illustrated in table 4.3 according to Boyle's (1996) study price increases have contributed to the beef consumption decreases. However, these price changes for beef have not contributed to the chicken consumption increases. Unlike beef, chicken consumption change appears to be largely attributed to the influence of non-economic factors.

These findings provide substantiation to Bansback's (1996) findings that economic factors, in particularly price, have played a significant role in influencing the decline of beef consumption.

Table 4.3: Own and cross-price elasticities for beef, pork and chicken 1990.

\begin{tabular}{|c|c|c|c|}
\hline \multirow[b]{2}{*}{$\begin{array}{l}\text { Percentage change } \\
\text { in the sales of } \\
\text { Commodity }\end{array}$} & \multicolumn{3}{|c|}{ A price change of $1 \%$ in } \\
\hline & Beef & Pigmeat & Chicken \\
\hline Beef & -1.07 & 0.53 & -0.12 \\
\hline Pigmeat & 0.32 & -1.04 & -0.42 \\
\hline Chicken & -0.20 & -1.17 & 0.00 \\
\hline
\end{tabular}

Source: Adapted from Boyle, G.E. (1996) A MAIDS Model of Irish Meat Demand. The Social and Economic Review. Vol.27. No.4. July, p.315.

The timeseries data illustrated in figure 4.4 reveals that beef consumption has been decreasing steadily since 1981. From 1981 - 1996 there was a decrease of over $50 \%$. Although consumption rates have steadied on a number of occasions they have never increased at any period since 1981, with the exception of 1986. 
Figure: 4.5 Per capita beef consumption 1976 - 1996.

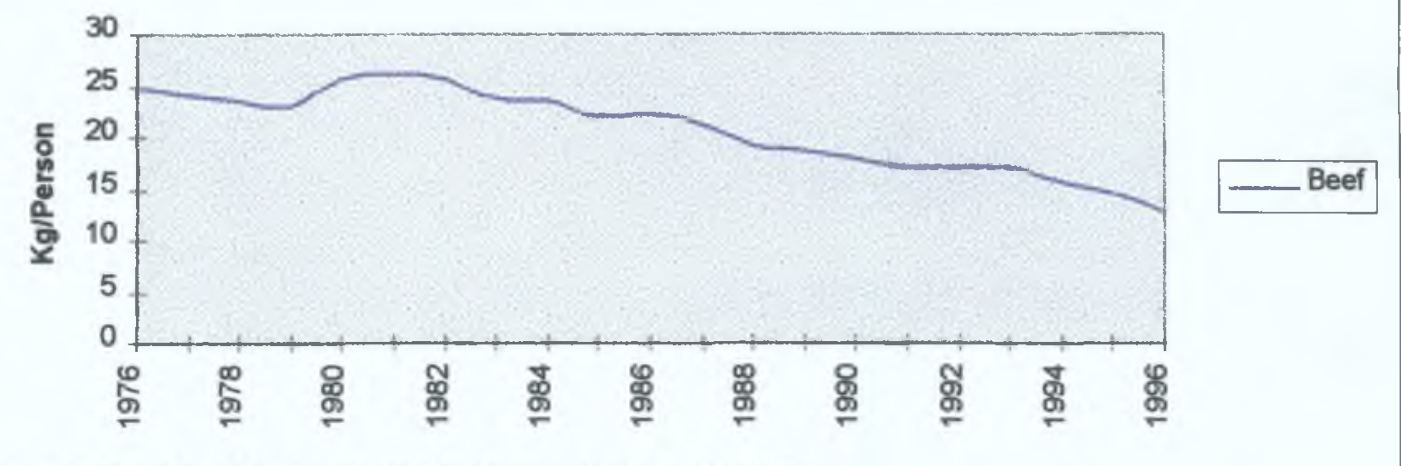

Source: C.S.O., (1998), personal communication. Cork. ${ }^{1}$

Together with the dairy industry the beef industry is one of Ireland's most important agricultural sectors and is regarded as extremely important to the economy. It contributed 33\% to a Gross Agricultural Output of $£ 3.3 \mathrm{bn}$ in 1997 which was far in excess of the contribution of pigmeat $(8 \%)$ and poultry (4\%) (DOAF, 1998). This contribution for beef is considerably above the EU-12 average of $11.8 \%$ (European Commmision, 1996). The EU is the world's largest exporter of beef with more than 1.2 million tonnes exported in 1993 and 1994, whereas only about 0.5 million tonnes were imported. Almost half of the extra-EU-exports was Irish beef (Eurostat, 1996).

Despite the importance of beef to the national economy, its importance is not, however, reflected in the national diet. As previously discussed fresh beef consumption in Ireland has been decreasing at a consistent rate over the last decade, indicating a gradual but fundamental shift in Irish beef consumption behaviour. Nonetheless, it is expected that 1997 per capita beef consumption rates will recover above 1996 but below the 1995 level. The explanation behind this development is that due to the announcement in March of 1996 a portion of the market disappeared instantly, however, as with scares of this type previous sales trends return, albeit from a lower base. In other words although consumption rates have increased slightly for 1997 they will continue to decline in accordance with the trend prior to 1996.

\footnotetext{
${ }^{1}$ Contact was made by telephone with the C.S.O., Cork in order to obtain the figures for this graph.
} 
Evidence for this line of reasoning is supplied by Thompson et al. (1997) who in projecting sales of beef to the year 2002 in the EU (Figure 4.5), forecasted that while the consumption of beef will recover somewhat in 1997, the rate of decline would nevertheless continue in line with the trend prior to the announcement.

\section{Figure: 4.5 EU Beef Consumption - Recent trends and future prospects}

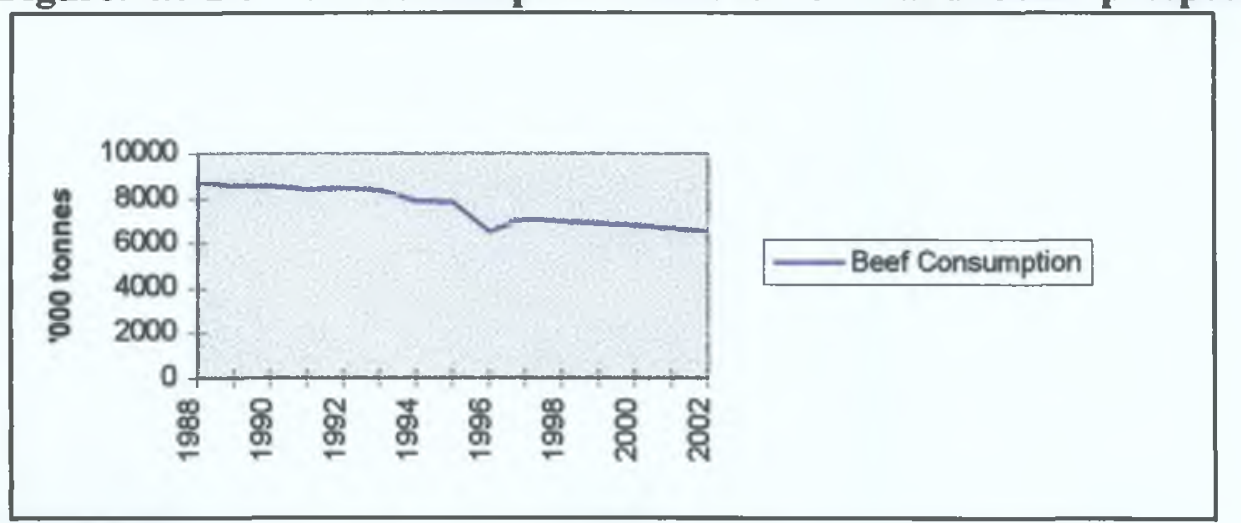

Source: Thomson, K.J., Kelly, R. and Anderson, C., 1997. The Grampian/UK Beef Market in the European Union. Grampian Enterprise Limited.

\subsection{Structure of the Beef Sector}

Each link in the distribution chain from farmer through slaughterhouse to retailer is important in order to provide the consumer with a piece of beef which possesses the demanded quality. It can be said that each of the three links: the farmer, the slaughterhouse/cutting plant and the retailer are responsible for one third of the quality (Nielsen, 1998). Figure 4.6 depicts an illustration of the important links in the beef distribution chain. The following section traces these links in the context of the Irish beef sector. In particular farmers, meat markets, slaughtering, retailers and consumers will be studied. 
Figure 4.6: Important links in the distribution chain.

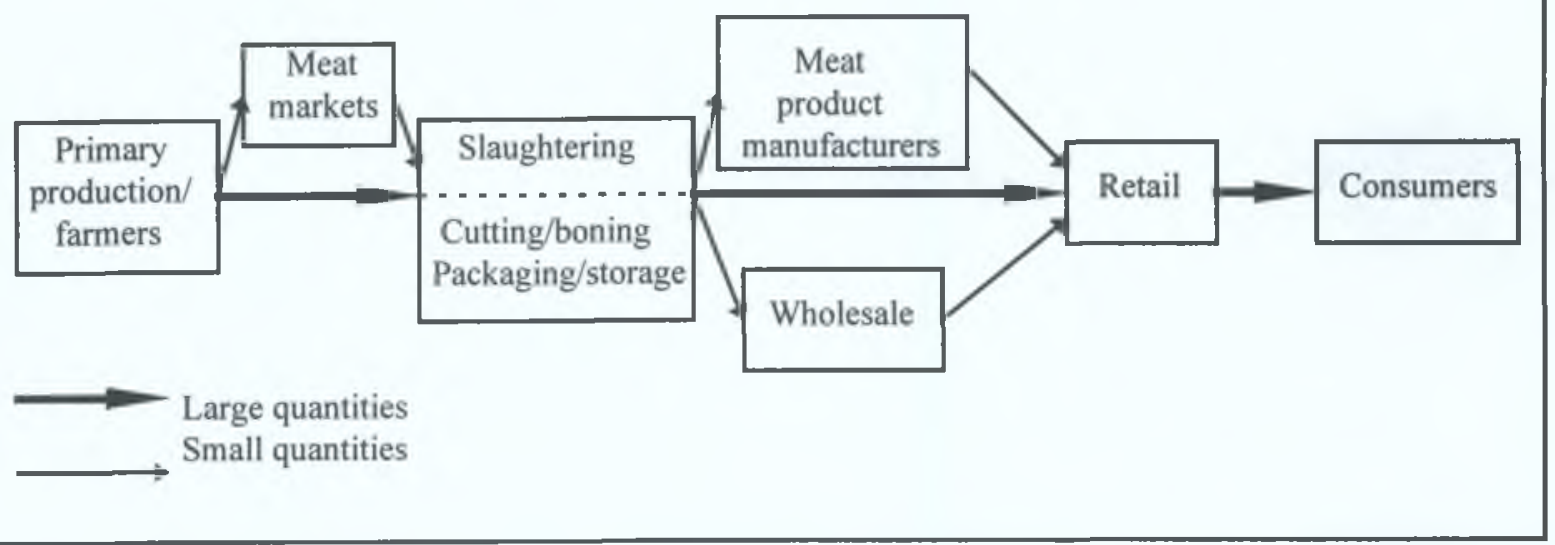

Source: Nielsen, N.A. (1998) The Beef Market in the European Union. The Aarhus School of Business, p.23

\subsubsection{Farmers}

As depicted on table 4.4 there has been a distinct reduction in the number of cattle holdings with an increase in the average number of cattle per holding in Ireland over the period 1991 - 1995. However, the size of holding varies widely, for instance, the West has a lower proportion of large holdings than the South, where dairying predominates.

Table 4.4: No. of Holdings and Avgerage No. of Animals per Holding, 1991, 1993 and 1995.

\begin{tabular}{|l|c|c|c|}
\hline & $\mathbf{1 9 9 1}$ & $\mathbf{1 9 9 3}$ & $\mathbf{1 9 9 5}$ \\
\hline No. of holdings & 170,578 & 159,000 & 153,400 \\
\hline Avg. no. animals/ holding & 40.3 & 45.0 & 48.1 \\
\hline
\end{tabular}

Source: CSO, Cork. (1998)

In $199747 \%$ of cows used in beef production in Ireland were suckler cows (i.e. they are not milked) with the remaining production coming from dairy cows (DOAF, 1998). This suckler figure as illustrated in table 4.5 represents a $24 \%$ increase on the 1985 figure. These figures indicate a trend away from beef produced from dairy herds.

Table: 4.5 Cow Numbers ('000's)

\begin{tabular}{|l|l|l|l|}
\hline & $\mathbf{1 9 9 2}$ & $\mathbf{1 9 9 7}$ & \% Change \\
\hline Dairy & $1,288.4$ & $1,309.6$ & $+6 \%$ \\
\hline Suckler & 886.0 & $1,160.3$ & $+24 \%$ \\
\hline Total Cow Number & $2,174.3$ & $2,469.9$ & $+12 \%$ \\
\hline
\end{tabular}

Source: Adapted from Department of Agriculture \& Food. (DOAF). (1998) The 1997 Annual Review and Outlook: For Agriculture \& The Food Industry, p.17. 
A similar trend towards specialised beef production rather than beef cattle supplied from dairy herds is evident across Europe. The suckler figure was 34\% in 1995, which represented a 10\% increase on the 1987 figure (Eurostat, 1996). This shift in the composition of the national cow herd reflects the increased attractiveness of the suckler cow premium as well as the restrictions imposed on the dairy herd in term of the volume of milk output that may be produced (Drennan, 1993). Furthermore, this transition means that the quality of beef sold to the consumer will be improved as suckler herds are regarded as better in eating quality terms than dairy herds.

In contrast to most European countries cattle production in Ireland is predominantly grass based. Elsewhere beef is produced from feeding concentrates. Grass based feeding, however, results in a highly seasonal production and slaughtering pattern with a concentration in the fourth quarter of the year (Sept. - Nov.). As part of the CAP (Common Agricultural Policy) Reform agreement the Deseasonalisation Slaughter Premium was introduced to overcome Ireland's steer slaughtering seasonality problems. The scheme has been very effective with the proportion of the kill in Autumn declining from $50 \%$ in 1992 to $31 \%$ in 1997 while at the same time the percentage kill in the Jan. - April period increased from $23 \%$ to $39 \%$ (See table 4.6). This transition in production has boosted Ireland's competitiveness in export markets through allowing consistent production output all year round.

Table 4.6: Steer Slaughterings in Ireland (\%) 1992-1997

\begin{tabular}{|c|c|c|}
\hline & Jan. - April & Sept. - Nov. \\
\hline $\mathbf{1 9 9 2}$ & $23 \%$ & $50 \%$ \\
\hline $\mathbf{1 9 9 3}$ & $33 \%$ & $41 \%$ \\
\hline $\mathbf{1 9 9 4}$ & $35 \%$ & $41 \%$ \\
\hline $\mathbf{1 9 9 5}$ & $40 \%$ & $36 \%$ \\
\hline $\mathbf{1 9 9 6}$ & $31 \%$ & $37 \%$ \\
\hline $\mathbf{1 9 9 7}$ & $39 \%$ & $31 \%$ \\
\hline
\end{tabular}

Source: DOAF (1998). 1997 Annual Review and Outlook: For Agriculture \& The Food Industry, p.14.

\subsubsection{Meat Markets}

The majority of cattle reared in Ireland are exported. They can be exported either live or as beef. From 1991 to 1994 the number of cattle exported live rose dramatically. 
However, this trend has reversed since 1994 in an even more dramatic manner as illustrated in table 4.7. This decrease in live cattle exports is to a large extent a result of the BSE crisis. The decrease has been most evident in Ireland's exports to third countries (i.e. countries outside the EU). From 1995 - 1997 live exports to third countries fell from 264,000 to just under 7,000 cattle. Table 4.7 also indicates that cattle slaughtering for domestic consumption (i.e. other slaughterings) has been declining steadily. However, current estimates for 1997 from the C.S.O. (as denoted under the heading 'Other slaughterings' in table 4.7) indicate a recovery in domestic consumption.

Table 4.7: Output Volume of Cattle and Calves (000's) 1991-1997

\begin{tabular}{|l|l|l|l|l|l|l|l|}
\hline & 1991 & 1992 & 1993 & 1994 & 1995 & 1996 & 1997 \\
\hline Live Exports & 138 & 187 & 384 & 413 & 370 & 191 & 47 \\
\hline Export Slaughterings & 1,497 & 1,512 & 1,417 & 1,271 & 1,363 & 1,514 & 1,631 \\
\hline Other Slaughterings & 217 & 205 & 184 & 165 & 152 & 135 & 148 \\
\hline Total Disposals & 1,851 & 1,904 & 1,985 & 1,850 & 1,885 & 1,841 & 1,826 \\
\hline
\end{tabular}

Source: CSO - Statistical Bulletin, September 1997

is Estimate

The Irish beef industry, particularly in the early 1990s, has used the intervention system as a market outlet instead of its intended role as a market support mechanism,. In 1991, for instance, intervention represented approximately $38 \%$ of total slaughterings (see figure 4.8). However, this situation changed when Common Agricultural Policy (CAP) reform imposed restrictions on beef for intervention, both in terms of the quantity and quality of animal which may be accepted, in order to limit its attractiveness as an outlet. Furthermore, there was a 15\% reduction in intervention price from July 1993 until July 1995 (Nielsen, 1998). However, while reliance on intervention was negligible from 1994 - 1995 it is again playing a role in supporting the price of cattle in Ireland due to the BSE crisis as illustrated in figure 4.7. 
Figure: 4.7 Beef Export Market and Intervention ('000t cwe)

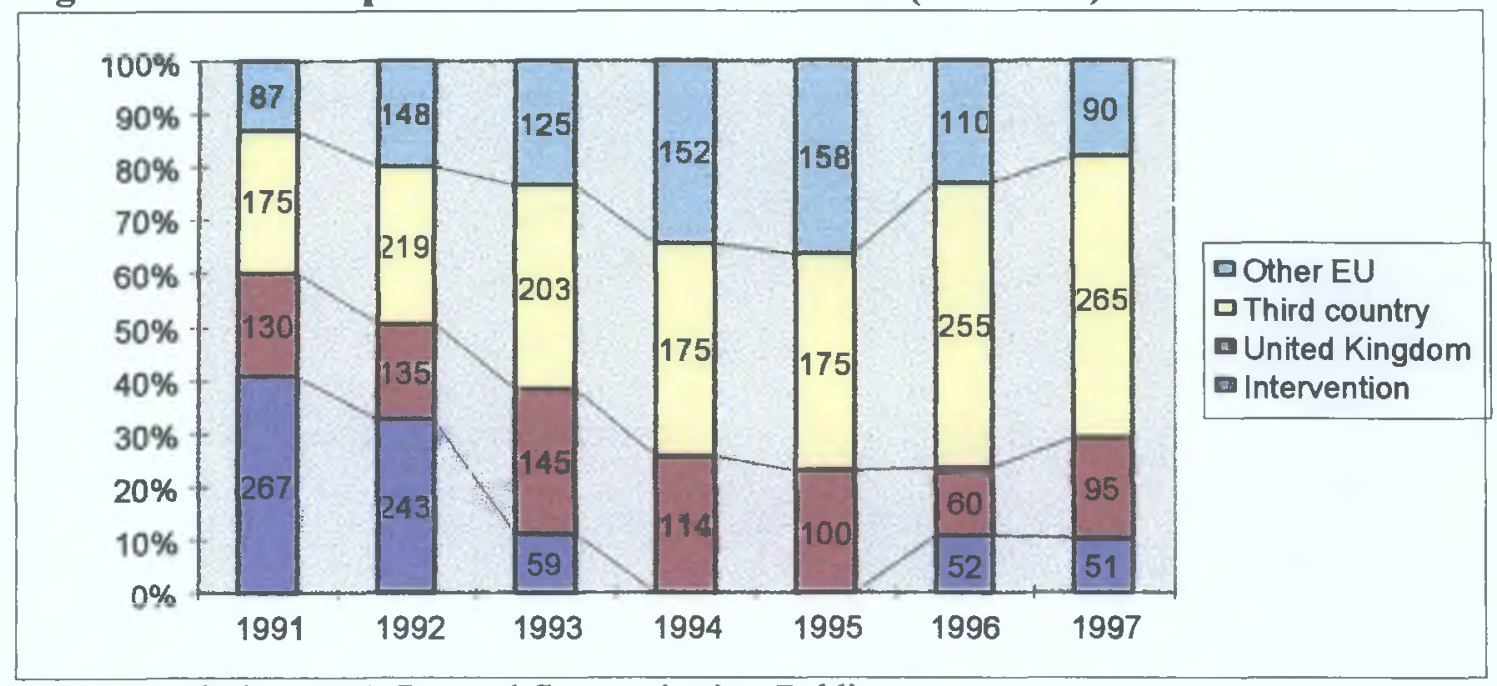

Source: Bord Bia. (1998). Personal Communication. Dublin.

In the aftermath of the BSE crisis, exports to other EU countries have reduced by $43 \%$ between 1995 - 1997. The two main reasons for this decrease are, firstly, the decrease in consumption due to BSE and secondly, the related development of a strong preference in major EU markets for domestically produced beef. Nonetheless, the British market as an outlet for Irish beef recovered somewhat in 1997 despite the decrease in 1996, as illustrated in figure 4.7.

In order to compensate for the market decreases attributed to intervention, the U.K. and other EU markets, Irish beef exports to third countries has increased by $33 \%$ since 1995 as denoted in figure 4.7. A significant element which has allowed this increase to occur has been the dramatic cessation of live exports to third countries. In an ironic sense this situation has proved beneficial to export licensed slaughter plants as they now do not have to compete with live cattle exports which in 1994 in particular (see table 4.6) were causing a reduction in export slaughterings.

In 1995 the Forbairt $(1995,74)$ Food Development Strategy report highlighted the effect at this time of the increased live export figures for 1994 on the industry as a whole: 
'The decline in the number of animals slaughtered was one of the factors that led to a reduction in the level of profitability in the sector and resulted in increased short time working and in a number of plants being closed for several months during the year'.

The increase in slaughtered exports going to third countries have, therefore, occurred as a result of the decreased live exports to these countries. Indeed such is the benefit of this development that Ireland's largest beef slaughter, Irish Food Processors, trebled its pre-tax profits to $£ 9.3 \mathrm{~m}$ for its financial year ending March, 1997; the twelve months following one of the largest crises in the history of the beef industry (Farmers Journal, 1998). However, while the processors have profited through this good fortune, farmers have suffered severely as a result of the BSE crisis with the under demand driving down cattle prices to the detriment of farmer profits, irrespective of whether cattle are slaughtered at home or abroad.

In the long term the dependence on third country markets is not a viable strategy. In 1997 alone export refund rates ${ }^{\prime}$ were cut by over 30\% (DOAF, 1998). This rate reduction is part of the General Agreement on Tariffs and Trade (GATT) agreement the Uruguay Round - which was settled in December 1993. The broad philosophy behind the GATT agreement is to liberalise trade through lower import tariffs and export subsidies and to reduce the impact of trade-distorting farm support policies. The agreement seeks to see a reduction in global support for agriculture of $20 \%$ between 1986/88 (base period) and 2000 (Ministry of Food and Agriculture, 1993). Further amendments will be made in the next round of talks which will take place sometime in the period $2000-2005$.

\subsubsection{Slaughtering/ Cutting}

The beef slaughtering industry can be classified into four broad categories (Henchion, 1997):

\footnotetext{
${ }^{1}$ Export refunds compensate EC exporters for the difference between internal community price(usually somewhat below the threshold price) and the lower world price.
} 
1) meat export premises which slaughter for the export market and trade in fresh meat in carcass and boneless form as well as vac-packed and frozen beef.

2) specialised boning halls which purchase carcasses from the export slaughter premises for cutting up meat for export as vac-packed or frozen or boneless beef.

3) meat processing plants which engage in the processing of beef into canned and convenience foods for export.

4) slaughterhouses and meat products processing premises which cater for the domestic market only.

There are 82 plants engaged in the beef export trade (33 are export slaughtering premises, 27 are specialised boning operations and 23 specialise in the manufacture of processed products). Twenty eight of the 33 slaughtering premises have deboning and vacuum packing facilities while nine of the slaughtering and specialised boning plants also engage in the manufacture of processed products such as canned beef, beef burgers and other convenience foods. There are 528 plants slaughtering specifically for the domestic market with kills ranging from 50 - 1,000 per annum (Operational Programme for Industrial Development, Food Sub-Programme, 1995). The number of domestic plants is expected to decline due to the application of EC directive 93/43, also called the Fresh Meat Directive.

The Fresh Meat Directive is a horizontal directive setting general rules of hygiene for food products and methods for controlling the observance of such regulations such as HACCP (Hazard Analysis and Critical Control Points). The regulations in the directive requires slaughtering companies to make investments which many small companies are unable to make. In effect small slaughtering companies selling at a national level now have to meet the same hygiene requirements as were already in effect for slaughtering companies approved for intra-community trade (Nielsen, 1998).

The beef processing sector in Ireland is highly concentrated. The major plants are Irish Food Processors, with $30 \%$ of the total beef kill in 10 plants; Kepak with $12 \%$ in three plants; Dawn Meats also with $12 \%$ in three plants; Avonmore with $10 \%$ in two plants; 
with the remaining $36 \%$ of the kill being dispersed among the other players in the sector (See figure 4.8)

Figure 4.8: The five biggest companies share of total adult cattle slaughterings.

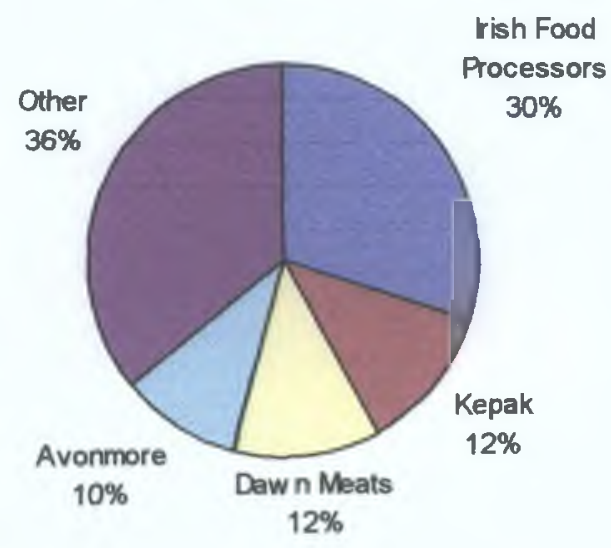

ct rish Food Processors

- Kepak

$\square$ Daw n Meats

口 Avonmore

Other

Source: Product Board for Livestock and Meat (PVV) (1996) Livestock, meat and eggs in the Netherlands. Issues 1994-1996. The Netherlands.

The larger players, such as Irish Food Processors, also have significant meat operations in other member states giving them a marketing scale comparable with other major companies in Europe in a sector which does not have major economies of scale beyond the plant level (Forbairt, 1995). Through positioning plant facilities in other European countries Irish meat processors are able to serve their customers more profitably while also being able to avoid the intermittent cost effects in Ireland caused by EU beef management policies. It is, for example, estimated that Irish companies control more than $50 \%$ of British beef processing operations (Maguire \& Mooney, 1998a).

Though cattle slaughtering is concentrated in Ireland and in many other European (EU-15) countries it is, however, fragmented at the European level. As table 4.8 shows, the company slaughtering the largest number of cattle slaughters only $3 \%$ in the EU as a whole. Note that Irish Food Processors only accounts for $2 \%$ of total slaughterings. 
Table: 4.8 The ten largest slaughtering companies in the EU-15 by share of total adult cattle slaughterings in 1995

\begin{tabular}{|l|l|l|}
\hline Company & Share of slaughterings & Activities in \\
\hline 1. Arcadie-Bigard & $3 \%$ & France \\
\hline 2. Moksel & $3 \%$ & Germany \\
\hline 3. Socopa & $3 \%$ & France \\
\hline 4. Sudfleisch & $3 \%$ & Germany \\
\hline 5. Irish Food Processors & $2 \%$ & Ireland \\
\hline 6. SVA & $2 \%$ & France \\
\hline 7. INALCA & $2 \%$ & Italy \\
\hline 8. Vital-Sogeviandes & $2 \%$ & France \\
\hline 9. Nordfleisch & $1 \%$ & Germany \\
\hline 10. Annuss & $1 \%$ & Germany \\
\hline
\end{tabular}

Source: PVV, 1996. Livestock, meat and eggs in the Netherlands. Issues 1994-1996, Product Boards for Livestock, Meat and Eggs in the Netherlands. The Netherlands.

One of the biggest problems which the beef slaughtering in industry in Europe faces is overcapacity. In Ireland the total capacity of the industry is estimated at $2.2-2.5$ million head per annum and it has been suggested that this figure represents an overcapacity of about $50 \%$ (Curran, 1997). One of the main reasons why this situation has occurred in Ireland is because the sector was built for scale to deal with the seasonality problem. However, as stated previously the deseasonalisation premium has now effectively handled this issue.

Besides higher costs of excess capacity, slaughter houses also have difficulty in being selective in sourcing their cattle. The slaughterhouses are more than willing to accept almost any quality of cattle. The incentive of the slaughterhouse to limit their sourcing of cattle to animals with certain specifications is not very strong. This has consequences downstream in the distribution chain resulting in beef of varying quality (Neilsen, 1998).

In Holland a scheme has already been established to deal with the overcapacity problem. Having been in a situation of $130 \%$ overcapacity the Food Product Board, a semi-state agency, has spent $£ 18 \mathrm{~m}$ reducing the number of plants in operation from 25 to 18. The idea has been to buy up plants on a voluntary basis and then shut them down. The Dutch are in the process of a second phase of 'capacity take-out', which will see them eventually reduce the number of plants to about 12 in a few years time 
(Curran, 1997). Plans to implement a similar rationalisation programme in Ireland is already underway and will be discussed later.

\subsubsection{Beef Retailing}

Current data on fresh meat retail outlets is not exact, therefore, two sources are cited here. The C.S.O. data in table 4.9 indicates that there were over 1500 outlets selling fresh meat in 1991. This includes supermarkets as well as independent butchers. (Data for 1996 does not break outlet figures into a fresh meat category). The second source Nielsen - table 4.10 - includes fish shops with butchers. Butchers constitute about $75 \%$ or 1,500 of this figure.

Table 4.9: Ireland - No. of Fresh Meat Outlets 1987 \& 1991

\begin{tabular}{|ccc|}
\hline & $\mathbf{1 9 8 7}$ & $\mathbf{1 9 9 1}$ \\
\hline Number of Outlets & 1,690 & 1,568 \\
\hline Turnover IR£m & 233 & 277 \\
\hline No. of Employees & 2,888 & 3,017 \\
\hline
\end{tabular}

Source: C.S.O. Census of Services, Vol. 1.

While there is increasing concentration in the retail industry in Ireland (table 4.10) with $2 \%$ of shops taking $50 \%$ of total turnover in 1993, the pace of such concentration is slower for small butchery shops where the number of outlets, at approximately 1,500 in 1993, was still quite significant. More and more Irish households appear to rely on once weekly shopping for major groceries but many still visit the local butcher for meat - a pattern accentuated during the current BSE crisis, when local butchers did not appear to suffer as much as other fresh meat outlets from the drop in sales (Keane \& Langan, 1996).

Table 4.10: Ireland - Trend for selected shops - numbers

\begin{tabular}{|l|l|l|l|}
\hline Shop type & $\mathbf{1 9 6 6}$ & $\mathbf{1 9 8 3}$ & $\mathbf{1 9 9 3}$ \\
\hline Grocers & 12681 & 7736 & 5552 \\
\hline Butchers/fishmongers & 2244 & 2090 & 2017 \\
\hline
\end{tabular}

Source: Nielsen Rerail Census, 1994 
Table 4.11: Ireland - Retail Sector - Concentration in Turnover

\begin{tabular}{|l|l|l|l|}
\hline & 1977 & $\mathbf{1 9 8 8}$ & $\mathbf{1 9 9 3}$ \\
\hline \% Shops & \multicolumn{3}{|c|}{ \% Turnover } \\
\hline 2 & 25 & 48 & 50 \\
\hline 10 & 47 & 66 & 70 \\
\hline 50 & 84 & 89 & 94 \\
\hline
\end{tabular}

Source: Nielsen Retail Census, 1994

\subsubsection{Household Meat Expenditure}

With regard to consumers, consumption rates have already been analysed previously and attitudes and perceptions have been examined in the literature review. This section therefore only deals with current meat expenditure.

Household expenditure on meat and meat products as a percentage of total food expenditure and of total household expenditure are combined in table 4.12 below. The figures illustrate that meat as a $\%$ of food expenditure and as a $\%$ of total expenditure is decreasing. Engel's law states that as income increases the proportion of income spent on food declines (Senaur et al. 1991). These figures indicate a variation of Engel's law in relation to meat.

Table 4.12: Expenditure on meat in Ireland as a \% of food expenditure and a \% of total household expenditure

\begin{tabular}{|l|c|c|}
\hline Year & Meat as \% of food & Meat as \% of total expenditure \\
$\mathbf{1 9 8 7}$ & 25.1 & 6.3 \\
$\mathbf{1 9 9 4 / 9 5}$ & 21.3 & 4.8 \\
\hline
\end{tabular}

Source : Household Budget Survey for 1987 and 1994/95.

\begin{tabular}{|c|c|c|}
\hline $\begin{array}{c}\text { Year } \\
\mathbf{1 9 9 3}\end{array}$ & $\begin{array}{c}\text { Meat as \% of food } \\
26.4\end{array}$ & $\begin{array}{c}\text { Meat as \% of total expenditure } \\
\end{array}$ \\
$\mathbf{1 9 9 4}$ & 26.0 & 5.4 \\
\hline
\end{tabular}

Source: CSO, National Accounts, Ireland. National Accounts do not include cost of food itself, only the service so they underestimate expenditure.

Table 4.13 shows that beef constituted one quarter, poultry one-fifth and pork just over one-eight of total household food expenditure for meat in 1994-'95. The figures for beef and chicken are extraordinary in the light of the per capita consumption rates in this 
period and highlight the expensiveness of beef relative to chicken. In 1994 beef consumption was $15.7 \mathrm{~kg} /$ head while chicken consumption was $23 \mathrm{~kg} / \mathrm{head}$.

Table 4.13: Proportion of beef, pork, poultry and other meat products as a \% of total household meat expenditure in 1994-1995.

\begin{tabular}{|lr|}
\hline Beef & 25 \\
Pork & 14 \\
Poultry & 19 \\
Lamb & 9 \\
Bacon & 23 \\
Other & 10 \\
\hline Total & $100 \%$ \\
\cline { 2 - 2 } Source: Adapted trom the Household Budget Survey, &
\end{tabular}

\subsection{Strategic outlook}

Clearly the Irish beef industry is strategically weak. In practice this is to a great extent caused by regular changes in global, European and national policies which act as major barriers to growth and development. In 1992 a report for the Industrial Policy Review Group ${ }^{1}$ endorsed a target of $60 \%$ sales to EC consumer markets and $40 \%$ to third country markets within five years (PA Consulting, 1992). This target has not been met. In 1997 approximately $50 \%$ of exports went to third country markets while approximately only $35 \%$ went to EC consumer markets. (Nearly half of the exports to EC markets went to the U.K.).

In order to solve the many problems facing the beef sector, such as over-capacity and the unhealthy balance of exports, the Government plans to establish a Strategic Development Plan for the Beef Industry. An international consultancy is nearing completion of the initial task of conducting a major study of the entire industry. In order to monitor the evolution of the plan a steering group, made up of Forbairt, The Department of Agriculture \& Food, the Irish Meat Association and An Bord Bia has been established. The terms of reference of the study are to examine the fundamental competitiveness of the Irish beef sector, its markets, economics, structures and policy environment with a view to (DOAF, 1998: 16):

\footnotetext{
' The Industrial Policy Review Group was established in June 1991 by the Minister of Industry and Commerce, Mr. Desmond O'Malley to independently review industrial policy.
} 
a) preparing an agreed beef industry development strategy up to 2005; and

b) recommending initiatives to enhance competitiveness, increase profitability and drive growth by matching best international practice in the context of European Union policy.

At present competitiveness in the beef sector is to a large extent focused on price as a consequence of the lack of branding, the lack of differences in product quality and the lack of new product development in the sector (Nielsen, 1998). As beef is predominantly a commodity type product price is the main factor determining the terms of trade. This focus leads to a constant vulnerability to market fluctuations. To alleviate the fluctuations caused by the recent crisis intervention purchasing recommenced and volumes accepted into intervention were immediately raised in an attempt to maintain market prices. Nonetheless, cattle prices in 1996 declined by $15 \%$ and by a further 4\% in 1997 (DOAF, 1998).

Henchion (1996) outlines the key success factors which the Irish beef industry must aim to achieve:

- an ability to understand and capitalise upon changing CAP and intervention supports;

- an ability to produce quality meat products under least cost conditions. Allied to this is the ability to deliver the final product to the consumer in a fresh quality state;

- an ability to maintain high quality standards and to market to both trade and consumers the value of Irish meat purchase over that of competitors;

- innovation of product presentation in both the raw and processed form;

- marketing ability that maintains the dominant share of the domestic market while opening new consumer markets for Irish meat products in Europe.

\subsection{Adding value to beef products}

The more value which is added to beef products the higher the financial return and employment levels. Table 4.14 quantifies the benefits of adding value which were estimated by the Irish Fresh Meat Exporters Society in 1981. Processing beef for 
'uncooked portion control', which includes burgers and ready meals, clearly increases value both in financial and employment terms.

Table 4.14: Added Value and Employment Potential of Downstream Processing

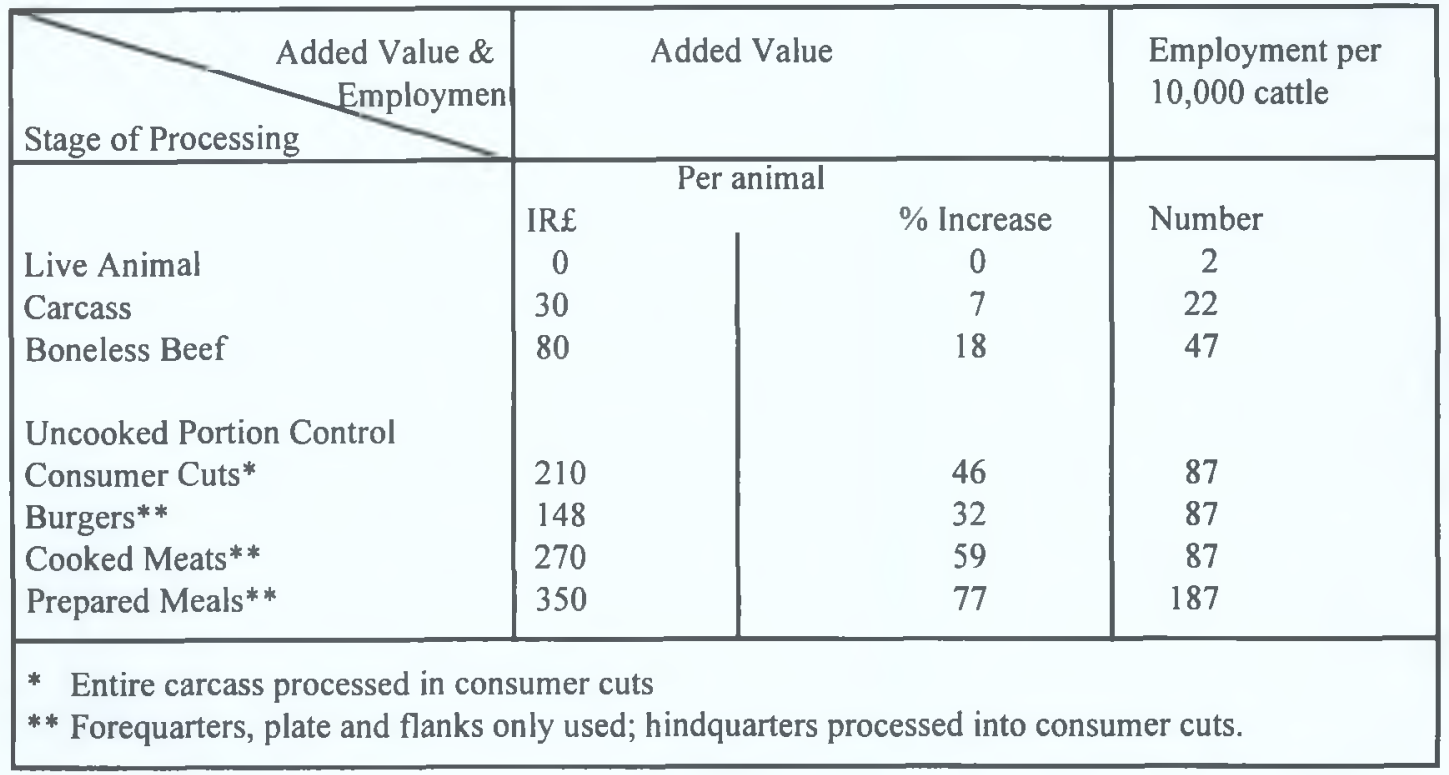

Source: Irish Fresh Meat Exporters Society, Ltd., 1981. A Strategy for the Development of Irish Cattle and Beef Industry.

However, processing beef for 'uncooked portion control' encompassed only $8 \%$ of overall exports in 1995 as table 4.15 highlights. The only area in which value has been added to beef products to any great effect has been in the trade of vacuum-packed beef cuts. Vacuum packed beef extends shelf life and offers advantages for the retailer including reduced transportation costs, reduced in-store investment and improved inventory control. Ireland is the leading exporter of vac-packed beef within the EC with nearly $46 \%$ of chilled boneless beef or $10 \%$ of total exports being processed in this manner (Keane \& Langan, 1996). Increasing exports of vac-packed beef is one of the main focus points for strategic development in the industry (Forbairt, 1995).

Table 4.15: Exports of Irish Beef (\%)

\begin{tabular}{|l|c|c|}
\hline Product Category & 1994 & 1995 \\
\hline Chilled bone-in & 15 & 13 \\
Chilled boneless & 22 & 23 \\
Frozen bone-in & 6 & - \\
Frozen boneless & 52 & 56 \\
Processed & 5 & 8 \\
\hline Source: Kcane, J.B. \& Langan, J.W. (1996) National Meat Quality \\
Policy in Ireland: Outline Report. EU Report. (EU FAIR-CT95-0046).
\end{tabular}


The pursuit of added value initiatives such as vac-packed beef are only being vigorously pursued now because of amendments to CAP in 1992 and GATT in 1993. EC support systems have always favoured the production and sale of commodity type beef; carcasses and live animals. For instance, in 1992 when one-third of Irish beef was exported into intervention it was observed that: 'Sales of vacuum packed beef to supermarkets currently involves additional costs and therefore lower returns than sales to intervention' (PA Consulting, 1992: 24). However, these support systems are being slowly removed, forcing the beef sector to become more market orientated. In addition to vacuum-packed beef two additional techniques for adding value which are inter-related have been recently developed; quality assurance schemes and retailer branding.

\subsubsection{Quality Assurance Schemes}

In response to the BSE crisis the beef industry put in place several 'farm assurance' schemes, designed to reassure the public of the quality and treatment of animals. This development has undoubtedly helped, particularly where butchers could say with certainty that beef came from a BSE free herd.

Retailers in Ireland, such as Tesco's and Superquinn, implemented their own quality assurance schemes in order to restore confidence and integrity to their outlets. Indeed it has been reported that Superquinn's beef sales actually rose during the beef crisis as a result of the implementation of their traceability scheme, which had been in place since 1991 (Fitzgerald, 1997). These schemes have been designed to become more proactive towards the needs of the consumer. For instance, while concern about animal welfare may not as yet have caused many consumers to cease or reduce their beef consumption this issue is, nonetheless, growing in importance and is therefore incorporated as a major part of the schemes.

These schemes not only ensure the traceability of the beef but also control product quality. For instance, controls are made for feeding and animal welfare. The whole slaughtering process including maturation is controlled by inspectors employed by the retail chain in order to secure tenderness, texture, taste and colour of the beef. 
Cattle produced for these schemes are provided under contractual agreement which leads to better co-ordination of supply and a better product. The majority of beef produced by farmers, however, is not sold in this manner (Keane \& Langan, 1996). Many farmers feel that they are not properly compensated for quality of product which they produce according to the guidelines of the retailer scheme. However, retailers argue that consumers will not pay extra for beef produced through the scheme. Factors such as traceability to ensure safety are regarded by consumers as a prerequisite. Harrington (1995: 3) provides further comments on this point:

'Farm and other quality assurance schemes will have little impact if they are seen as premium-earning niche activities. This is because the claims that can be reasonably made for such schemes in terms of welfare, adherence to withdrawal periods, hygiene and so on will be looked upon by the consumer as the minimum that the industry should adhere to. But if these assurance schemes can embrace the bulk of production - and themselves be embraced by the multiple and quality retailers for which consumers have a high regard - then they can provide the focus of a confidence-building operation for worried consumers'.

Beyond retailer quality schemes there are voluntary schemes such as those of Bord Bia and ISO9002. Generally the uptake of voluntary standards in the meat sector is poor with only one beef boning hall registered to ISO9002. Most beef plants, however, are members of the Bord Bia Beef Quality Assurance due to the provision of promotional support on the export market and also the use of Bord Bia's mark - the 'green shamrock' label (Keane \& Langan, 1996).

While the above schemes are voluntary the government has designed a regulated national beef assurance scheme which will be fully implemented by the end of 1998 . Spurred by the BSE crisis the scheme has been slow to set up due to the reluctance of farmers to participate (Business \& Finance, 1997). One of the main elements of the scheme which has already been initiated is the monitoring of the movements of every calf ('from cradle to table') born from January $1^{\text {st }} 1997$ by means of a computerised system of identification. This system will not only help restore consumer confidance in traceability procedures but also effectively rid the industry of the possibility of performing 'questionable practices' which were uncovered by the Beef Tribunal in the early 1990's. 


\subsubsection{Branding}

Meat is often perceived as an un-branded commodity which explains why promotional expenditure on meat and meat products in general tends to be extremely low in comparison with other food markets. For instance, main media expenditure on beef and veal in the U.K. amounted to just $0.1 \%$ of sales in 1994 (EIU, 1995). Because of the lack of branding in the beef sector, promotion in Ireland is normally carried out by Bord Bia or retail outlets, in particular Superquinn, on a generic basis. Furthermore, retailers are creating their own supreme quality brands through their quality assurance schemes. The strategy here is that, for instance, Superquinn's beef has become the brand. Superquinn are therefore capitalising on consumer brand loyalty and brand equity to the store name and extending these associations to the beef sold in the store. The development of retailer branding is already evident in many other product categories.

In-store branding is usually executed on a national or regional basis. For instance, in Tesco's and Marks and Spencers there's Aberdeen Angus beef. In the U.K. Asda supplies Scotch beef and Yorkshire beef. In Ireland's export markets beef is branded as Irish.

Furthermore, by putting in place assurance schemes retailers can expect consumers to turn to the store/brand name they trust if and when another beef scare or heightened concern about other issues such as animal welfare occurs. Again a main point one should glean from the branding issue is that there are no manufacturer's trade marks in the beef market. The multiple retailers have become powerful players in the beef sector in EC markets.

\subsection{Beef sector studv - preliminary findings}

Preliminary results for the strategic development plan referred to were released towards the completion of this study. The McKinsey consultancy group who conducted the study stated that the profitability of the Irish beef sector could be increased by between $£ 120 \mathrm{~m}$ and $£ 160 \mathrm{~m}$ plus per annum, provided a number of key initiatives were implemented (Maguire \& Mooney, 1998a). Table 4.16 highlights 
these initiatives which can be grouped into three categories, namely processing, market and production.

\subsubsection{Processing}

In order to eliminate the excess capacity McKinsey's recommend that the number of beef processing companies in the country should be reduced to around four, which is likely to take some time. At present there are sixteen companies with 38 plants. Eliminating the excess capacity will yield large immediate savings of $£ 19 \mathrm{~m}$ a year, plus the opportunity for longer term strategic gains associated with the capture of EUmarkets and disciplined selling in Third Countries (Maguire \& Mooney, 1998a).

As previously stated four companies, namely Irish Food Processors, Kepak, Dawn Meats and Avonmore control approximately two-thirds of the processing in the sector. It is likely, therefore, that these companies will be involved in buying-out the remaining twelve companies which control only one-third of processing in the sector.

\subsubsection{Market}

Eliminating under cutting and improving bargaining power versus Third Countries would yield an additional $£ 20 \mathrm{~m}$ a year. Closing part of the gap that has opened between the value realised by Irish and European beef through the launch of marketing initiatives would yield anywhere between $£ 30 \mathrm{~m}$ to $£ 60 \mathrm{~m}$ a year (Maguire \& Mooney, 1998a). Incidentally, in line with this recommendation An Bord Bia the Irish Food Board recently announced a $£ 7 \mathrm{~m}$ promotion plan to target $50 \%$ of Irish beef exports into the EU by 2,002 (Maguire \& Mooney, 1998b). Currently, 37\% of Irish beef exports go to the EU. The lack of value added initiatives is reiterated by McKinsey's, however, the consultants envisage only small benefits from increasing the value added content of Irish beef for the foreseeable future. 
Table 4.16: Mc Kinsey's summary of opportunities for the Irish beef industry

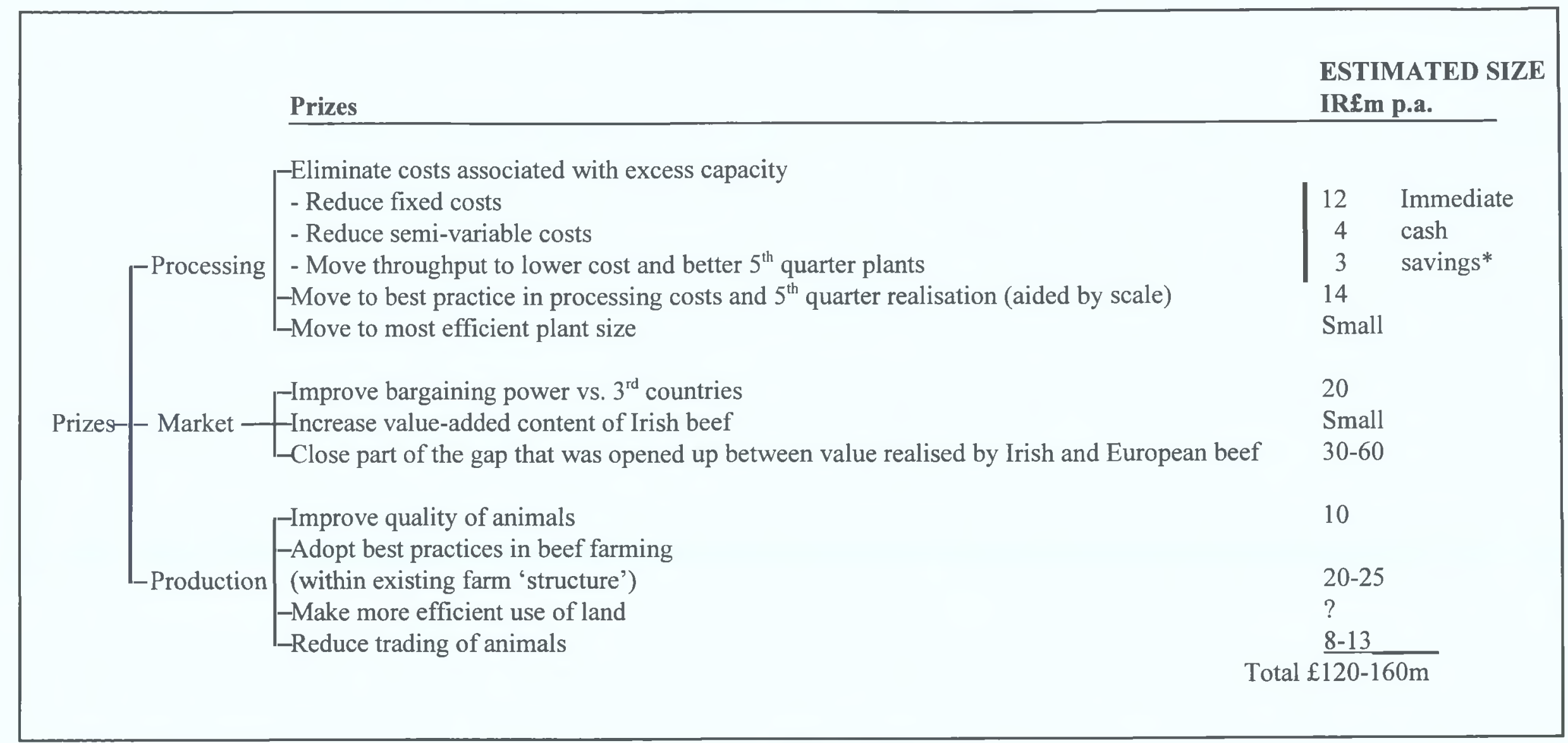

Source: Maguire, D. \& Mooney, P., 1998. 'Meat groups should be slashed to four', Irish Farmers Journal, June $6^{\text {th }}$, p.4.

* Before deduction for redundancy costs 
McKinsey's also recommend the formation of 'market groups' to improve vertical integration between retailers, processors and groups of farmers (Maguire \& Mooney, 1998a). As stated previously, many of the major retailers have already initiated a form of backward integration through their quality assurance schemes. Through these initiatives the retailers have strengthened their position on the beef supply chain and have arguably become the most powerful players.

\subsubsection{Production}

The vertical integration and elimination of excess capacity in the sector is likely to improve production through reducing the trading of animals and also develop a willingness among farmers to improve the quality of animals, provided they are rewarded for differential quality. In addition, the adoption of the best practices in beef farming could yield $£ 20 \mathrm{~m}-£ 25 \mathrm{~m}$ per annum. The trend towards specialised beef production, discussed previously, highlights that there is already a move towards meeting this recommendation.

\subsection{Conclusions}

The future of the beef industry presents many challenges but few strategic opportunities. The industry has been slow to adopt a market orientation not only through lack of initiative but also through lack of opportunity as revealed by Mc Kinsey's findings. Adverse market conditions in recent times and over capacity in the sector have prompted the industry to consider product, process and market recommendations by McKinsey's. However, change will take time to permeate through the industry. As one commentator put it the industry is like a massive supertanker that takes a long, long time actually to change course after getting its signals from the bridge (Gunner, 1989: 99). The re-orientation of beef industry together with the revival of beef consumption in the EU is arguably one of the greatest marketing and business challenges of the century. 


\section{CHAPTER 5}

\section{RESEARCH METHODOLOGY}




\subsection{Introduction}

The objective of this chapter is to outline the research methodology employed. Each stage of the research process will be explained.

The research methodology employed can be summarised as follows:

\section{Stage 1: Problem definition}

\section{- Establishment of broad area of interest}

Beef demand and perceptions of meat quality.

\section{- Data gathering/ conceptual framework}

The determinants of perceived meat quality (Issanchou, 1996; Lister, 1996).

\section{- Generation of hypotheses for investigation}

Derived from literature review.

\section{Stage 2: Research Design}

- Nature of study: Questionnaire.

- Data collection method: Telephone interviewing.

- Unit of analysis: Main food purchaser in meat eating households.

- Sampling design: Random sampling method in each of the main dialling code areas in the state.

Stage 3: Data analysis and evaluation: Univariate, bivariate and multivariate statistical analysis.

Before proceeding it is worth bearing in mind that only the questions from the questionnaire relevant to the thesis will be examined and discussed. All other questions and their results can be found in Cowan \& Mannion (1998). 


\subsection{Problem definition}

Since 1981 there has been a consistent decline in the consumption of beef in Ireland. No empirical work has yet been carried out to examine this adverse trend. The literature review has uncovered a number of key concepts and studies which give indications as to the types of variables which are likely to have influenced the decline in consumption rates. Non-economic factors were found to be have increasing influence and importance in meat demand (Bansback, 1996). A related but more specific finding is the PIMS research which correlates perceived quality and market share. Indeed many of the factors which have been reported in previous studies to have influenced the decline of beef consumption are quality factors.

The approach taken in this thesis to examine this area centres on the examination of two consumer groups, those who have reduced their beef consumption and those who have not. In examining those who reported a reduction consumption, only those who reported a partial as opposed to complete avoidance were studied.

The examination of the two groups will take place within the context of the framework of perceived quality outlined in the literature review and reproduced for convenience in figure 5.1 .

Figure 5.1: Framework for analysing perceived meat quality

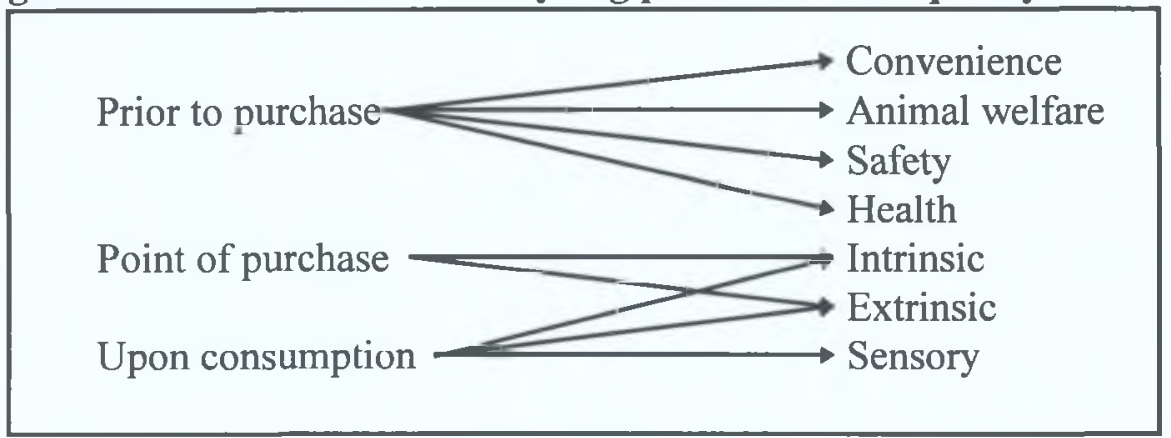

\subsubsection{Research agenda}

A three part research agenda is proposed for the study. Firstly, there is a need to operationalise the seven quality constructs. This aspect of the study is important since there must be a high degree of correspondence between abstract constructs and the procedures used to operationalise them (Peter, 1981). This condition for theory 
development and testing is referred to as construct validity and will be discussed further later in the chapter. The measurement of the seven quality constructs will be carried out at the lower attribute level of abstraction. The proposed procedure is as follows:

- In order to address intrinsic cues, extrinsic cues and sensory factors two questions have been designed with the objective of addressing perceived quality factors at the point of purchase and at the point of consumption.

- To address the safety construct a series of concerns will be examined.

- Finally, the four remaining quality constructs will be tested using a series of attitude statements.

Figure 5.2 which depicts an outline of the questionnaire provides an overview of these four questions. Before discussing each question in detail the three parts of the research agenda will be examined.

\subsubsection{First part of research agenda}

Using the attribute level data developed from the above questions a number of comparisons can be made as to how the two groups being addressed in the main research question score on various questions. The three topics which will be examined are:

a) the attributes used as indicators of quality at the point of purchase,

b) attributes which are deemed important at the point of consumption,

c) the attributes concerning safety.

All three questions are clearly outlined in figure 5.2. Because of the lack of adequate comparative descriptive evidence in the literature, formal hypotheses will not be proposed. Instead the comparison of both groups on these attributes will be examined in an exploratory manner. In addition, on a general level two propositions suggested by Zeithaml (1988) can be examined: 
Figure 5.2: Questionnaire outline

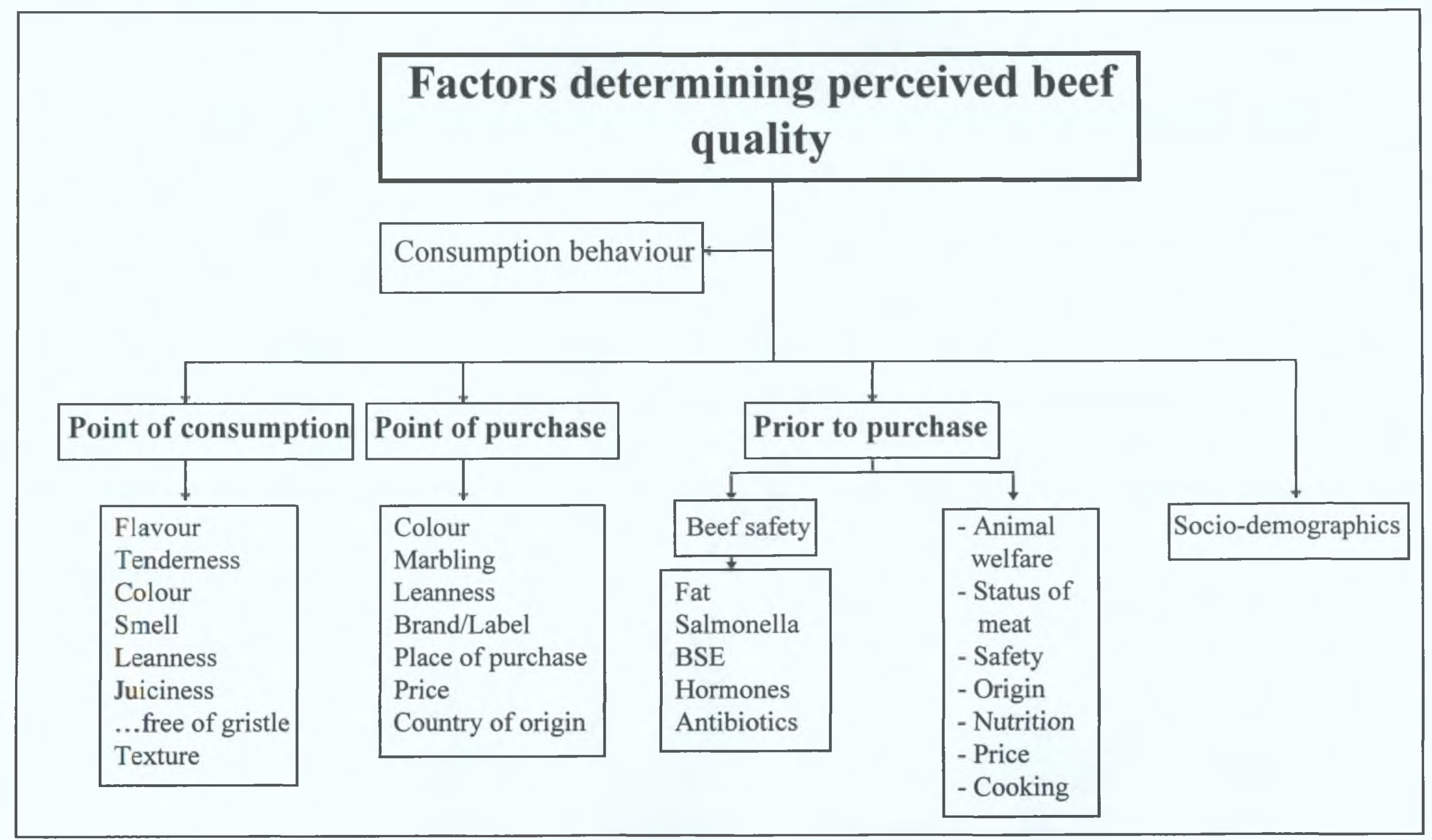


$\mathbf{H}_{1}$ : Consumers depend on intrinsic attributes more than extrinsic attributes in prepurchase situations when intrinsic attributes are search attributes (rather than experience attributes).

$\mathbf{H}_{\mathbf{2}}$ : Price is among the least important attributes associated with quality.

Furthermore, with regard to safety a finding in O'Neill's (1993) study can be tested.

$\mathbf{H}_{3}$ : Irish consumers regard fat as being of lesser importance than antibiotics and hormones in beef

\subsubsection{Second part of research agenda}

The second dimension of the research agenda is to transform the lower level attributes measured into the higher (quality) level of abstraction using a perceptual mapping technique. Perceived quality is a second order phenomenon and so must be examined at this level of abstraction. It is hypothesised that the resulting perceptual map will encompass the seven quality constructs outlined in figure 5.1 .

$\mathbf{H}_{4}$ : Irish consumers perceive beef quality according to the seven quality constructs proposed by Issanchou (1996).

\subsubsection{Third part of research agenda}

In the third and final part of the research agenda the perceptual map developed will be used to address the main question of whether Irish consumer perceptions of beef quality have influenced consumption behaviour. The following hypotheses for investigation drawn from the results of studies reviewed in the literature review, in particular that of the LRFA (1994) will be tested:

$\mathbf{H}_{5}$ : Those who have decreased their beef consumption are more inclined to be concerned about the healthiness of the product than those who have not. 
$\mathbf{H}_{6}$ : Those who have decreased their consumption are more concerned about the safety of the product than those who have not.

$\mathbf{H}_{7}:$ Those who have decreased their consumption are more susceptible to the issue of price than those who have not.

$\mathbf{H}_{\mathbf{8}}$ : Those who have decreased their consumption have done so for taste reasons.

$\mathbf{H}_{\mathbf{9}}$ : Those who have decreased their consumption are more concerned about animal welfare than those who have not.

In addition analysis will be carried out on the demographic variables of both groups in order to detect possible differentiating variables. Due to the lack of comparative descriptive evidence no formal hypotheses will be proposed for this research question. Instead the comparison of both groups on these variables will be examined in an exploratory manner.

\subsection{Research Design}

Due to the specificity with which the research problem was formulated from the literature review there was no direct requirement for primary exploratory research. Nonetheless, exploratory research was a component of the European project, which provided the stimulus for this thesis. The objective of the overall project was to examine attitudes and perceptions of consumers in six European countries towards meat quality. An exploratory study was carried out with the objective of capturing cultural nuances of meat consumption in the various countries.

\subsubsection{Focus groups}

In Ireland two focus groups; ABC1's and C2DE's, were carried out in May 1996. These were conducted by Mr. Cathal Cowan prior to the authors involvement in the research project. The overall objective of these discussions was to examine Irish attitudes and perceptions to meat quality. Specifically the objectives were: 
- To study how Irish consumers felt about meat; positive/negative aspects, like/dislike.

- To examine their consumption habits.

- To discuss the place of purchase.

- Finally, to examine the vocabulary used by respondents to describe what they looked for in a piece of meat both at the point of sale and when eating it at home.

\subsubsection{Ouestionnaire}

After conducting the focus groups, descriptive research of a cross sectional nature was conducted using a questionnaire. The questionnaire was designed by the participants of the countries involved in the project, a process in which the author was involved. However, the purpose for which the questionnaire was designed was different though related to that of the direction taken for this thesis. The questionnaire was primarily intended to study attitudes and perceptions to meat quality and safety in each respective participating country, and as mentioned at the beginning of this thesis, the Irish report of the overall questionnaire findings was submitted to Brussels in October of 1997 (Cowan \& Mannion, 1997).

To use the questionnaire with the objective of exploring possible quality factors influencing consumption was not at any point suggested during various meetings with the partner countries. Naturally, therefore, there are some shortcomings in the questionnaire design in relation to this thesis. Specifically, a problem lies in the fact that some dimensions of perceived quality as outlined by Issanchou (1996) have not been covered adequately. Any inadequacies will be highlighted at relevant points in the following discussion.

While there are short comings with the questionnaire in the light of the research problem which this thesis addresses the questionnaire was designed to be robust in nature and covered aspects of meat quality which this thesis will not discuss. For instance, many of the questions were not only asked for beef but also for pork and chicken. 


\subsubsection{Unit of analysis}

The unit of analysis was the individual responsible for the main grocery shopping in households where meat is eaten. The questionnaires were professionally administered by telephone for all participating countries in the project by Market Research Consultancy (Ireland) Limited in March of 1997 over a period of three weeks.

\subsubsection{Sample Design}

The sampling frame used by Market Research Consultancy (MRC) is based on the telephone code area network, as defined by Telecom Eireann. The sample was drawn in proportion to the number of telephone households in each of the main dialling code areas. Within each dialling code area, telephone numbers were selected at random. The number of households in the Republic of Ireland, as published in the 1996 Census was $1,127,318$. This included 1,114,974 permanent private households, 8,264 temporary private households and 4,080 non-private households. The penetration for residential telephones in the Republic of Ireland in 1997 was 83\% (Byrnes, 1997).

Unlike conventional telephone studies which operate on a quota sampling basis, the MRC telephone approach employed a more 'statistically-pure' random sampling methodology as the company has devised an industry approved method of contacting non-listed telephone households. In conducting the research MRC used a CATI (Computer-assisted Telephone Interviewing) approach.

\subsubsection{Data collection method}

The rationale for conducting the study by telephone as opposed to a postal survey or personal interview technique are as follows:

- Speed: The time frame required to carry out telephone interviews is shorter.

- Cost-effective: The telephone interview technique is cheaper to conduct.

- Sampling : Telephone interviews are particularly suitable for a random sampling approach.

- Convenience: It was possible for one company to carry out the whole survey for each country from one location. 
- Response rates: Response rates for telephone interviews are significantly higher than for postal surveys.

\subsection{Ouestionnaire design}

After the eligibility of the respondent (as main food shopper in the household) was clarified respondents were told that the questionnaire dealt with fresh meat. Fresh, they were told, included frozen but not processed meat.

\subsubsection{Consumption behaviour}

The questionnaire began with a number of questions examining consumption behaviour for beef, pork and chicken. Firstly, the frequency of weekly consumption of each meat in the household was questioned.

If none of the meats were eaten the interview was terminated. Also if a particular meat or meats was never eaten questions pertaining specifically to that meat throughout the questionnaire were excluded for that particular respondent.

A seven point scale was designed in order to gauge the frequency of meat consumption as illustrated in table 5.1. A don't know category was also included.

Table 5.1: Frequency of consumption

\begin{tabular}{|c|c|c|c|c|c|c|c|}
\hline Never & $\begin{array}{c}\text { Less often } \\
\text { than once } \\
\text { a month }\end{array}$ & $\begin{array}{c}\text { Less than once a } \\
\text { week but more than } \\
\text { once a month }\end{array}$ & Once & Twice & Three+ & It varies & $\begin{array}{c}\text { Don't } \\
\text { know }\end{array}$ \\
\hline
\end{tabular}

Two additional questions relating to consumption behaviour were asked with the objective of deriving the dependent variable for the study. Respondents were finally asked whether the amount of each meat eaten in the household had changed or not in the previous five years; since 1992. Of those who had changed their consumption of a particular meats or meats an additional question was asked to gauge the direction of this change; whether consumption had increased or decreased. 
The sensory, intrinsic and extrinsic quality constructs were operationalised in the next two questions, namely quality cues used at the point of consumption and at the point of purchase.

\subsubsection{Upon consumption}

The next question examined the characteristics which consumers use to assess the eating quality of beef at the point of consumption. Eight characteristics were examined in all. Five were of a sensory nature namely flavour, tenderness, smell, juiciness and texture, while three were intrinsic attributes namely colour, beef free of gristle and leanness. A five point importance scale $(1=$ very important, $5=$ not at all important). A don't know category was also included. Importance was conceptualised in terms of change as defined by Jaccard et al. $(1986,463)$ : 'An attribute is said to be important if a change in the individual's perception of that product attribute leads to a change in the attitude toward the product'.

\subsubsection{Place of purchase}

Next respondents were asked to rate on a five point scale $(1=$ very helpful, $5=$ not at all helpful), the quality indicators needed to predict the eating quality of beef. Seven indicators were examined in all, three intrinsic cues namely colour, marbling, and leanness, and four extrinsic cues namely the place of purchase, a brand or quality assurance label, price and country of origin.

The remaining four quality constructs of health, animal welfare, safety and convenience were operationalised in the questions addressing perceived quality prior to purchase. Unfortunately, most of these constructs, with the exception of safety were operationalised for meat in general and not beef in particular.

\section{$\underline{\text { 5.4.4 Prior to purchase }}$}

The safety consideration of beef prior to purchase was next examined. Respondents were asked to rate their concerns ( 1 = very concerned, $5=$ not at all concerned $)$ about four safety issues and a health issue; antibiotics, salmonella or other bacteria, BSE, hormones and fat/cholesterol. 
The next question examined attitudes concerning the remaining prior to meat purchase considerations; healthiness, animal welfare and convenience, using a five point likert scale $(1=$ strongly agree, $5=$ strongly disagree). This scale also included a don't know category.

There were no statements in the original questionnaire addressing the perceived convenience of beef. Two statements examining cooking habits were examined however and will be used as proxy variables for studying convenience. Clearly, these variables do not operationalise the construct convenience adequately but will be examined nonetheless:

- I like experimenting with new recipes.

- I do not enjoy cooking very much but it is a task which has to be done.

Animal welfare considerations were also measured using two statements:

- I prefer to buy meat from animals which I know have been treated well.

- We should have more respect for animals.

Health considerations were predominantly measured through measuring nutritionally related statements for meat in general:

- Meat is an essential part of a meal.

- There is no source of protein like meat.

- Meat is essential for a balanced diet.

- I always check the nutritional labelling on foods before buying them.

The shortcoming with the operationalisations for animal welfare and the remaining health variables is that they are examined within the context of meat in general but not beef in particular. Other additional statements predominantly related to considerations at the place of purchase were also tested.

Although not part of the framework for investigation price variables were measured in the questionnaire also. 
- Price is the main thing I consider when buying meat.

- You have to be prepared to pay a higher price to get good quality meat.

Statements addressing origin were also tested:

- I prefer to buy food which is produced locally.

- It is important that I know the country where the meat I buy has been produced.

There was a statement addressing a general view on food safety:

- I am confident that food in the shops is safe.

Finally, there was one question addressing social acceptability:

- I would never serve a meal without meat for visitors.

\subsubsection{Socio-demographics}

Finally, a number of socio-demographic questions were asked:

- The occupation of the respondent was examined. A 23 point scale designed by MRC was used (see appendix 1, question number C1).

- The respondent was asked if they contributed most to the household income.

- The occupation of the person who did contribute most was questioned again using the 23 point scale.

- The number of people living in the household.

- The number of children under 16 living in the household.

- Age of respondent.

- Age when leaving full time education.

- The gender of the respondent.

- Finally, the total gross annual income of the respondent was asked. The income categories were designed according to the income deciles for the country using C.S.O. data (see appendix 1).

The outline of the questionnaire is, as stated, illustrated in figure 5.2. 


\subsection{Data Analvsis}

According to Kinnear \& Gray $(1994,50)$ the process of data analysis should be thought of as taking place in two phases:

1. Exploration and description of the data.

2. Confirmation of data characteristics.

It is to the second phase of analysis that formal statistical testing belongs. Tests in this phase confirm that the patterns observed in the data (phase 1) are not merely chance occurrences and are 'robust', in the sense that they would be replicated were the research project to be repeated.

Kinnear \& Gray (1994, 50-51) warn against proceeding straight into formal statistical testing without having considered the first phase of analysis:

There are two main reasons for taking such a cautious approach. Firstly, the user who proceeds immediately to carry out various tests miss the most illuminating features of the data. Secondly, the performance of a statistical test always presupposes that certain assumptions about the data are correct. Should these assumptions be false, the results may be quite misleading.

In order to adequately illustrate the proposed use in this study of Kinnear \& Gray's recommendations for data analysis question five from the questionnaire - 'How important or unimportant are each of the following for assessing the eating quality of beef?' - will be analysed according to the two phases outlined. The procedure for analysis which follows will also be applied to questions 6 and 7. In other words the procedure is being proposed to address the first part of the research agenda the findings of which will be provided in Chapter 6 .

Firstly, the frequency scores for question 5 were calculated. Figure 5.3 presents this data in the form of a histogram. The first clear observation is that the responses are highly skewed; most respondents felt that all the factors were important.

From the results of the first phase of data analysis it is difficult to distinguish the extent of differentiation between the results due to the skewed results. Therefore, in 
order to test the degree of relationship and difference between these variables a formal statistical test must be applied to the data. Table 5.2 presents a classification of statistical tests each one being suited for a specific case.

\section{Figure 5.3: Histogram of importance of attributes for beef $(n=392)$}

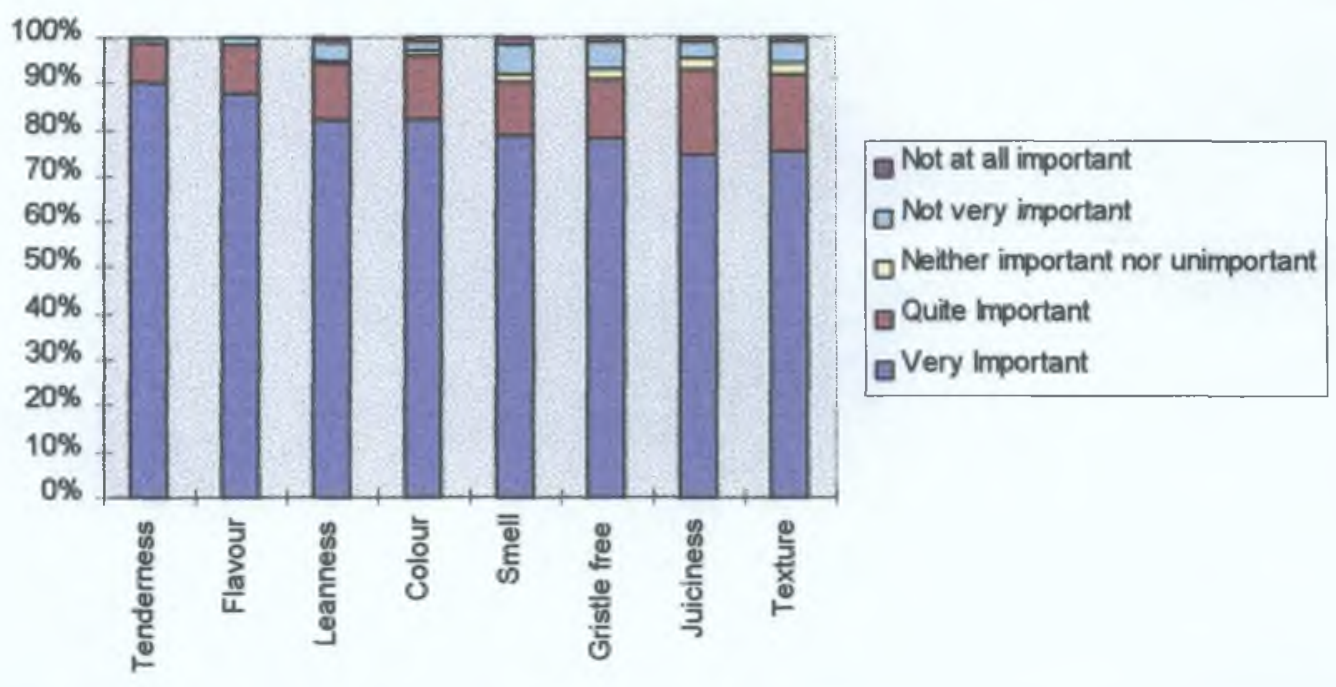

In question 5 being studied a test is required which is characterised by:

An ordinal scale: The data is derived from a five point scale; "Very important" to "Not at all important".

More than two samples: Since the importance of several beef characteristics cannot be compared the responses to each characteristic are regarded as being a specific sample. Consequently the number of samples corresponds to the number of characteristics.

Related samples: Since the same respondents answered several questions the samples are no longer independent. 
Table 5.2: Choosing a test for comparing averages of two or more samples of scores.

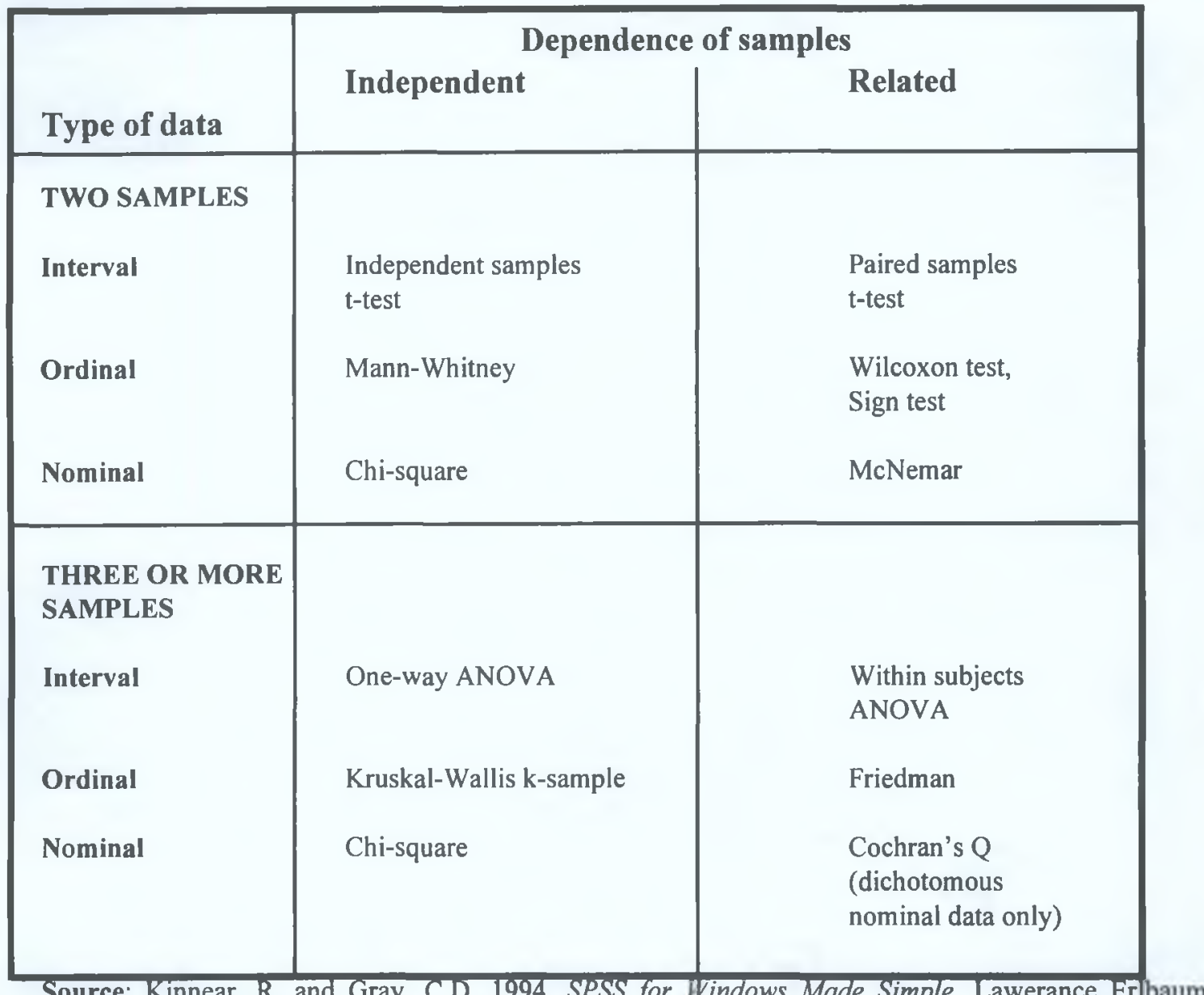

Source: Kinnear, R. and Gray, C.D. 1994. SPSS for Windows Made Simple. Lawerance Erlbaum Associates, U.K. p.75.

The test which conforms with these data characteristics is the Friedman test. However, the $\mathrm{H}_{0}$ of the Friedman test is that there are no differences in the average importance of beef characteristics. Thus, using this test will only detect some differences $\left(\mathrm{H}_{1}\right)$, but will not give any indication as to where and in which way the relationships and differences lie.

To overcome this problem multiple Wilcoxon tests or a sign test can be applied. Although these tests are designed for two related samples it can be applied to more than two by carrying out the tests on each pair of characteristics. In other words in order to compare the 8 beef characteristics the tests must be carried out on $(n \times$ (n1)) $/ 2=28$ different pairs. Puri (1996) notes that the Wilcoxon signed ranks-test for matched-pairs is more powerful than the sign test. 
The Wilcoxon signed-ranks test for matched-pairs is a non-parametric test of difference. The term non-parametric means that a less stringent requirement than normality is made for the population distribution (Zikmund, 1994). Also, the meaning of the phrase non-parametric test has been extended to include any test that uses nominal-scaled or ordinal -scaled data. The procedure:

$$
\mathrm{Z}=\frac{T^{+}-\mathrm{N}(\mathrm{N}+1) / 4}{\mathrm{~N}(\mathrm{~N}+1)(2 \mathrm{~N}+1) / 24}
$$

Table 5.3: Wilcoxon results of tenderness/flavour pairing

\begin{tabular}{|l|l|r|l|c|}
\hline \multirow{2}{*}{ Importance of tenderness - } & & N & Mean rank & Sum of ranks \\
\cline { 2 - 5 } Importance of flavour & Negative ranks & 28 & 26.14 & 732 \\
& Positive ranks & 21 & 23.48 & 493 \\
& Ties & 343 & & \\
\cline { 2 - 5 } & Total & 392 & & \\
\cline { 2 - 5 } & \multicolumn{3}{|c|}{$Z=-1.284 \quad 2$ tailed $P$ value $=.199$} \\
\hline
\end{tabular}

The negative ranks indicate that tenderness is of less importance to these respondents, whereas positive ranks indicate that tenderness is of greater importance than flavour. Ties highlights respondents who scored tenderness and flavour in the same importance category.

Firstly, the mean score of each attribute was calculated using $\operatorname{SPSS}^{\circledR}$ 7.5. These attributes were then ranked in accordance to scores found. The Wilcoxon signed-rank test for matched-pairs was then applied to each pair of characteristics - 28 pairs in all.

Next a significance test matrix (table 5.5) was designed to arrange all 28 calculations into a systematic and orderly fashion. The rankings already calculated using the mean scores (shown in table 5.4) are used to determine the order of column and row headings. 
Table 5.4: Ranking of attributes according to mean scores

\begin{tabular}{|l|c|c|c|c|c|c|c|c|}
\hline & $\begin{array}{l}\text { TENDER- } \\
\text { NESS }\end{array}$ & FLAVOUR & COLOUR & LEANNESS & JICINESS & TEXTURE & GRISTLE & SMELL \\
\hline Mean & 1.13 & 1.16 & 1.25 & 1.30 & 1.35 & 1.35 & 1.36 & 1.43 \\
\hline $\begin{array}{l}\text { Standard } \\
\text { deviation }\end{array}$ & .42 & .48 & .64 & .76 & .73 & .77 & .82 & .96 \\
\hline
\end{tabular}

Table 5.5 : Importance of attributes in assessing the eating quality of beef $(\mathbf{n}=392)$

\begin{tabular}{|c|c|c|c|c|c|c|c|c|}
\hline & Tender & Flavour & Colour & Leanness & Juiciness & Texture & Gristle & Smell \\
\hline Tender & - & & $* * *$ & $* * *$ & $* * *$ & $* * *$ & $* * *$ & $* * *$ \\
\hline Flavour & & - & ** & ** & $* * *$ & $* * *$ & $* * *$ & *** \\
\hline Colour & & & - & N.S. & $*$ & $*$ & $*$ & $* * *$ \\
\hline Leanness & & & & - & As? & N.S? & N.S. & ? \\
\hline Juiciness & & & & & - & N.S. & N.S. & N.S. \\
\hline Texture & & & & & & - & N.S. & N.S. \\
\hline Gristle & & & & & & & - & N.S. \\
\hline Smell & & & & & & & & - \\
\hline
\end{tabular}

Visual inspection was used to identify areas of consistency. These areas have been shaded and signify variables in which differences are not statistically significant from one another; indicated by their respective $p$-values. Table 5.5 displays three areas of consistency. These three 'groupings' are ranked below in figure 5.4.

Figure 5.4: Results of Wilcoxon test for the eating quality of beef

\begin{tabular}{|lll|}
\hline Flavour & & Leanness \\
Tenderness & Colour & Smell \\
& & Juiciness \\
& & Texture \\
& Gristle \\
\hline
\end{tabular}

These results indicate that consumers perceive flavour and tenderness to be the most important factors for assessing the eating quality of beef. Furthermore, both of these factors are statistically significantly more important in the eyes of the consumers than colour and subsequently, colour is seen as statistically significantly more important than all remaining factors for assessing the eating quality of beef. 
The next section discusses the multivariate technique which will be used to address the second part of the research agenda, namely the perceptual map of perceived beef quality.

\subsection{Factor Analysis}

Before describing the factor analysis technique there will be a discussion surrounding the reasons for its choice in this study.

\subsubsection{Rationale for factor analysis use}

Two types of multivariate techniques are useful for developing a perceptual map; factor analysis and discriminant analysis. In order to address the research question discriminant analysis would be the preferred technique as it would highlight the discriminating factors which distinguish those who have reduced their beef consumption in Ireland and those who haven't. However, when using discriminant analysis one assumption is that no independent variables either interact or are correlated (Speed, 1994). Including two perfectly correlated variables, where one predicts the other, introduces considerable instability into the coefficients. This effect is termed multi-collinearity or simply collinearity.

The possibility of multi-collinearity occurring in the research being carried out is very high due to the number of variables involved in the analysis. In order to handle the collinearity problem factor analysis must be first carried out.

The other explanation for using the factor analysis construct relates to the question of the operationalisation of the perceived quality construct. Churchill (1979: 69) highlights that: 'Factor analysis can indeed be used to suggest dimensions, and the marketing literature is replete with articles reporting such use. Much less prevalent is its use to confirm or refute components isolated by other means'. As stated it is the intention of this study to confirm or refute Issanchou's (1996) proposal that the perceived quality construct is determined by seven dimensions $\left(\mathbf{H}_{4}\right)$. In consumer research this form of analysis is referred to as an investigation for nomological validity. Nomological validity is defined by Zaltman et al. $(1973,104)$ as the extent to 
which predictors based on the concept which an instrument purports to measure is confirmed. It is the theory and nature of the constructs investigated (in the case Issanchou's (1996) seven constructs) which determine whether empirical results support or invalidate measures of nomological validity. However, Peter $(1981,143)$ highlights that '...programmatic research usually results in changes in theory, constructs and/or measures because most of the logical and empirical evidence suggest that:

1) the theory as originally proposed is wrong

2) constructs as originally proposed are misspecified

3) measures as originally developed are invalid.

Nonetheless, Peter (1981) provides a reminder that it is the theory and nature of the constructs which provide the guidelines for interpreting empirical results.

In addition to examining the nomological validity, factor analysis will facilitate the examination of content validity in the study. Zaltman et al. $(1973,104)$ define content validity as '...the degree to which an operationalisation represents the concept about which generalisations are to be made'. In Chapter 3 the uncertainty surrounding the operationalisation of quality constructs such as health was discussed. Through using an exploratory (as opposed to confirmatory) form of factor analysis an examination can be made of the content validity of quality constructs such as health. To illustrate, the health construct has been operationalised previously as encompassing fat and nutrition in line with previous studies. Should these variables measuring the construct health load on the same factor' ${ }^{\prime}$ then content validity will have been met.

\subsubsection{The factor analysis technique}

Factor analysis is often referred to as a data reduction technique or a technique which analyses inter-dependence. As Kachigan $(1986,382)$ notes: 'At one and the same time it summarises data and identifies relationships among variables, two basic functions

\footnotetext{
'Essentially a factor is a dimension or construct which is a condensed statement of the relationships between a set of variables (Kline, 1994).
} 
of statistical analysis....redunancy is removed from a set of correlated variables and the variables are represented with a smaller set of derived variables, or factors'. Loosely factor analysis can be thought of as the grouping of variables. To illustrate the technique schematically figure 5.5 shows nine variables reduced to three factors. All the variables within each factor are highly correlated and as Brown $(1980,471)$ states: '...getting at a common concept'.

Figure 5.5: Nine variables reduced to three factors

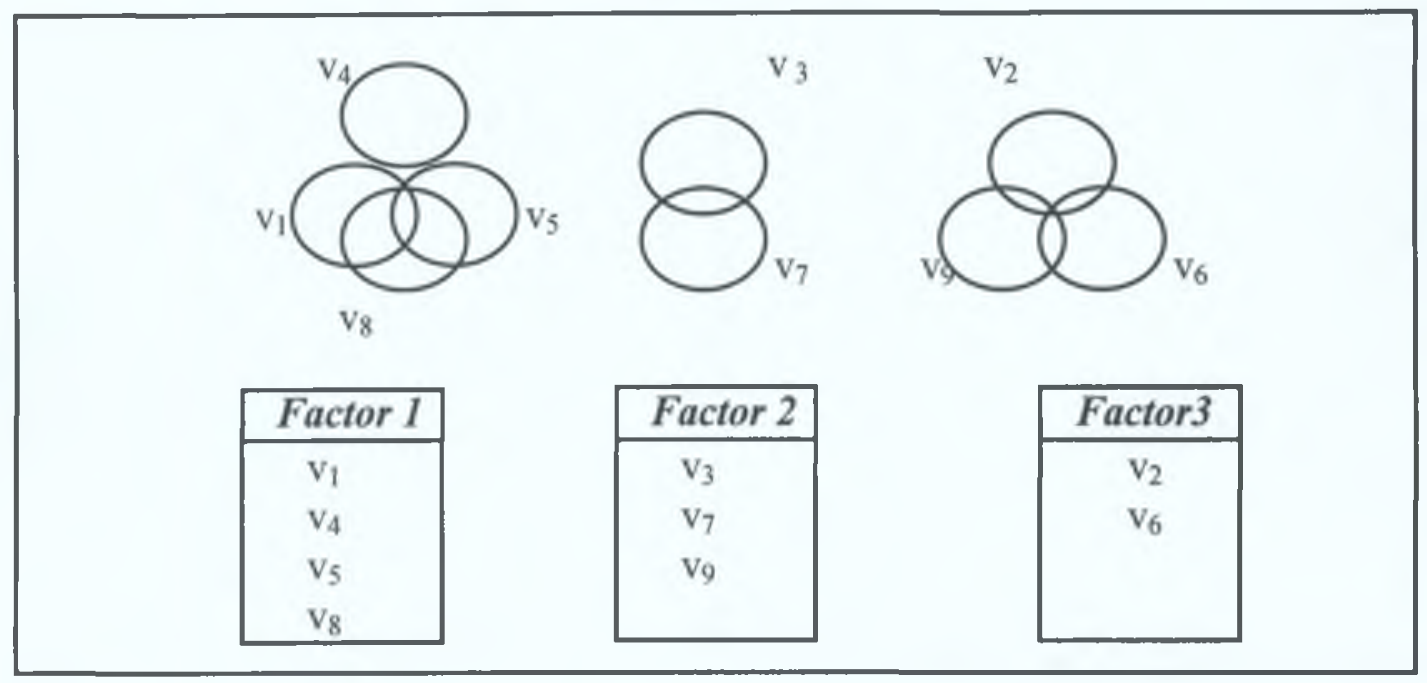

Source: Kachigan, S.K. 1986 Statistical Analysis: An Interdisciplinary Introduction to Univariate and Multivariate Methods. Radius Press, New York. p.378

To illustrate the technique further just two variables; height and weight, are used. Figure 5.6 is a scatter diagram of a correlation of scores of 10 people plotted on two axes, each representing one test. The diagram also depicts how factor analysis summarises these two variables into a single factor while retaining as much of the original information as possible. The height and weight of 10 people are mapped and the task is to establish a line on the graph which minimises the dispersion of the points from the line (Brown, 1980). Height and weight covary in that the pairwise correlations between the variables in each set are uniformly high. Height and weight are therefore a manifestation of the underlying dimension size. 
Figure 5.6: Scatter diagram. Height and weight and the resulting factor of size.

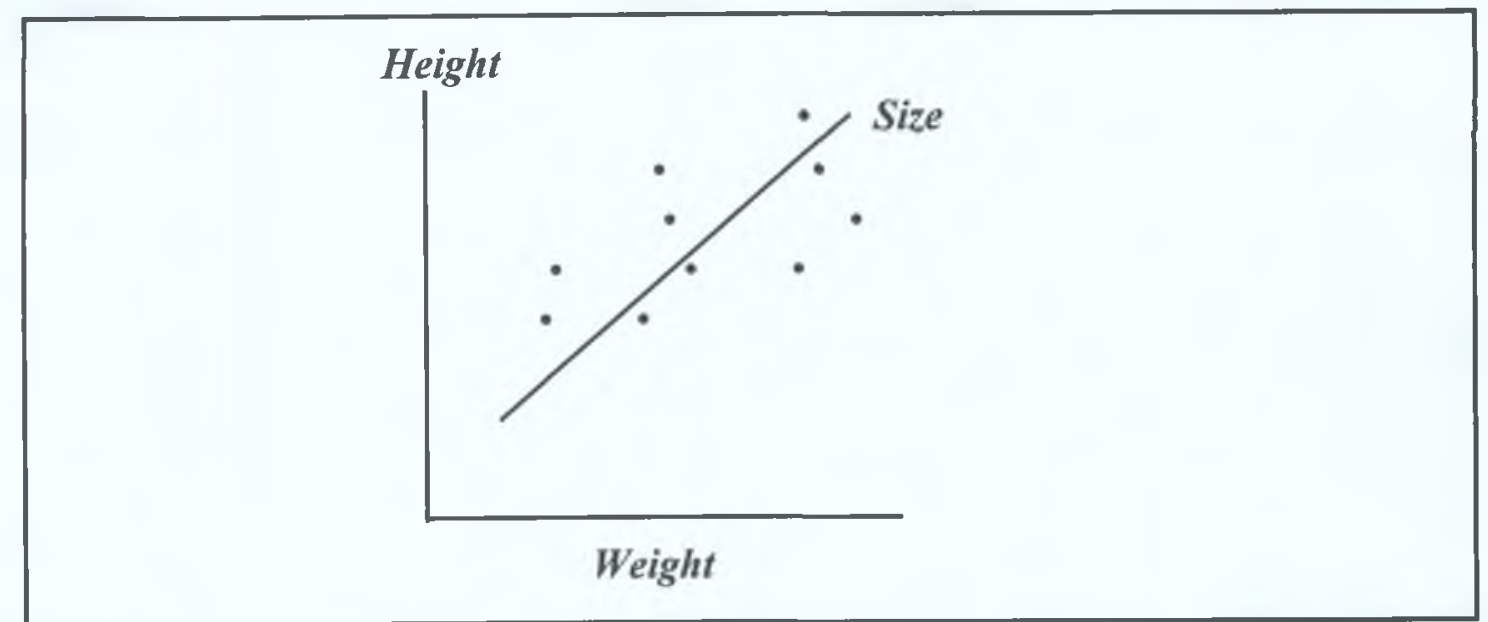

Source: Adapted from Brown, F.E. 1980. Marketing Research: A Structure for Decision Making. Addison-Wesley Publishing Company. p.471.

Kachigan (1986) highlights three key stages in the factor analysis procedure; the data matrix, the correlation matrix and the factor matrix.

Figure 5.7: Key stages in the factor analysis procedure

(a)

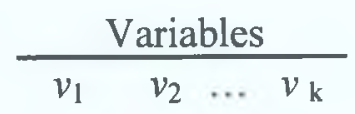

$F_{\mathrm{m}}$

$\mathrm{O}$

b

j

e

c

$\mathrm{t}$

s

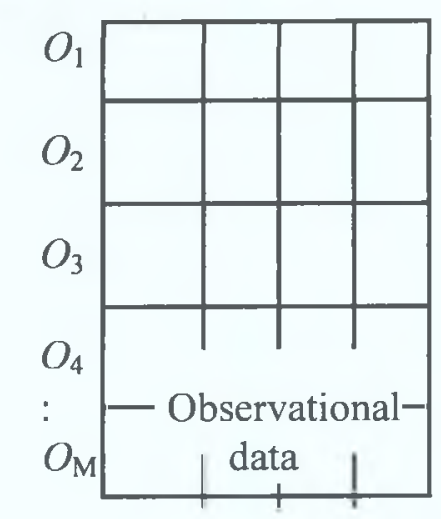

(b)

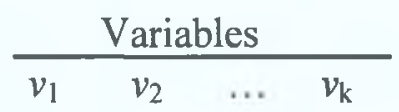

(c)

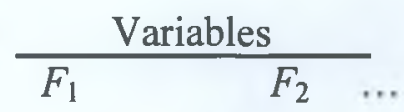

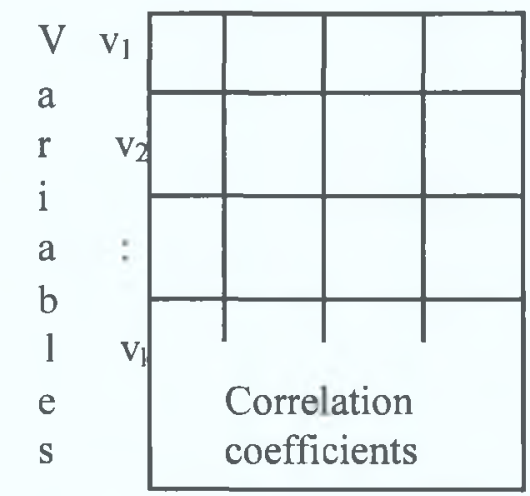

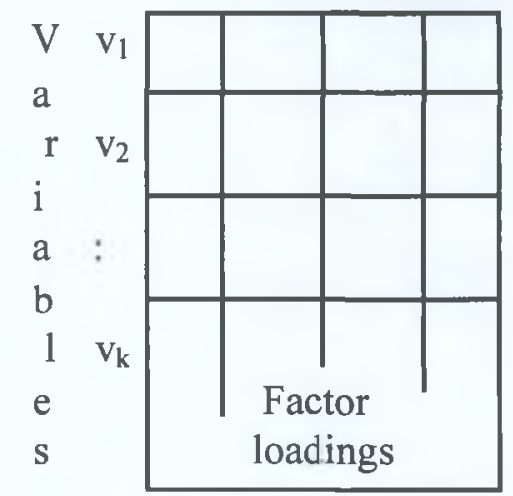

Original data matrix

Correlation matrix

Factor matrix

Source: Kachigan, S.K. 1986 Statistical Analysis: An Interdisciplinary Introduction to Univariate and Multivariate Methods. Radius Press, New York. p.383. 
In a previous section of this thesis; figure 5.7, a matrix was designed while conducting the Wilcoxon signed-ranks tests for matched-pairs. However, in that case scores of significance replaced the correlation coefficients ${ }^{1}$ between variables. Visual inspection of the matrix allowed variables that were highly correlated with each other to be identified through the examination of the $p$-values. However, in this case where there are a great number of variables, the number of correlation coefficients makes it virtually impossible to summarise the matrix by visual inspection alone. For instance, with 40 variables there would be $(40 \times(40-1)) / 2=780$ correlation coefficients to examine. The development of factor analysis helped solve this data reduction need. Once the correlation matrix has been formed a series of operations employing matrix algebra are performed to produce the factor loadings ${ }^{2}$ in the factor matrix; part (c) of figure 5.7 (see Cathell (1978) for a detailed discussion of the matrix algebra employed in factor analysis). Further discussion of factor loadings and the factor matrix will be carried out later in this chapter.

Factor analysis is the name given to a family of procedures. For this study the most common variation - principle components analysis (PCA) will be used. This variation has also been used on the two most significant studies on the perceived quality of meat to date; Steenkamp (1989) and Grunert (1996). In principle components analysis, Brown $(1980,472)$ indicates that '...the factors are derived sequentially, using the criteria of maximum reduction in variance and non-correlation among factors... [he further comments]... The first factor identıfied by PCA is selected on the criterion of reducing variance as much as possible'. In other words the first extracted factor typically accounts for the largest part of the total variance of the data collection. Kachigan (1980) provides a hypothetical PCA solution (table 5.7) illustrating this point.

\footnotetext{
${ }^{1}$ A correlation is a numerical measure of the degree of agreement between two sets of scores. It runs from +1 to $-1:+1$ indicates full agreement, 0 no relationship and -1 complete disagreement (Kline, 1994, 3).

${ }^{2}$ Factor loadings are the correlations of a variable with a factor (Kline, 1994, 5).
} 
Table 5.6: The percentage of total variance accounted for, and the associated eigenvalues, for the successively extracted factors in a factor analysis of a set of nine variables (principle components solution).

\begin{tabular}{|c|c|c|c|c|}
\hline \multirow{2}{*}{ The extracted factors } & \multicolumn{2}{|c|}{$\begin{array}{c}\text { \% of total variance } \\
\text { accounted for }\end{array}$} & \multicolumn{2}{c|}{ Eigenvalues } \\
\cline { 2 - 5 } & Incremental & Cumulative & Incremental & Cumulative \\
\hline$F_{1}$ & 41 & 41 & 3.69 & 3.69 \\
$F_{2}$ & 23 & 64 & 2.07 & 5.76 \\
$F_{3}$ & 14 & 78 & 1.26 & 7.02 \\
$F_{4}$ & 7 & 85 & .63 & 7.65 \\
$F_{5}$ & 5 & 90 & .45 & 8.10 \\
$F_{6}$ & 4 & 94 & .36 & 8.46 \\
$F_{7}$ & 3 & 97 & .27 & 8.73 \\
$F_{8}$ & 2 & 99 & .18 & 8.91 \\
$F_{9}$ & 1 & 100 & .09 & 9.00 \\
\hline
\end{tabular}

Source: Kachigan, S.K. 1986. Statistical Analysis: An Interdisciplinary Introduction to Univariate and Multivariate Methods. Radius Press, New York. p.387.

Notice that the first factor $\left(F_{1}\right)$ extracted accounts for $41 \%$ of the total variance inherent in the data. Extracting the second factor adds another $23 \%$ for a cumulative total of $64 \%$. So these two factors account for nearly two-thirds of the data's variation. Each variable on average accounts for $11 \%$ of the total variation; $100 \% \div 9=11 \%$. The eigenvalues (highlighted on the right hand side of table 5.6) utilise this average. 'An eigenvalue', states Kachigan $(1986,387)$, 'corresponds to the equivalent number of variables which the factor represents'. For example, as indicated $F_{1}$ accounts for $41 \%$ of the variance. This is equivalent to the sum of 3.69 variables; $3.69 \times 11 \%=$ $41 \%$. The function of the eigenvalue is to provide a guideline as to how many factors to retain. Factors are retained to the point where an additional factor accounts for less variance than a typical variable. In table $5.6, F_{4}$ only accounts for a variance .63 of a variable therefore, only the first three factors should be extracted.

Usually, however, the initial factor extraction does not give interpretable factors. Here the factors should be rotated. 'One of the purposes of rotation is to obtain factors that can be named and interpreted' (SPSS ${ }^{\circledR} 7.5$ Base, 291). Using just two factors Brown (1980) using a diagram illustrates this point. Firstly, part $\boldsymbol{A}$ of figure 5.8 shows the factor loadings (the degree to which each of the variables correlates with each of the 
factors) for eight variables on each of the two factors; I and II. When the axes are rotated $45 \%$ (part $\boldsymbol{B}$ of figure 5.8) the desired effect is achieved; the factors have been redefined allowing variables to be distinctly associated with one factor or the other. In practice this distinction is not always clear cut particularly when 3 or more factors are being rotated simultaneously.

An important point noted by Kachigan $(1980,391-392)$ is that '...factor rotation does not result in a change in the number of factors, nor in the total variance explained. It only redefines factors with respect to the manner in which variables load on (correlate with) the factors'.

\section{Figure 5.8: Scatter diagram before and after rotation in factor analysis.}

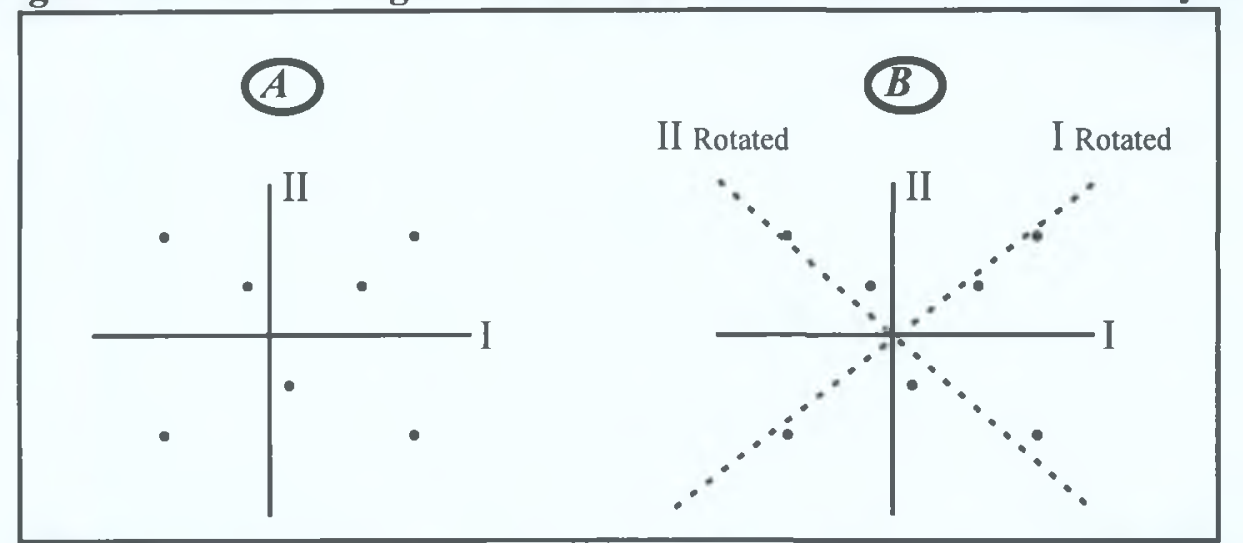

Source: Adapted from Brown, F.E. 1980. Marketing Research: A Structure for Decision Making. Addison-Wesley Publishing Company. p.479.

There are several rotation methods available in SPSS ${ }^{\circledR}$ which can be classified into two groups; ortogonal and oblique rotations. Varimax, Quartimax and Equimax are orthogonal rotations, meaning the resulting factors (or components) are uncorrelated. The Direct Oblimin and Promax rotations are oblique rotations, meaning the resulting factors are correlated with one another (SPSS ${ }^{\circledR}$ Base, 1997).

Kachigan $(1986,393)$ states: 'The interpretation of the factor loading matrix is primarily dependent on the overall configuration of loadings'. After rotation the loadings tend to be at extremes, either high or low with relatively few medium-sized loadings. At this point in the analysis the high-loading variables of each factor are studied and an attempt to give a descriptive name to the factors is made. Table 5.7 below presents the factor loading matrix after rotation in a study examining the quality 
attributes of saveloy (a seasoned dry sausage) (Steenkamp, 1989). The high loading variables are highlighted (high negative loadings also contribute to the interpretation of the factor). The study revealed three independent quality dimensions. The variables which loaded high on each factor were used as a guide to naming the factor/quality dimension. For example, the variables which loaded highly on Factor 1 were: taste, unwholesomeness ${ }^{1}$, tender, natural, fresh and juicy. Steenkamp (1989), therefore, labelled Factor 1 - sensory perception. Subsequently, Factors 2 and 3 were labelled unwholesomeness and keepability, respectively.

Table 5.7: Principle component loadings relating quality attributes to quality dimensions after varimax rotation for saveloy (salient loadings are underlined)

\begin{tabular}{|c|c|c|c|}
\hline Attribute & Factor 1 & Factor 2 & Factor 3 \\
\hline Taste & .777 & -.223 & .108 \\
\hline Fat & -.127 & .613 & -.194 \\
\hline Colouring agents & -.138 & .609 & .255 \\
\hline Unwholesome &.- .400 & .401 & -.130 \\
\hline Tender & .761 & -.101 & .185 \\
\hline Salt & .091 & .508 & .218 \\
\hline Keepable & .152 & -.117 & .764 \\
\hline Perservatives & -.101 & .395 & .559 \\
\hline Natural & .616 & -.136 & -.289 \\
\hline Bad for the figure & -.057 & .633 & -.068 \\
\hline Fresh & .683 & .125 & -.388 \\
\hline Juicy & .818 & .017 & .146 \\
\hline Cumulative variance $(\%)$ & 245 & 398 & 512 \\
\hline
\end{tabular}

Source: Steenkamp, J-B.E.M. 1989. Product Quality. Van Gorcum. The Netherlands. p.151.

The figure for the cumulative variance; $51.2 \%$ highlighted at the bottom right corner of table 5.7, indicates that the three factors encompass half of the information represented in the variables analysed.

\footnotetext{
' In table 5.7 unwholesomeness has a high negative loading which indicates that the meaning of the factor will be opposite to that of the variable.
} 


\subsection{Proposal for application of factor analvsis}

Having described the factor analysis technique the next section outlines the proposed application of the technique for the study. Hair et al. (1995) indicate seven stages for carrying out factor analysis:

1. Objectives.

2. Research design.

3. Assumptions.

4. Deriving and assessing overall fit.

5. Interpreting the factors.

6. Validation of factor analysis.

7. Additional usage of factor analysis results.

\subsubsection{Objectives}

As stated previously, factor analysis can identify the structure of a set of variables as well as provide a process for reduction. In this study all variables with the exception of those pertaining to consumption behaviour and demographics will be factor analysed. Therefore, it is proposed that 34 variables from four questions in the questionnaire will be analysed:

Question 5: Importance of attributes for eating quality - eight variables.

Question 6: Helpfulness of attributes at the place of purchase - seven variables.

Question 7: Safety concerns - five variables.

Question 9: Attitude statements - 14 variables.

The objectives of the analysis are firstly, to examine if the variables can be 'grouped' and secondly, to reduce the 34 variables to a smaller number.

\subsubsection{Designing the factor analysis}

Hair et al., (1995) suggest that the sample size should be 100 or larger. Furthermore, the acceptable level of respondents to variables should be at least five-to-one. The more acceptable range would be ten-to-one. 


\subsubsection{Assumptions}

The critical assumptions underlying factor analysis are more conceptual than statistical. The correlation matrix must have sufficient correlations to justify the application of factor analysis. In order to determine the appropriateness of factor analysis to this study two statistical tests; Barlett test of sphericity and the measure of sampling adequacy (MSA) will be used. These measures examine the entire correlation matrix which in this study will consist of 561 correlations; $(34 \times(34-1)) / 2$ $=561$. The Barlett test of sphericity provides a statistical probability that the correlation matrix has significant correlations among at least some of the variables. In MSA the index of measurement for the appropriateness of carrying out factor analysis ranges from zero to one, reaching one for perfect prediction without error. The measure can be interpreted with the following guidelines: 0.90 or above, excellent; 0.80 or above, meritorious; 0.70 or above, middling; 0.60 or above, mediocre; 0.50 or above, not good and below 0.50, unacceptable (Hair et al., 1995: 374).

\subsubsection{Deriving factors and assessing overall fit}

As stated previously, PCA analysis will be applied to the correlation matrix. Another form of analysis, common factor analysis is also available. Grousuch (1983), however, indicates that in most applications, both component analysis and common factor analysis arrive at essentially identical results if the number of variables exceeds 30 which in the case of this study it does.

In relation to the number of factors to be extracted, only factors with eigenvalues greater than one are considered significant. Another criterion for factor extraction is the percentage of variance criterion. Here the cumulative percentages of the variance extracted by successive factors are the criterion. The purpose is to ensure practical significance for the derived factors. Hair et al. (1995) indicate that in the social sciences a solution which accounts for 60 percent of the total variance is a satisfactory solution.

\subsubsection{Interpreting the factors}

An important tool for interpreting factors is the rotation of the initial factor solution which in this study will be varimax rotation. In the factor matrix resulting from the 
rotation the rule-of-thumb which will be used in selecting factor loadings of significance is that they are greater than 0.40 . When all the variables have a significant loading on a factor a meaning will be assigned in accordance with the pattern of factor loadings.

\subsubsection{Validation for factor analysis}

The proposed form of factor analysis being used in this study is, as stated, exploratory in nature. This is due to the lack of empirical work examining the perceived quality construct as defined in its broader sense. Hair et al. (1995) recommend that the most direct method of validating the results is to move to a confirmatory factor analysis. Confirmatory factor analysis tests hypotheses factor structures using, for example, structural equation modelling (SEM). SEM is a technique designed to test various different models, in other words hypothesised relationships between variables. However, carrying out confirmatory factor analysis is not feasible for many studies (Hair et al., 1995). In addition, Peter (1981) suggests that considerably more attention should be given to the conceptual aspects of theory development and testing before rigorous construct validation studies are performed.

Therefore, the alternative test for validity proposed for use in this study is to examine the nomological validity. Churchill (1979) recommends that researchers consult the literature when conceptualising constructs and specifying domains. The literature should indicate how the variable has been defined previously and how many dimensions it has. In this study the perceived quality construct is hypothesised to have seven dimensions. If the resulting factorial structure should produce the seven dimensions proposed it could be interpreted as supportive evidence of construct validity. In addition, the content validity will be studied through the examination of whether the variables operationalising the seven quality constructs loaded together. Clearly, one cannot have nomological validity without also having content validity.

In addition to assessing validity the reliability of the factor analysis must also be examined. The reliability will be assessed through the examination of the internal consistency among variables loading on each factor by means of the Cronbach alpha test. The assumption regarding internal consistency of a set of items is that '... if a set 
of items is really measuring some underlying trait or attitude, then the underlying trait causes covariation among the items. The higher the correlations, the better items are measuring the same construct' (Bohrnstedt 1970:93). The Cronbach alpha can be interpreted as a correlation coefficient and so ranges in value from 0 to 1 .

The suitable value of the Cronbach alpha depends on the purpose of the research. For early stages of basic research, Nunnally (1967: 226) suggests reliabilities of 0.50 to 0.60 suffice and that increasing reliabilities beyond 0.80 is probably wasteful. In many applied settings, however, where important decisions are made with respect to specific test scores a reliability of 0.90 is the minimum that should be tolerated, and a reliability of 0.95 should be considered the desirable standard. Since this study cannot be considered as either an early stage of basic research nor an applied stage of research the gauge for the test scores taken for this study will be between 0.60 and 0.90 .

An important note in the discussion of validity and reliability is that if a measurement is found to be valid it is then inherently reliable. However, if a measurement is found to be reliable it is regarded as a necessary, but not sufficient, condition for validity (Churchill, 1987).

A measurement is valid if it measures what it is intended to measure and is reliable if it yields similar results when different people administer it and when alternative forms are used. For instance, a test that requires students to do mirror drawing and memorise nonsense syllables may be quite reliable, but it is a poor indicator of mastery of the concepts of psychology. The test has poor validity (SPSS, 1997).

\subsubsection{Additional usage of the factor analysis results}

Discriminant analysis will be carried out on the factors derived from the factor analysis. Composite factor scores will be computed to represent each of the factors. These factor scores will be used as independent variables in the discriminant analysis.

PCA explicitly assumes that the sample of respondents is homogenous; that is, all respondents are treated alike and no underlying group structure is explicitly recognised. Dillion et al. (1989) warn that this may cause difficulty when carrying out 
further multivariate analysis on the factor scores when examining differences in a set of groups as in this study intends to do. The difficulty arises when a variable or variables does not 'make the cut' and subsequently are not represented in any of the components extracted. The problem is that this variable or variables may, however, contribute to the understanding of group structure in the data. Because they are not represented in the components extracted, information of value will have been left out, which will be of great importance in the second multivariate analysis technique to be used. To avoid the proverbial danger of 'throwing the baby out with the water', Dillion et al. (1985) suggest an examination of across group variation (AGV) accounted for by each component. However, the problem can be avoided altogether if all the variables which have been factor analysed are accounted for/loaded in the extracted components.

The next section discusses the final data analysis technique used in this study which will address the third part of the research agenda, namely finding the perceived quality factors which discriminate between the two groups of consumers being studied.

\subsection{Two-group discriminant analysis}

The following section will examine discriminant analysis in the context of dependent variables with two categories only, hence two-group discriminant analysis. In the case of this thesis these categories are those who have reduced their consumption of beef in the previous five years and those who have not.

By weighting the values of various independent variables a single variable - the discriminant function - can be derived. The discriminant function is a linear combination of the independent variables and is labelled $\mathbf{Z}$ in figure 5.9.

The discriminant function is derived from an equation that takes the following form (Kachigan, 1986):

$Z=W_{1} X_{1}+W_{2} X_{2}+w_{3} X_{3}+\ldots W_{n} X_{n}$ 
where

$\mathrm{Z}=$ Discriminant score

$\mathrm{W}_{\mathrm{i}}=$ Discriminant weight variable for variable $\mathrm{i}$

$\mathrm{X}_{\mathrm{i}}=$ Independent variable $\mathrm{i}$

Each respondent will have a single discriminant score on the discriminant function in place of their score on the various independent variables. At the same time a cut off score (see figure 5.9) will be determined such that when the two groups of the dependent variable are compared with respect to the discriminant scores the errors of classification are minimised. In figure 5.9, where there are two variables represented in the discriminant function the general procedure of assigning weights to these variables; $\mathrm{X}_{1}$ and $\mathrm{X}_{2}$, and selecting a cutoff score so as to minimise the errors of classification can be seen intuitively and graphically. Further elements of figure 5.9 will be discussed later.

The next section will examine the application of discriminant analysis through a sixstage model outlined by Hair et al. (1995):

\section{Objectives}

2. Research design.

3. Assumptions.

4. Estimation of the discriminant model and assessing overall fit

5. Interpretation of results.

6. Validation of the results. 
Figure 5.9: Geometric representation of two-group discriminant analysis for two independent variables

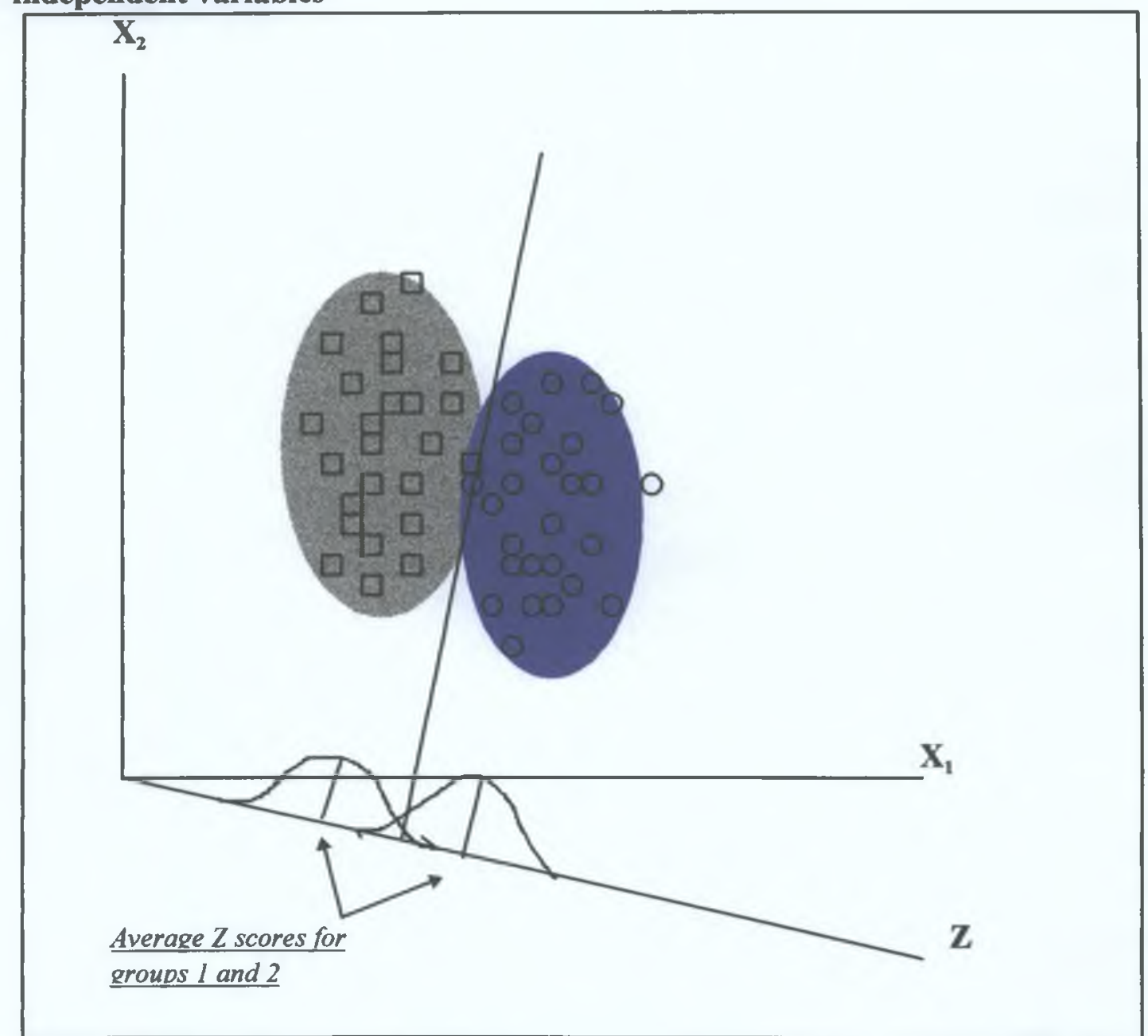

Source: Hair, J.F., Anderson, R.E., Tatham, R.L. and Black, W.C. (1995) Multivariate Data Analysis with Readings. $4^{\text {th }}$ Ed. Prentice Hall, Englewood Cliffs, N.J. p. 187.

\subsubsection{Objectives}

The objectives of discriminant analysis is to classify persons or objects into two or more categories, using a set of intervally scaled independent variables (Tull et al., 1987). The use of discriminant analysis has proved beneficial for three major purposes (Green et al., 1978):

1. Developing predictive models to classify individuals into groups.

2. Profiling characteristics of groups which are most dominant in terms of discriminantion.

3. Identifying the major underlying dimensions which differentiate among groups. 
The third purpose represents the use for which discriminant analysis is being used in this study; to identify the underlying dimensions of perceived quality which differentiate those who have reduced their beef consumption and those who haven't.

\subsubsection{Research Design}

The dependent variable as stated above represents two categories. The independent variable will encompass the components derived from PCA. Discriminant analysis is quite sensitive to the ratio of sample size to the number of independent variables. Many studies suggest a relation of 20 observations for each independent variable (Hair et al., 1995). This study aims to meet this requirement. In addition to the overall sample size, the analyst must also consider the sample size of each group. If the groups vary widely in size, this may impact the estimation of the discriminant function and the classification of observations.

\subsubsection{Assumptions}

In discriminant analysis multivariate normality is used. Here to put it simply there are two bell shaped symmetric distributions, one for each group as illustrated in the lower half of figure 5.9. The behaviour similarly can be characterised by two parameters for each distribution; a mean and a variance. In order to derive the optimal direct prediction of group membership two assumptions are required (SPSS ${ }^{\star}$ Base, 1997):

1. Multivariate normality of the independent variables. Thus independent variables must be quantitative and follow a normal distribution.

2. Both groups have different mean vectors but equal variance-covariance matrices.

With regard to the first assumption, no tests are currently feasible for testing the normality of all linear combination of sampling distributions of means of independent variables (Tabachnick et al., 1989). By studying box plots of the within-group distributions of each independent variable an examination can be made of whether the first assumption is met. A box plot is a graphic representation of central tendencies, percentiles, variabilities and the shapes of frequency distributions (Zikmund, 1994: 581). Severe skewness and/or the presence of outliers in variable data will cause a failure in meeting the first assumption. 
In order to examine and explain the second assumption of equal variance-covariance a scatter plot or scatterplot matrix can be used. Figure 5.9 illustrates a scatter plot represented by the squares and circles. In the scatter plot of variable $\mathbf{X}_{1}$ and $\mathbf{X}_{2}$, the circle is the plot symbol for cases in one group and squares for the other group. Grey and blue ellipses of concentration have also been added. If the assumption of equal variances holds, the ellipses for each pair of variables should have almost the same shape and tilt across groups. Furthermore, in order to meet the second assumption both groups must have different mean vectors which means different mean scores as illustrated at the bottom right corner of figure 5.9.

Failure to meet the second assumption can adversely affect the classification process as respondents are over-classified into groups with large covariance matrices. In order to test for the second assumption Box's M test will be used.

If the above assumptions are not met logistic regression represents an alternative method of classification.

Another characteristic that can affect the data is multicollinearity among independent variables. This consideration becomes especially critical when stepwise procedures are employed (Hair et al., 1995). The problem of multicollinearity has been dealt with in this study through the use of PCA.

\subsubsection{Estimation of the discriminant model and assessing overall fit}

To derive the discriminant function a method of estimation must be decided upon. Two computational methods can be utilised in deriving a discriminant function (Hair et al., 1995):

- Direct method - the discriminant function is estimated using all independent variables simultaneously regardless of the discriminating power.

- Stepwise estimation - here the independent variables are entered sequentially based on their ability to discriminate among groups. This method is useful when 
the analyst wants to consider a relatively large number of independent variables in the function.

The number of components derived from PCA will therefore dictate the method of estimation in this study.

After the discriminant function has been computed the level of significance must be assessed. A number of different tests are available which have different statistical criteria. If a stepwise method is used for estimating the discriminant function, the Mahalanobis $\mathrm{D}^{2}$ and Rao's V measures are most appropriate. In general, Mahalanobis is the preferred procedure when one is interested in the maximal use of available information. The Mahalanobis $\mathrm{D}^{2}$ procedure performs a stepwise discriminant analysis. This stepwise procedure is designed to develop the best one-variable model, followed by the best two-variable model, and so forth, until no other variables meet the desired selection rule. The selection rule in this procedure is to maximise Mahalanobis distance $\left(\mathrm{D}^{2}\right)$ between groups (Hair et al., 1995).

Once the significant discriminant function has been identified, the attention shifts to ascertaining the overall fit of the retained function. The statistical tests for assessing the significance of the discriminant function does not tell how well the function predicts. The construction of a classification matrix allows for the determination of predictive ability. The holdout sample addressed earlier is used for developing this matrix. The overall percentage of cases correctly classified is known as the hit ratio.

\subsubsection{Interpretation of the results}

There are three methods for determining the relative importance of each independent variable (Hair et al., 1995):

- The discriminant weight (sometimes referred to as a discriminant coefficient) assigned to each variable in computing the dscriminant function. When the sign is ignored, each weight represents the relative contribution of its associated variable to the function. 
- Discriminant loadings examines the structural correlations, or in other words the correlations between each variable and the discriminant function.

- When the stepwise method is selected, an additional means of interpreting the relative discriminating power of the independent variables is available through the use of partial F values.

\subsubsection{Validation of the results}

The most frequently utilised procedure for validating the discriminant function is to divide the groups randomly into analysis and holdout samples. This involves developing a discriminant function with the analysis sample and then applying it to the holdout sample.

When selecting the individuals for the analysis and holdout groups, a proportionately stratified sampling procedure is usually followed. If the categorical groups for the discriminant analysis are equally represented in the total sample, an equal number of individuals is selected.

However, more sophisticated methods based on estimation with multiple subsets of the sample have been suggested for validating discriminant functions. The two most widely used approaches are the $U$-method and the jackknife method. Both methods are based on the 'leave-one-out' principle, where the discriminant function is fitted to repeatedly drawn samples of the original sample. The most prevalent use of this method has been to estimate $k$ - 1 samples, eliminating one observation at a time from the sample of $k$ cases. Each case is classified onto one group according to the classification functions computed from all the data except the case being classified. Both sets provide the most valid and consistent estimate of the classification accuracy rate (Hair et al., 1995) In the computer package SPSS 7.5 being used for this study the 'leave-one-out' classification is available; however, it is not specified whether it refers to the $U$-method or the jacknife method. Nonetheless, the 'leave-one-out' estimate will be used in this study. 


\subsection{Conclusion}

The research agenda for this study has been divided into three parts. Table 5.8 summarises the first part which involves addressing the exploratory question of comparing the two groups on the objective quality attributes being measured in questions five, six and seven of the questionnaire using the Wilcoxon signed-ranks test for matched-pairs. Four general hypotheses for investigation have also been formulated.

The second part of the research agenda involves the development of a perceptual map of beef quality. The objective of designing this map is to elicit the second order phenomenon required to operationalise the perceived quality construct. In order to derive the map, 34 variables will be placed into PCA (table 5.9). It is hypothesised that the constructs derived will match those proposed by Issanchou (1996).

The final part of the research agenda involves utilising the perceptual map developed to address the main research question of finding the factors associated with perceived quality influencing beef consumption in Ireland. Table 5.10 outlines the five hypotheses which have been developed from the literature review. Two-way discriminant analysis will be used to address the hypotheses. The dependent variable for analysis is the change in the rate of consumption of beef in beef eating households over the previous five years (since 1992). Finally, an exploratory examination will be made to uncover any demographic variables that may discriminate between both groups. 
Table 5.8: First part of research agenda

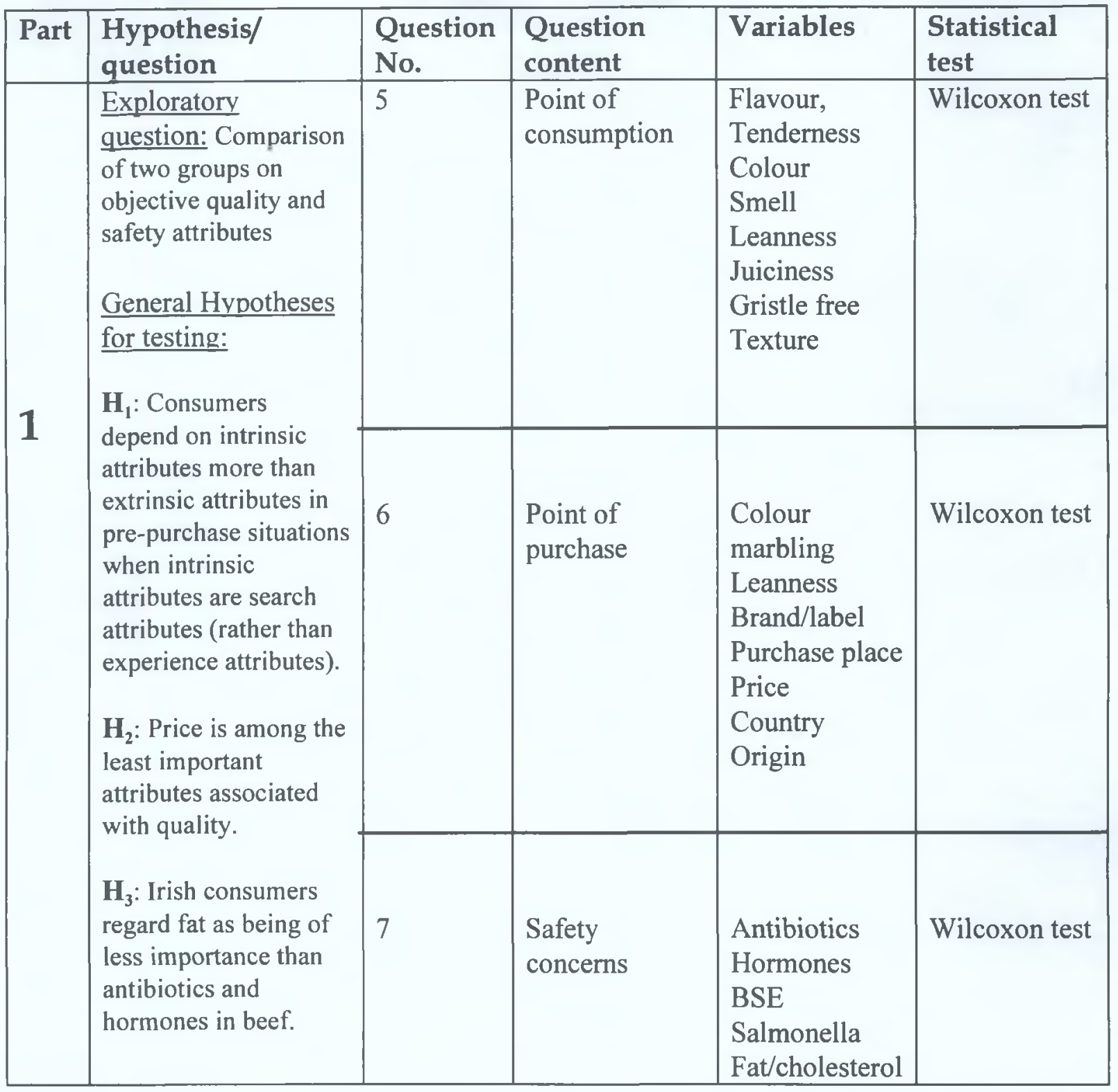

Table 5.9: Second part of research agenda

\begin{tabular}{|l|l|l|l|l|l|}
\hline Part & $\begin{array}{l}\text { Hypothesis/ } \\
\text { question }\end{array}$ & $\begin{array}{l}\text { Question } \\
\text { No. }\end{array}$ & Question content & Variables & $\begin{array}{l}\text { Statistical } \\
\text { analysis }\end{array}$ \\
\hline 2 & $\begin{array}{l}\mathbf{H}_{4} \text { : Irish consumers } \\
\text { perceive beef } \\
\text { quality according to } \\
\text { the seven quality } \\
\text { constructs outlined } \\
\text { by Issanchou } \\
\text { (1996). }\end{array}$ & $5,6,7,9$ & $\begin{array}{l}\text { Point of consumption } \\
\text { Place of purchase } \\
\text { Safety concerns } \\
\text { Prior to purchase }\end{array}$ & $\begin{array}{l}34 \\
\text { variables }\end{array}$ & $\begin{array}{l}\text { PCA (variamx } \\
\text { rotation) }\end{array}$ \\
\hline
\end{tabular}


Table 5.10: Third part of research agenda

\begin{tabular}{|c|c|c|c|c|c|}
\hline Part & Hypothesis/ question & $\begin{array}{l}\text { Question } \\
\text { No. }\end{array}$ & $\begin{array}{l}\text { Question } \\
\text { content }\end{array}$ & $\begin{array}{l}\text { Independent } \\
\text { Variables }\end{array}$ & $\begin{array}{l}\text { Statistical } \\
\text { analysis }\end{array}$ \\
\hline \multirow{6}{*}{3} & $\begin{array}{l}\mathbf{H}_{5}: \text { Those who have reduced } \\
\text { their beef consumption are } \\
\text { more inclined to be } \\
\text { concerned about the } \\
\text { healthiness of the product } \\
\text { than those who have not. }\end{array}$ & - & - & $\begin{array}{l}\text { Components } \\
\text { derived from } \\
\text { PCA }\end{array}$ & $\begin{array}{l}\text { Two-way } \\
\text { discriminant } \\
\text { analysis }\end{array}$ \\
\hline & $\begin{array}{l}\mathbf{H}_{6}: \text { Those who have reduced } \\
\text { their beef consumption are } \\
\text { more concerned about the } \\
\text { safety of the product than } \\
\text { those who have not. }\end{array}$ & - & - & $\begin{array}{l}\text { Components } \\
\text { derived from } \\
\text { PCA }\end{array}$ & $\begin{array}{l}\text { Two-way } \\
\text { discriminant } \\
\text { analysis }\end{array}$ \\
\hline & $\begin{array}{l}\mathbf{H}_{7}: \text { Those who have reduced } \\
\text { their beef consumption are } \\
\text { more susceptible to the issue } \\
\text { of price than those who have } \\
\text { not. }\end{array}$ & - & - & $\begin{array}{l}\text { Components } \\
\text { derived from } \\
\text { PCA }\end{array}$ & $\begin{array}{l}\text { Two-way } \\
\text { discriminant } \\
\text { analysis }\end{array}$ \\
\hline & $\begin{array}{l}\text { H8: }_{\mathbf{8}} \text { Those who have } \\
\text { decreased their consumption } \\
\text { have done so for taste } \\
\text { reasons }\end{array}$ & - & - & $\begin{array}{l}\text { Components } \\
\text { derived from } \\
\text { PCA }\end{array}$ & $\begin{array}{l}\text { Two-way } \\
\text { discriminant } \\
\text { analysis }\end{array}$ \\
\hline & $\begin{array}{l}\text { H9: Those who have } \\
\text { decreased their consumption } \\
\text { are more concerned about } \\
\text { animal welfare than those } \\
\text { who have not }\end{array}$ & - & - & $\begin{array}{l}\text { Components } \\
\text { derived from } \\
\text { PCA }\end{array}$ & $\begin{array}{l}\text { Two-way } \\
\text { discriminant } \\
\text { analysis }\end{array}$ \\
\hline & $\begin{array}{l}\text { Exploratory question: The } \\
\text { influence of demographic } \\
\text { variables }\end{array}$ & $\begin{array}{l}\mathrm{C} 4, \mathrm{C} 7 \\
\text { and C9. }\end{array}$ & $\begin{array}{l}\text { - Education } \\
\text { - Income } \\
\text { - No. of } \\
\text { children }\end{array}$ & & $\begin{array}{l}\text { Two-way } \\
\text { discriminant } \\
\text { analysis }\end{array}$ \\
\hline
\end{tabular}


CHAPTER 6

\section{DATA ANALYSIS}




\subsection{Introduction}

The objective of this chapter is to present the univariate, bivariate and multivariate statistical analysis results. Firstly, the response rate will be calculated. Then univariate results of the sample characteristics will be examined. Next, bivariate analysis in the form of Wilcoxon tests to address the first part of the research agenda will be presented. Then factors analysis and discriminant analysis results will be presented to address the second and third parts of the research agenda respectively. The results will be discussed in Chapter 7.

\subsection{Response rate}

The interviews lasted 20 minutes on average. Telephone interviews were conducted until the requirement of 500 completed interviews was reached. In order to reach this requirement 1,232 calls were carried out. The response rate was calculated in accordance with the approach outlined by Wiseman et al. (1984). The approach deemed most suitable to the study was for a single-stage sample with an eligibility requirement.

Table 6.1 : Telephone interview response results

\begin{tabular}{|l|c|}
\hline Completed interviews. & 500 \\
\hline No answer/reply'. & 129 \\
\hline Engaged numbers. & 22 \\
\hline $\begin{array}{l}\text { Appointments for interviews } \\
\text { never met because they fell } \\
\text { after the end of fieldwork. }\end{array}$ & 101 \\
\hline Refusals & 392 \\
\hline Vegetarian & 8 \\
\hline $\begin{array}{l}\text { Ineligible: No main grocery } \\
\text { shopper, servants, home-help } \\
\text { etc. }\end{array}$ & 80 \\
\hline Total number of calls & 1,232 \\
\hline
\end{tabular}

Eligible respondents were defined as those who report meat to be eaten in the household. When using an eligibility requirement Wiseman et al. (1984) recommend estimating the number of eligibles among non-respondents. This is done by using the eligibility 
percentage $^{2}[(500 / 588)=85 \%]$, which is obtained among respondents successfully screened. This percentage is then applied to non-respondents. Thus of the 644 nonrespondents (no answer, no reply, fallen appointments and refusals), 85\% (547) were estimated to have been eligible and the estimated response rate therefore, becomes $(500 / 1135)$ or $44 \%$. A telephone response rate of this size has been deemed sufficiently large in other studies to make statistical inferences (e.g. Dant et al., 1990).

\subsection{Sample characteristics}

Various socio-demographic changes influence the development of food consumption patterns. While some of these factors influence food consumption directly most have an indirect influence according to household income and preferences. As the sample for the survey is representative of meat eating households rather than the population in general, information on the socio-demographic structure of the Irish population is not compared to the socio-demographic profile of the sample.

\subsubsection{Gender}

The proportions of male and female respondents, who usually carry out most of the shopping for food in the household, was $13 \%$ and $87 \%$ respectively. With regard to the male respondents a quarter of them lived in single-households, thereby making them the obvious main food shoppers, while another quarter lived in a two person household. In Ireland, therefore, the traditional role which females have of being the main food purchaser is predominant.

\subsubsection{Age of respondents}

Over half of the respondents (56\%) were aged between 30 and 49. About one-fifth were aged between 50 and 59 with a similar figure for those 60 or more. The average age of respondents in the sample was 45 .

\footnotetext{
${ }^{1}$ Numbers which were engaged or where there was no reply were called back ten times.

${ }^{2}$ The eligibility percentage is the number of completed interviews divided by the sum of completed interviews and ineligible interviews and vegetarians.
} 
Table 6.2 : Sample age group statistics (\%)

\begin{tabular}{||l|c||}
\hline \hline Age Groups & Sample \\
\hline $\mathbf{1 5}-\mathbf{3 0}$ & $\mathbf{8}$ \\
\hline $\mathbf{3 0 - 3 9}$ & 27 \\
\hline $\mathbf{4 0 - 4 9}$ & 29 \\
\hline $\mathbf{5 0 - 5 9}$ & 18 \\
\hline $\mathbf{6 0}+$ & 17 \\
\hline
\end{tabular}

\subsubsection{Occupation}

As depicted in table 6.2, half of the respondents were housewives. Over one fifth were categorised in 'Other employed' positions (see Appendix 1, question C1). Those retired, self employed and employed professionally each accounted for $8 \%$ of the sample. (See Appendix 1, question number $\mathrm{C} 1$ for full classification of occupations).

Table 6.3 :Occupation of respondents

\begin{tabular}{||l|c||}
\hline \multicolumn{1}{|c|}{ OCCUPATION } & $\%$ \\
\hline Housewife & 52 \\
\hline Student & 1 \\
\hline Retired & 8 \\
\hline Not Working & 1 \\
\hline Self-employed & 8 \\
\hline $\begin{array}{l}\text { Employed professional or } \\
\text { management }\end{array}$ & 8 \\
\hline Other Employed position & 22 \\
\hline
\end{tabular}

Persons in the categories other employed positions, self-employed and employed professional or management respectively made up the main occupations of those who contribute most to household income.

Table 6.4 : Occupation of person who contributes most to household income

\begin{tabular}{||l|c||}
\hline \multicolumn{1}{|c|}{ OCCUPATION } & $\%$ \\
\hline Retired & 12 \\
\hline Not Working & 5 \\
\hline Self-employed & 31 \\
\hline $\begin{array}{l}\text { Employed professional or } \\
\text { management }\end{array}$ & 17 \\
\hline Other Employed position & 35 \\
\hline
\end{tabular}




\subsubsection{Household Size}

The average household size in the sample was 3.9 people. Table 6.5 illustrates the distribution of households by size.

Table 6.5: Household size

\begin{tabular}{|c|c|}
\hline Number of People & \% \\
\hline $\mathbf{1}$ & 9 \\
\hline $\mathbf{2}$ & 19 \\
\hline $\mathbf{3}$ & 17 \\
\hline $\mathbf{4}$ & 20 \\
\hline $\mathbf{5}$ & 17 \\
\hline $\mathbf{6 +}$ & 18 \\
\hline
\end{tabular}

With the exception of one person households, which constituted $9 \%$ of respondents, all other household categories from two to six or more people were equally represented in the sample. The number of one person households in the sample is under represented compared to the number in the national statistics in which oneperson households represents $21 \%$ of all households (C.S.O., 1991). The reason might be that singles households were more difficult to contact by telephone or that they more often refused to be interviewed than others.

\subsubsection{Children}

As illustrated in Table 6.6 nearly half of the households in the survey had no children under 16. Those over 16 were regarded as adults. Close to two-fifths of respondents had two children or more and those with one child consisted of $16 \%$ of the sample.

Table 6.6: Children under 16

\begin{tabular}{||c|c|}
\hline Number of Children & $\%$ \\
\hline $\mathbf{0}$ & 47 \\
\hline $\mathbf{1}$ & 16 \\
\hline $\mathbf{2}$ & 17 \\
\hline $\mathbf{3}$ & 12 \\
\hline $\mathbf{4 +}$ & 7 \\
\hline
\end{tabular}




\subsubsection{Completion of full-time education}

The length of full-time education is used as an indicator of the educational level of the sample. The average age for completing full-time education was 17.3 years of age. This indicates that the majority of respondents completed their Leaving Certificate (final second level examination in Ireland). The table 6.7 below summarises the results into three categories. Approximately a third of respondents fall into each category giving equal representation among all educational levels.

Table 6.7: Age on completing full-time education

\begin{tabular}{||l|c|c|}
\hline \multicolumn{1}{|c|}{ Educational Level } & Years & \% \\
\hline Low (Intermediate Certificate) & $<17$ & 35 \\
\hline Middle (Leaving Certificate) & $17-18$ & 37 \\
\hline High (Third level) & $>18$ & 28 \\
\hline
\end{tabular}

\subsubsection{Income}

Income deciles were used in the questionnaire to classify the income levels of the sample. Deciles are ten (income) classes which are characterised by the fact that $10 \%$ of the population belong to each class. If a survey is representative and the income deciles used are correct, $10 \%$ of the sample ought to belong to each of the ten deciles. However, in the survey those at the upper and lower limits of the classes were underrepresented. Of the sample $17 \%$ refused to answer this question. This could possibly explain the low numbers of high and in particular low income groups. In addition, as already indicated, the sample is representative of household food purchasers and meat consumers rather than the full population.

Table 6.8 below reduces the number of income groups to five by adding every two decile groups. 
Table 6.8: Household Income

\begin{tabular}{|c|c|}
\hline Income & $\%$ \\
\hline Less than $£ 6,500$ & 11 \\
\hline$£ 6,501-£ 11,000$ & 15 \\
\hline$£ 11,001-£ 18,500$ & 19 \\
\hline$£ 18,501-£ 28,500$ & 21 \\
\hline$£ 28,501-£ 55,000+$ & 16 \\
\hline Refused & 17 \\
\hline
\end{tabular}

\subsection{Meat consumption behaviour of sample}

The following section outlines descriptive results of meat consumption behaviour reported by respondents in the questionnaire.

\subsubsection{Frequency of Consumption}

Consumers were asked how frequently each of the three fresh meats were eaten in their household. As illustrated in Table 6.9 below $29 \%$ of households didn't eat pork, 5\% didn't eat chicken and 19\% didn't eat beef.

Table 6.9 : Frequency of consumption of beef, pork and chicken in household (\%) $(n=496)$

\begin{tabular}{||l|c|c|c|c|c|c||}
\hline \hline & Never & $\begin{array}{c}\text { Less often } \\
\text { than once a } \\
\text { month }\end{array}$ & $\begin{array}{c}\text { Less than } \\
\text { once a } \\
\text { week but } \\
\text { more than } \\
\text { once a } \\
\text { month }\end{array}$ & $\begin{array}{c}\text { Once a } \\
\text { week }\end{array}$ & $\begin{array}{c}\text { Twice a } \\
\text { week }\end{array}$ & $\begin{array}{c}\text { Three or } \\
\text { more times } \\
\text { a week }\end{array}$ \\
\hline Beef & $19 \%$ & $3 \%$ & $9 \%$ & $23 \%$ & $20 \%$ & $25 \%$ \\
\hline Pork & $29 \%$ & $10 \%$ & $11 \%$ & $32 \%$ & $11 \%$ & $5 \%$ \\
\hline Chicken & $5 \%$ & $4 \%$ & $4 \%$ & $31 \%$ & $28 \%$ & $28 \%$ \\
\hline
\end{tabular}

Almost one third of the sample eat pork once a week whereas only $16 \%$ eat it twice or more times per week.

Almost one-third eat chicken once a week, however, over half $(56 \%)$ eat it twice or more times per week. 
With beef nearly one-quarter eat it once a week whereas $45 \%$ eat it twice or more times.

These figures indicate that chicken has both a wide and high level of consumption in the household. Pork on the other hand has a narrow and moderate rate of consumption. In this regard it should be noted that the bacon component of Irish pigmeat consumption is much higher than the pork component. Less of those interviewed were eating beef but those consuming it had a high rate of consumption.

\subsubsection{Changes since 1992}

Consumers were asked if the amount of each meat eaten in their households had changed in the last five years i.e. since 1992. Those who had changed were then asked if they were eating more or less of that meat. As can be seen from table 6.10 below just over half of all respondents have changed their consumption of beef in the past five years - most of these respondents $(90 \%)$ have reduced their consumption.

In the case of pork just over a third have changed, two-thirds of whom have reduced their consumption in the last five years.

Half of the respondents have changed their consumption of chicken in the past five years - a similar proportion to beef. However, unlike beef, the direction of change is positive. With chicken about three-quarters of those changing have increased their consumption in the last five years.

Table 6.10: Change and rate of change in consumption of beef, pork and chicken over the last five years (\%).

\begin{tabular}{||l|c|c|c|c||}
\hline \multirow{2}{*}{} & \multicolumn{2}{|c|}{ CHANGED } & \multicolumn{2}{c|}{$\begin{array}{c}\text { EAT MORE OR LESS } \\
\text { (Respondents who've changed } \\
\text { only) }\end{array}$} \\
\hline & Changed & Not Changed & More & Less \\
\hline Beef & $55 \%$ & $45 \%$ & $10 \%$ & $90 \%$ \\
\hline Pork & $34 \%$ & $66 \%$ & $33 \%$ & $67 \%$ \\
\hline Chicken & $51 \%$ & $49 \%$ & $77 \%$ & $21 \%$ \\
\hline
\end{tabular}




\subsubsection{Dependent variable}

The dependent variable for use in the discriminant analysis has been developed through the amalgamation of the results of questions 2(a) and 2(b) for beef, namely those examining the change and rate of change reported by respondents. As illustrated in table 6.11 there was close to an equal proportion of respondents in both of the proposed groups for study, namely those who had reduced their beef consumption and those who maintained it (i.e. those who did not change their consumption rate and those who increased it).

Table 6.11: Households where beef consumption has decreased and not decreased $(n=402)$

\begin{tabular}{||l|c|c|}
\hline \hline & LESS & NOT CHANGED/MORE \\
\hline Beef & $49.2 \%$ & $50.8 \%$ \\
\hline
\end{tabular}

\subsection{Wilcoxon test results}

The following section compares the results of those who decreased their consumption of beef and those who did not on their responses for three questions:

Question 5: Importance of quality characteristics at the point of consumption.

Question 6: Helpfulness of quality indicators at the point of purchase.

Question 7: Concern about safety issues.

The rank orderings which both groups assigned to these questions will be examined using the Wilcoxon signed-ranks test for matched-pairs:

\subsubsection{Wilcoxon results - point of consumption}

After eliminating cases which had missing values on one or more characteristics the total number of responses eligible for those who had not decreased their consumption was 220 and 169 for those who had. 
Altogether there was a high degree of concordance among both groups in their expectations about eating quality characteristics in terms of their importance. As illustrated in figures 6.1 and 6.2 tenderness, flavour and colour were rated as the three most important attributes in each group. The only difference between both groups was that texture was rated as more important than juiciness, beef free of gristle, leanness and smell for those who did not reduce their consumption.

Table 6.12: Importance of attributes in assessing the eating quality of beef for those who had not reduced their consumption $(n=220)$

\begin{tabular}{|l|c|c|c|c|c|c|c|c|}
\hline & Tender & Flavour & Colour & Texture & Juiciness & Gristle & Leanness & Smell \\
\hline Tender & - & & & $* * *$ & $* * *$ & $* * *$ & $* * *$ & $* * *$ \\
\hline Flavour & & - & & $*$ & $* * *$ & $* * *$ & $* * *$ & $* * *$ \\
\hline Colour & & & - & N.8. & $*$ & N.S. & $*$ & $* * *$ \\
\hline Texture & & & & - & N.S. & N.S. & N.S. & N.S. \\
\hline Juiciness & & & & & - & N.S. & N.S. & N.S. \\
\hline Gristle & & & & & & - & N.S. & N.S. \\
\hline Leanness & & & & & & & - & N.S. \\
\hline Smell & & & & & & & - \\
\hline
\end{tabular}

Figure 6.1: Results of Wilcoxon test for the eating quality of beef of those who did not reduce consumption.

$\begin{array}{lll}\text { Flavour } & & \text { Juiciness } \\ \text { Tenderness } & >\text { Texture } \quad>\quad \text { Gristle } \\ \text { Colour } & & \text { Leanness } \\ & \text { Smell }\end{array}$


Table 6.13: Importance of attributes in assessing the eating quality of beef for those who had reduced their consumption $(n=169)$

\begin{tabular}{|c|c|c|c|c|c|c|c|c|}
\hline & Tender & Flavour & Leanness & Colour & Juiciness & Gristle & Texture & Smell \\
\hline Tender & - & N.S & NS & & ** & $* *$ & $* * *$ & $* *$ \\
\hline Flavour & & - & NS & NS & * & ${ }^{*}$ & **** & ** \\
\hline Leanness & & & - & XS & $*$ & $*$ & ** & $* *$ \\
\hline Colour & & & & - & N.S. & N.S. & N.S. & N.S. \\
\hline Juiciness & & & & & - & N.S. & N.S. & N.S. \\
\hline Gristle & & & & & & - & N.S. & N.S. \\
\hline Texture & & & & & & & - & N.S. \\
\hline Smell & & & & & & & & - \\
\hline
\end{tabular}

Figure 6.2: Results of Wilcoxon test for the eating quality of beef of those who had reduced their consumption.

\begin{tabular}{|c|c|c|}
\hline $\begin{array}{l}\text { Flavour } \\
\text { Tenderness } \\
\text { Colour }\end{array}$ & $>$ & $\begin{array}{l}\text { Juiciness } \\
\text { Gristle } \\
\text { Texture } \\
\text { Smell } \\
\text { Leanness }\end{array}$ \\
\hline
\end{tabular}

\subsubsection{Wilcoxon results - point of purchase}

In question six, after eliminating cases which had missing values on one or more characteristics, the total number of responses eligible for those who had not decreased their consumption was 178 and 144 for those who had for question 6.

Further commonality of expectations between the two groups was found in the rating of the helpfulness of quality indicators at the point of purchase. As illustrated in figures 6.3 and 6.4 colour, the place of purchase, the country of origin of the beef and leanness were rated as being the most helpful indicators for assessing eating quality at the point of purchase by both groups. The only difference between both groups was that price was regarded as the least most helpful indicator for those who reduced their consumption. On the other hand those who had not reduced their consumption rated price equal to marbling and a brand/quality assurance label in its ability to help assess eating quality. 
Table 6.14: Helpfulness of attributes in assessing the eating quality of beef of those who had not reduced their consumption $(n=178)$.

\begin{tabular}{|c|c|c|c|c|c|c|c|}
\hline & Colour & Place & Country & Leanness & Marbling & Labelling & Price \\
\hline Colour & - & N.S & 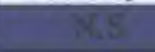 & 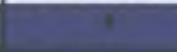 & $* * *$ & $* * *$ & $* * *$ \\
\hline Place & & - & $\sqrt{53}$ & W.: & $* * *$ & **** & **** \\
\hline Country & & & - & $\sqrt{2}$ & $* \neq *$ & **** & **** \\
\hline Leanness & & & & - & $* * *$ & **** & $* * *$ \\
\hline Marbling & & & & & - & N.S. & 24 \\
\hline Labelling & & & & & & - & N.S. \\
\hline Price & & & & & & & - \\
\hline
\end{tabular}

Figure 6.3: Results of Wilcoxon test for the eating quality of beef of those who had not reduced their consumption.

\begin{tabular}{|c|c|c|}
\hline Colour & & Marbling \\
\hline Place & $>$ & Labelling \\
\hline Country & & Price \\
\hline Leanness & & \\
\hline
\end{tabular}

Table 6.15: Helpfulness of attributes in assessing the eating quality of beef of those who have reduced their consumption $(n=144)$.

\begin{tabular}{|c|c|c|c|c|c|c|c|}
\hline & Colour & Place & Leanness & Country & Marbling & Labelling & Price \\
\hline Colour & - & & & & $* * *$ & $* * *$ & *** \\
\hline Place & & - & $\overline{17}$ & I. & *** & $* * *$ & $* * *$ \\
\hline Leanness & & & - & 1. & $* * *$ & $* * *$ & $* * *$ \\
\hline Country & & & & - & $* * *$ & **** & *** \\
\hline Marbling & & & & & - & B. & *** \\
\hline Labelling & & & & & & - & $* * *$ \\
\hline Price & & & & & & & - \\
\hline
\end{tabular}

Figure 6.4: Results of Wilcoxon test for the eating quality of beef

\begin{tabular}{|lllll|}
\hline Colour & $>$ & Marbling & $>$ & Price \\
Place & & Labelling & & \\
Leanness & & & & \\
Country & & & & \\
\hline
\end{tabular}




\subsubsection{Wilcoxon results - safety concerns}

In question seven, after eliminating cases which had missing values on one or more concerning issues, the total number of responses eligible for those who had not decreased their consumption was 218 and 168 for those who had.

The level and rate of concern across all safety issues between the two groups was similar with the exception of one concern, BSE. In both groups hormones, antibiotics and salmonella were rated as being of equal concern. In the case of those who've reduced their consumption BSE was ranked among these concerns. However, in the case of those who had not reduced their consumption BSE was regarded as being of less concern. With regard to fat/cholesterol both groups ranked this issue as being of least concern.

Table 6.16: Concerns about beef of those who have reduced their consumption $(n=168)$.

\begin{tabular}{|l|c|l|l|c|c|}
\hline & BSE & Hormones & Antibiotics & Salmonella & Fat \\
\hline BSE & - & & & & $* * *$ \\
\hline Hormones & & - & & & $* * *$ \\
\hline Antibiotics & & & - & & $* * *$ \\
\hline Salmonella & & & & - & $*$ \\
\hline Fat & \multicolumn{2}{|l|}{} & & & - \\
\hline$p$-values: NS = Not Significant, ${ }^{*}<0.05,{ }^{* *}<0.01,{ }^{* * *}<0.001$ & & \\
\hline
\end{tabular}

Figure 6.5: Results of Wilcoxon test for the safety of beef of those who reduced their consumption.

BSE

Hormones

$>\quad$ Fat

Antibiotics

Salmonella 
Table 6.17: Concerns about beef of those who have not reduced their consumption $(\mathbf{n}=\mathbf{2 1 8})$.

\begin{tabular}{|l|c|l|c|c|c|}
\hline & Salmonella & Hormones & Antibiotics & BSE & Fat \\
\hline Salmonella & - & & & ${ }^{* * *}$ & ${ }^{* * *}$ \\
\hline Hormones & & - & & ${ }^{* * *}$ & ${ }^{* * *}$ \\
\hline Antibiotics & & & - & ${ }^{* *}$ & ${ }^{* * *}$ \\
\hline BSE & & & & - & $* *$ \\
\hline Fat & & & & & - \\
\hline$p$-values: NS = Not Significant, ${ }^{*}<0.05,{ }^{* *}<0.01,{ }^{* * *}<0.001$ & & \\
\hline
\end{tabular}

Figure 6.6: Results of Wilcoxon test for the safety of beef for those who did not reduce their consumption.

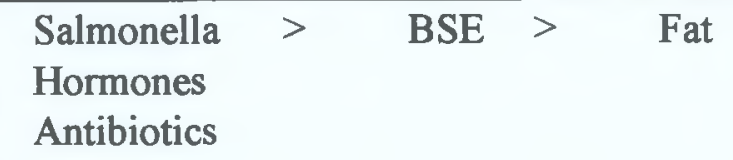

\subsection{PCA results}

The sample analysed fell short of the ideal size of ten respondents for every variable. Instead the sample was approximately nine-to-one. Though not ideal the sample was nonetheless, above the acceptable five-to-one level. In all 295 respondents were analysed on 34 variables. Although there were 402 respondents where beef was eaten in the household 107 of them were ineligible for analysis, due to a missing value on at least one of the 34 variables.

The results met the assumptions for factor analysis with the Barlett's test for sphericity proving significant to 0.001 while the MSA was 0.71 , which according to Hair et al. (1995) is middling though adequate.

Eleven factors accounting for $61 \%$ of the variance explained were derived. According to Hair et al. (1995) a variance of $60 \%$ is satisfactory. All eleven components had eigenvalues greater than one. The analysis produced a clean factor structure with all 34 variables loading strongly (at 0.40 or above) on one component only. Tables $6.19 \mathrm{a}$ and 
$6.19 \mathrm{~b}$ depict these results with each factor and the respective loading variables being displayed.

Five items were identified under Factor 1 with loadings ranging from 0.80 to 0.49 . An examination of these variables led to the interpretation that the items related to 'safety'. Antibiotics, hormones, salmonella, BSE and fat/cholesterol all loaded on Factor 1. In other words all of the safety issues examined in Q.7 loaded on Factor 1. There is also a health related variable, fat/cholesterol loading on this factor, indicating the interaction between health and safety; the loading is however weaker $(0.50)$ than the safety variables which are all over 0.70 . The Cronbach alpha test for reliability is a satisfactory 0.82 .

Factor 2 named 'status' identified factor loadings ranging from 0.80 to 0.50 . There were five items in all; three related to nutrition, one to social acceptability and one to food safety. The item related to food safety has, however, a weak loading $(0.50)$ relative to the other variables which are all at or over 0.70 . The Cronbach alpha is a satisfactory 0.77 .

Factor 3 addressed the 'absence of non-meat components' in beef. The two variables examining leanness in Q.5 and Q.6 loaded here as did the variable addressing beef free of gristle. Factor loadings ranged from 0.84 to 0.59 . The Cronbach alpha is a reasonable 0.69 .

Factor 4 identified four items which appeared to be related to 'freshness'. Both colour variables from Q.5 and Q.6 loaded here as did smell. Marbling also loaded on this factor though the loading was weak (0.42) compared to the other variables which had loading at approximately 0.70 and over. The Cronbach alpha is 0.62 . 
Table 6.19a : Principle Components Analysis (PCA) of perceived quality construct for meat (Varimax rotation; entries in table are rotated factor loadings $)^{1}(\mathrm{n}=\mathbf{2 9 5})$

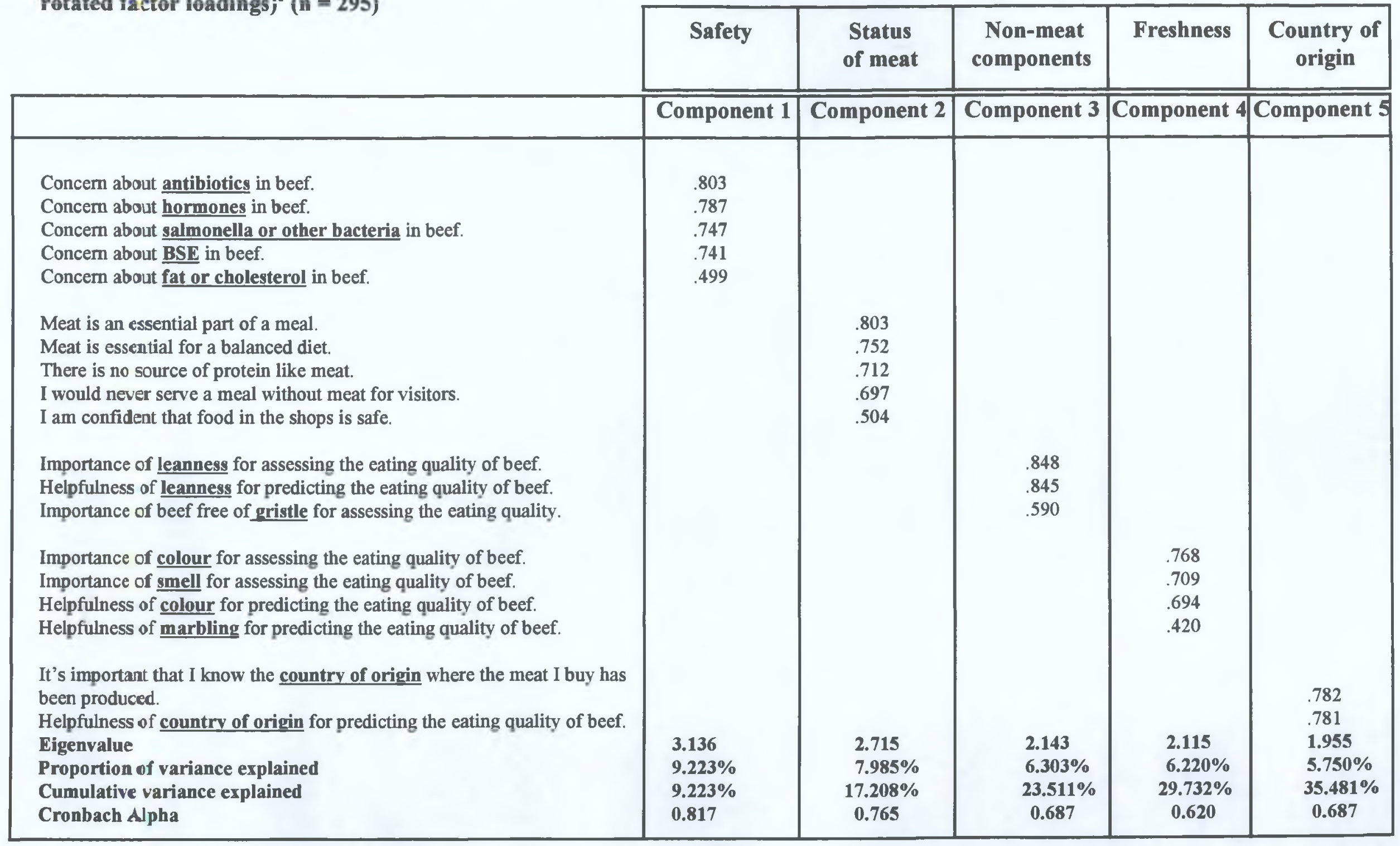

${ }^{1}$ Only loadings having absolute value greater than 0.40 are shown 
Table 6.19b Principle Components Analysis (PCA) of perceived quality construct for meat (Varimax rotation; entries in table are rotated factor loadings) ${ }^{1}(\mathrm{n}=\mathbf{2 9 5})$

\begin{tabular}{|c|c|c|c|c|c|c|}
\hline & $\begin{array}{c}\text { Place of } \\
\text { purchase }\end{array}$ & Sensory & Price & $\begin{array}{l}\text { Conven } \\
\text {-ience }\end{array}$ & $\begin{array}{l}\text { Animal } \\
\text { welfare }\end{array}$ & $\underline{\text { Unclear }}$ \\
\hline & Component 6 & Component 7 & Component 8 & Component 9 & Component 10 & Component 11 \\
\hline $\begin{array}{l}\text { Importance of iuiciness for assessing the eating quality of beef. } \\
\text { Helpfulness of labelling for predicting the eating quality of beef. } \\
\text { Helpfulness of place of purchase of purchase for predicting the eating } \\
\text { quality of beef. } \\
\text { I prefer to buy food which is produced locally. } \\
\text { I prefer to buy meat from animals which I know have been treated well. } \\
\text { Importance of flavour for assessing the eating quality of beef. } \\
\text { Importance of tenderness for assessing the eating quality of beef. } \\
\text { Price is the main thing I consider when buying meat. } \\
\text { Helpfulness of place of price for predicting the eating quality of beef. } \\
\text { I like experimenting with new recipes. } \\
\text { I do not enjoy cooking very much but it is a task which must be done. } \\
\text { We should have more respect for animals. } \\
\text { You have to be prepared to pay a higher price to get good quality meat. } \\
\text { 669 } \\
\text { I always check nutritional labelling on foods before buying them. } \\
\text { Importance of texture for assessing the eating quality of beef. } \\
\text { Eigenvalue } \\
\text { Proportion of variance explained } \\
\text { Cumulative variance explained } \\
\text { Cronbach Alpha }\end{array}$ & $\begin{array}{l}.660 \\
.587 \\
.541 \\
.531 \\
.426\end{array}$ & $\begin{array}{c}1.561 \\
4.592 \% \\
45.219 \% \\
0.564\end{array}$ & $\begin{array}{c}1.554 \\
4.571 \% \\
49.790 \% \\
0.443\end{array}$ & $\begin{array}{l}1.469 \\
4.322 \% \\
54.112 \% \\
-0.696\end{array}$ & $\begin{array}{c}1.246 \\
3.664 \% \\
57.775 \% \\
0.140\end{array}$ & $\begin{array}{c}.443 \\
-.504 \\
\\
1.183 \\
3.478 \% \\
61.254 \%\end{array}$ \\
\hline
\end{tabular}


Factor 5 was unquestionably identified as 'country of origin' with both variables from Q.6 and Q.9 addressing country of origin loading here. Loading scores were identical at 0.78. The Cronbach alpha is a reasonable 0.69 .

Factor 6 had a complex and rather unclear number of variables loading on it and has been called 'place of purchase'. Variables related to place of purchase, juiciness, labelling and food which is produced locally, all of which had factor loading over 0.50 . Another variable relating to the purchase of meat from animals which have been treated well also loaded here though the loading was relatively weaker at 0.42 . The Cronbach alpha is a disappointing 0.53 .

Factor 7 identified two items which were related to the 'sensory' attributes most desired from meat; tenderness and flavour. Both had factor loadings greater than 0.70 . The Cronbach alpha is a disappointing 0.56 but because the items were conceptually related (construct validity) they were regarded as satisfactory.

Factor 8 addressed 'price'. Two price variables loaded here with factor loadings of 0.71 and .68. The Cronbach alpha was a very low 0.44. Nevertheless, both items are conceptually related.

Factor 9 identified two items which were related to 'cooking' from Q.9. The statement 'I like experimenting with new recipes' loaded at 0.80 , however, the statement 'I do not enjoy cooking very much but it is a task which must be done' loaded at -0.59 indicating that the meaning of the component is opposite to that of the variable. The Cronbach alpha was a reasonable -0.69 .

Factor 10 was very clear as only one variable related to 'animal welfare' loaded here at 0.77. As there is only one variable in this factor there can be no Cronbach alpha score. 
Finally, Factor 11 was very unclear. Items loading here were related to price, nutritional labelling on food and texture and the Cronbach alpha was only 0.14 indicating little if any reliability.

There was no need for examination of across group variation as proposed by Dillion et al. (1985) since each of the 34 variables loaded on one component.

The nomological and content validity of the resulting factor structure will be discussed in the next chapter.

\subsection{Two-wav discriminant analvsis results}

Only three cases included in PCA were excluded from the discriminant analysis. Altogether the total number of valid cases was 293; 134 represented those who had decreased their consumption and 159 represented those who hadn't. The resulting sample size met the sample size criterion of 20 respondents for every dependent variable.

The study was successful in meeting the assumptions for discriminant analysis. The significance probability of Box's M statistic (Table 6.20) was 0.000 indicating equal group covariance matrices.

Table 6.19: Box's M statistic

\begin{tabular}{|l|l|}
\hline Box's M & 21.048 \\
\hline F Approx. & 6.963 \\
\hline Significance & .000 \\
\hline
\end{tabular}

The test of equal variances across groups was also be examined through studying box plots of the eleven independent variables. The goal in studying box plots is to compare the within-group distribution of the eleven variables. For instance, the distribution of safety in the group who didn't report a reduction in consumption is compared with the group who did. Visual inspection of figure 6.7 reveals that the symmetry of each group is equal. 
Figure 6.7: Boxplots of within group distributions of each independent variable .

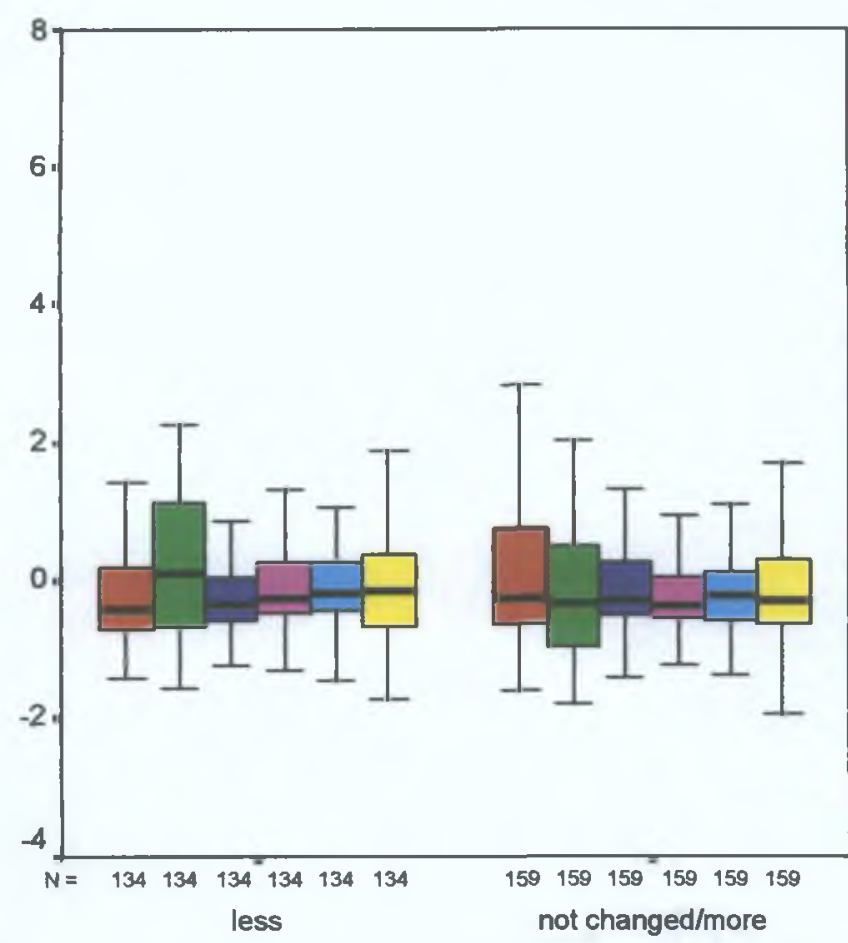

므ERR factor score

X1 = Safety

REGR factor score

$X_{2}=$ Status

REGR factor score

$\mathrm{X} 3=$ Non-meat

REGR factor score

X4 = Freshness

REGR factor score

$\mathrm{X} 5$ = Country origin

REGR factor score

X6 = Purchase Place

REGR factor score

$X 7=$ Sensory

REGR factor score

$X 8=$ Price

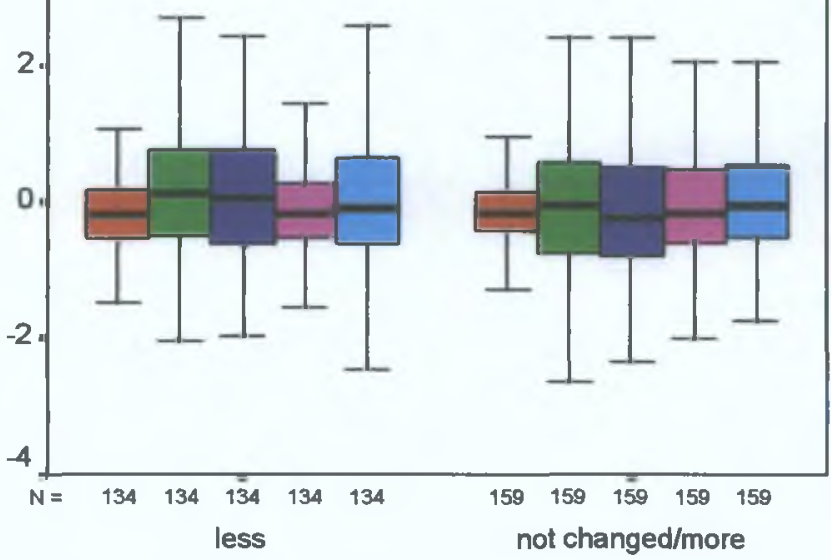

REGR factor score

X9 $=$ Convenience

REGR factor score 1

$\mathrm{X} 10=$ Animal welfare

REGR factor score 1

X11 = Unclear! 
As stated the stepwise method using the Mahalanobis $\mathrm{D}^{2}$ measure for variable selection was used to estimate the discriminant function. The stepwise procedure begins with all of the variables excluded from the model and selects the variable that maximises the Mahalanobis distance between the groups. In this study a minimum $F$ value of 3.84 (the default value in SPSS 7.5) was required for entry.

After two steps this limitation eliminated all variables but two; safety and status of meat, from consideration for possible entry into the discriminat function. An illustration of the resulting discriminant function is geometrically represented in figure 6.8 which features a scatter plot of Safety $\left(\mathrm{X}^{1}\right)$ against Status of meat $\left(\mathrm{X}^{2}\right)$. Cases where a reduction in consumption was reported are signified by circles; cases which didn't reduce consumption are signified by squares. The discriminant function which best discriminates between both groups is illustrated by the axis $Z$. The black line perpendicular to the discriminant function indicates the best line for group separation.

The multivariate aspects of the model are reported in table 6.21. Note that the discriminant function is highly significant $(0.000)$ and displays a canonical correlation of 0.278 . The canonical correlation measures the association between the discriminant scores and the two groups. One interprets this correlation by squaring it; thus $(0.278)^{2}=$ 0.077 , concluding that only $7.7 \%$ of the variance in the dependent variable, beef consumption, can be accounted for (explained) by this model, which includes just two independent variables.

Table 6.20: Summary of canonical discriminant function

\begin{tabular}{|c|c|c|c|c|c|c|}
\hline Function 1 & Eigenvalue & $\%$ of variance & $\begin{array}{c}\text { Canonical } \\
\text { correlation }\end{array}$ & $\begin{array}{c}\text { Wilks' } \\
\text { Lambda }\end{array}$ & Chi-square & Significance \\
\hline 1 & 0.084 & 100.0 & 0.278 & 0.923 & 23.278 & .000 \\
\hline
\end{tabular}


Figure 6.8: An illustration of the resulting two-group discriminant analysis for the study

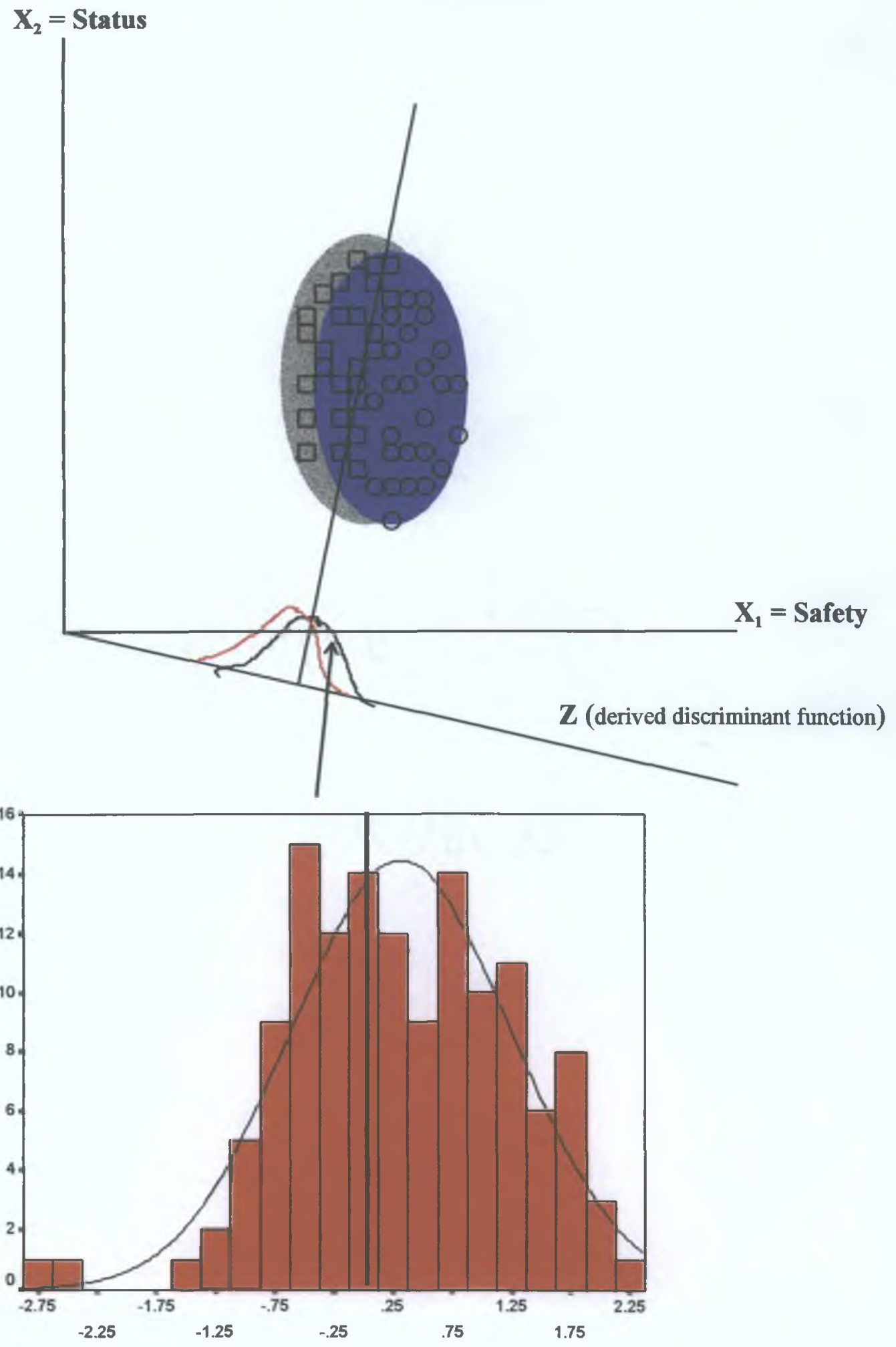


Wilks' Lambda in table 6.20 is the proportion of the total variance in the discriminant function not explained by differences among the two groups. As denoted in table 6.20 just over $90 \%$ of the variance is not explained by group differences. Notice that Wilks' Lambda plus the canonical correlation squared is equal to one.

In all, the information in table 6.20 indicates that while the discriminant function is statistically significant it only explains $7.7 \%$ of the variance between those who've reduced their consumption and those who haven't. More specifically, the combined effect of factors 1 and 2, safety and status of meat, which are the only quality variables which discriminate between both groups, provide only limited insight into the reasons why Irish consumers have been reducing their beef consumption in recent years.

The group centroids, which represent the mean of the individual discriminant function scores for each group, can be used to interpret the discriminant function results from a global or overall perspective. Figure 6.9 reveals that the group centroid for those who didn't reduce their household consumption was -0.264 (denoted by the blue line), while the group centroid for those who did report a reduction of household consumption was 0.314 , as illustrated in figure 6.10 by the blue line. (The distribution in figure 6.10 has been incorporated into figure 6.8 to illustrate how those who've reduced their consumption would look on the discriminant function.) The overall mean of the two groups is zero and is plotted on both figures 6.9 and 6.10 by a thick black line. Visual inspection indicates how close both of the group centroids are to the overall mean (zero) giving further indication that the discriminant function derived fails to provide substantial explanation of the factors discriminating between both groups. Figure 6.8 illustrates how both normal curves would look on the discriminant function $(Z)$ derived together with a black line perpendicular to $\mathrm{Z}$ representing the overall mean; zero. 
Figure 6.9: Normal curve superimposed over the discriminant scores for those who have not decreased their consumption

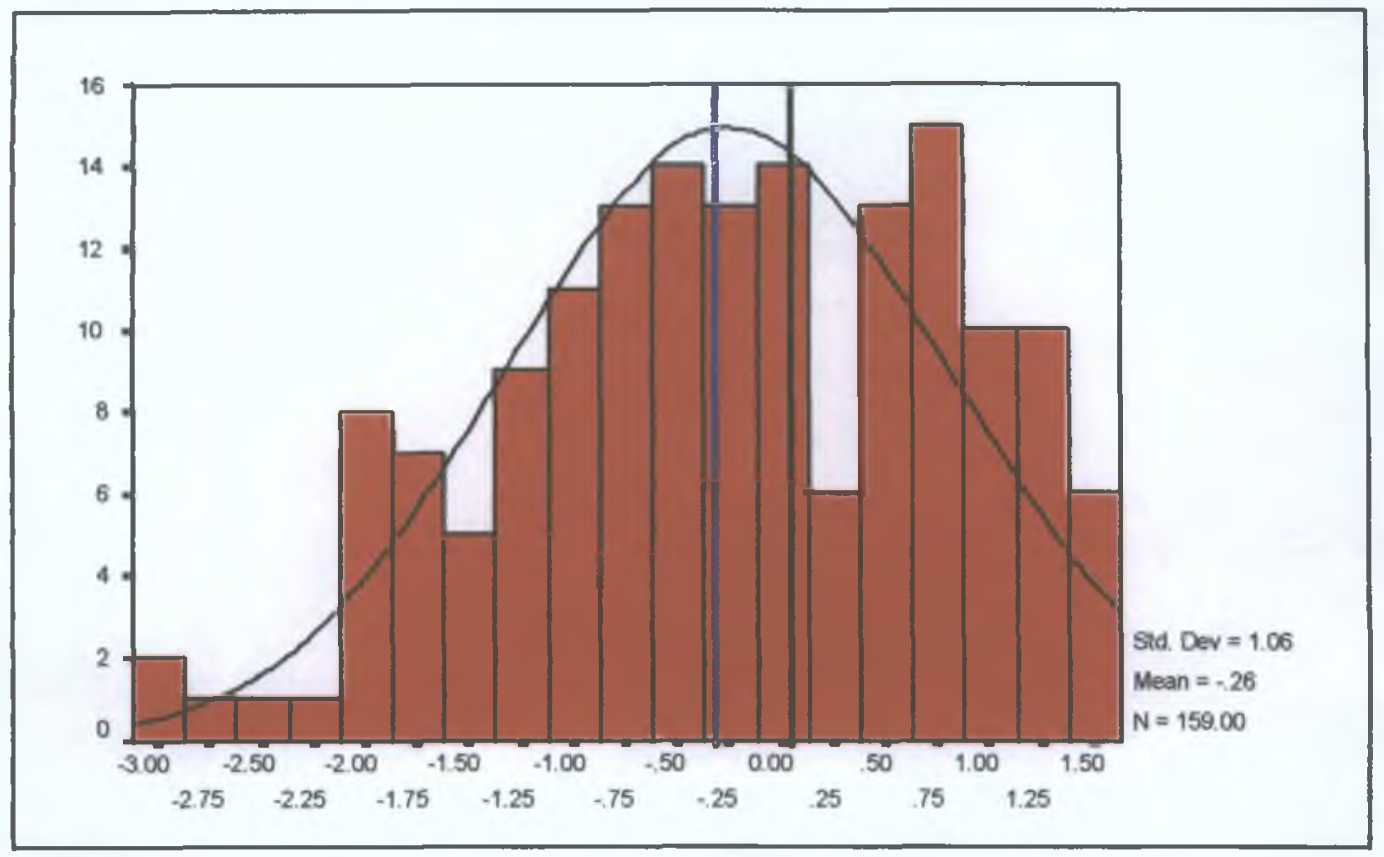

Figure 6.10: Normal curve superimposed over the discriminant scores for those who decreased their consumption

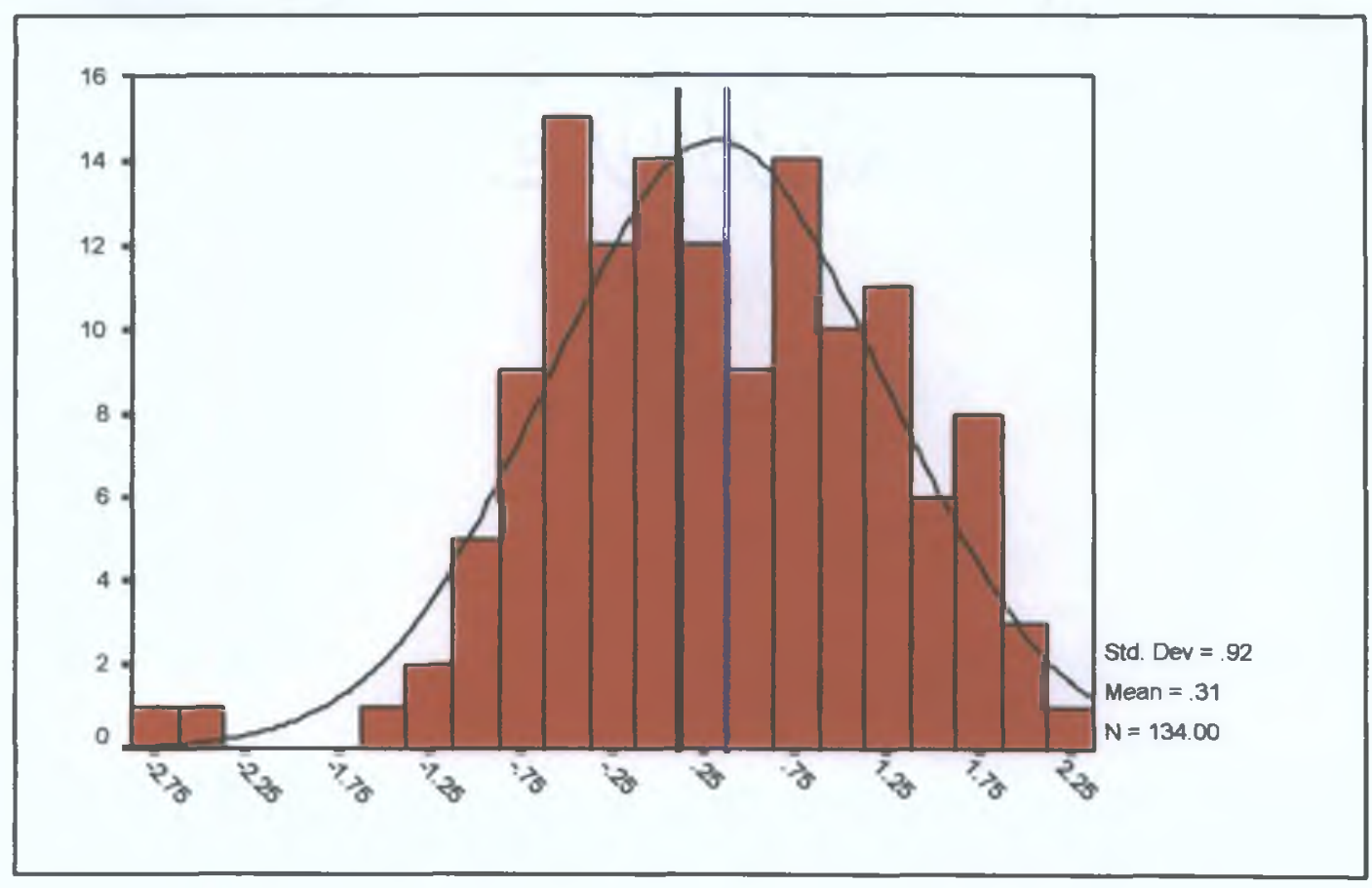


The last step in the estimation stage is to assess the predictive accuracy of the discriminant function using the 'leave-one-out' principle. $58 \%$ of the original grouped cases were correctly classified. The cross-validation of this finding using the 'leave-oneout' principle also resulted in 58\%. Hair et al. (1995) provide a rough estimate of the acceptable level of predictive accuracy; the classification accuracy should be at least one-fourth greater than that achieved by chance. In this study both groups were of roughly equal size making the chance probability $50 \%$. Thus the classification accuracy should be $62.5 \%$. At $58 \%$ the classification derived is just over $4 \%$ short of the required level of accuracy needed to provide meaningful information for identifying group membership.

\subsubsection{Two-wav discriminant analysis of demographic variables}

Three demographic variables were examined for discrimination:

- When respondents had finished full-time education.

- Income.

- No. of children in the household.

Only 373 cases were eligible for analysis. One hundred and ninety four cases encompassed those who had reduced their consumption, while 179 cases represented those who had maintained it. The resulting sample size more than met the sample criterion.

This particular analysis was unsuccessful in meeting the assumption for equal group covariance matrices as the Box's M statistic was not significant (table 6.22).

Table 6.21 Box's M test - demographics

\begin{tabular}{|l|l|}
\hline Box's M & 0.177 \\
\hline F Approx & 0.176 \\
\hline Significance & 0.675 \\
\hline
\end{tabular}


The stepwise method for variable selection yielded only one discriminating variable, namely income. The canonical correlation, however, was only 0.1 which when squared indicated that income only explained $1 \%$ of the variance between both groups. Nonetheless, because the analysis did not meet the covariance assumption this finding is regarded as unreliable.

\subsection{Conclusion}

In this chapter the quantitative findings of the three part research agenda were presented. It is the objective of the next chapter to examine these findings in the light of the hypotheses to be tested. 


\section{Chapter 7}

\section{Discussion and Conclusions}




\subsection{Introduction}

The objective of the following chapter is to discuss the research results and integrate them with existing theory and research.

\subsection{Beef consumption levels}

A comparison of consumption figures found in this study with McCarthy et al. 's (1998) findings reveals similar results. Sixteen percent of the respondents in McCarthy et al. 's (1998) study reported not eating beef compared to $19 \%$ in this study. A identical figure of $68 \%$ was found in both studies for those eating beef once a week or more. However, the breakdown of this result revealed different findings as illustrated in table 7.1 .

Table 7.1: Frequency of beef consumption

\begin{tabular}{||l|c|c||}
\hline & Mc Carthy et al. (1998) & Study findings \\
\hline Once a week & 34 & 23 \\
\hline Twice a week & 22 & 20 \\
\hline > twice a week & 12 & 25 \\
\hline
\end{tabular}

The main differences in results lie in the 'once a week' and ' $>$ twice a week' categories. Results for the former category in McCarthy et al. 's (1998) study are approximately $50 \%$ greater than the present study's results. On the other hand results for the latter category are approximately $50 \%$ lower than the present study's findings. Clearly the reported frequency of consumption in this study is greater than that reported in McCarthy et al. 's (1998) study. Bearing in mind that McCarthy et al. 's (1998) study was conducted four months after the present study was conducted one would not expect study results to be very different considering that no other scares were reported between studies.

Further examination of methodologies in table 7.2 reveals that both studies differ on various fronts including interviewing technique, sample size and sample design. However, examination of the type of respondents used provides clarification for the different consumption rates. In Mc Carthy et al. 's (1998) study respondents were asked to report their own consumption frequency levels whereas in this study 
respondents (who were the main food purchasers) were asked to report the frequency of consumption of the household. Naturally, therefore, the frequency of consumption reported for the household would be higher than that of a particular individual.

Table 7.2: Methodological comparison between both studies

\begin{tabular}{||l|l|l||}
\hline & McCarthy et al. (1998) & Current study \\
\hline Interviewing technique & Personal (Door-to-door) & Telephone \\
\hline Number of respondents & 800 & 500 \\
\hline Population & Households & $\begin{array}{l}\text { Meat eating } \\
\text { households }\end{array}$ \\
\hline Respondents & $\begin{array}{l}\text { Member of household }> \\
18 \text { years }\end{array}$ & $\begin{array}{l}\text { Main food purchaser } \\
\text { in the household }\end{array}$ \\
\hline Sample design & Stratified & $\begin{array}{l}\text { Random sample in } \\
\text { each of the main } \\
\text { dialling code areas. }\end{array}$ \\
\hline Study period & July, 1997 & March, 1997 \\
\hline Geographical coverage & $\begin{array}{l}12 \text { counties (Dublin, } \\
\text { Connaught, Munster } \\
\text { and the Midlands) }\end{array}$ & $\begin{array}{l}\text { Nationwide } \\
\text { Sampling frame }\end{array}$ \\
\hline Response rate & \multicolumn{1}{|c|}{ High } & $\begin{array}{l}\text { Telephone code area } \\
\text { network }\end{array}$ \\
\hline
\end{tabular}

\subsection{Part one of research agenda}

The first part of the research agenda sought to compare and contrast the two groups for analysis on three questions namely:

Question 5: attributes used as indicators of quality at the point of purchase, Question 6: attributes which are deemed important at the point of consumption, Question 7: the attributes concerning safety.

\subsubsection{Qualitv attributes at point of consumption}

Little difference was found between those who had reduced their consumption and those who had maintained it with regard to the perception of eating quality attributes considered important at the point of consumption. Hedonically both groups do not differ in their preference for various attributes. 
The general findings within both groups with regard to the most important quality attributes sought are comparable with previous Irish studies reviewed, namely Riordan (1974) and Gordon Simmons Research Group (1995). In both studies the sensory factors, tenderness and flavour were deemed most important. However, in the current study colour was also regarded as equally important to both of these attributes. This finding indicates that Irish consumers also 'eat with their eyes'. The colour of the beef is just as important as what it tastes like at the point of consumption.

\subsubsection{Ouality attributes at point of purchase}

In question six little difference was found between both groups in their perceptions of the helpfulness of various attributes in assessing eating quality. In both groups colour and leanness, the place of purchase and country of origin were all considered to be of equal helpfulness. (Recall that colour and leanness can be regarded as both intrinsic cues and search attributes). This result together with that of the previous question reveals colour to be both an important and helpful quality attribute at the point of consumption and the point of purchase.

The result for leanness indicates that Irish consumers consider the absence of visible fat a helpful indicator of what the product will be like at the point of consumption. This finding substantiates the expected/experienced paradox in relation to fat, namely that consumers want the conflicting requirement of not only a lean product but also a tasty and tender one (Steenkamp \& van Trijp, 1990; Grunert, 1996).

The helpfulness of the place of purchase was also found by Grunert (1990) to be a dominant cue in the formation of expected quality. While the country of origin was indicated as one of the most helpful quality cues its salience must nonetheless be questioned.

The cue 'country of origin' cannot be regarded as salient or determinant ${ }^{1}$ to Irish consumers since all fresh beef sold in this country is of Irish origin. However, in many other European countries, where beef is imported, country of origin would be

\footnotetext{
${ }^{1}$ A determinant attribute is one which is used to differentiate one object from another (Churchill, 1987: 342).
} 
considered a salient quality cue. (The questionnaire was designed with five other countries in mind). Although the country of origin result should not be ignored the point made should be kept in mind.

Zeithaml's (1988) proposition that consumers depend on intrinsic attributes more than extrinsic attributes in pre-purchase situations when intrinsic attributes are search attributes (rather than experience attributes) $\left(\mathbf{H}_{1}\right)$ is a matter of contention. In all four attributes; two intrinsic and two extrinsic, were found to be the most helpful attributes for assessing eating quality. However, if consideration is made for the argument concerning country of origin and its salience then this extrinsic cue should be dropped. This leaves two intrinsic cues which are also search attributes; colour and leanness, and only one extrinsic cue. With this change Zeithaml's (1988) proposition is supported to some extent.

Both groups did not rate price as a very helpful attribute; those who had reduced their consumption rated it the least helpful attribute, while those who had maintained consumption rated price as least helpful along with marbling and a brand/quality label. Thus in the case of both groups $\mathbf{H}_{2}$ was supported. This result illustrates how weak the price/quality relationship for beef is for consumers in Ireland.

\subsubsection{Safety Concerns}

In question seven the most significant difference between both groups was the fact that those who had reduced their consumption regarded BSE as being of more concern than those who had maintained their consumption rates. This finding is not surprising and considering that the BSE crisis had begun twelve months previously to the study, the result gives an indication that its effect on safety perceptions of beef of those who had reduced their consumption was still maintained.

Respondents' perceptions that hormones and antibiotics in beef are of equal concern is comparable to findings in O'Neill \& Shanahan's (1993) study, thus substantiating the proposition that Irish consumers are confused about various safety issues. The fact that 'salmonella or other bacteria' was regarded by both groups to be of equal concern 
to antibiotics and hormones substantiates this proposition. The risk of getting food poisoning from bacteria in meat can be controlled through proper preparation and storage (New Scientist, 1998a). On the other hand, consumers have no direct control over hormone and antibiotic residues in meat.

In both groups fat/cholesterol was considered to be of least concern indicating that the safety issues predominate over one of the main health issues. This finding is also comparable to results in O'Neill's (1993) study and so supports $\mathbf{H}_{\mathbf{3}}$. A possible explanation for this result centres on the consumers' perceived ability to control the risk. The presence of antibiotics and hormones in beef is not identifiable whereas the amount of fat both intramuscular and on the rim is. Therefore, the perception of risk for hormones and antibiotics is higher due to the lack of perceived control. Indeed LMR (1987) found that the housewives level of concern about hormones and antibiotics was closely related to a lack of trust in law enforcement. Hence, the perceived lack of control of the risk appears to affect the level of concern.

\subsection{Part two of the research agenda}

The second part of the research agenda sought to transform the lower level attributes measured into the higher order quality level of abstraction using a perceptual mapping technique. It was hypothesised that the resulting perceptual map of perceived quality would encompass the seven quality constructs outlined by Issanchou (1996).

Figure 7.1 provides an illustration of the perceived quality constructs as proposed by Issanchou (1996) and those derived after PC analysis. From this illustration points of comparison and contrast can be delineated. PC analysis derived ten clear components/ quality constructs. The place of price and country of origin in this conceptual framework must, however be brought into question. Firstly, price is more a concept of value than of quality. Secondly, as stated country of origin is not a salient quality attribute in Ireland. The remaining eight components, therefore will be used to crossexamine Issanchou's (1996) seven constructs. 
Figure 7.1: A comparison of the perceived quality constructs as proposed by Issanchou (1996) and those derived in the study.

\begin{tabular}{|c|c|}
\hline Components Derived & Issanchou (1996) \\
\hline Point of consumption Freshness & $\begin{array}{l}\text { Pensory } \\
\text { Intrinsic cues of consumption } \\
\text { Extrinsic cues } \\
\text { Animal welfare purchase } \\
\text { Convenience } \\
\text { Safety } \\
\text { Healthiness }\end{array}$ \\
\hline
\end{tabular}

\subsubsection{The intrinsic and extrinsic constructs}

One of the main differences identified between both frameworks revolved around Issanchou's (1996) constructs of intrinsic and extrinsic cues. Intrinsic and extrinsic cues were measured in the questions examining cues used at the point of consumption and the place of purchase. In the PC analysis three components represented these cues namely freshness, the absence of non-meat components (fat and gristle) and the place of purchase. In other words, the cues did not fit neatly into intrinsic and extrinsic. The findings of this study are substantiated by previous research. Freshness and the absence of non-meat components were found by Steenkamp \& van Trijp (1989) to be the main quality cues used by consumers when forming quality expectations at the point of purchase. In addition, Grunert (1996) found the fat and the place of purchase were the two factors which dominated expected quality perceptions formation.

Therefore, when discussing quality perception at the point of purchase, instead of referring to the fact that consumers use intrinsic and extrinsic cues to assess eating quality as proposed by Issanchou (1996) a more refined description would be to refer to the quality constructs of freshness, the absence of non-meat components and the place of purchase. 
The findings failed to support the content validity requirement for the intrinsic and extrinsic constructs since they failed to operationalise as proposed in Chapter 5. Even more importantly, nomological validity for the intrinsic and extrinsic constructs were not found. This study and previous empirical evidence suggest that these constructs as proposed by Issanchou (1996) are misspecified.

\subsubsection{Health and safety constructs}

Another difference between both frameworks centred on Issanchou's (1996) quality constructs of healthiness and safety. The PC analysis did not reveal a clear delineation between safety and health as operationalised. For instance, while the safety variables examining BSE, hormones, salmonella and other bacteria and antibiotics all loaded on the same factor, the health variable fat/cholesterol did also. In relation to the remaining health variables which dealt with nutrition, these loaded onto a factor along with a variable measuring social acceptability and another addressing general food safety. This factor was called 'status of meat'.

These findings bring into question the content validity of the constructs health and safety; they did not operationalise as proposed. Furthermore, the manner with which the constructs of health and safety have been traditionally operationalised is brought into question.

An alternative operationalisation was proposed by Harrington (1994) and Allen (1992) who argued that both health and safety were perceived as the same issue. While not found to be the case entirely, empirical evidence here, however, does indicate this to be a more realistic proposition of the way in which consumers perceive these issues than the manner in which they have been traditionally operationalised.

\subsubsection{Cooking/Convenience}

As stated in Chapter 5 the statements for cooking (both of which incidently both into a factor) were used as proxy variables to measure the convenience of beef. It is concluded here that this factor is an unsuitable operationalisation for this construct; it lacks content validity. 
The remaining two quality constructs namely, sensory factors and animal welfare, were deemed to have content and nomological validity.

\subsubsection{Conclusion}

Overall, some of the constructs examining prior to purchase quality constructs, in particular convenience, were not operationalised adequately; this weakened the content validity. Of those that met a suitable content validity requirement the examination of nomological validity revealed that just two constructs, namely sensory and animal welfare, were reflected in Issanchou's (1996) proposed framework.

Empirical evidence here indicates that the content validity requirements for health and safety in particular need to be reassessed as the traditional operationalisations are deemed inadequate and may not measure what they purport to measure.

The nomological validity requirements for the intrinsic and extrinsic quality constructs need to be re-examined. In this and previous studies place of purchase, the absense of non-meat components and freshness are considered more suitable determinants of perceived quality.

\subsection{Third part of the research agenda}

The final part of the research agenda examined the discriminating quality factors between both groups which had influenced consumers reported beef consumption patterns since 1992. A number of hypotheses were drawn up.

\section{Health $\left(\mathbf{H}_{\underline{S}}\right)$}

The quality construct health was operationalised in this study in terms of fat/cholesterol and nutrition. Although these variables did not load on the same factor they were nevertheless encompassed in the two factors which were found to discriminate between both groups. $\mathbf{H}_{\mathbf{6}}$ is therefore accepted. 


\section{$\underline{\operatorname{Safetv}\left(\mathbf{H}_{x}\right)}$}

The safety factor derived from PC analysis was one of the two discriminating factors. Therefore, $\mathbf{H}_{6}$ is accepted.

\section{Cost $\left(\mathbf{H}_{7}\right)$}

Price was one of the eleven components derived from PC analysis but did not feature as a discriminating variable. However, empirical evidence, most notably from Bansback (1995) and Boyle (1996) gave clear indication that price was one of the main factors influencing beef demand. An explanation for the seemingly contrary result derived from this study is that price was measured here as an aspect of quality. However, price is a value component and should be operationalised accordingly.

\section{Taste ( $\left.\mathbf{H}_{\mathbf{Q}}\right)$}

Taste was manifested in the PC analysis as the 'sensory' factor but did not feature as a discriminating factor. A probable explanation for this result is the halo effect. The halo effect refers to the inter-dependency between perceived image and the perception of product properties. As the image of beef for many of those who've reduced their consumption is negative, there is likely to be a tendency towards the selective perception of negative product properties. In this case it is taste. The reason why taste may have not manifested itself in this study as a factor of discrimination is because the study was designed not to allow respondents the opportunity to rationalise their behaviour.

\section{Animal welfare $\left(\mathbf{H}_{0}\right)$}

While featured as one of the eleven factors derived from PC analysis it did not, however, discriminate between the groups studied. Only one variable -'we should have more respect for animals' - loaded on this factor. The other animal welfare variable examined loaded under the factor entitled 'place of purchase' which featured a diverse range of variables deemed to relate to the place where consumers purchased their beef. However, as both of the statements measuring animal welfare did not load together, the content validity of this factor is brought into question. 


\subsubsection{Perceived quality and beef demand}

Probably the most notable result from the third part of the research agenda and indeed the whole study itself is that the combined effect of the 'safety' and 'status of meat' factors only explained $7.7 \%$ of the variance between the two groups being studied. In other words, the perceived quality construct as operationalised (albeit inadequately on some dimensions) provided surprisingly little explanation for beef consumption decreases in recent years. There are a number of possible interpretations of this result.

\section{- PIMS research}

In Chapter 3 some misgivings were noted with the intention of relating the PIMS finding concerning the relationship between perceived quality and market share to the beef industry. These included firstly, the fact that the PIMS research related to companies and not industries and secondly, that beef is largely an unbranded product.

\section{- Operationalisation of perceived quality constructs}

The second explanation concerns the operationalisation of the health and safety constructs reported in previous studies as the two main quality factors driving the decline in beef consumption. As stated the PC analysis revealed that the variables measuring the constructs of health and safety 'mixed'. Indeed the discriminant analysis revealed that it was the combined effects of the components measuring these variables which discriminated between both groups, albeit at a low variance level.

One proposition for this finding is that in order to fully understand and explain health and safety one must not examine them as a combination but as a fusion of effects resulting from them. This proposition has been argued previously in psychology in relation to the environment versus heredity debate. Rose $(1967,216)$ states that psychologists:

'....tend to pose questions about the sources of human behaviour in terms of combinations of discrete hereditary and environmental influences. That is, to use an analogy from chemistry, they unwittingly conceive of concrete human behaviours as mixtures of forces from hereditary and environmental sources, whereas they might often be more accurately conceived of as compounds of such 
forces. Mixtures retain the characteristics of their constituent elements, whereas compounds usually exhibit entirely new characteristics and properties'.

Whatever the explanation one point is clear, the constructs of health and safety as traditionally operationalised do not appear to measure the concepts which they purport to measure.

\section{- Symbolism of beef}

Results from this study support Fiddes' (1991) argument that dietary advice from the nutritional sciences may support changing public perceptions towards red meat consumption but it cannot fully explain then. Fiddes' (1991) proposition that conventional explanations are not entirely adequate and that fuller answers must be sought by interpreting what meat stands for in our culture, namely the social aspects of the phenomenon of meat eating. Approaching the original research question for this perspective may provide a better understanding of beef consumption behaviour in Ireland.

\section{- Social influences}

Other social forces besides symbolism have been identified as affecting consumption behaviour, namely normative and informational social influences.

The normative or social pressure on consumers' beef consumption behaviour has been identified by Zey \& McIntosh (1992), Sapp \& Harrod (1989) and Sapp (1991). Indeed it was noted in these studies that behavioural intentions to consume beef was not under attitudinal control but was affected by what was felt to be the opinion of the respondents' larger social system.

With regard to informational social influences, the media has been found to be the most notable influencer on changes in red meat consumption in recent times (e.g. Burton \& Young, 1997; Mc Intosh et al., 1995; Konradi et al., 1994). 
It is likely that both normative and informational social influences have simultaneously affected consumer decisions to reduce beef consumption.

\subsubsection{Socio-demographics and beef demand}

The lack of real impact by income, education, or number of children in the household indicates that socio-demographic factors fail to discriminate between those who have and those who have not reduced their beef consumption. This finding substantiates previous propositions about Irish consumers as people who do not conform to traditional mass marketing or niche marketing approaches and do not divide clearly along socio-demographic factors, but retain an identity all of their own (Turley, 1986; Behaviour \& Attitudes, 1995).

\subsection{Limitations of the research conducted}

It is the nature of the research process that every study will have some limitations which may affect the validity or the generalisability of the results. The following are the main limitations of the study. Some of them could have been avoided in hindsight and others simply reflect the method of research used.

\section{- Operationalising quality constructs}

Some of the quality constructs were not operationalised adequately. The variables addressing nutrition and animal welfare were measured for meat in general and not beef. One of the quality constructs, namely convenience was not measured at all. These limitations reflect the fact that the questionnaire was not designed with the main research question addressed in this study in mind.

\section{- Specific beef cuts}

Unlike previous Irish studies where the perceptions towards beef quality were examined (e.g. Mc Carthy et al., 1998; O’Riordan, 1974), specific beef cuts were not examined here. In O'Riordan's (1974) study the perception of eating quality attributes varied for different cuts, while Mc Carthy et al. (1998) found the perceived risk of BSE to be varied for different cuts. In this study beef was examined at the general level to the detriment of parsimony. 


\section{- Female respondents}

As the respondents were the main food purchasers in the household, not surprisingly over $80 \%$ of the sample were female. The high incidence of female responses may lead to a bias in the findings. Women may well have different perceptions towards beef. For instance, Lister \& Hodges (1994) argued that young women tend to avoid red meat because the masculine images of strength associated with it are incongruent with their self-concepts.

\section{- Context}

This study was performed in such a way that context was not specified. Meat choice and the variables influencing it can be contextual. For instance, factors which affect the perceptions of beef quality during the week may or may not be the same factors that affect perceptions at the weekend because more time is available and so on. The culinary context is particularly important for meat.

\subsection{Practical implications}

The understanding of current dietary trends is important to the future of the beef industry. The following are a number of implications which may have practical value for the meat industry.

\section{- Beef promotion}

The findings of this study provide indications that changes in beef consumption behaviour are not driven by cognitive or utilitarian reasoning. This has an implication for advertising strategy and supports von Alvensleben et al. 's (1998) proposition that communication should put more emphasis on the emotional aspects of meat consumption.

\section{- Quality attributes at the point of consumption}

Tenderness, flavour and colour were found to be the most important attributes at the point of consumption and subsequently all three attributes loaded on the same component which was called 'sensory'. Thus all three variables must perform to standard in order for the 'sensory' dimension to be fulfilled for the consumer. 
Chambers \& Bowers (1993) argue that if consumers are not entirely satisfied with the sensory properties of meat then other quality dimensions become irrelevant. This finding has implications for the focus of product design initiatives.

\section{- Quality indicators at the point of consumption}

The finding that Irish consumers use the place of purchase, the absence of non-meat components and freshness to predict the eating quality of beef at the point of purchase is useful information for retailers. The finding of the helpfulness of the place of purchase will be of particular interest to major retailers in their quest to develop their own generic brand of beef.

\section{- Safety concerns}

The PC analysis revealed that Irish consumers do not distinguish between the various safety factors but perceive then all as one dimension. In addition, this dimension was found to be one of the discriminating factors.

In the Wilcoxon tests BSE was identified as an issue which those who had reduced their consumption were more concerned about, hence indicating that even a year after the crisis the effect of the announcement was still apparent. The beef industry has reacted to the BSE crisis through the development of initiatives such as the formation of beef quality assurance schemes which also deal with safety issues. Nonetheless, the beef industry must be more proactive in dealing with future scares which could even involve the same issues.

One suggestion is that the industry must adopt crisis management techniques to deal with potential crisis situations. After the announcement in March 1996, while the press were printing disturbing headlines, there was little clear decision-making from the government or the beef industry. Most appeared to have adopted a wait-and-see policy to begin with, which proved disastrous. The lack of a clear information and the sounding of many diverse viewpoints from such parties as scientists, farmers and the media created a Tower of Babel effect. In addition, previous to the announcement the BSE issue had been smouldering away for many years, creating a vacuum in 
consumers' minds filled by rumour and speculation. The public has become highly sensitised to food scares. Swift and decisive reaction to potential scares in the future will not only reduce the potential damage but may also provide the beef industry with an opportunity to demonstrate its integrity.

\subsection{Theoretical implications}

The following section outlines the theoretical implications of this study.

The findings only demonstrated a general support for Issanachou's (1996) proposition of seven determinants of perceived quality. There are three reasons for this result. Firstly, a couple of the quality constructs, namely convenience and animal welfare were not operationalised adequately. Secondly, the constructs of health and safety as traditionally operationalised are not adequate to understand these factors. Finally, the constructs of intrinsic and extrinsic cues as proposed can be more suitably be refined as freshness, absence of non-meat components and the place of purchase. These factors have also been found in previous studies by Steenkamp \& Van Trijp and Grunert (1996).

Despite the inadequacies in operationalising the perceived quality construct the ten components derived from the PC analysis were deemed a suitable measure of perceived quality for investigating the main research question concerning perceived quality and its usefulness in explaining the recent changes in beef consumption behaviour in Ireland. Contrary to indications from PIMS research, perceived quality as operationalised explained only a small proportion of the difference between the groups studied. This finding indicates that many of the quality factors thought to influence the reduction in beef consumption in previous studies (e.g. LFRA, 1994; Woodward, 1988) may not adequately explain the motivations driving consumption change.

Additional findings were that consumers from both groups studied did not differ in the importance which they perceived quality attributes to have at the point of consumption or the helpfulness of quality indicators at the point of consumption. 
These questions were examined in an exploratory manner due to the lack of comparative studies.

The findings concerning the perceived safety of beef supported findings by O'Neill \& Shananhan (1993) and also has implications for future studies examining the perceived risk of food safety issues. The results indicated confusion and a perceived lack of control about the risk of antibiotics, salmonella and hormones in beef.

\subsection{Suggestions for further research}

The section suggests the next reasonable step in forwarding a program of research in the area of understanding beef consumption behaviour.

Some previous empirical work reviewed in the literature concerning changes in beef consumption behaviour has focused on social and cultural influences namely, normative, informational and symbolic influences.

This study, on the other hand, although purporting to examine perception approached the question in a generalist and objective manner. An approach which sought explanation as opposed to understanding. An approach which was contextindependent instead of being contextual and socially constructed. Future research examining changes in beef consumption behaviour is likely to benefit by following an interpretivist approach of investigation instead of the positivist one used in this study. A greater understanding of changes in behaviour may come through studying consumers in their natural context and in a holistic manner; consumers should not be studied out of context or reduced to variables.

The findings of this research indicate that research into the area studied needs to move on to new pastures so as to avoid the 'convenient light syndrome':

Late one evening a policeman comes upon a young man who is down on his knees feverishly searching under a light post. The policeman asks what he is looking for. He replies that he has lost his wallet. The policeman inquires 
where he last had it. The young man replies that he purchased some flowers from a vendor about half a block away. 'Why not look there?' the policeman responds. Questioningly, the young man looks up and states, 'The light is better here ' (Zaltman et al. 1982, 145).

\subsection{Concluding remarks}

A shortcoming with much of the previous research examining the reasons for red meat reduction behaviour concerns the methodology used. Firstly, consumers are generally asked to state their reasons for reducing consumption in which case respondents may attempt to rationalise their behaviour. In addition, this research technique fails to address the interaction of various underlying motivations driving the change in consumption behaviour.

In this study all of the dimensions of perceived quality were measured and were subsequently analysed simultaneously. The cumulative effect of nutritional reports, scandals, ethical concerns and lifestyle changes has meant that the factors thought to influence the perceptions of meat quality must be broadened. In the literature review underlying dimensions of perceived quality proposed by Issanchou (1996) and these were operationalised in the primary research in order to understand recent changes in beef consumption behaviour in Ireland.

Results revealed that changes in beef consumption behaviour are not influenced strongly by perceptions of quality as operationalised in this study. It is likely that a better understanding of this behaviour would come from research at a social level rather than at an individual psychological one. 


\section{BIBLIOGRAPHY}


Ajzen, I., 1985. 'From intentions to actions: a theory of planned behaviour', in Action control: From Cognition to behaviour, Khul, J. and Beckmann, J.,eds. Heidelberg, Springer, 22-39.

Ajzen, I. and Fishbein, M., 1980. Understanding Attitudes and Predicting Social Behaviour. Englewood Cliffs, NJ, Prentice Hall.

Allen, M, 1992. 'Repositioning food products to meet current consumer needs'. In Reciprocal Meat Conference Proceedings. American Meat Science Association. Vol.45. pp.141-144.

Andersen, E.S., 1994. The evolution of credence goods: A transaction approach to product specification and quality control. MAPP working paper no. 21: The Aarhus School of Business.

Audenaert, A. \& Steenkamp, J-B.E.M., 1997. 'Means-end Chain Theory and Laddering in Agricultural Marketing Research', in Agricultural Marketing and Consumer Behaviour in a Changing World, Wierenga, B., Tilburg, A, Grunert, Steenkamp, J-B. E.M. \& Wedel, M., eds. Kluwer Academic Publishers. pp.217-230.

Ashwell, M. \& Lambert, J., 1992. 'Nutritional aspects and consumer perception of meat' in The European Meat Industry in the 1990's. Ed. Smulders, J.M. (ECCEAMST). Audet Tijdschriften, The Netherlands. pp.293-321.

Bansback, B., 1995. 'Towards a Broader Understanding of Meat Demand Presidential Address'. Journal of Agricultural Economics. 46(3).p.289.

Beardsworth, A.D., 1990. 'Trans-science and Moral Panics: Understanding Food Scares'. British Food Journal. Vol.92. No.5. p.12.

Beardsworth, A.D. \& Keil, E.T., 1991. 'Vegetarianism, veganism and meat avoidance: recent trends and findings'. British Food Journal. Vol.93, pp.19-24.

Behaviour \& Attitudes, 1995. Changing Attitudes in Ireland. Behaviour \& Attitudes Ltd.

Bohnstedt, G.W., 1970. 'Reliability and Validity Assessment in Attitude Measurement'. In G.F. Summers ed., Attitude Measurement. Chicago: Rand Mc Nally and Company, pp.80-99.

Boyle, G.E., 1996. 'A MAIDS Model of Irish Meat Demand'. The Social and Economic Review. Vol.27. No.4. July, pp.309-319.

Breidenstein, B.C., 1988. 'Changes in Consumer Attitudes Toward Red Meat and Their Effect on Marketing Strategy'. Food Technology. January. pp.112-116.

Brown, F.E. 1980. Marketing Research: A Structure for Decision Making. AddisonWesley Publishing Company. 
Browne, G.M., Merrell, P.W., Rickard, M.W. and Wythes, J.R., 1996. 'Q Safe: Meeting the Challenge of Food Safety' in Meat for the Consumer - Proceedings of $42^{\text {nd }}$ ICoMST. 1996.

Burton, M. and Young, T., 1997. 'Measuring meat consumers' response to perceived risks of BSE in Great Britain'. Risk Decision and Policy.Vol.2 No.1, pp.19-28.

Business \& Finance, 1997. 'The Beef Pickle', Business \& Finance. $24^{\text {th }}$ July. p.10.

Byrnes, Heather, 1997. Associate Research Director of MRC. Personal Communication.

Cadogan, S., 1994. 'Was Hormone Ban a Mistake?' Cork Examiner. October $3^{\text {rd }}$.

Callanan, H., 1996. 'Irish Beef Laced with Angel Dust', Sunday Business Post. $18^{\text {th }}$ February.

Cathell, R.B., 1978. The Scientific Use of Factor Analysis in Behavioural and Life Sciences, New York: Plenum Press.

CEC., 1993. Report of the Scientific Veterinary Committee, the Scientific Committee for Animal Nutrition and the Scientific Committee for Food on the basis of the report of the Scientific Group on Anabolic Agents in Animal Production, Report EUR.8913.

Central Statistics Office (C.S.O.),1996. Census of Services, Vol. 1.

Central Statistics Office (C.S.O.), 1997. Statistical Bulletin, September.

Chaiken, S., 1980. 'Heuristic versus systematic information processing and the use of source versus message cues in persuasion'. Journal of Personality and Social Psychology. 37, pp.752-766.

Chambers, E. \& Bowers, J.R., 1993. Consumer Perception of Sensory Qualities in Muscle Foods. Food Technology. Vol.47, pp.116-120.

Chavas, J-P., 1986. 'On the structure of Demand for meat', in The Economics of Meat Demand. Ruben C. Buse (Ed.) Proceedings of the Conference on the Economics of Meat Demand. Oct. 20 $0^{\text {th }}-21^{\text {st }}$. Charleston, South Carolina, pp.125-135.

Churchill, G.A., 1987. Marketing Research: Methodological Foundations. $4^{\text {th }}$ Ed. The Dryden Press.

Cocks, R. and Bentley, R., 1996. $£ 300$ Billion, Government Spending: The facts. Reading: Databooks.

Coghlan, A., 1998. 'Is Anything Safe to Eat?', New Scientist. $3^{\text {rd }}$ Janruary. 
Conner, M.T., 1993. 'Understanding Determinants of Food Choice: Contributions From Attitude Research'. British Food Journal. Vol.95, No.9, pp.27-31.

Cooper, R.J. \& Mc Laren, 1992. 'An empirically Orientated Demand System with improved Regularity Properties'. Canadian Journal of Economics, XXV, No.3, pp.652-668.

Cotter, A., 1998. 'Irish Beef: The Marketing Challenge', in Challenges for the Meat Industry in the Next Millennium. 14 $4^{\text {th }}$ May. Dublin, Ireland. Teagasc, The National Food Centre.

Cowan, C. \& Mannion, M., 1997. Ireland - Consumer perceptions of meat quality. EU FAIR-CT 95-0046. Report for the European Commission.

Cowan, C. (1997) 'Irish and European views on Food Safety' in 'From Producerism to Consumerism - the Implications of Change'. Proceedings of The National Food Centre Conference on Food Safety. $6^{\text {th }}-7^{\text {th }}$ November 1997. pp. 1-26.

Crocker, J., Fiske, S.T. and Taylor, S.E., 1984. 'Schematic bases of belief change', in Attitudinal Judgement, Eiser, J.R. (ed.) New York, Springer-Verlag.

Daily Mirror, 1996. 'The Proof'. Thursday March $21^{\text {st }}$, p.1.

Dant, R.P., Lumpkin, J.R., Bush, R.P., 1990. 'Private physicans or walk-in clinics: Do the patients differ?', Journal of Health Care Marketing, Vol.10, No.2, pp.25-35.

Department of Agriculture \& Food (DOAF), 1998. 1997 Annual Review and Outlook: For Agriculture \& The Food Industry. Department of Agriculture \& Food . April.

Department of Agriculture \& Food (DOAF), 1998a. 'Press release - O'Keefe releases residue analysis results for first quarter'. Department of Agriculture \& Food. $26^{\text {th }}$ May.

Dillion, W.R., Frederick, D.G., Tangpanichee, V., 1985. 'Decision issues in building perceptual product spaces with multi-attribute rating data'. Journal of Consumer Research. Vol.12. No.1, pp.47-63.

Drennan, M., 1993. Planned Suckler Beef Production. Teagasc, Beef Series No.4.

Eagly, A.H. and Chaiken, S., 1993. The Psychology of Attitudes. Harcourt Brace College Publishers.

East, R., 1997. Consumer Behaviour: Advances and Applications in Marketing. Prentice Hall, London.

Ehrlichman, J., 1990. 'Meat eaters swallow food poison risk', Guardian, 29 ${ }^{\text {th }}$ January, p.3. 
EIU Retail Business, 1995. Meat, part 2: Beef and veal. No.444, pp.84-105.

EUROSTAT, 1996. Panorama of EU-industry 1995-1996. Luxembourg: The European Commission.

Evers, M., 1983. 'Consumerism in the Eighties'. Public Relations Journal. (August), pp.24-26.

Farmers Journal, 1998. 'Goodman profits treble', Farmers Journal. Vol. 50, No.15, April $11^{\text {th }} \cdot$ p.1.

Fiddes, N., 1991. Meat: A natural symbol. Routledge. London.

Fine, B. and Leopold, E., 1993. The World of Consumption. Routledge, London and New York.

Fishbein, M. \& Ajzen, I., 1975. Belief, attitude, intention and behaviour. Reading, MA-Addison-Wesley.

Fitzgerald, A., 1997. Have Passport, will Travel, Irish Independent. January $10^{\text {th }}$.

Food Advisory Committee, 1980. Report on Fats and Oils in Human Health. Food Advisory Committee. December, Dublin.

Food Advisory Committee, 1984. Guidelines for preparing information and advice to the general public on healthy eating. Food Advisory Committee. May, Dublin.

Food Advisory Committee, 1986. Report on public health policy on diet and heart disease. Food Advisory Committee. May, Dublin.

Forbairt, 1995. Food Development Strategy 1995 - 1999: An Action Plan for Growth. Wilton Park House, Wilton Place, Dublin 2.

Gale, B.T., 1994. Managing Customer Value. The Free Press. New York.

Geistfeld, L.V., Sproles, G.B. and Badenhop, S.B., 1977. 'The concept and Measurement of a Hierarchy of Product Characteristics', in Advances in Consumer Research. Vol.4. W.D. Perrault Jr. Ed. Ann Arbor, M.I.: Association for Consumer Research, pp.302-307.

Gordon Simmons Research Group, 1995. European Attitudes to Meat. Summary Report - Eire. London

Green, P.E. \& Tull, D.S., 1978. Research for Marketing Decisions. $4^{\text {th }}$ Ed. Prentice Hall. Inc., Englewood Cliffs, N.J.

Grousch, R.L., 1983. Factor Analysis. Hillsdale, N.J.: Erlbaum. 
Grunert, K.G., 1988. 'Research in Consumer Behaviour: Beyond Attitudes and Decision-Making', European Research. Vol.16, No.3, pp.172-183.

Grunert, K.G., 1995. 'Food Quality: A Means-End Perspective'. Food Quality and Preference. No.6. pp.171-176

Grunert, K.G., 1996. 'What's in a Steak? A cross-cultural Study on the Quality Perception of Beef'. MAPP Report. Working Paper No.39. Denmark.

Grunert, K.G., Harmsen, H., Larsen, H.H., Sorensen, E. and Bisp, S., 1997a. 'New Areas in Agricultural and Food Marketing', in Agricultural Marketing and Consumer Behaviour in a Changing World. 1997. eds. Wierenga, B., van Tilburg, A., Grunert, K., Steenkamp, J.B. and Wedel, M. Kluwer Academic Publishers, Boston, pp.3-30.

Grunert, K.G., Larsen, H.H., Madsen, T.K. and Baadsgaard, A., 1997b. Market Orientation in Food and Agriculture. Kluwer Academic Publishers.

Gunner, D., 1989. 'Market Trends for Meat'. Farm Management. Vol.7. No.2, pp.95101.

Hair, J.F., Anderson, R.E., Tatham, R.L. and Black, W.C., 1995. Multivariate Data Analysis with Readings. $4^{\text {th }}$ Ed. Prentice Hall, Englewood Cliffs, N.J.

Harris, P. and O'Shaughnessy, N., 1997. 'BSE and marketing communication myopia: Daisy and the death of the sacred cow'. Risk Decision and Policy. Vol.2, No.1, pp2939.

Harrington, G., 1985. Meat in the Modern World, Milton Keynes: Meat and Livestock Commission.

Harrington, G., 1994. 'Consumer Demands: Major Problems Facing Industry in a Consumer-Driven Society'. Meat Science. Vol.36. pp.5-18.

Harrington, G., 1995. 'Look at it this way', Outlook on Agricultue. Vol.24, No.1, pp.3-5.

Henchion, M., 1997. The Irish Beef Industry. Working Paper L97/03. Irish Food Competitiveness Project: Logistics Working Paper Series.

Henson, S. \& Northen, J., 1998. "Consumer perceptions of beef safety and the implications for quality policy', in Long Term Prospects for the Beef Industry. 56 ${ }^{\text {th }}$ EAAE Seminar. Paris, $26^{\text {th }}-27^{\text {th }}$ February, 1998.

Herbig, P.A. and O'Hara, B.S. ,1994. 'Quality is in the Eye of the Beholder', Journal of Professional Services Marketing, Vol. 10(2), pp.19-33. 
Holbrook, M.B. \& Corfman, K.P., 1985. 'Quality and Value in the consumption experience: Phaedrus rides again', in Perceived Quality, ed. J. Jacoby \& J.C. Olson. Lexington Books, Lexington, pp.31-57.

Hollingsworth, P., 1997. 'Steering a New Course for Beef'. Food Technology. October. Vol.51., No.10. p.30.

Household Budget Survey, $1994-1995$.

Horton, R.L., 1984. Buyer Behaviour: A Decision-Making Approach. Charles E. Merrill Publishing Company.

Irish Farmers Journal, 1997. 'E.Coli bug found here'. Irish Farmers Journal, 15 th $^{\text {th }}$ November, p.1.

Irish Fresh Meat Exporters Society, Ltd., 1981. A Strategy for the Development of Irish Cattle and Beef Industry. Irish Fresh Meat Exporters Society, Ltd.

ISO, 1986. 'ISO-8402' Quality Vocabulary'. International Organisation for Standardisation, Geneva, Switzerland.

Issanchou, S.,1996. 'Consumer Expectations and Perceptions of Meat and Meat Product Quality'. Meat Science, Vol.43. Elsevier Science Ltd, pp.S5-S19.

Jaccard, J., Brinberg, D., and Aakerman, Lee, 1986. 'Assessing attribute importance: A comparison of six methods'. Journal of Consumer Research. Vol.12, March, pp.463-468.

Jacoby, J., Szybillo, G. and Busato-Schach, J., 1977. 'Information acquisition behaviour in brand choice situations', Journal of Consumer Research, Vol.3, March, pp.209-216.

Janssen, W.G. \& Tilburg, A., 1997. 'Marketing Analysis for Agricultural Development: Suggestions for a New Research Agenda', in Agricultural Marketing and Consumer Behaviour in a Changing World, Wierenga, B., Tilburg, A, Grunert, Steenkamp, J-B. E.M. \& Wedel, M. (eds.) (1997). Kluwer Academic Publishers.

Jeremiah, L.E., 1982. 'Review of factors influencing consumption, selection and acceptability of meat purchases', Journal of Consumer Studies and Home Economics. Vol.6, pp.137-154.

Kachigan, S.K., 1986. Statistical Analysis: An Interdisciplinary Introduction to Univariate and Multivariate Methods. Radius Press, New York.

Kahneman, D. and Tversky, A., 1972. 'Subjective probability: A judgement of representativeness', Cognitive Psychology, 3, pp.430-54. 
Keane, J.B. \& Langan, J.W., 1996. National Meat Quality Policy in Ireland: Outline Report. EU Report. (EU FAIR-CT95-0046)

Kline, P., 1994. An Easy Guide to Factor Analysis. Routledge, London and New York.

Konradi, G.W. and Marthaler, E., 1994. 'More money for defect-free meat products and sausages', Fleischere. Vol.45, No.9, pp.92-93.

Kordupleski, R.E., Rust, R.T. and Zahorik, A.J., 1993. 'Why improving quality doesn't improve quality (or whatever happened to marketing?), California Management Review. Spring, pp.82-95.

Kotler, P., Armstrong, G., Saunders, J. and Wong, V., 1996. Principles of Marketing. The European Edition. Prentice Hall.

Landsdowne Market Research, 1987. Attitudes to Meat Qualitative Research. Landsdowne Market Research. May.

Lassen, J., 1993. Food Quality and the Consumers. MAPP Report. The Aarhus School of Business.

Leatherhead Food Research Association, 1994. The UK Meat and Poultry Products Report. Leatherhead Food Research Association, September. p.23.

Lee, J-Y., 1986. 'Effect of socio-demographics on at-home red meat consumption in the United States', in The Economics of Meat Demand. R.C. Buse (Ed.) Proceedings of the Conference on the Economics of Meat Demand. Oct. $20^{\text {th }}-21^{\text {st }}$. Charleston, South Carolina, pp. 243-255.

Levy, S.J., 1981. 'Symbols, Selves and Others'. Advances in Consumer Research, Vol.9, pp.542-543.

Lichtenstein, S., Slovik, P., Fischoff, B., Layman, M. and Combs, B., 1978. 'Judged frequency of lethal events', Journal of Experimental Psychology: Human Learning and Memory, 4, pp.551-78.

Lilen, G.L., Kotler, P. and Moorthy, K.S., 1992. Marketing Models. Prentice Hall.

Lister, D. 1995 . The meat we eat: Notions of quality today and tomorrow. In: $41^{\text {st }}$ International Congress of Meat Science and Technology. San Antonio, Texas. August 20-25, 3-12.

Lister, D., 1996. 'The Meat We Eat: Notions of Quality For Today and Tomorrow'. Outlook on Agriculture. Vol. 25. No.3, pp.193-197.

Lister, D. \& Hodges, K.E., 1994. 'Is Meat Macho?', Meat Focus International. November. p.437. 
Lynch, R., 1997. Corporate Strategy. Pitman Publishing. London.

Macey, C., 1997. 'Cowen to clear beef on bone 'within days'. Sunday Independent. December $7^{\text {th }}$.

Maguire, D. \& Mooney, P., 1998a. 'Meat groups should be slashed to four', Irish Farmers Journal, June $6^{\text {th }}$, p. 4 .

Maguire, D. \& Mooney, P., 1998b. 'Irish beef brand proposed for U.K.', Irish Farmers Journal, April $11^{\text {th }}$, p.1.

Mc Carthy, M. O'Reilly and Barton, J., 1998. 'Irish consumer perception and beef consumption patterns: An analysis', in Long Term Prospects for the Beef Industry. $56^{\text {th }}$ EAAE Seminar. Paris, 26 ${ }^{\text {th }}-27^{\text {th }}$ February, 1998, pp.305-312.

Mc Intosh, W.A., Fletcher, R.D., Kubena, K.S. and Landmann, W.A., 1995. 'Factors associated with sources of influence/information in reducing red meat by elderly subjects', Appetite. Vol.24, pp.219-230.

Meat and Livestock Commission, 1994. Market Overview. Issues 1994-1995. U.K.

Meat Trades Journal, 1989. 'Farmers Flout Loophole in Hormone Ban', Meat Trades Journal, London: International Thomson, $27^{\text {th }}$ July.

Miller, J.A., Topel, D.G. and Rust, R.E., 1976. 'USDA Beef Grading: A Failure in Consumer Information?' Journal of Marketing, Vol. 40 (January) pp.25-31.

Ministry for Agriculture and Food (MAFF), 1993. The GATT Agricultural Agreement, Discussion Document, December.

Moloney, E. \& Lavery, M., 1998. 'Government targets fat addicts in bid to cut diet diseases'. Irish Independent. Saturday, May $9^{\text {th }}$

Myers, L.H., 1986. 'What do we Know and What Does it Mean?', in The Economics of Meat Demand. ed. Buse, R.C. Proceedings of the Conference on the Economics of Meat Demand. Oct. 20-21. Charleston, South Carolina.

Nelson, P., 1970. 'Information and consumer behaviour'. Journal of Political Economy, 78, pp.311-329.

New Scientist, 1998. 'Editorial: We are what we eat'. New Scientist, New Science Publications, $3^{\text {rd }}$ January, p.1.

New Scientist, 1998a. 'Editorial - We are what we eat', New Scientist. January $3^{\text {rd }}$, p.3.

Nielsen, N.A., 1998. The Beef Market in the European Union. The Aarhus School of Business.

Nielsen Retail Census, 1994 
Nunnally, J.C., 1967. Psychometric Theory. New York: McGraw-Hill Book Company.

O’Connor, 1996. 'CJD has killed 20 since 1980, survey finds'. Irish Times. October $21^{\text {st }}$.

Olson, J.C., 1977. 'Price as an informational cue: Effects in Product Evaluation', in Consumer and Industrial Buying Behaviour, Arch G. Woodside, Jagdish N. Sheth, and Peter D. Bennett, Eds. New York: North Holland, pp.267-286.

Olson, J.C. and Reynolds, T.J., 1983. 'Understanding consumers' cognitive structures: Implications for advertising strategy'. Advertising and Consumer Psychology, L. Percy and A Woddwaside, Eds. Lexington, MA: Lexington Books.

O'Neill, F. and Shanahan, U., 1993. Dietary concerns of Irish consumers - second update, Socio Economic Research Series, No.12, Teagasc.

Operational Programme for Industrial Development, Food Sub-Programme, 1995. 1994-1999, Government Publication, Molesworth Street, Dublin 2.

O'Sullivan, M.G., Cloak, O., Guillet, A., Thueux, S. and Sheridan, J.J., 1996. Incidence of Salmonella in retail products and their antibiotic resistance profile. The Teagasc Research Report. pp.71-72.

Oude, P.A.M. \& Van Trijp, H.C.M., 1995. 'Perceived Quality: A Market Driven and Consumer Orientated Approach', Food Quality and Preference. Vol.6. pp.177-183.

PA Consulting, 1992. The Food Industry. A report to the Industrial Policy Review Group. Dublin.

Palmer, C.M., 1996. 'A week that shook the meat industry: the effects on the UK beef industry of the BSE crisis'. British Food Journal. Vol.98, No.11. pp.17-25.

Paton, N., 1997. 'Tesco takes meat to new world'. Supermarketing. $26^{\text {th }}$ September. p.17.

Peter, J.P., 1981. 'Construct Validity: A Review of Basic Issues and Marketing Practices'. Journal of Marketing Research. Vol.XVIII, May, pp.133-45.

Petty, R.E. and Cacioppo, J.T., 1981. Attitudes and Persuasions: Classic and Contemporary Approaches. Dubuque, IA: Brown.

Pitcher, G., 1996. 'Beefy price cutting leads to an outbreak of 'feel mad' disease'. Marketing Week. April $5^{\text {th }}$, p.27.

Pirsig, R.M., 1974. Zen and the Art of Motorcycle Maintenance. Bantam Books, New York. 
Smith, M.J., 1991. 'From policy community to issue network: Salmonella in eggs and the new politics of food'. Public Administration. Vol. 69. Summer, pp.235-255.

Smyth, P., 1998. 'EU declares most British beef fit for export'. The Irish Times. June $11^{\text {th }}$. p. 12 .

Speed, R., 1994. 'Regression Type Techniques and Small Samples: A Good Guide to Practice', Journal of Marketing Management, pp.89-104.

Sperber, D., 1975. Rethinking Symbolism, Cambridge: Cambridge University Press.

Spitters, P.J.A., Tazelaar, R.J. and Gerats, G.E., 1991. 'The Image of Meat and the Consumer's Perception of the Industry' in The European Meat Industry in the 1990's. Ed. Smulders, J.M. (ECCEAMST). Audet Tijdschriften, The Netherlands. pp.271291.

Spitters, P., 1993. 'Image and meat consumption', in Meat consumption in the European Communities, Brussels and Luxemburg: The European Commission.

SPSS $^{\circledR}$, 1997.BASE 7.5 Applications Guide. SPSS Inc.

Stayman, D.M., Alden, D.L. and Smith, K.H., 1992. 'Some effects of Schematic processing on consumer expectations and disconfirmation judgements'. Journal of Consumer Research. Vol.19. September. pp240 - 255.

Stanley, Th.J. and L.M. Robinson, 1980. 'Opinions on Consumer Issues: A Review of Recent Studies of Executives and Consumers'. Journal of Consumer Affairs, 14, pp.207-220.

Steenkamp, J-B.E.M. \& Van Trijp, H.C.M., 1989. 'Quality Guidance: A ConsumerBased Approach for Product Quality Improvement' in G.J. Alvonitis et al. (eds.), Marketing Thought and Practice in the 1990's. Proceedings of the $18^{\text {th }}$ Annual Meeting of the European Marketing Academy, Vol. 1, Athens: EMAC, pp.717-736.

Steenkamp, J-B, E.M. 1996. 'Dynamics in Consumer Behaviour with Respect to Agricultural and Food Products'. in Agricultural Marketing and Consumer Behaviour in a Changing World. 1997. eds. Wierenga, B., van Tilburg, A., Grunert, K., Steenkamp, J.B. and Wedel, M. Kluwer Academic Publishers, Boston, pp.143-188. Steenkamp, J-B.E.M., 1986. Product Quality: An investigation into the concept and how it is perceived by consumers. Van Gorcum. Maastricht, The Netherlands.

Sujan, $M$ and Bettman, J.R., 1989. 'The effects of brand positioning strategies on consumer's brand and category perceptions: Some insights from schema research', Journal of Marketing Research. Vol.XXVI, (November), pp.454-67.

Tabachnick, B.G. \& Fidell, L.S. (1989) Using Multivariate Statistics. $2^{\text {nd }}$ Ed. Harper \& Row publishers. 
Pollack, J., 1997. 'Beef group wants meal solutions for dinner table'. Advertising Age. August $4^{\text {th }}$.

Product Board for Livestock and Meat (PVV), 1991. Vacatures in de industriale vleessector. PVV Rijswijk, The Netherlands. Report 9101a.

Product Board for Livestock and Meat (PVV), 1997. Livestock, meat and eggs in the Netherlands. Issues 1994-1996, Product Boards for Livestock, Meat and Eggs in the Netherlands. The Netherlands.

Puri, B.K., 1996. Statistics in Practice: An Illustrated Guide to SPSS. Arnold, New York.

Richardson, N.J., 1994. 'U.K. Consumer Perceptions of Meat', Proceedings of the Nutrition Society. Vol.53. pp.281-287.

Richardson, N.J., Shepard, R. \& Elliman, N.A., 1993. 'Current attitudes and future influences on consumption in the U.K'. Appetite, 21, 41-51.

Richardson, N.J., Mac Fie, H.J.H. \& Shepard, R., 1994. Consumer Attitudes to Meat Eating. Meat Science. Vol.36, pp.57-65.

Riordan, E.B., 1974. 'Why not design beef for the housewife?', Farm and Food Research. Vol.5, No.5. Sept.-Oct. pp.100-102.

Rose, A.M., 1967. 'The relation of theory and method'. In Gross, L. (Ed.), Sociological Theory: Inquires and Paradigms (New York: Harper).

Santos, M.L.S. \& Booth, D.A., 1996. 'Influences on meat avoidance among British students', Appetite. Vol.27, pp.197-205.

Sapp, S.G. \& Harrod, W.J., 1989. 'Social acceptability and intentions to eat beef: A expansion of the Fishbein-Ajzen model using reference group theory', Rural Sociology, 54(3), pp.420-438.

Sapp, S.G., 1991. 'Impact of nutritional knowledge within an expanded rational expectations model of beef consumption', Society for Nutrition Education, Vol.23, pp.214-222.

Senaur, B., Asp, E. and Kinsey, J., 1991. Food Trends and the Changing Consumer. St Paul, Minnesota.

Shepard, R. \& Stockley, L., 1985. 'Fat consumption and attitudes towards food with a high fat content'. Human Nutrition: Applied Nutrition, 39A, pp.431-442.

Shepard, R. \& Towler, G., 1992. 'Nutrition knowledge, attitudes and fat intake: application of the theory of reasoned action'. Journal of Human Nutrition and Dietetics, 5, pp.387-397. 
Tazelaar, R.J. (1994) 'The Dutch Livestock and Meat Sector: Ready for the Future' in Proceedings of the $40^{\text {th }}$ International Congress of Meat Science and Technology 1994. The Netherlands. pp. 1222-1223.

Teagasc (1997) Irish Agriculture in Figures. $6^{\text {th }}$ Ed. Compiled by Rural Economy Staff.

The Realeat Survey, 1995. Changing Attitudes to Meat Consumption 1984-1995, Social Surveys (Gallup) Ltd., April.

Thomson, K.J., Kelly, R. and Anderson, C., 1997. The Grampian/UK Beef market in the European Union. Grampian Enterprise Limited.

Tilston, C. Neale, R. Gregson, K. \& Sear, R., 1993. Beef Consumption: The Impact of $B S E$. University of Nottingham. Horton Publishing Ltd.

Tull, D.S. \& Hawkins, D.I. (1987) Marketing Research: Measurement and Method. $4^{\text {th }}$ Ed. Macmillan Publishing Company.

Turley, D., 1986. 'Some Perspectives on the Irish Consumer', Irish Marketing Review. Vol.1.

van Dijk, G., 1994. 'The future of meat production', in the 40th International Congress of Meat Science and Technology, the Hague, the Netherlands. pp.12821289.

von Alvensleben, R.V., 1995. Den Imageverlust von Fleisch Bremsen, in: DLGMitteilungen 2/1995, pp.55-57.

von Alvensleben, R., 1997. 'Consumer Behaviour', in Agro-food Marketing, eds. D.I. Padberg, C. Ritson and L.M. Albsiu. CAB International, pp.202-224.

von Alvensleben, R.V. and Mahlau, G., 1998. 'The decline of the meat image and consequences for meat marketing in Germany', in Long Term Prospects for the Beef Industry. Proceedings Paris $26^{\text {th }}-27^{\text {th }}$ February, pp.189-197.

Webster, F., 1994. 'Meat and right: the ethical dilemma'. Proceedings of the Nutrition Society. Vol.53. No.2. pp.263-270.

Which, 1997. Antibiotics in Food. Which. March, pp.18-20.

Wilde, L.L., 1980. 'The economics of consumer information acquisition'. Journal of Business, 53. pp. 143-158.

Wilesmith, J.W., Wells, G.A.H., Cranwell, M.P. and Ryan, J.B.M., 1988. BSE: Epidmiological Studies. Ministry for Agriculture, Fisheries and Food. U.K. 
Wilkie, W.L., 1988. Consumer Behaviour. $3^{\text {rd }}$ Ed. John Wiley \& Sons.

Williams, T.G., 1982. Consumer Behaviour: Fundamentals and Strategies. West Publishing Company, New York.

Wiseman, F. \& Billington, M., 1984. 'Comment on a standard definition of response rates', Journal of Marketing Research. August, pp.336-338.

Woodward, J., 1988. 'Consumer Attitudes Towards Meat and Meat Products'. British Food Journal. Vol.90. No.3, pp.101-104.

World Food Regulation Review, 1996. 'European conference says growth hormones are safe to use in meat production'. World Food Regulation Review. Vol.5, No.8. p.21

Yankelovic, Skelly and White Inc., 1989. Marketing Intelligence. Prepared for the National Livestock and Meat Board, Chicago (IL).

Zaltman, G., Pinson, C. and Angelmar, R., 1973. Metatheory in Consumer Research. New York: Holt, Rinehart and Winston.

Zaltman, G., Le Masters, K., and Heffring, M., 1982. Theory Construction in Marketing: Some Thoughts on Thinking. John Wiley \& Sons.

Zeithaml, V.A., 1988. 'Consumer Perceptions of Price, Quality and Value: A MeansEnd Model and Synthesis of Evidence, Journal of Marketing, 52, July. pp.2-22.

Zey, M. \& Mc Intosh, W.M., 1992. 'Predicting intent to consume beef: Normative versus attitudinal influences', Rural Sociology. 52(2), pp.250-265. 
APPENDIX 1 


\section{THE NATIONAL FOOD CENTRE QUESTIONNAIRE}

Good morning/afternoon/evening. My name is (NAME OF INTERVIEWER) and I am calling from MRC, a research agency in Dublin. We are carrying out a survey today for The National Food Centre about attitudes towards food. Can I please speak with the person who does most of the shopping for food in your household?

\section{THEN: (IF YOU ARE TRANSFERRED TO SOMEONE ELSE REPEAT ABOVE} INTRODUCTION)

Before we begin the questionnaire, I would just like to emphasise that the aim of the survey is to obtain your views on food in Ireland today. There are no right or wrong answers. We are interested in your opinions. Also, MRC is a member of the Market Research Society and will treat all your answers confidentially.

\section{AFTER RESPONDENT AGREES:}

This questionnaire deals with fresh meat - fresh includes frozen but not processed meats (includes frozen chicken but not sausages).

Q.1 On average, how often, if at all, is ..... eaten in your household each week?

\begin{tabular}{|c|c|c|c|c|c|c|c|c|}
\hline & Never & $\begin{array}{l}\text { Less often } \\
\text { than once } \\
\text { a month }\end{array}$ & $\begin{array}{l}\text { Less than once a } \\
\text { week but more than } \\
\text { once a month }\end{array}$ & Once & Twice & Three+ & It varies & $\begin{array}{l}\text { Don't } \\
\text { know }\end{array}$ \\
\hline Beef & 1 & 2 & 3 & 4 & 5 & 6 & 7 & 0 \\
\hline Pork & 1 & 2 & 3 & 4 & 5 & 6 & 7 & 0 \\
\hline Chicken & 1 & 2 & 3 & 4 & 5 & 6 & 7 & 0 \\
\hline
\end{tabular}

\section{IF ALL THREE CODED AS NEVER, CLOSE \& RECRUIT SUBSTITUTE}

Q.2a Has the amount of ..... eaten in your household changed or not in the last five years, that is since 1992 ?

\begin{tabular}{|c|c|c|c|c|c|c|}
\hline & \multicolumn{3}{|c|}{ Q.2A - Changed } & \multicolumn{3}{|c|}{ Q.2B - EAT MORE OR LESS } \\
\hline & Changed & Not changed & Don't know & More & Les: & Don't know \\
\hline Beef & 1 & 2 & 0 & 1 & 2 & 0 \\
\hline Pork & 1 & 2 & 0 & 1 & 2 & 0 \\
\hline Chicken & 1 & 2 & 0 & 1 & 2 & 0 \\
\hline
\end{tabular}

\section{FOR EACH CHANGED ASK:}

Q.2b And does your household now eat more or less .... than it did in 1992? CODE IN GRID ABOVE

Q.3 Which, if any, of the following meats do you personally eat nowadays?

\begin{tabular}{|c|c|}
\hline Beef & 1 \\
\hline Pork & 2 \\
\hline Chicken & 3 \\
\hline None of these & 4 \\
\hline Don't know & 0 \\
\hline
\end{tabular}


FOR EACH TYPE OF MEAT SERVED AT ALL IN HOUSEHOLD AT Q.1 ASK:

Q.4 Where do you mainly buy fresh (raw) ....?

\begin{tabular}{|c|c|c|c|}
\hline & BEEF & PORK & CHICKEN \\
\hline Weekly market & 01 & 01 & 01 \\
\hline Mega-market & 02 & 02 & 02 \\
\hline Hyper-market & 03 & 03 & 03 \\
\hline Supermarket & 04 & 04 & 04 \\
\hline Butcher & 05 & 05 & 05 \\
\hline Local shop & 06 & 06 & 06 \\
\hline Direct from farmer & 07 & 07 & 07 \\
\hline Open market & 08 & 08 & 08 \\
\hline Other (please state) & 09 & 09 & 09 \\
\hline It varies & 10 & 10 & 10 \\
\hline Don't know & 00 & 00 & 00 \\
\hline
\end{tabular}

Q.5 Now I want to ask you about meat quality. How important or unimportant are each of the following for assessing the eating quality of ...?

\begin{tabular}{|c|c|c|c|c|c|c|}
\hline & $\begin{array}{c}\text { Very } \\
\text { important }\end{array}$ & $\begin{array}{c}\text { Quite } \\
\text { important }\end{array}$ & Neither & $\begin{array}{c}\text { Not very } \\
\text { important }\end{array}$ & $\begin{array}{l}\text { Not at all } \\
\text { important }\end{array}$ & $\begin{array}{l}\text { Don't } \\
\text { know }\end{array}$ \\
\hline The flavour of the ... & 1 & 2 & 3 & 4 & 5 & 0 \\
\hline The tenderness of the $\ldots$ & 1 & 2 & 3 & 4 & 5 & 0 \\
\hline The colour of the ... & 1 & 2 & 3 & 4 & 5 & 0 \\
\hline The smell of the .... & 1 & 2 & 3 & 4 & 5 & 0 \\
\hline The leanness of the ..... & 1 & 2 & 3 & 4 & 5 & 0 \\
\hline The juiciness of the ... & 1 & 2 & 3 & 4 & 5 & 0 \\
\hline .... free of gristle & 1 & 2 & 3 & 4 & 5 & 0 \\
\hline The texture of the ... & 1 & 2 & 3 & 4 & 5 & 0 \\
\hline
\end{tabular}

Q.6 I would now like you to think about shopping for ..... When you are shopping for .... how helpful or otherwise are each of the following for predicting the eating quality of the ....?

\begin{tabular}{|l|c|c|c|c|c|c|}
\cline { 2 - 6 } \multicolumn{1}{c|}{} & $\begin{array}{c}\text { Very } \\
\text { helpful }\end{array}$ & $\begin{array}{c}\text { Quite } \\
\text { helpful }\end{array}$ & Neither & $\begin{array}{c}\text { Not very } \\
\text { helpful }\end{array}$ & $\begin{array}{c}\text { Not at all } \\
\text { helpful }\end{array}$ & $\begin{array}{c}\text { Don't } \\
\text { know }\end{array}$ \\
\hline Colour of the ... & 1 & 2 & 3 & 4 & 5 & 0 \\
\hline Marbling of the $\ldots$ (beef/pork only) & 1 & 2 & 3 & 4 & 5 & 0 \\
\hline Leanness of the ... & 1 & 2 & 3 & 4 & 5 & 0 \\
\hline A brand or quality assurance label & 1 & 2 & 3 & 4 & 5 & 0 \\
\hline The place of purchase & 1 & 2 & 3 & 4 & 5 & 0 \\
\hline The price of the ... & 1 & 2 & 3 & 4 & 5 & 0 \\
\hline The country of origin of the .... & 1 & 2 & 3 & 4 & 5 & 0 \\
\hline
\end{tabular}


Q.7 How concerned or unconcerned are you personally about each of the following when buying ... nowadays?

\begin{tabular}{|l|c|c|c|c|c|c|}
\cline { 2 - 6 } \multicolumn{1}{c|}{} & $\begin{array}{c}\text { Very } \\
\text { concerned }\end{array}$ & $\begin{array}{c}\text { Quite } \\
\text { concerned }\end{array}$ & Neither & $\begin{array}{c}\text { Not very } \\
\text { concerned }\end{array}$ & $\begin{array}{c}\text { Not at all } \\
\text { concerned }\end{array}$ & $\begin{array}{c}\text { Don't } \\
\text { know }\end{array}$ \\
\hline Hormones in ... & 1 & 2 & 3 & 4 & 5 & 0 \\
\hdashline Antibiotics in ... & 1 & 2 & 3 & 4 & 5 & 0 \\
\hline Fat or cholesterol in ... & 1 & 2 & 3 & 4 & 5 & 0 \\
\hline Salmonella or other bacteria in $\ldots$ & 1 & 2 & 3 & 4 & 5 & 0 \\
\hline BSE (beef only) & 1 & 2 & 3 & 4 & 5 & 0 \\
\hline
\end{tabular}

Q.8 And how helpful or otherwise are each of the following in assessing the safety of ...?

\begin{tabular}{|c|c|c|c|c|c|c|}
\hline & $\begin{array}{c}\text { Very } \\
\text { helpful }\end{array}$ & $\begin{array}{c}\begin{array}{c}\text { Quite } \\
\text { helpful }\end{array} \\
\end{array}$ & Neither & $\begin{array}{c}\begin{array}{c}\text { Not very } \\
\text { helpful }\end{array} \\
\end{array}$ & $\begin{array}{c}\text { Not at all } \\
\text { helpful }\end{array}$ & $\begin{array}{l}\text { Don't } \\
\text { know }\end{array}$ \\
\hline What the animal was fed on & 1 & 2 & 3 & 4 & 5 & 0 \\
\hline A brand or quality assurance label & 1 & 2 & 3 & 4 & 5 & 0 \\
\hline Name of producer or farmer & 1 & 2 & 3 & 4 & 5 & 0 \\
\hline Organically produced ... (beef/pork only) & 1 & 2 & 3 & 4 & 5 & 0 \\
\hline Country of origin of the ...... & 1 & 2 & 3 & 4 & 5 & 0 \\
\hline The price of the .... & 1 & 2 & 3 & 4 & 5 & 0 \\
\hline The freshness of the ... & 1 & 2 & 3 & 4 & 5 & 0 \\
\hline Free range (chicken only) & 1 & 2 & 3 & 4 & 5 & 0 \\
\hline
\end{tabular}


ASK ALL:

Q.9 Now I would like to read out some statements which other people have made about food and meat generally. For each one, please tell me how much you personally agree or disagree. You may agree strongly, agree a little, neither agree nor disagree, disagree a little or disagree strongly.

You can assess the quality of beef in the shop just by looking at it

You can assess the quality of pork in the shop just by looking at it

You can assess the quality of chicken in the shop just by looking at it

I like experimenting with new recipes

I do not enjoy cooking very much but it is a task which has to be done

I would never serve a meal without meat for visitors

Meat is an essential part of a meal

Price is the main thing I consider when buying meat

I prefer to buy meat from animals which I know have been treated well

We should have more respect for animals I prefer to buy food which is produced locally

It is important that I know the country where the meat I buy has been produced I am confident that food in the shops is safe Meat is essential for a balanced diet I always check the nutritional labelling on foods before buying them You have to be prepared to pay a higher price to get good quality meat There is no source of protein like meat

\begin{tabular}{|c|c|c|c|c|c|}
\hline $\begin{array}{c}\text { AGREE } \\
\text { STRONGLY }\end{array}$ & $\begin{array}{c}\text { AGREE A } \\
\text { LITTLE }\end{array}$ & NEITHER & $\begin{array}{c}\text { DISAGREE } \\
\text { A LITTE } \\
\end{array}$ & $\begin{array}{l}\text { DISAGREE } \\
\text { STRONGLY } \\
\end{array}$ & $\begin{array}{l}\text { DON'T } \\
\text { KNOW }\end{array}$ \\
\hline 1 & 2 & 3 & 4 & 5 & 0 \\
\hline 1 & 2 & 3 & 4 & 5 & 0 \\
\hline 1 & 2 & 3 & 4 & 5 & 0 \\
\hline 1 & 2 & 3 & 4 & 5 & 0 \\
\hline 1 & 2 & 3 & 4 & 5 & 0 \\
\hline 1 & 2 & 3 & 4 & 5 & 0 \\
\hline 1 & 2 & 3 & 4 & 5 & 0 \\
\hline 1 & 2 & 3 & 4 & 5 & 0 \\
\hline 1 & 2 & 3 & 4 & 5 & 0 \\
\hline 1 & 2 & 3 & 4 & 5 & 0 \\
\hline 1 & 2 & 3 & 4 & 5 & 0 \\
\hline 1 & 2 & 3 & 4 & 5 & 0 \\
\hline 1 & 2 & 3 & 4 & 5 & 0 \\
\hline 1 & 2 & 3 & 4 & 5 & 0 \\
\hline 1 & 2 & 3 & 4 & 5 & 0 \\
\hline 1 & 2 & 3 & 4 & 5 & 0 \\
\hline 1 & 2 & 3 & 4 & 5 & 0 \\
\hline
\end{tabular}

Q.10 Which quality symbols or labels do you normally look for when buying ....? PROBE FULLY \& RECORD VERBATIM

\begin{tabular}{|c|c|c|}
\hline BEEF & PORK & CHICKEN \\
\hline 1. & 1. & 1. \\
\hline 2. & 2. & 2. \\
\hline 3. & 3. & 3. \\
\hline 4. & 4. & 4. \\
\hline 5. & 5. & 5. \\
\hline 6. None & 6. None & 6. None \\
\hline 7. Don't know & 7. Don't know & 7. Don't know \\
\hline
\end{tabular}


Q.11 When looking for information on the safety of meat who or what do you most trust? (UP TO THREE MENTIONS ONLY) SPONTANEOUS - DO NOT READ LIST

\begin{tabular}{|c|c|c|c|}
\hline & $1^{\text {ST }}$ MENTION & $2^{\mathrm{ND}}$ MENTION & $3^{\text {RD }}$ MENTION \\
\hline Government & 01 & 01 & 01 \\
\hline Government - The Department of Agriculture & 02 & 02 & 02 \\
\hline Government - The Department of Health & 03 & 03 & 03 \\
\hline Consumer Groups & 04 & 04 & 04 \\
\hline Independent retailers/butchers & 05 & 05 & 05 \\
\hline Butcher in the supermarket & 06 & 06 & 06 \\
\hline Friends & 07 & 07 & 07 \\
\hline Magazines & 08 & 08 & 08 \\
\hline Reports & 09 & 09 & 09 \\
\hline Radio Reports & 10 & 10 & 10 \\
\hline Newspapers & 11 & 11 & 11 \\
\hline Food writers & 12 & 12 & 12 \\
\hline The local doctor/other medical & 13 & 13 & 13 \\
\hline Meat companies & 14 & 14 & 14 \\
\hline Meat Industry organisations & 15 & 15 & 15 \\
\hline Farmer representatives & 16 & 16 & 16 \\
\hline The Food Safety Board & 17 & 17 & 17 \\
\hline My mother/Other family member & 18 & 18 & 18 \\
\hline Other - please specify & 19 & 19 & 19 \\
\hline
\end{tabular}




\section{Classification}

Any now just a few questions about you, yourself.

C.1 What is your
current occupation?

\begin{tabular}{|c|c|c|}
\hline $\begin{array}{r}\text { Responsible for ordinary shopping, looking } \\
\text { after the home eg., housewife }\end{array}$ & 01 & \multirow{6}{*}{$\begin{array}{l}\text { NoT } \\
\text { WORKING }\end{array}$} \\
\hline Student & 02 & \\
\hline Unemployed & 03 & \\
\hline Retired & 04 & \\
\hline Not working, lives with private means & 05 & \\
\hline $\begin{array}{r}\text { Non active, long-term sickness or physical } \\
\text { disability }\end{array}$ & 06 & \\
\hline Farmer & 07 & \multirow{6}{*}{ SELF-EMPLOYED } \\
\hline Fisherman & 08 & \\
\hline $\begin{array}{r}\text { Professional (lawyer, medical practitioner, } \\
\text { accountant, architect) }\end{array}$ & 09 & \\
\hline $\begin{array}{r}\text { Owner of shop, craftsman, other self- } \\
\text { employed person }\end{array}$ & 10 & \\
\hline $\begin{array}{l}\text { Business proprietor/owner (full or partner) } \\
\text { of a company with } 0-5 \text { employees }\end{array}$ & 11 & \\
\hline $\begin{array}{r}\text { Business proprietor/owner (full or partner) } \\
\text { of a company with } 6+\text { employees }\end{array}$ & 12 & \\
\hline $\begin{array}{r}\text { Employed professions (employed doctor, } \\
\text { lawyer, accountant, architect) }\end{array}$ & 13 & \multirow{5}{*}{$\begin{array}{c}\text { EMPLOYED } \\
\text { PROFESSIONAL OR } \\
\text { MANAGEMENT } \\
\text { (NOT SUPERVISORS) }\end{array}$} \\
\hline $\begin{array}{l}\text { General management, director or top } \\
\text { management (managing director, director } \\
\text { general, other director) with } 0-5 \text { employees }\end{array}$ & 14 & \\
\hline $\begin{array}{l}\text { General management, director or top } \\
\text { management (managing director, director } \\
\text { general, other director) with } 6+\text { employees }\end{array}$ & 15 & \\
\hline $\begin{array}{l}\text { Middle management/other management } \\
\text { (department head, junior manager, teacher, } \\
\text { technician) with } 0-5 \text { employees }\end{array}$ & 16 & \\
\hline $\begin{array}{l}\text { Middle management/other management } \\
\text { (department head, junior manager, teacher, } \\
\text { technician) with } 6+\text { employees }\end{array}$ & 17 & \\
\hline $\begin{array}{r}\text { Employed position working mainly at a } \\
\text { desk }\end{array}$ & 18 & \multirow{6}{*}{$\begin{array}{l}\text { OTHER EMPLOYED } \\
\text { POSITION } \\
\text { (INCLUDING } \\
\text { SUPERVISORS }\end{array}$} \\
\hline $\begin{array}{r}\text { Employed position, not at a desk but } \\
\text { travelling (salesman, driver) }\end{array}$ & 19 & \\
\hline $\begin{array}{r}\text { Employed position, not at a desk but in a } \\
\text { service job (hospital, restaurant, police, } \\
\text { fireman) }\end{array}$ & 20 & \\
\hline Supervisor & 21 & \\
\hline Skilled manual worker & 22 & \\
\hline Other (unskilled) manual worker, servant & 23 & \\
\hline
\end{tabular}

C.2 Are you the person in your household who contributes most to the household income?

\begin{tabular}{|r|l|l|}
\hline Yes & 1 & \\
\hline No & 2 & Go To C.3 \\
\hline Refusal & 3 & \multicolumn{1}{|}{} \\
\cline { 1 - 2 }
\end{tabular}


IF NO AT C.2 ASK:

C. 3 What is the occupation of the person who contributes most to the household income?

\begin{tabular}{|c|c|c|}
\hline $\begin{array}{l}\text { Responsible for ordinary shopping, looking } \\
\text { after the home eg., housewife }\end{array}$ & 01 & \multirow{6}{*}{$\begin{array}{c}\text { NOT } \\
\text { WORKING }\end{array}$} \\
\hline Student & 02 & \\
\hline Unemployed & 03 & \\
\hline Retired & 04 & \\
\hline Not working, lives with private means & 05 & \\
\hline $\begin{array}{r}\text { Non active, long-term sickness or physical } \\
\text { disability }\end{array}$ & 06 & \\
\hline Farmer & 07 & \multirow{6}{*}{ SELF-EMPLOYED } \\
\hline Fisherman & 08 & \\
\hline $\begin{array}{r}\text { Professional (lawyer, medical practitioner, } \\
\text { accountant, architect) }\end{array}$ & 09 & \\
\hline $\begin{array}{r}\text { Owner of shop, craftsman, other self- } \\
\text { employed person }\end{array}$ & 10 & \\
\hline $\begin{array}{r}\text { Business proprietor/owner (full or partner) } \\
\text { of a company with } 0-5 \text { employees }\end{array}$ & 11 & \\
\hline $\begin{array}{r}\text { Business proprietor/owner (full or partner) } \\
\text { of a company with } 6+\text { employees }\end{array}$ & 12 & \\
\hline $\begin{array}{r}\text { Employed professions (employed doctor, } \\
\text { lawyer, accountant, architect) }\end{array}$ & 13 & \multirow{5}{*}{$\begin{array}{c}\text { EMPLOYED } \\
\text { PROFESSIONAL OR } \\
\text { MANAGEMENT } \\
\text { (NOT SUPERVISORS) }\end{array}$} \\
\hline $\begin{array}{l}\text { General management, director or top } \\
\text { management (managing director, director } \\
\text { general, other director) with } 0-5 \text { employees }\end{array}$ & 14 & \\
\hline $\begin{array}{l}\text { General management, director or top } \\
\text { management (managing director, director } \\
\text { general, other director) with } 6+\text { employees }\end{array}$ & 15 & \\
\hline $\begin{array}{l}\text { Middle management/other management } \\
\text { (department head, junior manager, teacher, } \\
\text { technician) with } 0-5 \text { employees }\end{array}$ & 16 & \\
\hline $\begin{array}{l}\text { Middle management/other management } \\
\text { (department head, junior manager, teacher, } \\
\text { technician) with } 6+\text { employees }\end{array}$ & 17 & \\
\hline $\begin{array}{r}\text { Employed position working mainly at a } \\
\text { desk }\end{array}$ & 18 & \multirow{6}{*}{$\begin{array}{c}\text { OTHER EMPLOYED } \\
\text { POSITION } \\
\text { (INCLUDING } \\
\text { SUPERVISOR) }\end{array}$} \\
\hline $\begin{array}{l}\text { Employed position, not at a desk but } \\
\text { travelling (salesman, driver) }\end{array}$ & 19 & \\
\hline $\begin{array}{r}\text { Employed position, not at a desk but in a } \\
\text { service job (hospital, restaurant, police, } \\
\text { fireman) }\end{array}$ & 20 & \\
\hline Supervisor & 21 & \\
\hline Skilled manual worker & 22 & \\
\hline Other (unskilled) manual worker, servant & 23 & \\
\hline
\end{tabular}

WRITE IN

WRITE IN

C.5 And how many children aged under 16 are living at home?

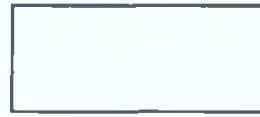

WRITE IN 
C.7 How old were you when you stopped full-time education?

WRITE IN

\section{INTERVIEWER INSTRUCTION: IF NECESSARY EXPLAIN:}

This does not take into account any apprenticeship, professional training or periods of study which you may have had later in your life.

\section{C.8 RECORD SEX FROM VOICE AND ASK IF NECESSARY:}

\begin{tabular}{|r|r|}
\hline Male & 1 \\
\hline Female & 2 \\
\hline
\end{tabular}

C.9 In order to analyse the results of this survey it would be helpful to know roughly what is the total gross annual income of your household, before tax?

\begin{tabular}{|r|r|r|}
\hline 1 & Less than 10,000 & 01 \\
\hdashline 2 & $10,001-15,000$ & 02 \\
\hline 3 & $15,001-20,000$ & 03 \\
\hdashline 4 & $20,001-25,000$ & 04 \\
\hline 5 & $25,001-30,000$ & 05 \\
\hdashline 6 & $30,001-40,000$ & 06 \\
\hdashline 7 & $40,001-50,000$ & 07 \\
\hdashline 8 & $50,001-70,000$ & 08 \\
\hdashline 9 & $70,000+$ & 09 \\
\hdashline 10 & Refused & 10 \\
\hdashline 11 & Don't know & 00 \\
\hline
\end{tabular}

Thank you very much for your time. That's all my questions. I would just like to confirm that my name is (INTERVIEWER) calling from MRC, a research agency based in Dublin. 